This is the final peer-reviewed accepted manuscript of:

Garralda M.D., Maureille B., Le Cabec A., Oxilia G., Benazzi S., Skinner M.M., Hublin J.J., Vandermeersch B., The Neanderthal teeth from Marillac (Charente, Southwestern France): Morphology, comparisons and paleobiology, Journal of Human Evolution 138, (2020).

The final published version is available online at: https://doi.org/10.1016/j.jhevol.2019.102683

(C) 2019. This manuscript version is made available under the Creative Commons AttributionNonCommercial-NoDerivs (CC BY-NC-ND) License 4.0 International (http://creativecommons.org/licenses/by-nc-nd/4.0/) 


\title{
The Neanderthal teeth from Marillac (Charente, Southwestern France): Morphology, comparisons and paleobiology
}

\author{
María Dolores Garralda a, *, Bruno Maureille b, 1, Adeline Le Cabec c, 1, Gregorio Oxilia d, \\ Stefano Benazzi c, d, Matthew M. Skinner e, c, Jean-Jacques Hublin c, Bernard Vandermeersch ${ }^{b}$ \\ a Departamento de Biodiversidad, Ecología y Evolución, Facultad de Ciencias Bioló gicas, Universidad \\ Complutense de Madrid, Ciudad Universitaria, 28040, \\ Madrid, Spain \\ b UMR5199 PACEA: de la pr'ehistoire a' l'actuel: culture, environnement et anthropologie, Universit'e de \\ Bordeaux, ba^t. B8. All`ee Geoffroy Saint-Hilaire - CS 50023, 33615 Pessac, France \\ c Department of Human Evolution, Max Planck Institute for Evolutionary Anthropology, Deutscher Platz 6, \\ Leipzig D, 04103, Germany \\ d Department of Cultural Heritage, University of Bologna, Via degli Ariani 1, 48121, Ravenna, Italy \\ e School of Anthropology and Conservation, University of Kent, Marlowe Building, Canterbury, CT2 7NR, UK
}

\begin{abstract}
Few European sites have yielded human dental remains safely dated to the end of MIS 4/beginning of MIS3. One of those sites is Marillac (Southwestern France), a collapsed karstic cave where archeological excavations (1967e 1980) conducted by B. Vandermeersch unearthed numerous faunal and human re- mains, as well as a few Mousterian Quina tools. The Marillac sinkhole was occasionally used by humans to process the carcasses of different prey, but there is no evidence for a residential use of the site, nor have any hearths been found. Rare carnivore bones were also discovered, demonstrating that the sink- hole was seasonally used, not only by Neanderthals, but also by predators across several millennia. The lithostratigraphic units containing the human remains were dated to $\sim 60 \mathrm{kyr}$. The fossils consisted of numerous fragments of skulls and jaws, isolated teeth and several post-cranial bones, many of them with traces of perimortem manipulations. For those already published, their morphological characteristics and chronostratigraphic context allowed their attribution to Neanderthals.

This paper analyzes sixteen unpublished human teeth (fourteen permanent and two deciduous) by investigating the external morphology and metrical variation with respect to other Neanderthal remains and a sample from modern populations. We also investigate their enamel thickness distribution in 2D and 3D, the enamel-dentine junction morphology (using geometric morphometrics) of one molar and two premolars, the roots and the possible expression of taurodontism, as well as pathologies and developmental defects. The anterior tooth use and paramasticatory activities are also discussed. Morphological and structural alterations were found on several teeth, and interpreted in light of human behavior (tooth-pick) and carnivores' actions (partial digestion). The data are interpreted in the context of the available information for the Eurasian Neanderthals.
\end{abstract}




\section{Introduction}

Southwestern France has yielded an exceptional collection of fos- sils assigned to the Neanderthals, spanning from MIS 6 to MIS 3. Very few predate MIS 5, such as those from Pradayrol (Se'ronie-Vivien and Tillier, 2002) and Combe-Grenal layer 60 (Maureille et al., 2010b). Remains related to MIS 5 are also scarce, examples of which are Regourdou 1 (Maureille, 2001), La Chaise Abri Bourgeois-Delaunay (Condemi, 2001) and Abri Suard (Piveteau, 1970). The MIS 4 pop- ulations are only represented by fossils corresponding to the end of this period and the beginning of MIS 3, such as levels L to N of La Quina Station Amont (Debe'nath and Jelinek, 1998; Verna, 2006), Combe-Grenal level 25 (Garralda and Vandermeersch, 2000) and Jonzac (Jaubert et al., 2008). The most recent Neanderthals are dated to MIS 3, as is the case of Saint-Ce'saire (Hublin et al., 2012), Grotte Vaufrey (Garralda et al., 2004), Rochelot (Couture and Tournepiche, 1997), $\mathrm{Ch}^{\wedge}$ ateauneuf-sur-Charente (Tillier, 1979), Monsempron-Libos (Scolan et al., 2012) and Pech de l'Aze' 4 (Maureille, 2018).

At the site of Marillac (France), several human remains have been recovered in a very well-described and dated context, in levels assigned to the end of the MIS 4/beginning of MIS 3. Among them, a series of sixteen teeth stands out which we aim to describe in the present study to improve our knowledge of these Neanderthal populations.

The comparative and morphometric analysis of the many Nean- derthal teeth found in important Eurasian sites (e.g., Krapina, see Gorjanovic-Kramberger, 1906) significantly contributed to enriching our understanding of the biology of these past human groups. In particular, and despite the fragmentary na ture of the fossil record, it has demonstrated its value to estimate individual, population, and tempo-spatial variability (Bayle et al., 2009; Crevecoeur et al., 2010; Willman et al., 2012; Hlusko et al., 2013; Garralda et al., 2014a; Trinkaus and Walker, 2017). The alterations related to para- and non-masticatory activities affected dental morphology during life, and thus offer important evidence about the behavior of the studied individuals (Garralda et al, 2004; Le Cabec et al., 2013).

After presenting the archeological context of the site, we describe the dental remains by specifically focusing on their morphometry, their enamel-dentine junction and root morphology, as well as their dental tissue proportions. We estimate the minimum number of in-dividuals, their age at death and the paleobiology of this fossil sample. We also report pathological, behavioral and taphonomic alterations observed on these Neanderthal teeth. Finally, we will discuss the findings in lightof Neanderthal dental variability and human behavior. Furthermore, for the first time, we describe and quantify in terms of enamel thickness the effect of the partial digestion of several human teeth that were most probably ingested by the types of carnivores identified in the deposit.

\section{The site of Marillac}

Marillac, also known as 'Les Pradelles', consists of a collapsed karstic cave located in the village of Marillac-leFranc (Charente, SW France). Bernard Vandermeersch undertook systematic archeological excavations (1967e1980) at the site, discovering numerous animal and human fragments, as well as few Mousterian Quina lithics (Vandermeersch, 1986; Meignen et al., 2007, 2010). Mớre recent excavations conducted by Bruno Maureille and Alan Mann (2001e2012; Maureille et al., 2010a) helped elucidate this complex archeological 'palimpsest' (Fig. 1). During the end of MIS 4/beginning of MIS 3, the Marillac sink- hole (lithofacies 2 and 4 , Fig. 1; Vandermeersch, 1980, 1986; Maureille et al., 2010a1 $)_{4}$ was occasionally used / $_{4}$ by humans to pro- cess carcasses e mainly of one ungulate cervid species (reindeers Rangifer tarandus) e and more rarely of horses (Equus ferus) or bison (Bison priscus), which were rich in food resources and hunted at other locations. There is no evidence of a residential site at Marillac (Delagnes and Rendu, 2011), nor have any traces of hearths been found (very rarely do flints and bones present evidence of burning). Several of the Mousterian Quina tools found at Marillac were made with local flint, but others were knapped with a non-local type and transported by the hunters (Meignen and Vandermeersch, 1987). This archeological data supports the hy- pothesis that the Marillac sinkhole was used by the Neanderthals for short periods of time as a hunting camp, probably only during autumn when animal migrations occurred (Costamagno et al., 2006). Some carnivore bones (i.e., hyena Crocuta c. spelaea, lion Panthera spelaea, and wolf Canis 1. spelaeus) were also found at the site, suggesting that they also occasionally visited the cavity.

In addition to making use of animals, Neanderthals also manipulated parts of human cadavers (from both 
children and adults), as a number of the remains found showed breaks by per- cussion or grooves made by lithic implements. The absence of some specific skeletal parts (e.g., the thorax and vertebral column), the relatively low representation of hand and foot elements, and few long bones, suggest that only certain elements of the human bodies were taken into the cave. It is difficult to discern whether these findings can be explained by cannibalism (Mussini, 2011) or other rituals (Garralda et al., 2014b, c). Furthermore, carnivores must have occasionally visited the cave during that period, since traces of their activities (e.g., gnaw marks) have been noted on some animal bones (Costamagno et al., 2006) and on one human femoral frag- ment (LP06-D12 \# 1434; Mussini, 2011).

The paleoenvironmental reconstruction shows the prevalence of open environment during a cold and harsh phase (end of MIS 4/ beginning of MIS 3), later evolving into the climate instability linked to the Heinrich event 4 (Royer et al., 2013). Chronometric dating places lithofacies $2 \mathrm{~b}$ (representing the major Neanderthal presence at the site) at $60 \mathrm{ka}$. The only piece of burnt flint from this lithofacies was TL- dated to $57.6 \pm 4.6 \mathrm{ka}$ (Maureille et al., 2010a). Furthermore, two OSL dates are now available for lithofacies 4a (overlying 2b): $56.8 \pm$ $7.3 \mathrm{ka}$ and $63.7 \pm 7.7 \mathrm{ka}$ (Frouin, 2014; Frouin et al., 2017). Soon after this period, as a result of the changing environmental conditions and an intense phase of destruction of the sinkhole's walls and roof, Marillac was abandoned by humans and used only by medium size carnivores such as wolves and foxes, which then became the only agents intro- ducing faunal remains into the site.

A total of 30 human fossils were found during B. Vander- meersch's excavations, of which only the following have been published in detail. First, an adult cranial fragment (Marillac 3, M3) which was affected by hyperostosis frontalis interna (Garralda et al., 2014b). Second, three infracranial remains (Garralda et al., 2014c) corresponding to the incomplete diaphysis of a right radius (M24) and a left fibula (M26), both from adults, and the diaphysis of the right femur (M25) from a 7 year-old immature individual. Furthermore, traces of perimortem manipulation were described on several fossils (Le Mort, 1987; Garralda et al., 2005; Garralda, 2008). Based on their morphological characteristics (David, 1935; Piveteau, 1957; Vandermeersch, 1980, 1986), and their chronostratigraphic context, the human specimens were soon identified as Neanderthals from the first discovery.

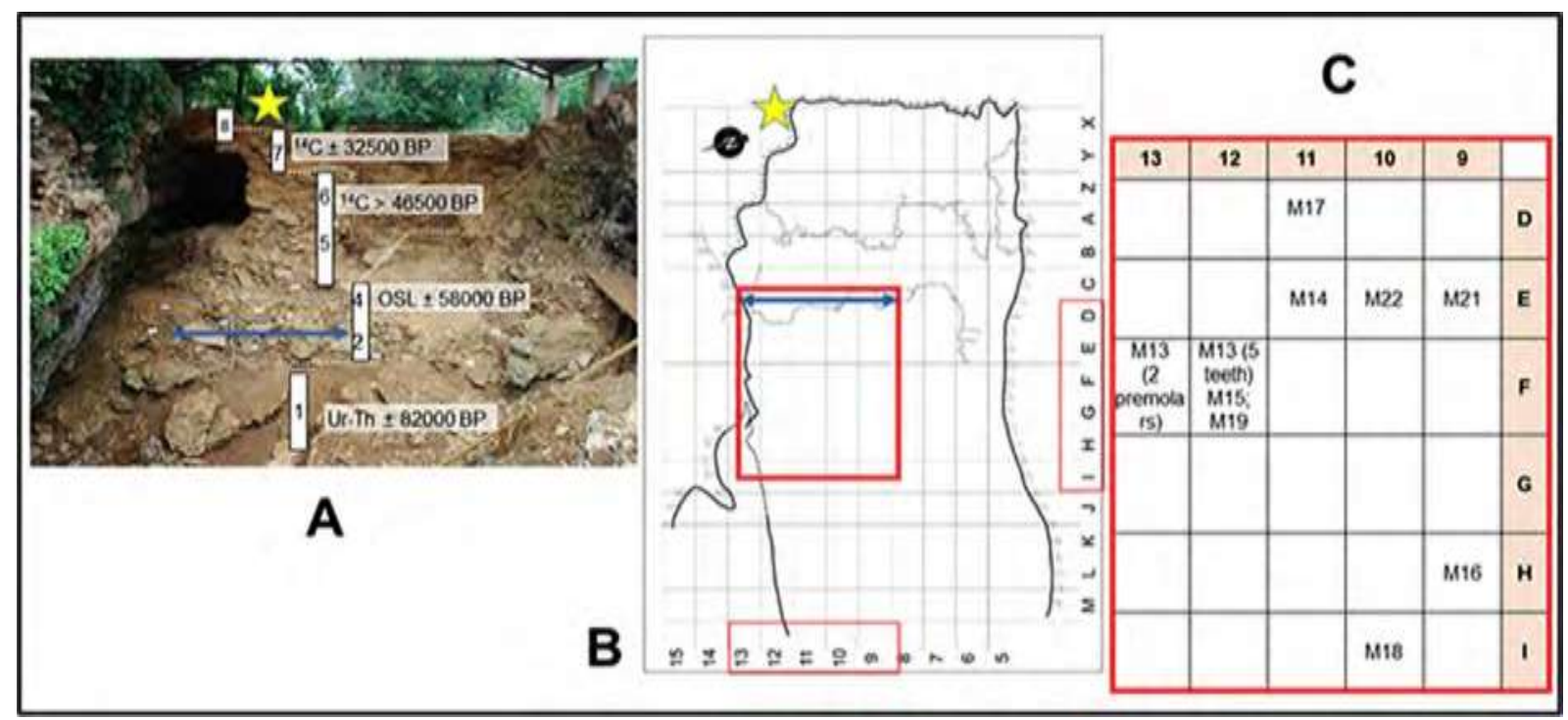

Figure 1. Marillac site. (A) View of the locus East (after the excavations led by Maureille and Mann) with details regarding its main lithofacies and their absolute dating (yellow star: collapsed roof). From the most recent to the most ancient: Lithofacies 6 and 5: very poor (undefined Mousterian, little fauna, carnivore dens, and no hominin remains); Lithofacies 4 and 2: very rich (Quina type Mousterian, reindeer, horse, bison, Dicrostonyx torquatus, hunting camp, numerous hominin remains); Lithofacies 1: sterile (karstic clays). (B) Overview of the excavation grid for the locus East. (C) Details of the squares (see red frame in B) where the hominin teeth were found. (For interpretation of the references to color in this figure legend, the reader is referred to the Web version of this article.) 


\section{Materials}

The Marillac Homo fossils are provisionally housed at the PACEA Laboratory (Universite' de Bordeaux, France) under the care of B. Maureille. The material consists of 16 Neanderthal teeth found during Vandermeersch's excavations at Marillac (1968e1980). These 14 permanent and two deciduous teeth (Fig. 1C, Table 1) were found within levels 9 and 10 (Vandermeersch's lithostratigraphy in Debe'nath, 1974), now part of lithofacies 2b and 2a (Maureille et al., 2010a). Among these dental remains, seven isolated teeth (labeled M13A to G) were found during the 1971 excavation (on August 10,

1971) and might be attributed to the same individual. These con- sisted of the four incisors, the right canine, and the two left pre- molars from the upper maxillary of a young individual. They were discovered in close proximity (Fig. 1C and Supplementary Online Material, SOM-S1), as if the maxillary bones had disintegrated leaving only the teeth to be found.

Another tooth, the M19 LM3, with broken (but perhaps incom- plete) roots, was found the same year (May 5, 1971) and in the same square (Fig. 1C) as the four incisors and the canine labeled M13A-E. This M19 molar could also very likely be assigned to individual M13 (and then could be labeled M13H), considering the color of its enamel, its stage of development, and the circumstances of its discovery. However, proof that the M19 LM3 belonged to individual M13 is not strong, therefore we prefer to consider it an isolated tooth.

The preservation of the juvenile specimens precludes any quantitative or direct assessment of age at death. Indeed, this would remain impossible using either virtual paleohistology techniques (Le Cabec et al., 2015), or classical histology which would require physically sectioning the teeth, and thus would not be allowed for human fossils discovered in France without the authorization of the French Ministry of Culture. Besides the fact that some teeth may be broken or partially digested, the adolescent M13 has no upper first molar preserved which would be necessary to anchor any age at death to birth time. All the other teeth are either isolated germs of permanent teeth or deciduous teeth, thus providing no information about birth or even time of death if the root is fully formed. Therefore, age at death was estimated using modern human standards following Liversidge and Molleson (2004), AlQahtani et al. (2010, 2014) and Shackelford et al. (2012). When necessary, the calcification stages of Moorrees et al. (1963a, b) were also considered.

Throughout the text we use the following abbreviations: the first letter refers to side (L: left or R: right), the second letter to the tooth type (I: incisor, C: canine, P: premolar, M: molar; a " $\mathrm{d}$ " before this letter would indicate the tooth is deciduous), and the number of the tooth locus. For instance, the LdM2 corresponds to the left deciduous second molar.

Table 1

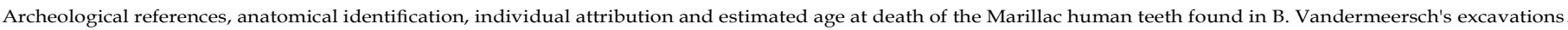

\begin{tabular}{|c|c|c|c|c|c|c|c|}
\hline Archeological reference & Tooth class & Specimen name & Short name & Formation stage & Wearc & Age class & Age estimated \\
\hline \multicolumn{8}{|l|}{ Permanent teeth } \\
\hline M71 C.10-F1293 & right $\mathrm{I}^{1}$ & Marillac 13A & M13A & & 3 & & \\
\hline M71 C.10-F12 93 & left $I^{1}$ & Marillac 13B & M13B & & 3 & & \\
\hline M71 C.10-F12 93 & right $\mathrm{I}^{2}$ & Marillac 13C & M13C & & 2 & & \\
\hline M71 C.10-F12 93 & left $\mathrm{I}^{2}$ & Marillac 13D & M13D & Complete & 3 & Adolescent & $\sim 15.5 \mathrm{yrs}$ \\
\hline M71 C.10-F12 93 & right C' & Marillac 13E & M13E & & 1 & & \\
\hline M70 C.9base-F13 3 & left $\mathrm{P}^{3}$ & Marillac 13F & M13F & & 2 & & \\
\hline M70 C.9base-F13 2 & left $\mathrm{P}^{4}$ & Marillac 13G & M13G & & 1 & & \\
\hline M72 C.10-E11 336 & right $\mathrm{I}^{1}$ & Marillac $14^{\star * f}$ & M14 & Complete & 3 & Adolescent? Young adult? & $\sim 18$ yrs \\
\hline M70 C.10-F12 54 & right $\mathrm{I}^{2}$ & Marillac $15^{* *}$ & M15 & Complete & 2 & Adolescent? & $\sim 14$ yrs \\
\hline M75 C.11-H9 3 & germ left $\mathrm{I}^{2}$ & Marillac $16^{* * a}$ & M16 & $\sim \mathrm{Cr}^{\mathrm{a}}$ & 1 & Child & $\sim 5.5 \mathrm{yrs}$ \\
\hline M78 C.9a-D11 21 & right $\mathrm{I}^{2}$ & Marillac 17 & M17 & Complete & 5 & Adult/Mature & \\
\hline M72 C.11-I10 22 & germ left $\mathrm{P}^{3}$ & Marillac $18^{* *}$ & M18 & $\mathrm{R} 1 / 2^{\mathrm{a}}$ & 1 & Child & $\sim 10.5 \mathrm{yrs}$ \\
\hline M71 C.9base-F12 73 & left $\mathrm{M}^{3}$ & Marillac 19 (Marillac 13H?) & M19 (M13H?) & $\mathrm{R} 3 / 4^{\mathrm{a}}$ & 1 & Adolescent & $\sim 16.1 \mathrm{yrs}$ \\
\hline $\begin{array}{l}\text { M71 C.10 ?e } \\
\text { Deciduous teeth }\end{array}$ & left $\mathrm{M}_{2}$ & Marillac $20^{* *}$ & M20 & Complete & 7 & Mature & \\
\hline M72 C.10-E9 284 & right $\mathrm{I}_{2}$ & Marillac 21 & M21 & $\mathrm{H} 2^{b}$ & 3 & Child & $>2.39 \pm 0.40^{\mathrm{b}} ; \sim 2.5 \mathbf{e} 3.5 \mathrm{yr}^{\mathrm{d}}$ \\
\hline M73 C.10-E10 ?e & left $M_{1}$ & Marillac $22^{* *}$ & M22 & $\mathrm{H} 2^{\mathrm{b}}$ & 5 & Child & $>2.91 \pm 0.35^{\mathrm{b}} ; \sim 4.5 \mathrm{yr}^{\mathrm{d}}$ \\
\hline
\end{tabular}


b Liversidge and Molleson (2004), stage 'H2' defined as 'Occlusal plane slightly worn, root complete'.

c Molnar (1971).

d AlQahtani et al. (2010).

e '?' in the archeological reference of M20 indicates absence of data regarding the square in which the tooth was found, and in M22 its absence of register number.

f Partially digested teeth are indicated by**.

\section{Methods}

\section{Imaging of the teeth}

All teeth were examined under a Leica S8 APO stereomicroscope in order to identify pathological conditions (e.g., carious lesions, enamel hypoplasias) or other kinds of modifications (e.g., toothpick grooves, animal digestive processes).

All teeth were radiographed at the PACEA Laboratory (UMR5199, University of Bordeaux, France) using an ODEL GENIUS 5001 generator.

Microtomography of all the Marillac teeth was performed in 2007 and 2015 on two portable micro-CT (mCT) scanners (Skyscan 1172 and then SkyScan 1173) in the Department of Human Evolu- tion, Max Planck Institute for Evolutionary Anthropology (Leipzig, Germany). All technical parameters concerning the mCT acquisitions are provided in SOM-S2. Isometric voxel sizes at acquisition ranged from 12.87 to $27.49 \mathrm{~mm}$. The $\mathrm{mCT}$ data were reconstructed as TIFF stacks using NRecon and the back-filtered projection algorithm, with some corrections for beam-hardening and ring artifacts. To facilitate image processing (segmentation), datasets at $<15$ $\mathrm{mm}$ were resampled to $26 \mathrm{~mm}$ using the Triangle filter in Avizo 6.3 (www.vsg3D.com). Complete image stacks of each tooth were filtered using a 3D median filter followed by a mean of least vari- ance filter (Kuwahara et al., 1976; Schulze and Pearce, 1994; each filter with a kernel size of 3) for reducing the background noise while preserving and enhancing edges. The filtered image stacks were imported into Avizo 6.3, where the enamel, dentine, and pulp chamber were segmented semi-automatically using region growing tools. Each dental component (i.e., enamel cap, enamel- dentine junction -EDJ-, dentine root surface, and pulp cavity) was visualized in $3 \mathrm{D}$ as a triangle-based surface model.

\section{Crown morphology and metrics}

All 16 teeth are first described individually, with notes on their preservation, occlusal and interproximal attrition, estimated ages at death following modern human standards, and considerations of the occlusal and root morphology. Pathological lesions and morphological alterations (Hillson, 1996, 2014; Maureille et al., 2017) are also recorded. Occlusal wear was scored using Molnar's (1971) classification. Furthermore, we report the crown metrics measured (to the nearest $0.1 \mathrm{~mm}$ ) on the original speci- mens with a digital caliper. Each crown measurement was repeated on three different days by two of the authors (M. D. G. and B. M.), and the inter- and intra-observer error between measurements was $<4 \%$. The average dimensions obtained are reported in Table 2. Crown-diameters were recorded following Martin and Saller (1957): the greatest mesiodistal diameter was taken parallel to the occlusal and buccal surfaces, while the greatest buccolingual diameter was measured between the buccal and lingual surfaces, perpendicular to the plane in which the mesiodistal diameter was measured (Hillson, 1996). Notably, both occlusal and interproximal wear affected the crown height and the mesiodistal diameter of several teeth (Table 2). Biocorrosion has altered the dimensions of the partially digested teeth. Based on these crown diameters, the crown index and robusticity module were calculated (Martin and Saller, 1957) as reported in Table 2. In addition, cervical diameters were measured following Hillson et al. (2005).

Morphological comparisons with other Neanderthal teeth were carried out using previously published specimens: Pín ar 7, Combe- Grenal, Vaufrey, Genay, El Salt, and Grotte Boccard (García-Sa’nchez et al., 1994; Garralda et al., 2004, 2008, 2014a; Garralda and Vandermeersch, 2000; Maureille et al., 2008, 2010b). Other orig- inal fossils were personally observed in various museums and in- stitutions. We had access to the original teeth from Krapina, Vindija, Saint-Ce'saire, Arcy-sur-Cure, Petit-Puymoyen, Saccopastore, Archi, Tabun, Montsempron, Montgaudier, Malarnaud, Ke’bara, Amud, Guattari, Devil's Tower, Forbes Quarry, Regourdou, Pech-de-l'Aze' 1, Roc-de-Marsal 1, and Lezetxiki for direct assessment. High quality casts represented specimens from Bourgeois-Delaunay, Shanidar and La Quina. 
For the statistical analyses of the buccolingual and mesiodistal crown diameters, bivariate scatterplots were constructed in Sta- tistica 7 using modern-population samples from Spitalfields and Poundbury in the UK, and Coxyde in Belgium (n 453 individuals; Maureille, 2001). The crown diameters of most of the available European and Middle-Eastern Neanderthals were obtained from their original publications (SOM-S3).

Table 2

Marillac tooth crown and cervical diameters (in $\mathrm{mm}$ ) and indices. ${ }^{\mathrm{a}}$

\begin{tabular}{|c|c|c|c|c|c|c|c|c|}
\hline \multicolumn{2}{|c|}{ Individual Tooth } & $\begin{array}{l}\text { M-D diameter } \\
\text { (M81) }\end{array}$ & $\begin{array}{l}\text { B-L diameter } \\
\text { (M81(1)) }\end{array}$ & $\begin{array}{c}\text { Crown index }(\mathrm{M} 81(1) / \\
\mathrm{M} 81 \times 100)\end{array}$ & $\begin{array}{l}\text { Crown Rob. module } \\
\text { M81 × M81(1) }\end{array}$ & $\begin{array}{l}\text { Cervical M-D } \\
\text { diameter }\end{array}$ & $\begin{array}{l}\text { Cervical B-L } \\
\text { diameter }\end{array}$ & $\begin{array}{c}\text { Cervical robustness } \\
\text { index }\end{array}$ \\
\hline \multicolumn{9}{|c|}{ PERMANENT } \\
\hline \multirow[t]{7}{*}{ M13 } & $\overline{\mathrm{A}} \mathrm{RI}^{1}$ & 9.9 & 7.92 & 80 & 74.41 & 6.5 & 7.35 & 47.8 \\
\hline & $\mathrm{B} \mathrm{LI}^{1}$ & 9.55 & 7.98 & 83.56 & 76.21 & 6.5 & 7.3 & 47.5 \\
\hline & $\mathrm{C} \mathrm{RI}^{2}$ & 8.4 & 8.1 & 96.43 & 68.04 & 5.7 & 7.4 & 42.2 \\
\hline & $\mathrm{D} \mathrm{LI}^{2}$ & 8.43 & 7.73 & 91.7 & 65.16 & 5.6 & 7.6 & 42.6 \\
\hline & $\mathrm{E} \mathrm{RC}^{\prime}$ & 8.63 & 9.56 & 110.77 & 82.51 & 6.3 & 8.9 & 56.1 \\
\hline & $\mathrm{F} \mathrm{LP}^{3}$ & 7.89 & 10.75 & 136.25 & 84.82 & 5.1 & 9.6 & 55.5 \\
\hline & $\mathrm{G} \mathrm{LP}^{4}$ & 7.6 & 10.18 & 133.95 & 77.37 & 5.86 & 9.4 & 55.1 \\
\hline $\mathrm{M} 14^{* * \mathrm{~b}}$ & $\mathrm{RI}^{1}$ & $8.6 ?^{c}$ & $>6.5 ?$ & $>75.58 ?$ & 55.9 & $>4 ?$ & $>4.6 ?$ & $18.4 ?$ \\
\hline M15** & $\mathrm{RI}^{2}$ & $>7.70 ?$ & $7.86 ?$ & $102.08 ?$ & $>60.52 ?$ & $5.6 ?$ & $7 ?$ & $39.2 ?$ \\
\hline M16** & $\begin{array}{l}\text { Germ } \\
\mathrm{LI}^{2}\end{array}$ & $8.23 ?$ & $6.73 ?$ & $81.77 ?$ & $55.39 ?$ & & & \\
\hline M17 & $\mathrm{RI}^{2}$ & $8.29 ?$ & $>7.03 ?$ & $84.8 ?$ & $58.28 ?$ & $5.5 ?$ & $5.9 ?$ & $32.5 ?$ \\
\hline M18** & $\begin{array}{l}\text { Germ } \\
\mathrm{LP}^{3}\end{array}$ & $7.01 ?$ & $9.2 ?$ & $131.24 ?$ & $64.49 ?$ & $5.3 ?$ & $8.7 ?$ & $46.1 ?$ \\
\hline M19 & $\mathrm{LM}^{3}$ & 9.5 & 12.88 & 135.58 & 122.36 & 7.9 & 11.3 & 89.3 \\
\hline $\mathrm{M} 20^{\star *}$ & $\mathrm{LM}^{2}$ & $>11.00 ?$ & $9.71 ?$ & $88.27 ?$ & $>106.81 ?$ & $9.13 ?$ & $8.13 ?$ & $74.2 ?$ \\
\hline \multicolumn{9}{|c|}{ DECIDUOUS } \\
\hline M21 & $\mathrm{RdI}_{2}$ & 5.8 & 5.01 & 86.38 & 29.06 & 4.1 & 4.6 & 18.9 \\
\hline $\mathrm{M} 22^{* *}$ & $\mathrm{LdM}_{1}$ & $>7.89$ & $>7.1$ & $89.99 ?$ & $56.02 ?$ & $>6.6 ?$ & $>6.6 ?$ & $43.6 ?$ \\
\hline
\end{tabular}

a Crown and cervical diameters and indices following Martin and Saller (1957) and Hillson et al. (2005), respectively.

b Partially digested teeth are indicated by**.

$c$ '?' and ' $>$ ' refer to minimal measured values in the case of digested teeth, incomplete tooth germs or teeth affected by interproximal wear.

\section{Crown discrete features}

The Arizona State University Dental Anthropology System (ASUDAS, Turner et al., 1991; Scott and Irish, 2017), or its expansion for Pleistocene humans (Bailey, 2002a, b, 2005; Martino'n-Torres et al., 2012), were used in the morphological description of the teeth depending on preservation. The ASUDAS is widely used to

describe Neanderthal teeth, and their plaques (as those from Burnett (1998) for the premolar accessory ridges) permit a more precise and accurate comparison at each degree of development, although we agree with Zapata et al. (2017) about the difficulties of making fine distinctions between adjacent grades.

The size and form of the toothpick grooves were described after Estalrrich et al. (2017).

\section{D and 3D enamel thickness}

For all of the Marillac teeth for which enamel, and in particular the EDJ, was visible on the mCT data (except for the partially digested M22 LdM1) the 3D distribution of enamel thickness was visualized in Avizo 6.3. To do so, we used the 'Surface distance' module and overlaid a color-coded map (modified after the 'physics.icol' colormap) onto the enamel surface.

We calculated the 2D and 3D enamel thickness indices (Martin, 1983, 1985; Kono, 2004; Olejniczak et al., 2008), and their respec- tive components for 11 teeth (10 permanent: M13A-G, M14, M15, M19, and one deciduous: M21) within the dental Marillac sample, following the guidelines provided by Benazzi et al. (2014; and SOMS4). For the crown, we calculated the enamel volume ( $\mathrm{mm} 3)$, the dentine plus pulp volume (DPV in $\mathrm{mm} 3$ ) and the EDJ surface area $(\mathrm{mm} 2)$. These measurements were used for the computation of both the average enamel thickness index (3D AET volume of the enamel divided by the EDJ surface area - this index is in 
millime- ters) and the relative enamel thickness index (3D RET 3D AET divided by the cubic root of the dentine volume - this index is scale-free) (Martin, 1985; see also Olejniczak et al., 2008). This was not possible for the other five teeth (M16, M17, M18, M20 and M22) because of their enamel alterations.

As far as dental wear is concerned, we did not perform a correction to compensate the reduction of dental tissues because protocols are not available for anterior teeth. For this reason, we preferred to provide enamel thickness values without introducing errors due to virtual reconstruction of digital model.

As a preliminary step for the analysis, the teeth were oriented in Geomagic Studio software (3D Systems, Rock Hill, South Carolina, USA) as explained in Benazzi et al. (2014a).

Results for M21 were solely compared to Neanderthal and modern human values found in the literature (Crevecoeur et al., 2010; Benazzi et al., 2015).

There are no comparative data on the enamel thickness of partially digested Neanderthal or other hominin teeth. When possible (i.e., in the case of M14 and M15), the comparison was undertaken with non- altered specimens of the same tooth class available in the Marillac dental sample (for both 2D and 3D enamel thickness; see Benazzi et al., 2015; Been et al., 2017; Buti et al., 2017). For instance, the partially digested M14 and M15 teeth were compared to the mean of M13A and M13B, and to the mean of M13C and M13D, respectively. Such comparisons are obviously not intended to increase our knowledge of Neanderthal enamel thickness variation, but to evaluate the ultimate effects of digestive (biocorrosive) processes.

\section{Morphology of the enamel-dentine junction (EDJ)}

A geometric morphometric (GM) analysis of the EDJ morphology was conducted on the LP3, LP4 and LM3 (the LM2 was deemed too worn to be included in the GM analysis). No GM analysis was per- formed on the EDJ of the M13E canine as we do not have compar- ative samples nor a landmark protocol for this tooth type. The comparative sample used for the EDJ analysis includes recent modern Homo sapiens, an early Neanderthal sample (ante- MIS 5e and MIS 5e Neanderthals dating to before $115 \mathrm{ka}$ ), and a late Neanderthal sample (post-MIS 5e Neanderthals dating to after $115 \mathrm{ka}$ ) [see SOM-S5 for a complete list of the comparative samples]. The voxel size of the comparative mCT data used for this analysis range from 15 to $50 \mathrm{~mm}$.

Geometric morphometric analysis of the EDJ was conducted using published protocols (Skinner, 2008; Skinner et al., 2008, 2009; Skinner and Gunz, 2010) and is summarized here as follows. The EDJ surface was extracted using Avizo 6.3 and landmarks were collected on the dentine horns, the marginal ridge running between the dentine horns, and around the cervix. For each specimen, homolo- gous landmarks and semilandmarks (Bookstein, 1997) were generated in Mathematica 8.0 (www.wolfram.com) using a soft- ware routine developed by Gunz et al. (2005), Skinner et al. (2008) and Gunz and Mitteroecker (2013). Afterwards, a principal component analysis (PCA) was performed on the homologous Procrustes shape coordinates to examine EDJ shape variation within the sample. Canonical variate analysis using principal components (PCs) was used to assess the morphological affinity of each tooth to the comparative taxa. In this case inclusive subsets of PCs were used

(LP3 e 3-14 PCs; LP4 e 3-14 PCs; and LM3 e 3-15 PCs) that explained

$\sim 95 \%$ of the variation in the PCA (Martin et al., 2017).

\section{Tooth root morphology}

Root metrics (i.e., root length, total root volume, pulp volume, total root surface area, and lingual and labial root surface areas for anterior teeth) were measured on the 3D models of twelve of the Marillac teeth (with complete or sub-complete root apex, thus excluding M16 and M18) as described in Le Cabec et al. (2013) and Kupczik and Hublin (2010). The Marillac root dimensions were then compared to the large samples of permanent maxillary and mandibular incisors and canines (Le Cabec et al., 2013), mandibular molars (Kupczik and Hublin, 2010), and maxillary third molars (Bailey, 2005). According to the statistical method described in Maureille et al. (2001) and in Scolan et al. (2012), adjusted z-scores (Azs) were used to test the position of the Marillac teeth with respect to the Neanderthal comparative samples (see SOM-S6 for details). In both deciduous and permanent molars, the degree of taur-odontism was assessed in two ways. First, the index defined by Wright (2007) was calculated on 2D virtual sections of the teeth. Second, using 3D models, the volume of the root stem was sepa- rated from the volume of the root apex at the level of the root furcation. This allowed us to calculate a volume index as described in Kupczik and Hublin (2010), and following Keene's 
(1966) clas- sification referring to different degrees of expression (see SOM-S6 for details). No comparative 3D data were found for the maxillary premolars, nor for the deciduous molar.

Some of the Marillac teeth had their root tips broken, the missing portions were thus modelled as cones for the anterior teeth (M14 and M15; see Le Cabec et al., 2013) and permanent molar (M19), or as a wedge for the deciduous molar M22. The linear dimensions of these geometric shapes were measured on virtual 2D sections of the broken teeth. This allowed for a correction of root length, surface area, and volume (including the 3D index for taur- odontism). This correction was applied also to partially digested teeth for which the root tip was clearly missing (M20 and M22), although this would not compensate for the whole loss of material. Finally, we describe the presence of hypertrophic cementum on some of the Marillac tooth roots, as described in d'Incau (2012) and Le Cabec et al. (2013). The diagnostic for hypercementosis was first based on the observation of the external root surface on the original specimens (i.e., rough and irregular surface of the root, as well as difference of color in comparison with the dentine). The inspection of the $\mathrm{mCT}$ scans allowed then for the identification of a hard tissue overlaying the dentine root surface, with a slight difference in contrast, and a more regular distribution around the root axis.

\section{Results}

Taking into account the degree of crown and root development, as well as the tooth type and the degree of occlusal wear, we es- timate a Minimum Number of Individuals (MNI) of nine (Table 1). Three are diagnosed as adults (M14, M17, M20) and six as immature individuals, five of which were juveniles bet ween $\sim 2.4$ and $\sim 14$ years old (M21, M22, M16, M18, and M15), the sixth and best represented individual corresponds to the adolescent M13, esti- mated to be $\sim 15.5$ years.

\section{Morpho-anatomical description}

Individual Marillac 13 (M13) As previously indicated, this juvenile individual is represented by five upper permanent anterior teeth, M13A-E (the four incisors, and the right canine) recovered in close proximity (Fig. 1C and SOM-S1) in level C10, square F12. The premolars M13F and M13G (square F13, probably from the base of C9; Fig. 1C) were also from individual M13.

The individual's age at death is estimated at 15.5 years using modern human standards (AlQahtani et al., 2010). This is suggested given the premolars' roots are completely formed and their apices closed. Additionally, none of the seven teeth show significant wear. Instead, using the averaged data for the estimated ages of both sexes (since there is no sex diagnosis for M13) published in Table A.1 (Shackelford et al., 2012), the age at death could be $\sim 14$ years (standard deviation of $\sim \pm 1.4$ years).

If the M19 LM3 belonged to M13, its age at death could be $16.1 / 16.5$ years based on modern human standards (AlQahtani et al., 2010; Shackelford et al., 2012). Even though age estimation is complicated by several limiting factors, it is possible to conclude that individual M13 died probably in the late juvenile period. M13A upper right permanent central incisor This RI1 is very-well preserved except for some cracks on the crown and another on the root, none of which have notably altered the size or morphology of the tooth (Table 2; SOM-S7:1e5). The crown shows little wear on the occlusal edge where the dentine is exposed as in Molnar's (1971) stage 3. The labial face (Fig. 2A) has a nearly straight mesial angle, whereas the distal one is rounded. M13A RI1 possesses a very convex buccal side (ASUDAS grade 4; Fig. 2F), while the cervical line is quite straight.

The lingual face (Fig. 2B) shows a very well developed basal tubercle (ASUDAS grade 4) and two marked lateral crests originate from it. Two small central and joined crests (digits), with very little relief, a lso originate from the basal tubercle. The typical 'shovel shape' shown by M13A RI1 matches ASUDAS grade 5 (strong). On the mesial face (Fig. 2C), the cervical line forms a pronounced curve towards the incisal surface where there is a small depression. The crown presents a minute and flat interproximal facet $(\sim 3.5 \mathrm{~mm}$ tall and $\sim 2.1$ $\mathrm{mm}$ wide). The occlusal edge is wide and in bevel towards the lingual side.

On the distal side (Fig. 2D), just above the cervix, there appears a small depression, and, on the crown, another small flat interprox- imal facet $(\sim 2.9 \mathrm{~mm}$ tall and $\sim 2.2 \mathrm{~mm}$ wide) is visible.

The root is robust, with the apical region (Fig. 2A-D) slightly inclined towards the mesial side, the apex is closed, and some hypercementosis occurs around the apical region (covering $12 \mathrm{~mm}$ ). The X-ray (Fig. 2E) as well as the mCT scans (SOM-S7: 3e4) show a wide pulp cavity.

Detailed macroscopic observation shows the presence of two linear enamel hypoplasias (Fig. 3G, arrows; SOMS7:1): the first and more cuspal is found $\sim 6.3 \mathrm{~mm}$ from the crown cervix, and the second at $\sim 4.2 \mathrm{~mm}$. 
Two very small hypoplastic pits are visible along the mesio- lingual marginal ridge (Fig. 2-F) and one pit occurs at the distal ridge. It is also worth noting that a small enamel chip broke off from the distal angle of the buccal face (Fig. 2D; SOM-S7:1), leaving an irregular patch of enamel ( $2.6 \mathrm{~mm}$ tall and $\sim 1.8 \mathrm{~mm}$ in its widest part) on the occlusal edge.

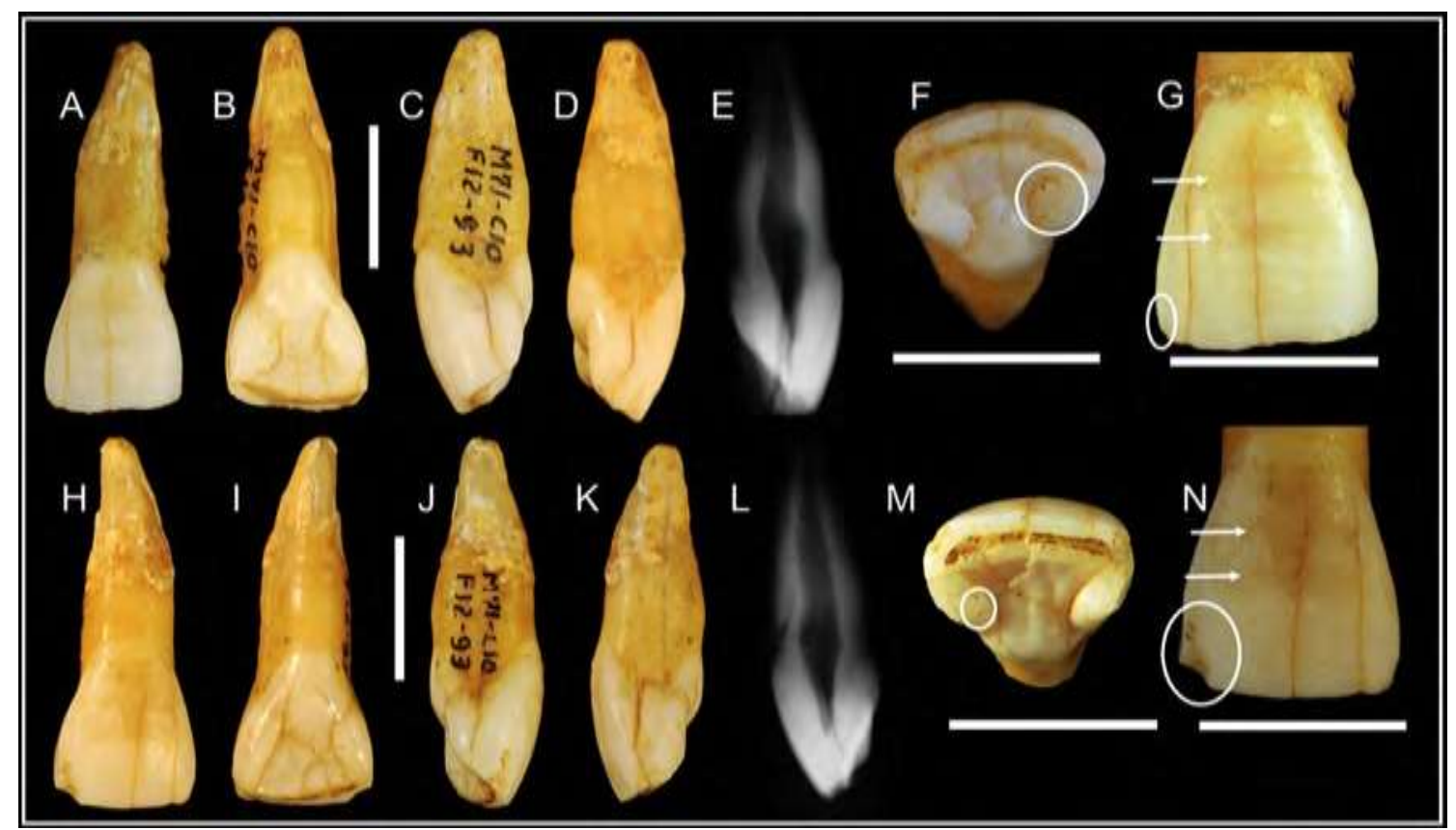

Figure 2. Marillac 13. M13A RI1: (A) Buccal, (B) Lingual, (C) Mesial, (D) Distal, (E) X-ray distal face, (F) Occlusal, (G) Crown buccal view of the two hyploplastic lines and mesial and distal chipping. M13B LI1: (H) Buccal, (I) Lingual, (J) Mesial, (K) Distal, (L) X-ray distal face, (M) Occlusal, (N) Crown buccal view of the two hyploplastic lines and mesial chipping. Scale: $10 \mathrm{~mm}$.

M13B upper left permanent central incisor This LI1 is well- preserved (Table 2; Fig. 2H-N. SOM-S8) except for a few cracks and a minor loss of substance at the root tip, affecting the hypercementosis. The tooth is very similar to M13A in color, shape, size and degree of incisal wear (stage 3, Molnar, 1971), and the two mild mesial interproximal facets fit perfectly. Therefore, M13B LI1 is undoubtedly the antimere of M13A RI1.

M13B possesses the same features as M13A (little curvature of the cervical line, nearly straight mesial margin, Fig. $2 \mathrm{H}$ ), as well as similar direction of the occlusal plane, and marked convexity of the labial face (ASUDAS grade 4).

The lingual face (Fig. 2I) is 'shovel-shaped' (ASUDAS grade 5, strong), with a very prominent lingual tubercle (grade 4) and marginal ridges, although within this particular tooth the small central crests have more relief and merge when reaching the lingual fossa.

On the mesial side (Fig. 2J), there is a deep inflection of the cervical line, and a small, oval interproximal facet ( $\sim 3.5 \mathrm{~mm}$ tall and $2.4 \mathrm{~mm}$ wide) very similar to that of M13A.

The distal face (Fig. $2 \mathrm{~K}$ ) shows a smaller oval contact facet $(\sim 2.3 \mathrm{~mm}$ tall and $\sim 1.9 \mathrm{~mm}$ wide).

The robust root also has a closed apex and the apical third shows a similar degree of hypercementosis (despite having lost a small part of it; SOM-S8:4e5), however reaching farther down (it is 13.8 mm tall) than on the RI1. The X-ray (Fig. 2L), and the mCT scans (SOM-S8:3e4) show a wide pulp cavity.

The presence of two linear hypoplasias (white arrows in Fig. 3N; SOM-S8:1) on the labial face are also noted on this tooth. The first is more cuspal and is found $\sim 6.3 \mathrm{~mm}$ from the cervix, and the second at $\sim 4.5 \mathrm{~mm}$. There are also two small hypoplastic pits (Fig. 2M) on the enamel of each of the lingual crests.

Furthermore, similar to what is seen on M13A, a small chip of enamel with the shape of an inverted V was lost antemortem (white circle in Fig. 2N; SOM-S8:1), from the incisal edge and next to the mesial angle.

M13C upper right permanent lateral incisor This RI2 is very well- preserved (Table 2, SOM-S9:1e5) with the exception of a vertical crack on the crown, clearly visible on the mesial and distal aspects. The occlusal edge shows little wear (Fig. 3F), with no dentine exposure (stage 2, Molnar, 1971), and slightly bevels towards the 
lingual face with respect to the corresponding anatomical position.

The labial face (Fig. 3A) has a mostly-vertical distal edge, whereas that of the mesial is oblique, creating a more acute angle on the occlusal plane.

The lingual side (Fig. 3B) shows the moderate development of the tubercle (ASUDAS grade 3) and the marked mesial and distal marginal ridges joined to it, giving rise to a deep and closed central depression. The general shape of this tooth is also 'shovel' - like, and matches ASUDAS grade 5 (strong). From an occlusal view, the strong curvature of the labial face can be observed (ASUDAS grade 4).

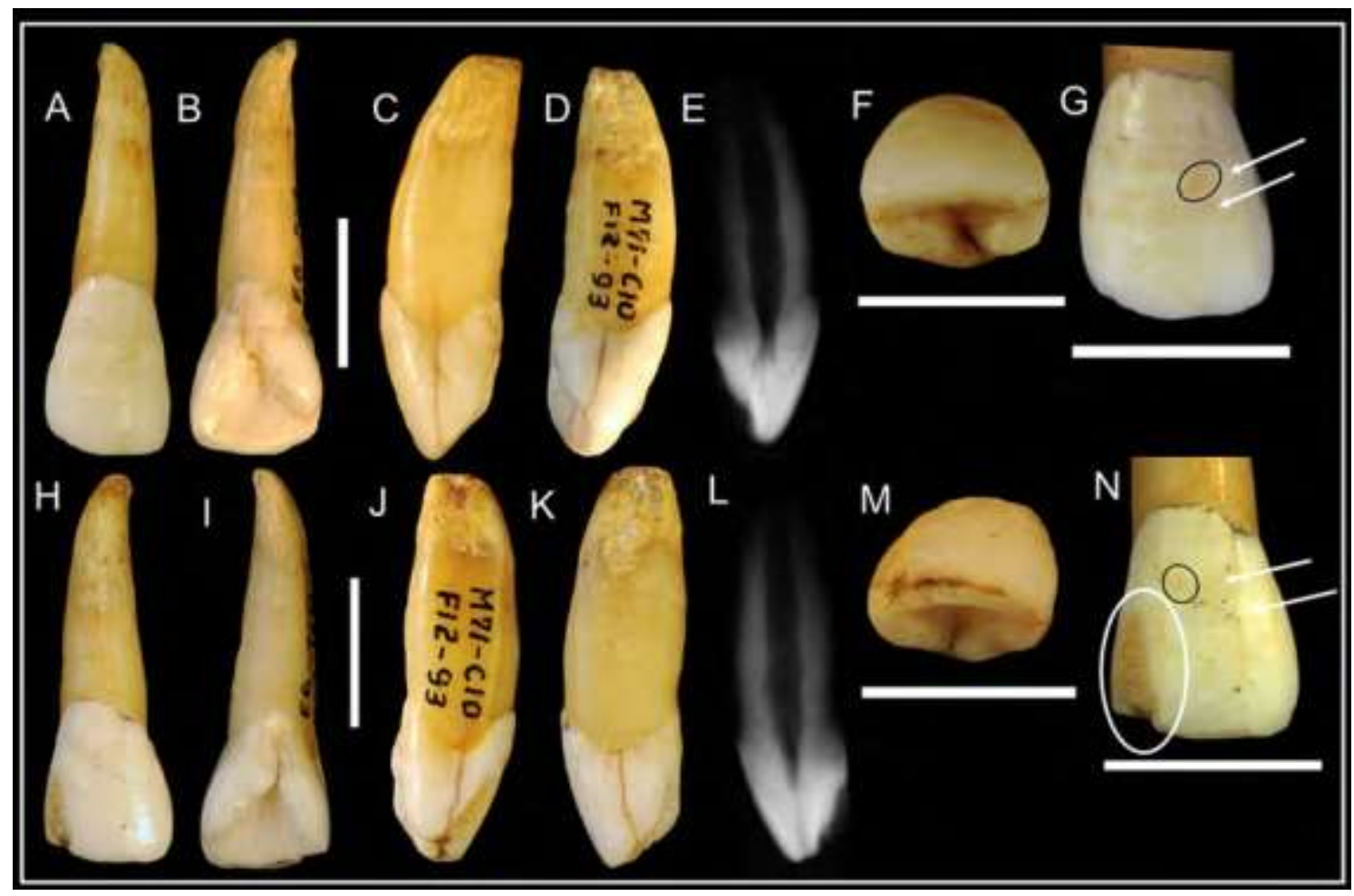

Figure 3. Marillac 13. M13C RI2: (A) Buccal, (B) Lingual, (C) Mesial, (D) Distal, (E) X-ray distal face, (F) Occlusal, (G) Crown buccal view of the hyploplastic lesions and the fossa (black circle). M13D LI2: (H) Buccal, (I) Lingual, (J) Mesial, (K) Distal, (L) X-ray distal face, (M) Occlusal, (N) Crown buccal view of the hyploplastic lesions, the fossa (black circle) and of the large mesial chipping. Scale: 10 $\mathrm{mm}$.

There is a small, oval interproximal facet $(\sim 3.2 \mathrm{~mm}$ tall and $\sim 2.1 \mathrm{~mm}$ wide) on the mesial side, joining the distal face of the RI1 M13A. The distal face (Fig. 3D) does not present any contact facet. The root is robust, with a slight depression on the mesial face.

The apex is closed and the apical third, with hypercementosis extending $\sim 7.5 \mathrm{~mm}$, is leaning to wards the distal side. The X-ray (Fig. 3E) and the mCT scans (SOM-S9:4) show a wide pulp cavity.

There are two hypoplastic linear defects at $\sim 6.7 \mathrm{~mm}$, and at $\sim 4.3 \mathrm{~mm}$ from the cervix on the labial face of the crown (Fig. 3G, white arrows; SOM-S9:1) and three small pits on each one of the lingual marginal crests (SOMS9:1). There is also a small and shallow oval depression $(\sim 2.51 .4 \mathrm{~mm})$ on the mesial side of the labial face (Fig. 3G, black circle; SOM-S9:1e2), running diagonally and $\sim 2.5 \mathrm{~mm}$ from the cervical line. Although the EDJ is damaged by a crack, this fossa can be seen in occlusal view affecting also the dentine (SOM-S9:1e2). Another smaller punctiform depression appears to concern only the enamel on the upper distal half of the crown.

M13D upper left permanent lateral incisor This LI2 is similar to M13C (Table 2, SOM-S10). It also shows a crack along the mesiodistal axis of the crown, and has a broken root tip. The labial face is quite convex (ASUDAS grade 4; Fig. 3M). A very prominent lingual tubercle (grade 4; Fig. 3I) is associated with the marginal ridges and the shovel shape matches ASUDAS grade 5 (strong). The occlusal edge (Fig. 3M) is slightly worn, with dentine exposed (stage 3, Molnar, 1971).

It has a small, oval interproximal facet ( $2.4 \mathrm{~mm}$ tall and $\sim 1.6 \mathrm{~mm}$ wide; SOM-S10:1) on the mesial face (which matches with the corresponding one on the LI1), but none on the distal side. The mesial face (Fig. 3J) shows one 
flat sulcus along the root, which is flatter on the distal face (Fig. 3K). The root is robust (SOM-S10) with traces of hypercementosis over $\sim 6.6 \mathrm{~mm}$ around the closed apex. The X-ray (Fig. 3L) and the mCT scans (SOM-S10) also show a wide pulp cavity.

This tooth has several enamel hypoplastic defects, such as seven small pits on the marginal lingual crests (4 on the distal, 3 on the mesial). There are also two linear hypoplasias (Fig. 3N; SOM-S10:1) at similar crown heights as on M13C, although slightly less pro- nounced. Furthermore on the labial face, at $\sim 2.3 \mathrm{~mm}$ from the mesial and $\sim 6.0 \mathrm{~mm}$ from the occlusal edges, there is an oval depression on the enamel (Fig. 3N, black circle; SOMS10:1) running diagonally with regard to the tooth's vertical axis. It is a similar lesion to that observed in M13C, although slightly larger. They are both located at the same height and on the mesial half of the crowns. Because the EDJ of M13D is not affected by any crack, one can safely identify the expression of this fossa on the dentine surface (SOM-S10:2).

Probably not long before the individual's death, a microtrauma caused the breakage of a large, inverted Vshaped enamel chip ( $\sim 5.2 \mathrm{~mm}$ tall and $2.6 \mathrm{~mm}$ wide on the occlusal edge) near the mesial angle (Fig. 3N; SOMS10:1). The edges of the lesion are slightly polished due to exposure to saliva, and abrasion against lips and food. M13E upper right permanent canine This RC1 is well preserved (Table 2; SOM-S11) except for a few cracks, a slight loss of enamel on the upper part of the crown (labial face), as well as a small break on the apical end of the root.

The crown shows no abrasion (stage 1, Molnar, 1971) so that the incisal edge is very pointed (Fig. 4A-G; SOMS11:1), with a shorter mesial margin compared to the distal, which gives rise to a rounded and prominent angle. The labial face is very convex (ASUDAS grade 4; Fig. 4A), with a marked central crest and pronounced lateral fossae. The root is robust and leans distally.

The lingual aspects of both the crown and root (Fig. 4B; SOM-S11:1) are narrower than the buccal ones, and very asymmetric. The lingual cingulum is very prominent (ASUDAS grade 5) with a small protrusion towards the mesial side; the marginal crests are prominent and form part of the lingual tubercle. The distal ridge is very big and the distal accessory ridge matches ASUDAS grade 5e ('DAR-UC'). The mesial crest is less developed than the distal one, and the accessory ridge is very prominent, more than in ASUDAS grade 3 ('CMR-Bushman canine'). The two lateral fossae are large, particularly the distal fossa.

The mesial face of the tooth is buccolingually thick (Fig. 4C; SOM-S11:1). The lingual outline is very irregular, with the promi- nent lingual tubercle, the concavity of the central part of the crown, and the protrusion on the mesial marginal crest. The cervical line forms a wide and deep depression. There is no trace of an inter-proximal facet. A ridge runs along the wide root, up to the apex.

The distal face (Fig. 4D; SOM-S11:1) is very similar to the mesial one, with a more accentuated protuberance of the marginal crest. The root's longitudinal ridge is less marked.

The crown is asymmetric in occlusal view (Fig. 4F), with a prominent cusp tip, mesial thickening, and the extension of the distal portion. The upper part of the root is slightly damaged, but traces of hypercementosis (SOM-S11:5) still remain $\sim 7 \mathrm{~mm}$ around the apex. The apex is broken but it could have been closed. The X- ray (Fig. 4E) and the mCT scans (SOM-S11:4e5) show a wide pulp cavity.

This canine has several enamel hypoplastic lines on the labial face, two of them very prominent (big arrows on Fig. 4G). The most cuspal line stands at $\sim 7.9 \mathrm{~mm}$ with regard to the cervical line, whereas the uppermost is at $\sim 5.0 \mathrm{~mm}$. There also are several other enamel-formation defects (some depressions and two pits; Fig. 4G, red ellipse; SOM-S11:1), all on the same side. The approximate age of formation of these hypoplastic defects is, bearing in mind the variation in the development of the crown, $\sim 3$ years according to modern human standards (Gustafson and Koch, 1974; Reid and Dean, 2006; Hillson, 2014). The breakage of an enamel chip (Fig. 4G; SOMS11:1) was noted on this canine, between the crown's apex and the inciso-distal angle. 


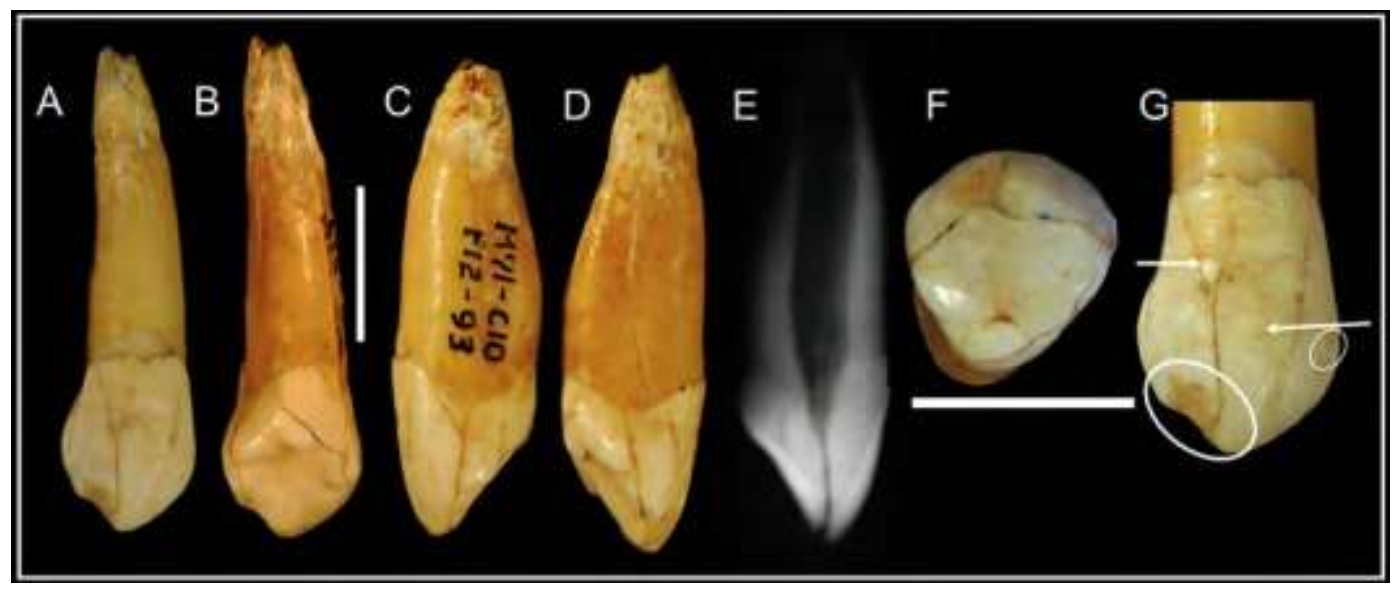

Figure 4. Marillac 13. M13E RC': (A) Buccal, (B) Lingual, (C) Mesial, (D) Distal, (E) X-ray distal face, (F) Occlusal, (G) Crown buccal view of the hyploplastic lines and mesial chipping. Scale: $10 \mathrm{~mm}$.

M13F upper left permanent first premolar This LP3 (Table 2; SOM- S12) is well preserved except for the loss of some root substance and some cracks. There are minimal wear traces (Fig. 5F) on the lingual cusp (stage 2, Molnar, 1971), and no interproximal facets.

The buccal face (Fig. 5A) widens towards the occlusal border, with prominent angles and a rounded cusp tip, slightly pointed in the middle. The root is conical and its apex leans distally.

The lingual cusp, mesially tilted (Fig. 5B), and the lingual root are smaller than the vestibular ones.

The mesial face (Fig. 5C) shows the differential development of the two cusps and the prominence of the buccal one, demarcated by an enamel hypoplastic line (Fig. 5F; SOM-S12:1). The mesial marginal ridge is clearly marked. The roots were joined by a con- necting plate of dentine and cementum up to more than half of their height (the layer is broken in its apical portion; see SOM- S12:1e5).

The distal face (Fig. 5D) is slightly different than the mesial one, with a shallower marginal ridge. The connecting plate of dentine and cementum between the two roots is pronounced. The broken apices show traces of hypercementosis.

The crown occlusal view (Fig. 5F) has the characteristic hexag- onal shape, with a protuberance of the central region of the vestibular cusp, the marked mesio- and distobuccal angles, and the convergence of the mesial and distal profiles towards the lingual region. The transverse crest is interrupted by the sagittal sulcus (grade 1; Martino'n-Torres et al., 2012). The tip of the paracone emerges from the thin essential crest (MxPAR grade 1; Burnett, 1998), extending toward the mesial side up to the central ridge. The essential crest of the protocone (MxPAR grade 1; Burnett, 1998) branches off towards the distal side. A small accessory ridge is present in the middle of the mesio-lingual region and another one on the distobuccal part (MxPAR grade 3; Burnett, 1998). The distal triangular fossa is deeper than the mesial one.

Both roots are not very robust. They have hypercementosis on their apices (the lingual root is broken), which were probably closed (Fig. 5G; SOM-S12:5). The X-ray (Fig. 5E) and the mCT scans (SOM-S12:4) show a wide pulp cavity and the spreading of the canals inside both roots (SOM-S12:3e4).

One enamel hypoplastic line (Fig. 5F, white arrow; SOM-S12:1) surrounds the crown and it is more noticeable on the vestibular face (at $\sim 5.9 \mathrm{~mm}$ from the cervical line), where there are also two very small hypoplasia pits near the distal side. No trace of these two developmental defects could be observed on the 3D models of the EDJ.

M13G upper left permanent second premolar This LP4 is well preserved (Table 2; SOM-S13:1e5) except for a few breaks on the root apices and some cracks on the crown. It also lacks interproximal facets and the occlusal wear (Fig. 5M) corresponds to Molnar (1971) stage 1.

The vestibular aspect of the crown (Fig. 5H) is quite similar to that of the M13F P3 previously described, although it is slightly larger, longer, and its mesio- and disto-buccal angles are more prominent. The root tilts distally. The lingual side (Fig. 5I) shows the different cusp sizes, with the buccal cusp being taller than the lingual.

The mesial face (Fig. 5J) lacks a mesial ridge on the marginal edge, and shows a convexity of the crown buccal side up to the cervical line. The two roots are joined up to $\sim 2.2 \mathrm{~mm}$ before the apices (broken).

There is a small and short groove on the crown distal face (Fig. 5K), which emerges from the middle of the marginal edge. The convexity of the crown and the lateral prominence of the two cusps, especially of the buccal 
one, are clearly visible. The two roots appear separated from $\sim 10.4 \mathrm{~mm}$, and the connecting plate of dentine and cementum on the mesial side is visible (SOM- S13:1e2).

In the occlusal view (Fig. 5M), the general profile is slightly ovoid, with quite rounded mesio- and disto-lingual angles. The transverse crest is interrupted by the sagittal sulcus (grade 1; Burnett, 1998; Martino'n-Torres et al., 2012). A wide, short, and tilted ridge branches out mesiodistally from the buccal cusp to-

wards the central ridge, and another smaller one emerges from the protocone (both grade 1; Burnett, 1998). The mesial and distal fossae are deep. A small accessory crest (MxPAR grade 3; Burnett, 1998) emerges next to the lingual crest, towards the mesial side. One enamel hypoplastic line surrounds the crown (Fig. $5 \mathrm{M}$ white arrow; SOM-S13:1), being more visible on the vestibular face (at $\sim 3.4 \mathrm{~mm}$ from the cervical line).

The roots are robust, also showing hypercementosis at $\sim 8.7 \mathrm{~mm}$ around the apices, with broken tips (Fig. $5 \mathrm{~N}$; SOM-S13:5). The X-ray (Fig. 5I) and the mCT scans (SOM-S13:3e4) show the root canal extensions and a wide pulp chamber, similar to that of M13F.

Isolated teeth Seven permanent and two deciduous isolated teeth were also found.

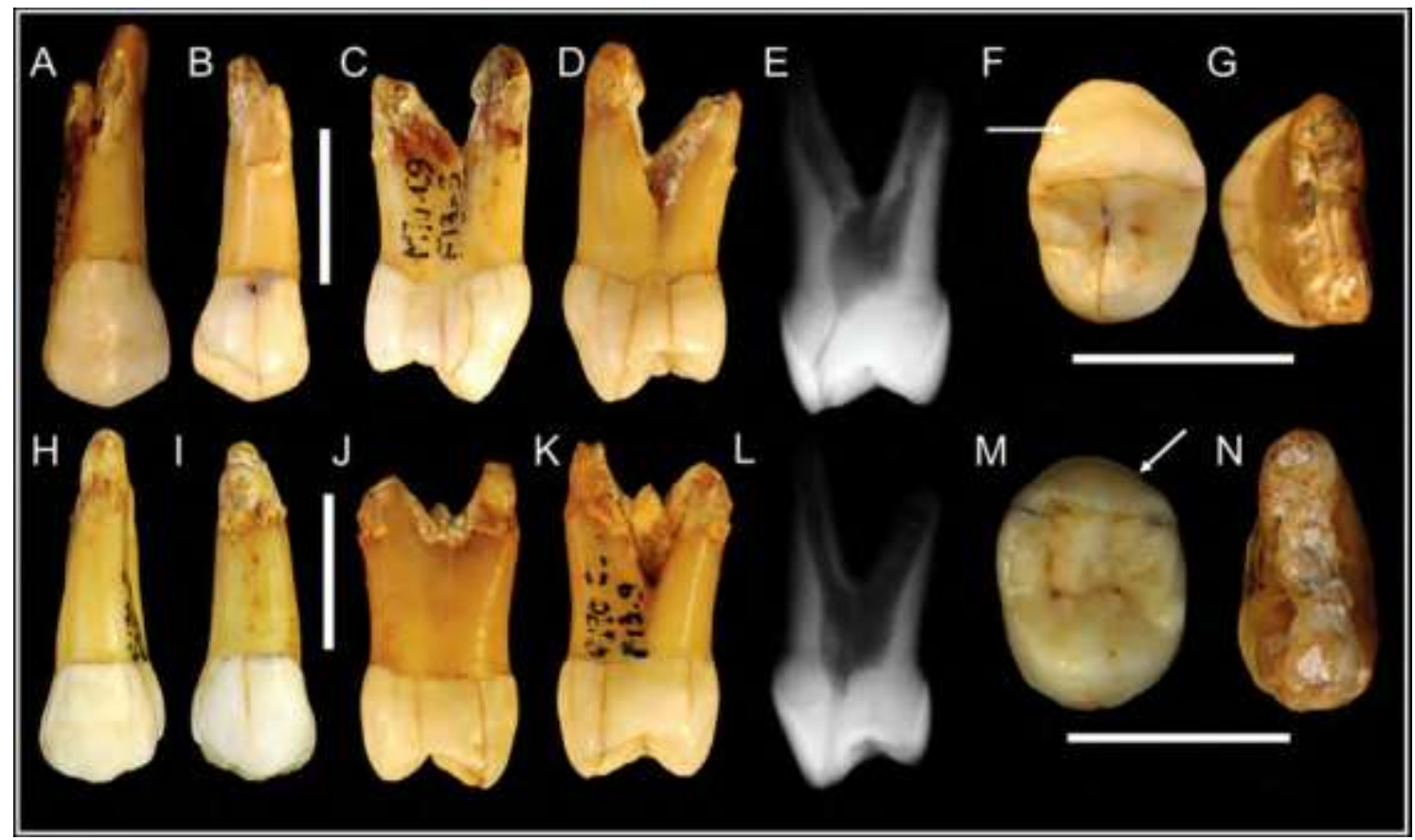

Figure 5. Marillac 13. M13F LP3: (A) Buccal, (B) Lingual, (C) Mesial, (D) Distal, (E) X-ray distal face, (F) Occlusal (arrow shows the hypoplastic line), (G) Root apices. M13G LP4: (H) Buccal, (I) Lingual, (J) Mesial, (K) Distal, (L) X-ray distal face, (M) Occlusal (arrow marks the hypoplastic line), (N) Root apices. Scale: $10 \mathrm{~mm}$.

M14 upper right permanent central incisor Partial digestion has extensively altered both the crown (Table 2) and the root of this RI1. The enamel has been nearly destroyed (Fig. 6AeD; SOM-S14:1) by abrasion and breakage in most of the upper part of the buccal, mesial and distal faces, as well as on the lingual tubercle. The remaining portion is white, pitted, faded, and rough to the touch. The root, with an open apex (Fig. $6 \mathrm{H})$, is very thin, as if its external layers of cementum and part of the dentine dissolved, leaving behind an internal layer protecting the pulp cavity. A small round hole opens in the lower buccal side (Fig. 6AeD; SOM-S14:1, 4).

The shovel-shaped crown (Fig. 6B) matches ASUDAS grade 2, whereas the labial convexity corresponds to grade 3 , but both (shovel-shaped and convexity) were altered. There is a prominent lingual tubercle (ASUDAS grade 3) from which two enamel digits and mesial and distal ridges emerge. The occlusal edge is straight and shows a line of dentine (Fig. 6G), as in Molnar's (1971) stage 3.

The X-rays (Fig. 6E) and the mCT scans (SOM-S14:4) show a wide pulp cavity. 
crown because it is missing at the cervical third and, when present, it is also very thin and faded, especially on the lingual side.

It shows a slight abrasion on the occlusal edge, which is altered, not horizontal and with a breakage on the mesial angle (Fig. 6O). It would therefore match stage 2 or 3 of Molnar (1971). We assigned M15 to a young individual. The labial face (Fig. 6I) is curved (ASUDAS grade 4) with a mostly-vertical mesial border, whereas the distal border tends to widen and form a more open angle. The lingual face (Fig. 6J) shows the prominent tubercle and marginal ridges joined to it, which gives rise to a deep central depression. This tooth is also shovel-shaped (ASUDAS grade 5). The mesial face (Fig. 6K) shows a large, oval, flat interproximal facet ( $3.4 \mathrm{~mm}$ wide and $\sim 1.8 \mathrm{~mm}$ high), and a deep concavity in the path of the cervical line. The distal face (Fig. $6 \mathrm{~L}$ ) does not show any interproximal facet, and both lateral sides show the bulging morphology of the buccolingual aspect of the crown. Despite the taphonomic alterations, the root (Fig. 6IeL) is rela-tively robust with a slight depression on the distal face, markedly curved and without reliefs. The apex is open (Fig. 6P; SOM-S15:1e2, 4). The X-rays (Fig. 6M N) and the $\mathrm{mCT}$ scans (SOM-S15:4) show a very wide pulp chamber.

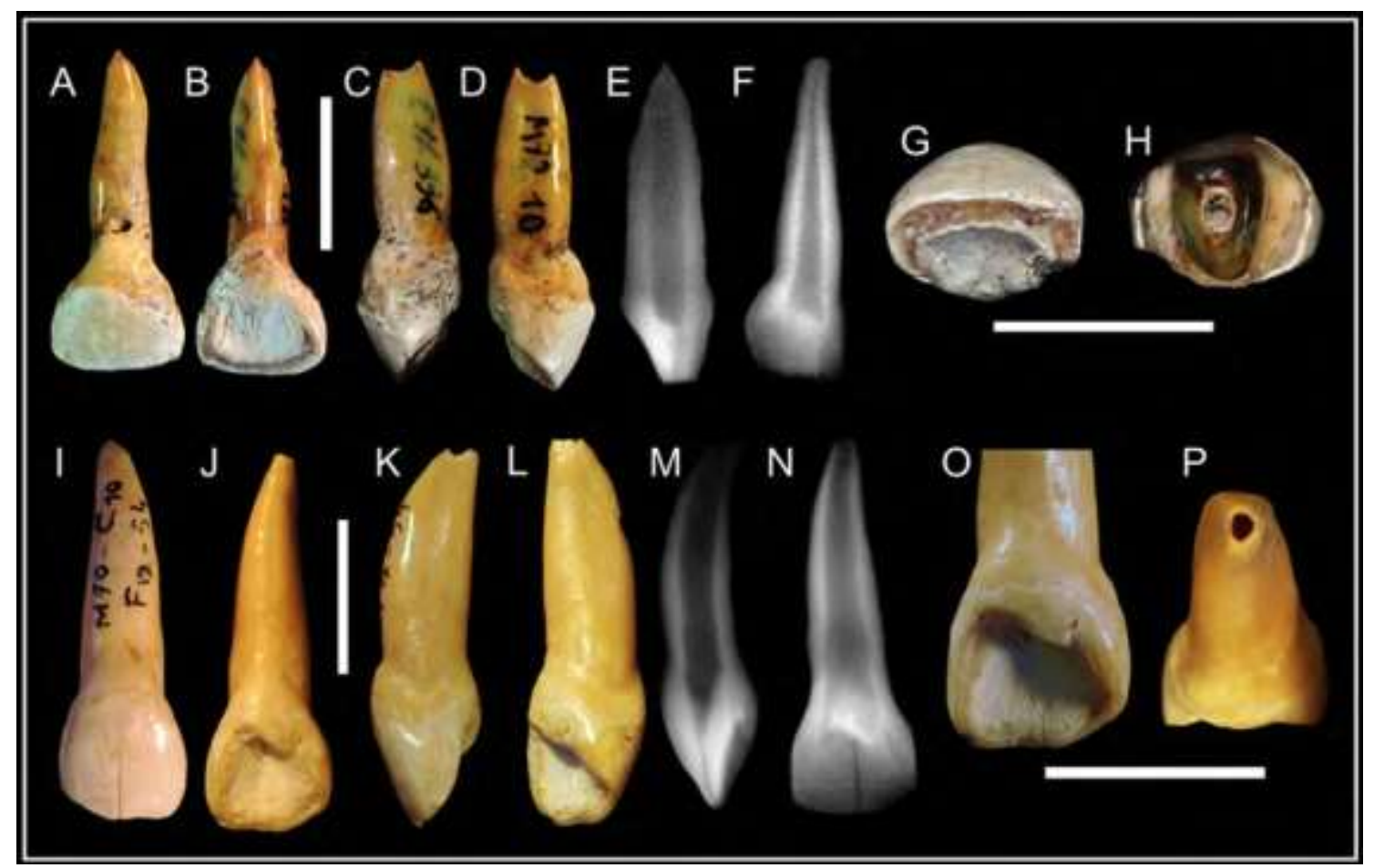

Figure 6. Marillac 14 RI1: (A) Buccal, (B) Lingual, (C) Mesial, (D) Distal, (E) X-ray distal face, (F) X-ray buccal face, (G) Occlusal, (H) Root apex. Marillac 15 RI2: (I) Buccal, (J) Lingual, (K) Mesial, (L) Distal, (MeN) X-rays distal and lingual faces, (O) Detail of lingual side, (P) Root apex. Scale: $10 \mathrm{~mm}$.

M16 upper left permanent lateral incisor This specimen is a fairly complete germ of a LI2 (maximum crown height $10 \mathrm{~mm}$ ). It was probably also ingested, modified by partial digestion and regurgi- tated or defecated. M16 has not yet reached crown completion as the lingual tubercle is still incomplete (Fig. 7B; SOM-S16). It almost matches Moorree's 'Crc' category (in AlQahtani et al., 2010), allowing estimation of the child's age at death to be around 5.5 years.

The crown is very well preserved (Table 2) except for a small chip that broke off post-mortem from the occlusal border (Fig. 7A- B), where the edge's lobes can be seen.

M16 is a large incisor, especially mesiodistally, with a very convex labial face (ASUDAS grade 4). The not fully developed lingual tubercle (Fig. 7B) is very prominent (suggesting a match to ASUDAS grade 3) with an enamel digit on the distal half, well demarcated by two ridges of which the mesial is larger. The mar- ginal ridges are also marked and the distal one is thicker. Its typical 'shovel-shaped' morphology scores between categories 4 and 5 of the 'Shov. UI-2' ASUDAS reference plaque. Mesial and distal faces (Fig. 7C-D) are bulging. The apical view exposes the wide pulp cavity (SOM-S16:1e2,4) and internal relief of the lingual tubercle. There is no sign of dental hypoplasia, but the enamel appears very altered and pitted, having lost its outer layers and shine. In addition, and because of the partial digestion of the tooth, the enamel is very altered and thin around the cervix 
and mainly in the cervical half of the distal region (Fig. 7A-D), exposing the dentine.

M17 upper right permanent lateral incisor This RI2 is well pre- served except for a vertical crack running down the lingual face (Fig. 7E), loss of substance on the crown mesial side, and slight root apex damage (SOM-S17). Pronounced occlusal wear removed half of the crown height (stage 5, Molnar, 1971), nearly reaching the lingual tubercle (Fig. 7F; SOM-S17:1). This worn tooth, M17, can be assigned to an adult, older than any of the Marillac individuals described above.

On the labial face (Fig. 7E), one can observe the curvature of the cervical line. On the lingual side (Fig. 7F), the tubercle (ASUDAS grade 5) is prominent and gives rise to two marginal crests (SOM- S17:1e2), yielding the typical shovel-shape morphology. The mesial part of the crown is broken (Fig. 7G), but the distal one (Fig. $7 \mathrm{H}$ ) shows a large flat contact facet (with the canine) approximately $4.7 \mathrm{~mm}$ wide and $4.0 \mathrm{~mm}$ high. The apex of the robust root tilts mesially, displays signs of hypercementosis (SOM- S17:4e5), and has an open tip probably caused by post-mortem erosion. The X-ray (Fig. 7I) and the mCT scans (SOM-S17:4) display a narrow pulp cavity (highly different from that of M13C and M13D) showing some adhesive sediment, or traces of pulp calcification. This incisor also shows evidence of a microtrauma that broke off a large enamel chip ( $\sim 4.5 \mathrm{~mm}$ tall and $2.3 \mathrm{~mm}$ wide on the occlusal edge) from the distal angle on the labial crown face (Fig. 7E -white circle-, and J. SOMS17:1).

Considering that the edges of the broken enamel patch are polished, the microtrauma might have occurred sometime before death. On its labial face, M17 has also two enamel linear hypopla- sias, the most cervical one is found at $\sim 2.5 \mathrm{~mm}$ from the cervix (SOM-S17:1 red arrows), and the most cuspal defect ( $4.9 \mathrm{~mm}$ below the cervical line) shows a small pit with no enamel.

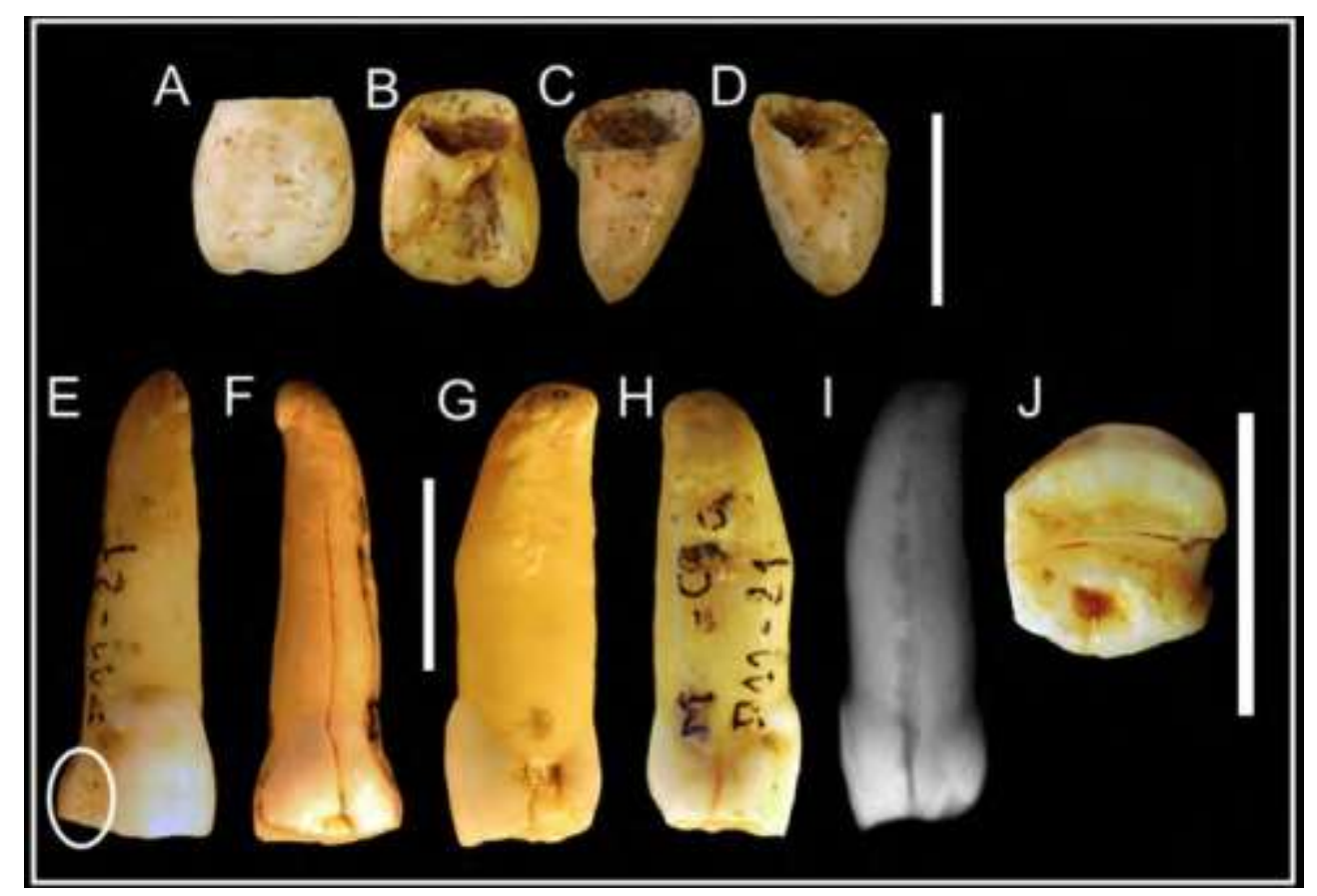

Figure 7. Marillac 16 LI2: (A) Buccal, (B) Lingual, (C) Mesial, (D) Distal. Marillac 17 RI2: (E) Buccal (white circle indicates the chipping lesion on distal angle), (F) Lingual, (G) Mesial,

(H) Distal, (I) X-ray mesial face, (J) Detail of occlusal side. Scale: $10 \mathrm{~mm}$.

M18 upper left permanent first premolar This germ of an imma- ture LP3 (Fig. 8A-G; SOM-S18) still has developing roots (stage R1/2 of Moorrees et al., 1963b) which reveal a wide and single pulp cavity. This is, therefore, an unerupted tooth, and in fact does not show occlusal wear (Fig. 8G; stage 1 of Molnar, 1971). The estimated age at death, following modern human standards, is approximately 10.5 years according to AlQahtani et al. (2010). The tooth is well preserved although it shows some small cracks and loss of enamel on the four sides, particularly on the buccal one, just before the cervix and at the distobuccal angle. Note that some enamel broke at the distobuccal angle after the capturing of the pictures; consequently, the angle is visible on Figure 8, but it is broken on SOM-S18:1 (red rectangle). The considerably thin enamel (not covering the whole crown), its 
color and texture, as well as the reduced root thickness (coated in Paraloid), suggest that this is another partially digested tooth. Consequently, its diameters (Table 2) were altered, and are smaller than those of M13F described above.

The vestibular face (Fig. 8A) widens at the cervix, with promi- nent angles (more accentuated on the distal portion) and a rounded and slightly pointed mamelon in the middle. The lingual cusp (Fig. $8 \mathrm{~B}$ ) is smaller and tilts mesially.

The mesial side (Fig. 8C) shows the differential development of the two cusps, with the vestibular one being the largest. The lingual profile is quite straight, and the cervical line formed a wide and shallow depression. The mesial marginal ridge groove is missing. The roots are fused throughout (SOM-S18:1e2, 4). The distal face (Fig. $8 \mathrm{D}$ ) is very similar to its mesial counterpart, though with a shallower ridge. The depression between the roots begins approximately $13.9 \mathrm{~mm}$ above the estimated position of the cer-vical line.

The occlusal face (Fig. 8G) has the classic hexagonal shape, with a protuberance of the vestibular cusp central region, the prominent mesio- and disto-vestibular angles, and the convergence of the mesial and distal profiles towards the lingual region. A single transverse crest descends from the paracone (pointing towards the mesial side), and another one from the protocone, towards the central ridge (MxPAR grade 1 in both cases; Burnett, 1998; Martino'n-Torres et al., 2012). The distal triangular fossa is larger and deeper than the mesial one. It has neither supernumerary crests (MxPAR grade 0, Burnett, 1998) nor marginal accessory tubercles. There are no traces of linear enamel hypoplasia. The X-ray (Fig. 8E) and the mCT scans (SOM-S18:4) show the width of the pulp cavity and the thinness of the highly altered enamel.

M19 upper left permanent third molar (or M13H) This LM3 is relatively well preserved except for some cracks (Fig. 8HeK; Table 2; SOM-S19). As previously indicated, it is possible that this M3 belonged to the same young individual identified as M13A-G as it was also found on square F12 the same year (1971) and very near the four incisors and canine of M13. The color of all of these teeth is similar, and the estimated age at death matches a young individual, with probably unerupted M3. However, proof that M19 LM3 belonged to individual M13 A$\mathrm{G}$ is not strong, therefore we prefer to consider it an isolated tooth.

The three roots are incomplete and broken (Fig. 8H-L) and their apices were likely not closed (probably corresponding to stage R3/4 in AlQahtani et al., 2010), although there is some evidence of hypercementosis on the regions preserved (SOM-S19:1). Very likely, this tooth was not yet fully erupted because of the absence of occlusal (stage 1, Molnar, 1971) and interproximal wear. The esti- mated age at death falls around 16.1e16.5 years following modern human standards (AlQahtani et al., 2010; Shackelford et al., 2012). The buccal face (Fig. 8H) shows an asymmetric crown, with a prominent paracone, a very small post-paracone tubercle ("Minor" according to Martin et al., 2017), and a slightly diagonal profile which is very convex on the distal side.

On the lingual side (Fig. 8I), the protocone appears well devel- oped (ASUDAS grade 5), whereas the hypocone is small (ASUDAS grade 3). The mesial margin is nearly vertical, while the distal is prominent. The large root is visible.

On the mesial face (Fig. 8J), both crown sides, especially the lingual one, are convex. The roots seem wide, particularly the mesiobuccal. The lingual face of the protocone has a small depression and a relief corresponding to the Carabelli complex (ASUDAS grade 3), which is more evident on the occlusal view (Fig. 8M-N; SOMS19:1).

In the distal view (Fig. 8K), all the cusps are prominent, with a central ridge on the marginal distal edge. The three roots are robust. In the occlusal view (Fig. 8M), the crown is markedly mesio- distally compressed, with a large paracone, a reduced metacone, and an almost absent hypocone. The protocone appears large and prominent. The central fossa is deep and marked, and a distobuccal groove runs for $\sim 2.1 \mathrm{~mm}$. The crown lacks any hypoplastic defects.

The X-ray (Fig. 8L) and the mCT scans show the wide pulp cavity and radicular canals (SOM-S19:3e4).

M20 lower left permanent second molar This tooth is considered a LM2 (SOM-S20) due to the likelihood that it had a regular rectangular crown outline, despite the current enamel loses on the distal margin. It appears to have belonged to an old individual based on extensive occlusal wear (stage 7, Molnar, 1971) and the complete development of its roots. The occlusal surface (Fig. 8T) is very worn and irregular, with a substantial area of exposed dentine and large mesial and distal depressions. Therefore, it has different chewing surfaces and retains the highest part of the crown on the buccal face (Fig. 8O) with a very short and thin enamel rim, lost on the distal face and with another fragment broken off on the lingual side (Fig. 8P). The crown's diameters (Table 2) have been strongly altered by different factors: abrasion, interproximal facets (the mesial one in particular) and partial digestion by a carnivore.

In the mesial view (Fig. 8P), we can observe the relatively flat outline of what remains of the crown on the buccal face and the incomplete interproximal facet. Below the cervical line, a small and deep oval surface appears (5 mm $1.2 \mathrm{~mm}$; SOM-S20:1) that cannot be related to the beginning of a cariogenic process. It is very 
different from the toothpick mark on the distal face (red ellipse), and from those documented by Estalrrich et al. (2017) and others since Siffre (1911). Therefore, its possible etiology remains unknown and taphonomic causes cannot be discarded.

The small oval toothpick groove $(3.7 \mathrm{~mm}$ long and $1.3 \mathrm{~mm}$ wide) on the distal face is just at the base of the crown and, as expected, it widens towards the buccal ed ge (Fig. 8Q; SOM-S20:1). Its morphology corresponds to grade 3 of Estalrrich et al. (2017).

Both roots are large and wide. The mesial one has a depression on its lower half, which ends in the apex (Fig. $8 \mathrm{Q}$ ). The distal root is thicker (Fig. 8R). Both have light traces of hypercementosis (SOM- S20:1, 4).

The X-ray reveals a small pulp cavity although its height must have been altered due to the strong abrasion affecting the occlusal plane and the formation of secondary dentine (Fig. 8R). The mCT scans offer more detailed information, showing the reduced pulp cavity, the thick distal canal, and the bifurcation of the mesial canal into two thin branches (SOM-S20:4).

This molar has a very thin enamel band ( $3.2 \mathrm{~mm}$ in its highest part, Fig. 8O-R, T) with numerous post-mortem losses. The enamel has also been reduced (not covering the cervical part) and strongly modified in the same way as the surfaces of the roots, which are polished and without relief (Fig. 8O-R, T; SOM-S20:1, 3e4). These alterations on the tooth morphology are interpreted as the result of its ingestion by a carnivore.

M21 lower right deciduous lateral incisor This RdI2 is well pre-served except for some small cracks and a slight loss of substance at the root apex (SOM-S21), which was presumably complete at the time of the child's death (the tip is now broken). Estimated age at death, utilizing modern human standards, ranges from $\sim 2.4 \pm 0.4$ years, following Liversidge and Molleson (2004), to 2.5e3.5 years according to AlQahtani et al. (2010).

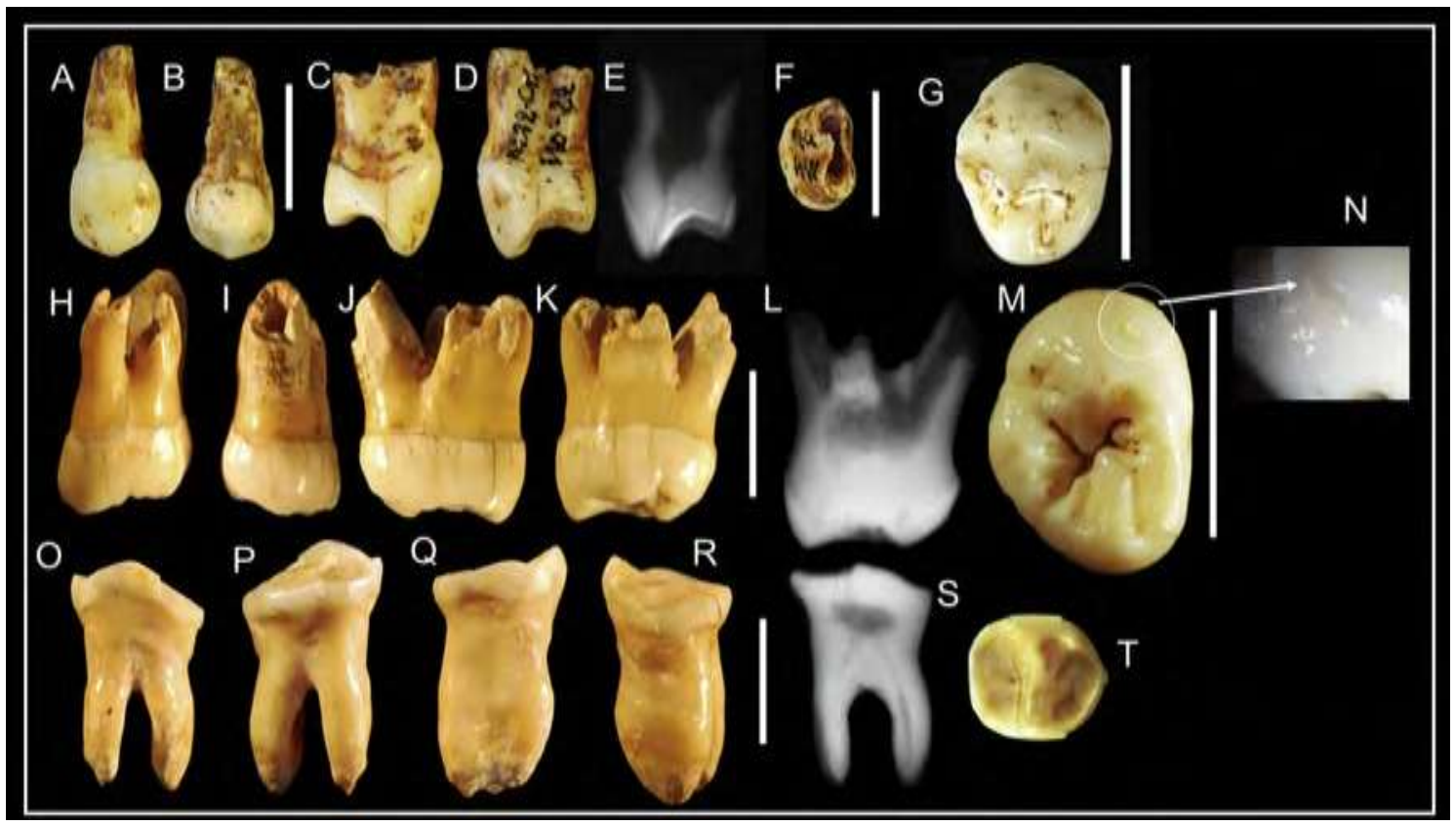

Figure 8. Marillac 18 LP3: (A) Buccal, (B) Lingual, (C) Mesial, (D) Distal, (E) X-ray distal face, (F) Root apex, (G) Occlusal. Marillac 19 (M13H?) LM3: (H) Buccal, (I) Lingual, (J) Mesial,

(K) Distal, (L) X-ray distal face, (M) Occlusal, (N) Carabelli tubercle. Marillac 20 LM2: (O) Buccal, (P) Lingual, (Q) Mesial, (R) Distal, (S) X-ray distal face, (T) Occlusal. Scale: $10 \mathrm{~mm}$.

The crown's labial face (Fig. 9A) is strongly curved and quite asymmetric, with the typical extension of the distal margin towards the same side and a rounded disto-incisal angle. This is in stark contrast to the mesial margin, 
which appears straight, as far as can be told from the preserved dentine, and in spite of the broken enamel. The lingual side (Fig. 9B) is somewhat worn, although the marked basal tubercle and the distal marginal ridge are clearly visible. The occlusal edge is slightly worn (as would be expected given the estimated age at death of this young individual; Fig. 9F), and similar to the recorded wear on the Roc-de-Marsal 1 child (estimated to be $\sim 3$ years old, Bayle et al., 2009; Madre-Dupouy, 1992).

The root is robust, slightly narrower on the lingual than on the vestibular face and, with the distal ridge more prominent than the mesial one (Fig. 9A-D; SOM-S21:1). The X-ray and the mCT scans reveal a relatively wide pulp cavity and a bit of hypercementosis on the apical region (Fig. 9A-E; SOM-S21:3e4).

M22 lower left first deciduous molar This fossil corresponds to a LdM1 (SOM-S22). The enamel is very thin, and both the enamel and dentine are very smooth. The occlusal plane appears to be worn (grade 5, Molnar, 1971) with several spots of dentine exposed. The small, but wide, roots were likely fully developed and not yet resorbed. However, they are broken and altered due to partial digestion (Fig. 9G-K).

The child's age at death could be estimated at $\sim 10.5$ years (AlQahtani et al., 2010), following modern human standards.

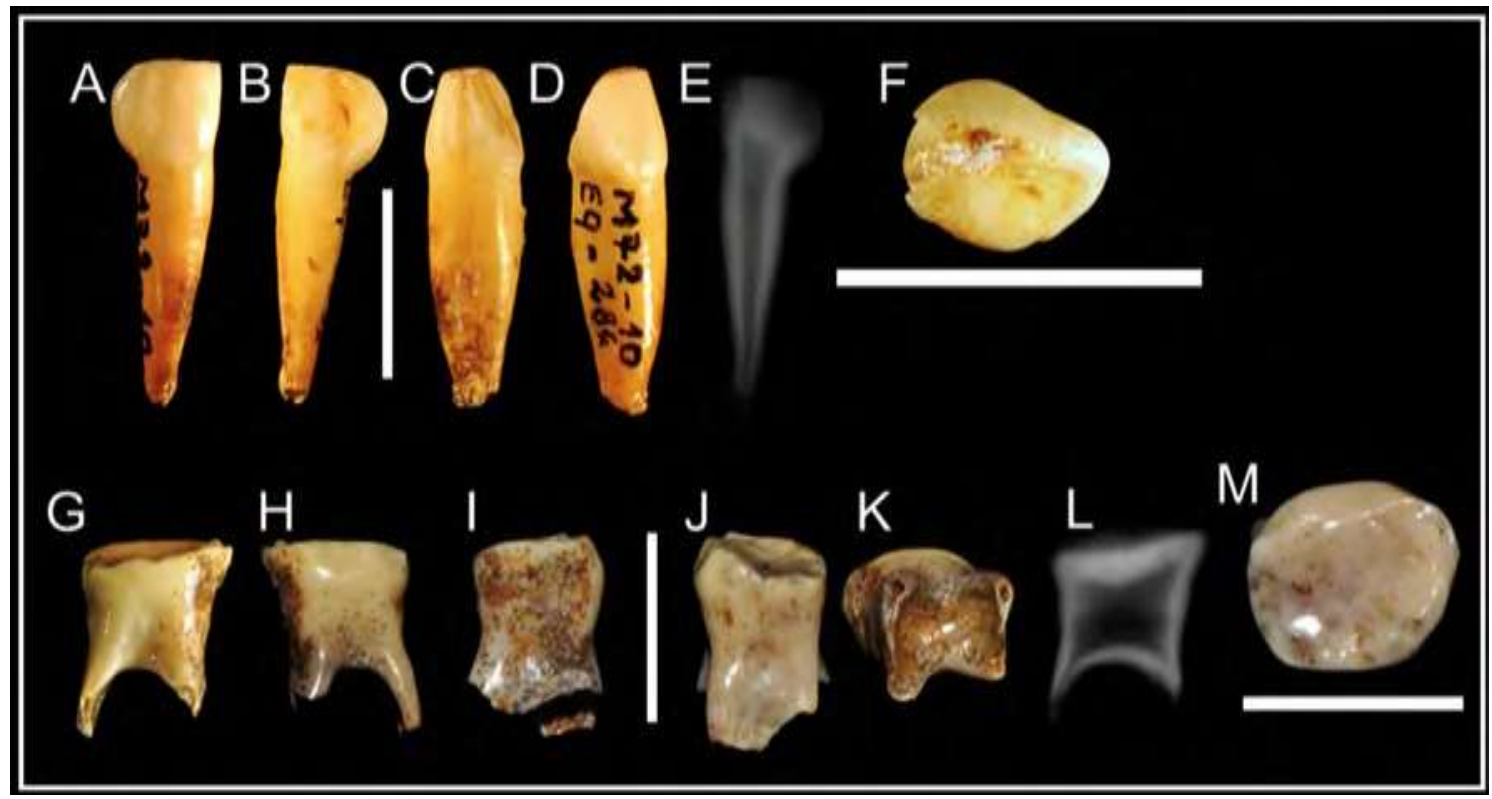

Figure 9. Marillac 21 RdI2: (A) Buccal, (B) Lingual, (C) Mesial, (D) Distal, (E) X-ray distal face, (F) Occlusal. Marillac 22 LdM1: (G) Buccal, (H) Lingual, (I) Mesial, (J) Distal, (K) Roots, (L) X-ray distal face, (M) Occlusal. Scale: $10 \mathrm{~mm}$.

On the occlusal view, the crown (Fig. 10M) is narrow and elon- gated (Table 2), with a marked prominence of the mesiobuccal region (tuberculum molare, SOM-S22:1). Although the surface is so worn (Fig. 9M) and altered, traces of the mesial marginal crest are observable, in addition to a small mesial fovea (SOM-S22:1).

The X-ray and the mCT scans show the roots' thickness as well as the wide pulp chamber and canals (Fig. 9I; SOM-S22:2e3).

Although a thick layer of consolidant (i.e., varnish) coats this molar, the enamel alterations on the four faces of the crown and the very polished roots are still clearly visible. It is possible that these changes were also caused by its partial digestion by carnivores while this deciduous tooth was in place on the child's mandible. On the CT data, no enamel can be distinguished from the dentine, due to a lack of contrast between the tissues (SOM-S22:1, 3). Therefore, we consider the partial digestion to have been long enough to have nearly destroyed/dissolved the enamel

\section{Crown metric comparisons}

Based on the crown mesiodistal and buccolingual diameters, bivariate plots are provided for each tooth type 
(Figs. 10e12). Given the small number of fossils, only the modern group's 95\% confi- dence ellipse is provided ( \pm 1.96 SD variation range). In Figure $10 \mathrm{~A}$ and B, M13A RI1 and M13B LI1 fall outside the modern human 95\% confidence ellipse, but amongst the Neander- thals with 'medium-sized' teeth. Thus they do not stand out as having extreme values. The partially digested M14 RI1 falls within the lower half of the ellipse (Fig. 10A), remaining separated from the smallest modern teeth.

The three isolated I2's (M15, M16, M17) and both I2's belonging to the M13 individual (M13C, M13D), also fall among the medium- sized Neanderthals (Fig. 10C and D). Both M13 I2's have very similar dimensions. The buccolingual diameter of M17 is smaller than that of other Neanderthals, and its mesiodistal diameter is slightly shorter because of marked interproximal abrasion. The partially digested M15 RI2 has a shorter mesiodistal diameter but still falls outside the MH 95\% confidence ellipse and among the smallest Neanderthal values. The M16 LI2 germ shows a reduced buccolin-gual diameter, probably due to the biocorrosion and incomplete crown development, yet it still falls outside the MH ellipse.

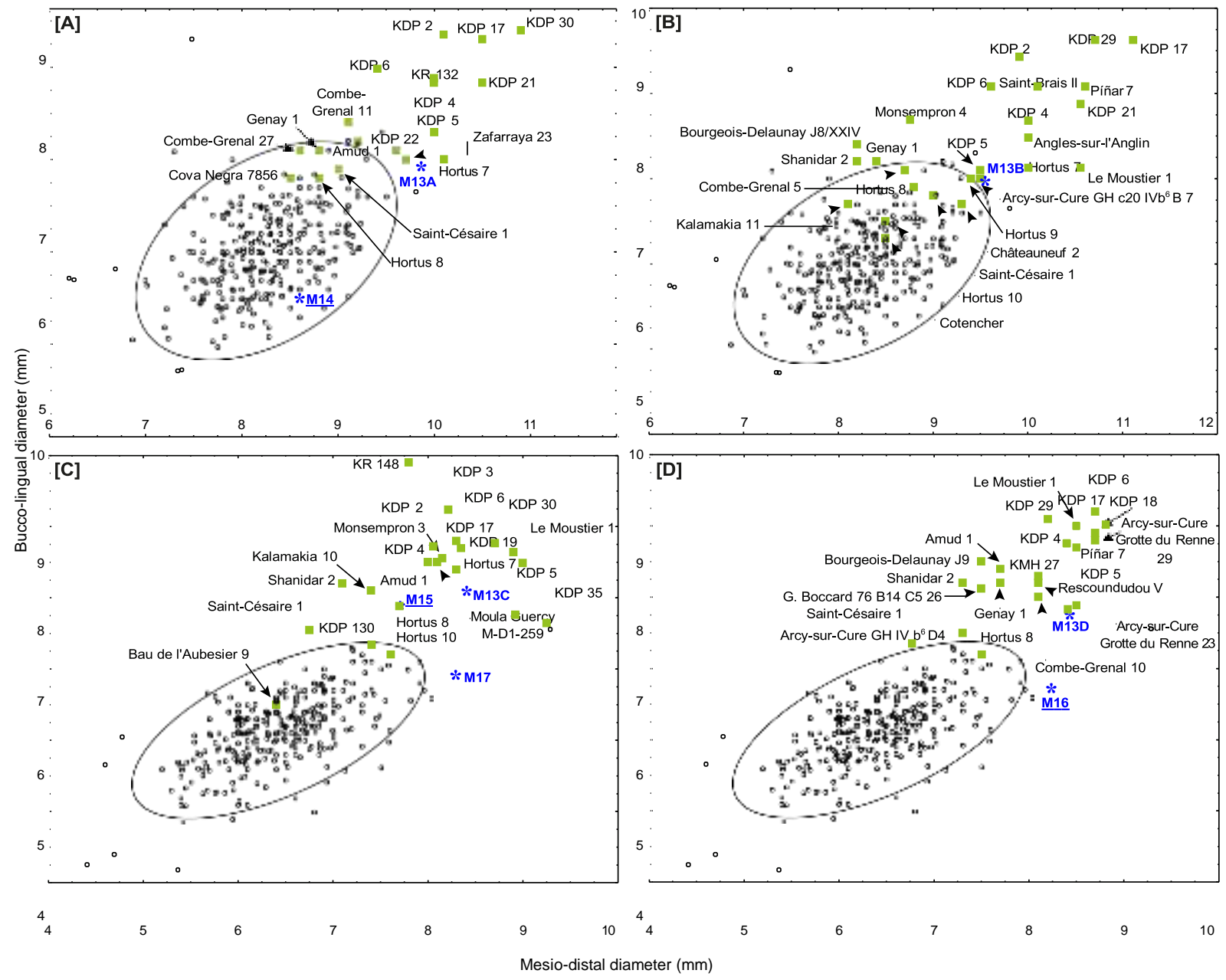

Figure 10. Scatterplots for the two crown diameters of the anterior permanent teeth. Blue stars: Marillac teeth. Filled green squares: Eurasian Neanderthals. Black circles: sub- actual MH samples. Black ellipses represent the $95 \%$ confidence interval of the MH variation ( $\pm 1.96 \mathrm{SD}$ ). The name of the partially digested specimens from Marillac is under- lined. (A) M13A and M14 RI1, (B) M13B LI1 (C) M13C, M15 and M17 RI2, and (D) M13D and M16 LI2. (For interpretation of the references to color in this figure legend, the reader is referred to the Web version of this article.)

M13E RC1 shows a medium-sized crown in comparison to other Neanderthals (as for M13's incisors) and falls just above the MH ellipse (Fig. 11A).

The M13F LP3 clearly falls outside the MH range and within the upper half of the Neanderthal variation (Fig. 11B). The partially digested immature M18 has small crown diameters falling amongst the smallest Neanderthal P3s and within the upper-half of the MH ellipse. 
The only LP4, M13G (Fig. 11C), plots outside the upper limit of the MH ellipse. This is similar for other Neanderthals which also have a broad range of variation partially overlapping with that of $\mathrm{MH}$.

The M19 LM3 falls just above the upper limit of the MH ellipse, and within the relatively larger Neanderthal molars, especially for the buccolingual diameter. Both Neanderthals and MH show well- known wide ranges of variability (Fig. 11D).

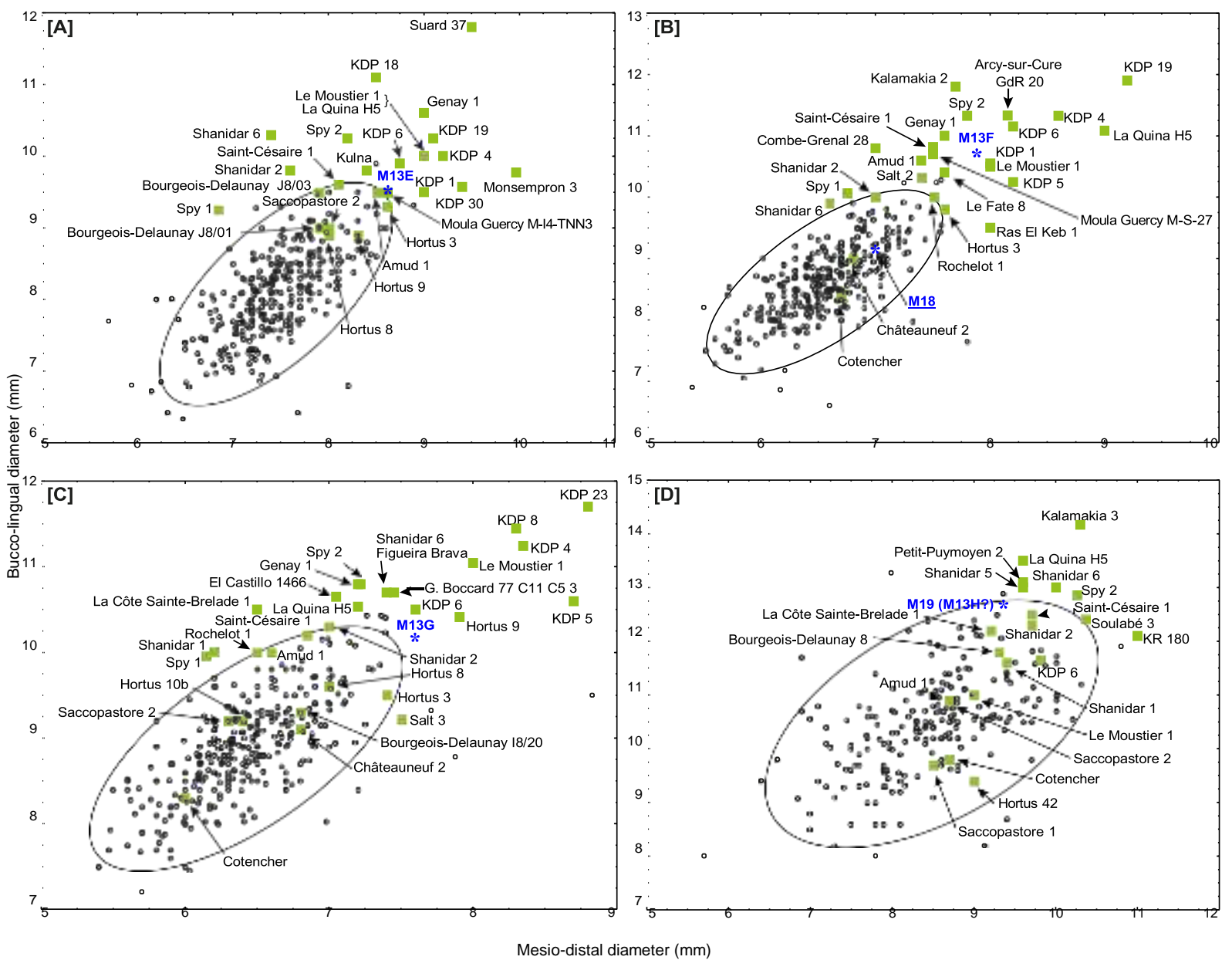

Figure 11. Scatterplots for the two crown diameters of the permanent canine, premolars and third molar. See Fig. 11 for symbols. (A) M13E LC', (B) M13F LP3 and M18, (C) M13G LP4, and (D) M19 LM3.

The M20 LM2 plots in the lower half of the MH variation (Fig. 12A), yet both crown diameters were altered by accentuated wear and biocorrosion. The Neanderthals also show a wide varia- tion for both crown diameters. Of the two deciduous teeth, the M21 RdI2 falls outside the modern children's ellipse and stands out amongst the largest Neanderthal values (Fig. 12B). Both M22 LdM1 crown diameters are strongly affected by partial digestion and fall close to the center of the modern child variability (Fig. 12C). It is of note that two other Neanderthal children, $\mathrm{Ch}^{\wedge}$ ateauneuf 2 and Valdegoba 2, plot within the lower half of the $\mathrm{MH}$ variation, show very small crown di- mensions, and no evidence of biocorrosion. 


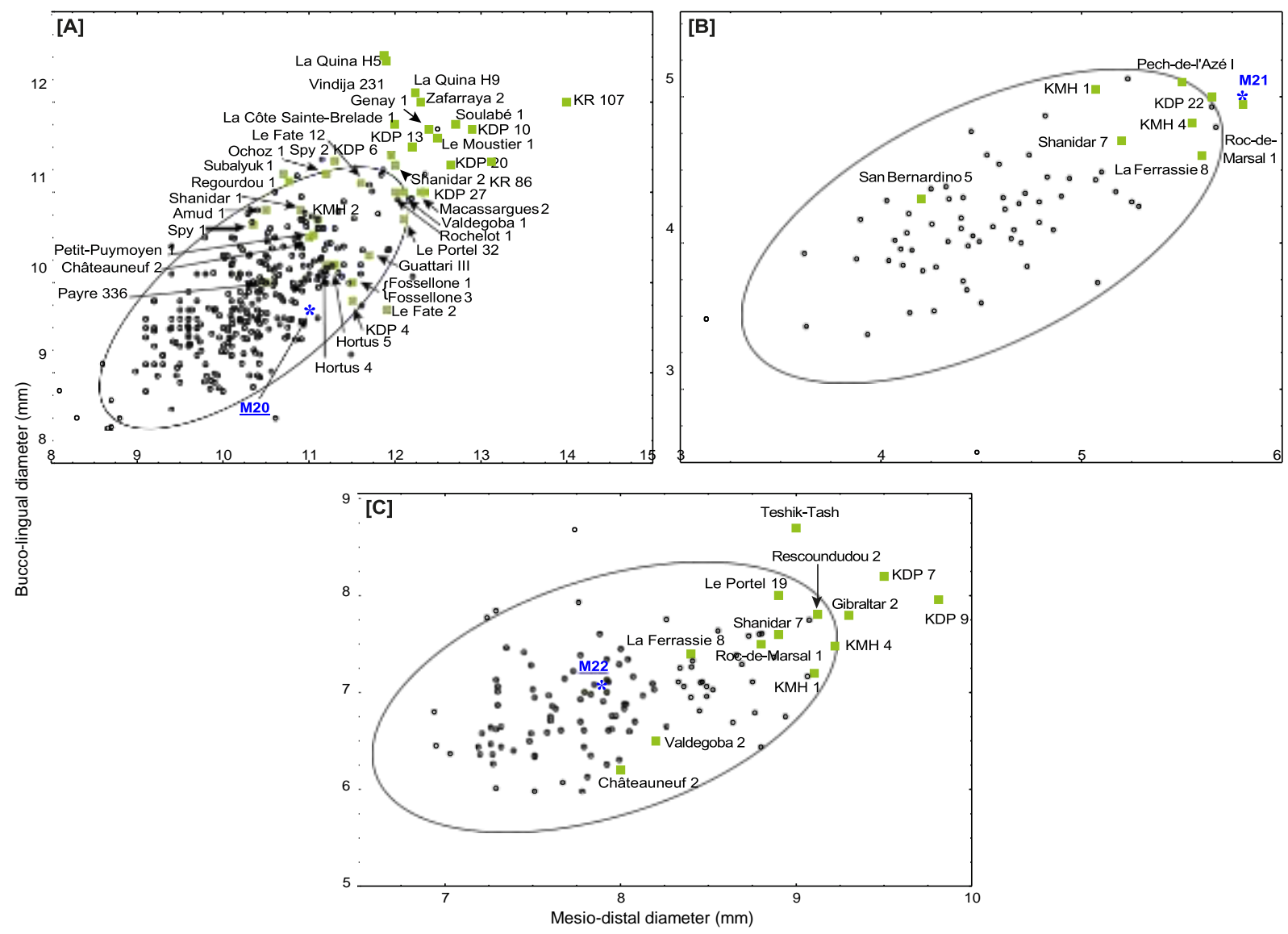

Figure 12. Scatterplots for the two crown diameters of the permanent lower second molar M20 LM2 (A) and the two deciduous teeth M21 LLdI2 (B) and M22 LLdM1 (C). See Fig. 10 for symbols.

\section{Microtomographic and morphometric analyses of the dental tissues}

Enamel thickness The components of 2D and 3D enamel thickness for 11 Marillac teeth are shown in SOMS23:A, B). For the eight nondigested permanent teeth, both 2D AET and 2D RET indices are generally low and close to the Neanderthal means (Table 3). The only exception is M13G P4, whose 2D RET falls between the means of Neanderthal and recent $H$. sapiens. No comparative data are available for M21 RdI2.

Table 3

2D enamel thickness of the Marillac teeth compared to Neanderthals, fossil and recent $H$. sapiens. ${ }^{a}$

\begin{tabular}{|c|c|c|c|c|c|c|c|c|c|c|c|c|}
\hline & \multicolumn{3}{|c|}{ Marillac } & \multicolumn{3}{|c|}{ Neanderthals } & \multicolumn{3}{|c|}{ Fossil H. sapiens } & \multicolumn{3}{|c|}{ Recent $H$. sapiens } \\
\hline & Wear ${ }^{b}$ & 2D AET & 2D RET & $\mathrm{N}$ & 2D AET & 2D RET & $\mathrm{N}$ & 2D AET & 2D RET & $\mathrm{N}$ & 2D AET & 2D RET \\
\hline M13A (RI') & 3 & 0.57 & 8.43 & 5 & 0.63 & 9.19 & 2 & 0.71 & 10.57 & 32 & 0.62 & 10.91 \\
\hline $\operatorname{M13B}\left(\mathrm{LI}^{1}\right)$ & 3 & 0.55 & 8.14 & & & & & & & & & \\
\hline M13C (RI') & 2 & 0.66 & 10.98 & 5 & 0.67 & 10.45 & 2 & 0.69 & 11.52 & 31 & 0.64 & 12.51 \\
\hline $\operatorname{M13D}\left(\mathrm{LI}^{2}\right)$ & 3 & 0.65 & 10.31 & & & & & & & & & \\
\hline M13E (RC') & 1 & 0.80 & 11.32 & 4 & 0.83 & 11.20 & 2 & 0.87 & 12.71 & 22 & 0.91 & 14.43 \\
\hline $\mathrm{M} 13 \mathrm{~F}\left(\mathrm{LP}^{3}\right)$ & 2 & 1.00 & 14.34 & 3 & 0.98 & 13.57 & 1 & 1.26 & 18.74 & 19 & 1.10 & 17.69 \\
\hline M13G $\left(L^{4}\right)$ & 1 & 1.07 & 16.82 & 4 & 1.04 & 15.03 & 1 & 1.31 & 20.11 & 26 & 1.14 & 18.55 \\
\hline M19 $\left(\mathrm{LM}^{3}\right)$ & 1 & 1.16 & 18.96 & 5 & 1.22 & 18.07 & & & & 52 & 1.38 & 21.76 \\
\hline$M 14^{* *}\left(R^{1}\right)^{c}$ & 3 & 0.22 & 5.27 & & & & & & & & & \\
\hline $\mathrm{M} 5^{* *}\left(\mathrm{RI}^{2}\right)$ & 2 & 0.39 & 8.88 & & & & & & & & & \\
\hline $\operatorname{M} 21\left(\mathrm{Ri}_{2}\right)$ & 3 & 0.19 & 4.70 & & & & & & & & & \\
\hline
\end{tabular}

Abbreviations as follows: AET: average enamel thickness; RET: relative enamel thickness. 
Both partially digested M14 and M15 have notably smaller 2D indices than those of the non-digested teeth M13A, and M13C and M17, respectively. Specifically, when compared to the mean values computed between both M13A and M13B I1's (2D AET $0.56 \mathrm{~mm}$; 2D RET 8.29), the 2D AET and 2D RET of M14 are $60 \%$ and 35\% lower, respectively. Compared with the mean between M13C and M13D I2's (2D AET 0.66 mm; 2D RET 10.65), the 2D AET and the 2D RET of M15 show a reduction of $\sim 40 \%$ and $17 \%$, respectively.

For the 3D enamel thickness, the reduced comparative samples prevented any conclusive assessment and the few possible con- siderations are limited to the C, P3, and M3, as well as to the de-ciduous lateral incisor (Table 4 and SOM-S23). As far as the central and lateral incisors are concerned, our comparative sample (which is clearly reduced at least for Neanderthals) does not show any clear difference between Neanderthals and modern humans. Moreover, most of the incisors of Marillac are characterized by wear stage 3, which contributes to reduce both the AET and RET indices, ulti- mately undermining any taxonomical attribution for the incisors of Marillac based on the 3D enamel thickness. In contrast, the 3D AET and RET computed for the canines, premolars and M3 differ be- tween the two human groups and the Marillac teeth perfectly fall within the Neanderthal range of variation (Table 4). Finally, both 3D AET and 3D RET values computed for the nondigested M21 Ri2 are closer to the Neanderthal mean (although the small comparative sample size must be taken into account).

Table 4

3D enamel thickness of the Marillac teeth compared to Neanderthals and recent H. sapiens (for $\mathrm{I}^{1}, \mathrm{I}^{2}, \mathrm{C}, \mathrm{P}^{3}, \mathrm{P}^{4}, \mathrm{M}^{3}$ and $\mathrm{dI}_{2}$ ).

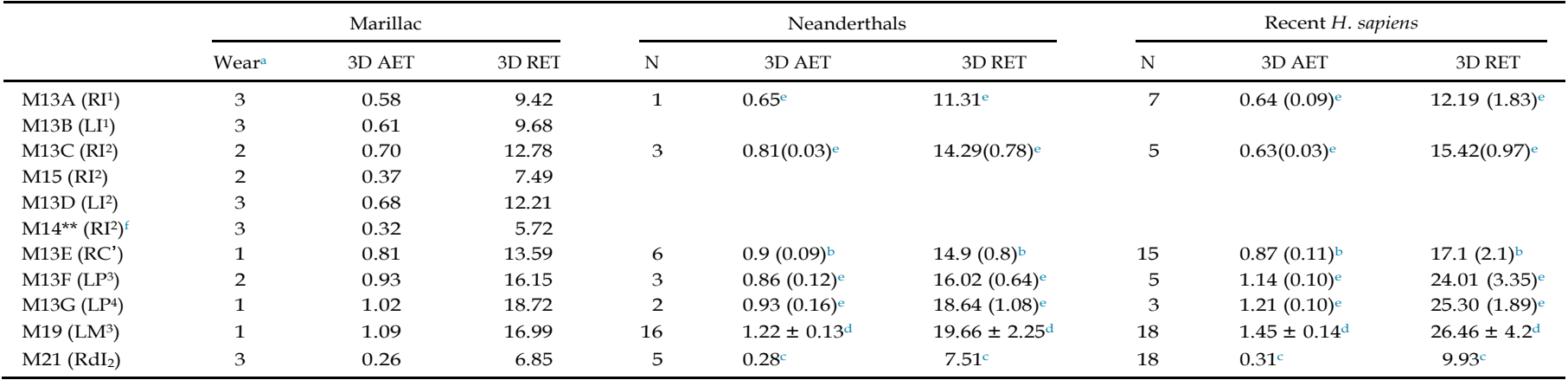

Abbreviations as follows: AET: average enamel thickness; RET: relative enamel thickness.

a Wear stage after Molnar (1971).

b Buti et al., 2017.

c Benazzi et al., 2014b.

d Been et al., 2017.

e Bayle et al. 2017 (only mean values are provided).

f Partially digested teeth are indicated by**.

When compared to their respective tooth classes, both partially digested M14 and M15 show a reduction in enamel thickness, with a decrease in 3D AET and 3D RET of $\sim 46 \mathrm{e} 47 \%$ and $40 \%$, similar to what was calculated in $2 \mathrm{D}$.

The 3D distribution of enamel thickness visualized using a color-coded map overlaying the enamel surface (Fig. 13) displays the al- terations suffered by the partially digested teeth (M22 LdM1 is not present because of its enamel could not be detected on the mCT data). Within the Marillac sample, M13A-G specimens show relatively thicker enamel. In particular, M13G LP4 and M19 LM3 (maybe belonging to M13) are the thickest, although the differences be- tween the two premolars are negligible $(0.02 \mathrm{~mm})$. 


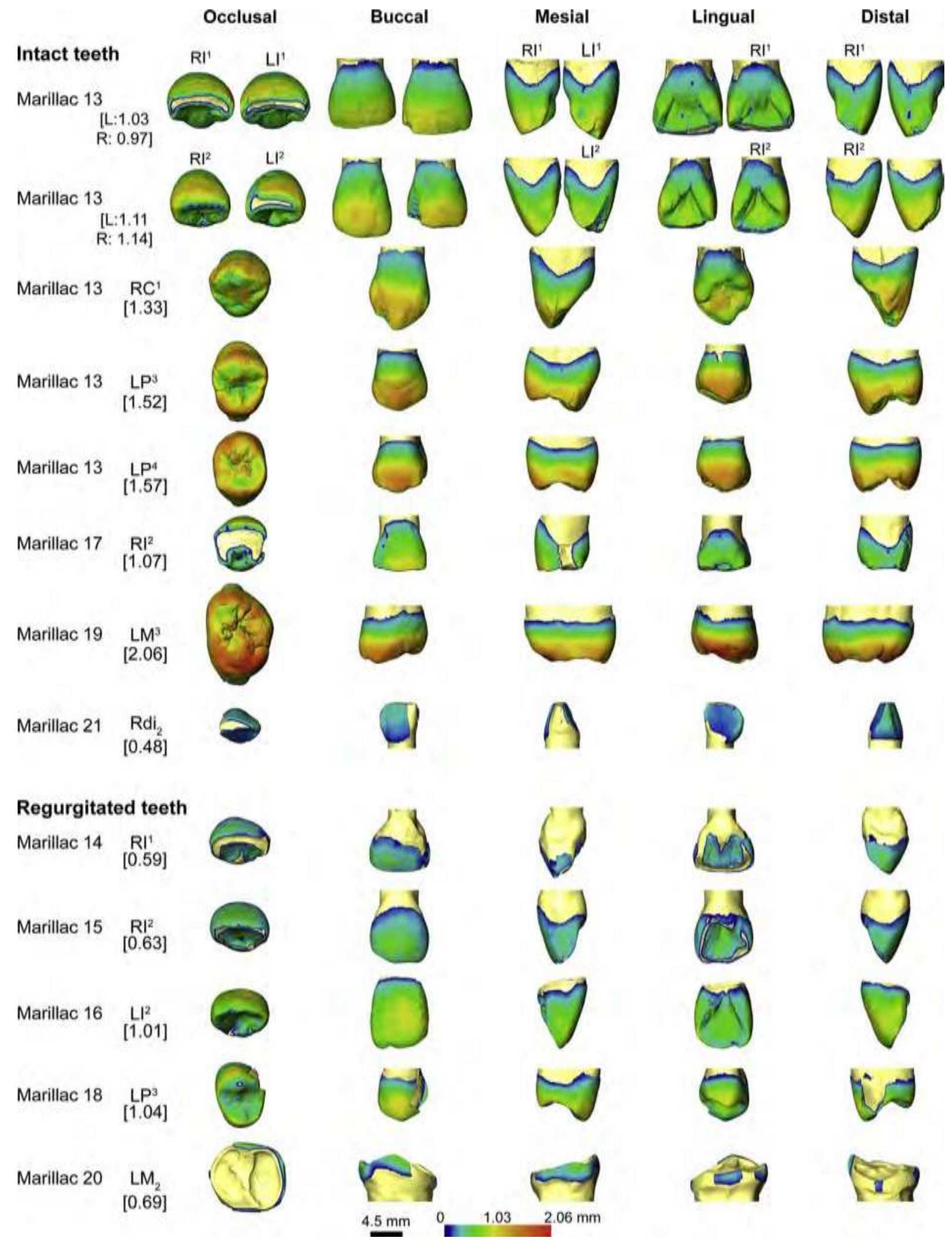

Figure 13. 3D colored enamel caps with the enamel thickness for 15 Marillac teeth. Maximal values (in mm) are reported in square brackets for each case. 
separation between the MH and Neanderthal samples (SOM-S5). Canonical Variate Analysis (CVA) classifies the Marillac specimens as follows: M13F LP3 (3e14 PCs - shape space 100\% late Neanderthal; form space 100\% as late Neanderthal); M13G LP4 (3e14 PCs e shape space 67\% late Neanderthal, 33\% early Neanderthal; form space 92\% late Neanderthal, 8\% early Neanderthal); M19 LM3 (3e15 PCs e shape space 50\% MH, 35\% early Neanderthal, 15\% late Neanderthal; form space $42 \%$ late Neanderthal, $42 \%$ early Neanderthal, $16 \% \mathrm{MH}$ ).

The differentiation between $\mathrm{MH}$ and Neanderthals in P3 is based on a taller, more distally placed protocone dentine horn in the MH and a buccally expanded cervix in Neanderthals. The M13F LP3 is close to the average Neanderthal shape in nearly all aspects of the marginal ridge and cervix. As with the P3, the differentiation between $\mathrm{MH}$ and Neanderthals in the $\mathrm{P} 4$ is based on a relatively tall protocone, but also a more triangular (being mesiodistally compressed on the lingual side of the occlusal basin) marginal ridge. The M13G LP4 closely matches the mean Neanderthal shape in both the marginal ridge and cervix. The differentiation between $\mathrm{MH}$ and Neanderthals in M3 is based on a relatively short M3 crown and a more prominent hypocone dentine horn in Neanderthals. It is common for M3 to exhibit diminutive hypocones, as is the case in M19, where it is man- ifested only as a crest running distally from the protocone with no apparent dentine horn. The diminutive hypocone in M19 is likely contributing to its classification in the shape analysis as a MH more often than a Neanderthal, while its relatively large size results in its classification as a Neanderthal in form space. Additionally, examination of the M19 EDJ reveals the previously described cingulum-like Carabelli's trait on the mesiolingual face of the protocone and a diminutive post-paracone tubercle (SOM-S5).

Root morphology This analysis concerned only the Marillac in- cisors, canines, and molars, both permanent and deciduous, which have (sub-) complete roots and for which comparative data were available for Neanderthals and $\mathrm{MH}$. Overall, the Marillac tooth roots are small and fall in the lower end of the Neanderthal range of variation (Table 5, 0 Azs 0.5; SOM-S6 for details). The partially digested teeth have considerably reduced root dimensions, which is a logical consequence of this taphonomic process (Maureille et al., 2017).

\begin{tabular}{|c|c|c|c|c|c|c|c|c|}
\hline & Tooth/Variable & RL & RSA & RV & RPV & RSA ling & RSA lab & RSA lab/RSA ling \\
\hline \multicolumn{9}{|c|}{ Permanent } \\
\hline $\mathrm{I}^{1}$ & M13A (R) & 15.6 & 266.6 & 369.4 & 46.8 & 188.4 & 148.6 & 1.3 \\
\hline$I^{1}$ & M13B (L) & 15.0 & 248.1 & 328.9 & 43.9 & 112.1 & 136.3 & 1.2 \\
\hline $\mathrm{I}^{1}$ & $\operatorname{M14}(\mathrm{R})^{* * \mathrm{~b}}$ & $13.6(11.7)$ & $156.6(149.1)$ & $137.0(134.7)$ & 46.33 & $87.7(84.2)$ & $68.9(65.2)$ & $0.8(0.8)$ \\
\hline$I^{2}$ & M13C (R) & 16.0 & 289.6 & 366.2 & 42.8 & 120 & 170.1 & 1.4 \\
\hline$I^{2}$ & M13D (L) & 15.9 & 287 & 363.3 & 43.2 & 120.3 & 167.1 & 1.4 \\
\hline $\mathrm{I}^{2}$ & $\operatorname{M15}(\mathrm{R})^{* *}$ & $16.2(14.9)$ & $224.0(220)$ & $248.3(247.4)$ & 56.9 & 86.5 (84.8) & 137.9 (135.3) & 1.6 \\
\hline $\mathrm{I}^{2}$ & $\operatorname{M16}(\mathrm{L})^{* *}$ & e & e & e & $\mathbf{e}$ & e & e & $\mathbf{e}$ \\
\hline $\mathrm{I}^{2}$ & M17 (R) & 16.8 & 298.0 & 370.4 & 17.2 & 117.7 & 180.9 & 1.5 \\
\hline $\mathrm{C}^{1}$ & M13E (R) & 20.0 & 384.9 & 552.5 & 91.9 & 183.3 & 202.3 & 1.1 \\
\hline $\mathrm{M}^{3}$ & M19 (L) & $15.4(13.0)$ & $511.8(442.3)$ & $568.7(531.5)$ & 112.0 & e & e & $\mathbf{e}$ \\
\hline $\mathrm{M}_{2}$ & M20 (L)** & 14.9 & 471.9 & 623.9 & 39.6 & $\mathbf{e}$ & $\mathbf{e}$ & $\mathbf{e}$ \\
\hline \multicolumn{9}{|c|}{ Deciduous } \\
\hline $\mathrm{I}_{2}$ & M21 (R) & 12.8 & 140.7 & 115.5 & 15.1 & 64.8 & 76.3 & 1.2 \\
\hline $\mathrm{M}_{1}$ & M22 (L)** & $9.1(8.0)$ & $195.7(163.2)$ & $150.8(142.5)$ & 54.9 & $\mathbf{e}$ & $\mathbf{e}$ & $\mathbf{e}$ \\
\hline
\end{tabular}

Abbreviations as follows: RL: root length; RSA: Root surface area; RV: root volume (including dentine, cementum and pulp); RPV: root pulp volume; RSA ling and RSA lab: root surface area of the lingual and labial aspects of the root (Le Cabec et al., 2013).

a For several teeth, some variables could not be measured and are indicated with "-." Values for teeth with broken root tips were corrected as explained in the methods, we

however report the actual value of the broken fossil in parenthesis. Values were rounded up to the first decimal. For M19, root length was measured on the lingual root, while for M20, the distal root was considered. Linear dimensions in mm, surface areas in mm2 and volumes in $\mathrm{mm} 3$.

b Partially digested teeth are indicated with **.

The total root volume (RV) of the M21 RdI2 is, however, smaller (Table 5; SOM-S6) than that reported for Spy 594a and Roc-de- Marsal 1 by Crevecoeur et al. (2010). The root pulp volume (RPV) of M21 is comparable to that of Roc-de-Marsal 1, and both are more than twice as small as that of Spy 594a (Table 5; SOM-S6).

Pulp cavities are, in general, large $(\mathrm{Azs}>0)$. The pulp chamber of M17 RI2 was almost obliterated by dense concretions (SOM-S17:4), but the original contours of its walls were still visible on the mCT data. This allowed us to segment the cavity excluding its dense filling.

In terms of root shape (labial/lingual proportions; Table 5), the Marillac anterior teeth have a slightly less labially convex root surface than other Neanderthals used for comparison (see first tab in SOM-S6). 
The estimated root length of M19 LM3 is very close to the Neanderthal mean value documented by Bailey (2005) (Azs $1 / 4$ 0, see SOM-S6), while all root dimensions of M20 LM2 are slightly smaller than the Neanderthal mean reported by Kupczik and Hublin (2010) (-0.77 Azs 0.31, see SOM-S6).

Ten out of 16 teeth found at the Marillac site are affected by hypercementosis. As documented with the 2D sections and 3D rendering, the accumulation of cementum is stronger in older in- dividuals (e.g., M17: SOM$S 17: 1,5)$ and may have been correlated with different kinds of biological processes (d'Incau, 2012; d'Incau et al., 2015). It is probable that some of these factors also influenced the development of the root hypercementosis even on M21 RdI2 (SOM-S21:4). In the 2D virtual sections, it was observed as a slightly darker grey value than in the dentine, and in 3D, as a modification of the shape of the root apex combined with an inhomogeneous aspect of the apical third root surface.

Nevertheless, because of the insufficient contrast between dentine and cementum in the mCT data, the cap of cementum could not be segmented and reconstructed in 3D to document the volume and the distribution of cementum around the root axis.

The quantification of the amount of taurodontism (Table 6) is consistently underestimated in 2D in comparison with the index calculated in 3D from the volumes of root stem and apices. This is not only due to the fact that the $2 \mathrm{D}$ index relies on a height spreading from the occlusal basin to the furcation level, which is thus affected by occlusal wear, but also because it misses the overall root shape and the amount of material that is distributed either in the root stem or in the root apices. The permanent molars M19 and M20 are mesotaurodont (3D index, Table 6) while the deciduous molar M22, despite its taphonomic alterations, displays hyper- taurodontic roots with a low furcation level (Fig. 9JeL; SOM- S22:1e3).

Table 6

2D and 3D taurodontism indices in the Marillac teeth. ${ }^{\mathrm{a}}$

\begin{tabular}{|c|c|c|c|c|c|c|}
\hline \multirow[b]{2}{*}{ Specimen/Tooth } & \multicolumn{2}{|c|}{ 2D Taurodontism index (Wright, 2007) } & \multicolumn{4}{|c|}{ 3D Taurodontism index (Kupczik and Hublin, 2010 following Keene, 1966's classification) } \\
\hline & & & VR(stem) & VR(apex) & & \\
\hline M19 $\left(\mathrm{LM}^{3}\right)$ & 1.15 & Hypotaurodont & 367.1 & $201.6(164.4)$ & $64.6(69.1)$ & Mesotaurodont (class III) \\
\hline $\mathrm{M} 20^{* *}\left(\mathrm{LM}_{2}\right)$ & 1.07 & Cynodont & 352.8 & 271.1 & 56.6 & Mesotaurodont (class III) \\
\hline $\mathrm{M}_{22 * *}\left(\mathrm{LdM}_{1}\right)$ & 1.45 & Mesotaurodont & 119.1 & $31.7(23.4)$ & $79.0(83.6)$ & Hypertaurodont (class IV) \\
\hline
\end{tabular}

Abbreviations as follows: VR(stem): total volume of the root stem (dentine p pulp) from the cervical plane to the furcation level;

VR(apex): total volume of the root apices from the furcation level to the root tips.

a All volumes are expressed in mm3. All measurements for the root apices take into account the correction for missing/broken root tips detailed in SOM S5, and the original

values of the broken fossil are reported for information in parentheses.

\section{Discussion}

\section{What can teeth tell us about the Marillac people?}

The sixteen teeth, found at the Marillac site during the excava-tions of B. Vandermeersch (1967e1980) and dated to $\sim 60 \mathrm{ka}$ (end MIS 4/beginning MIS 3), show morphometrical characteristics that have commonly been considered as representative of Neanderthals (e.g., Wolpoff, 1979; Bailey, 2002a, b, 2005; Bailey and Lynch, 2005; Bailey and Hublin, 2006; Crummett, 1994; Garralda and Vandermeersch, 2000; Garralda et al., 2004, 2008, 2014a; Maureille et al., 2008; Kupczik and Hublin, 2010; Martino'n-Torres et al., 2012; Le Cabec et al., 2013; Trinkaus, 2017). Specifically, these characteristics concern the labial convexity, shovel shape, development of the lingual tubercle, margins and digits of the maxillary incisors, and the 'cyrtodont-like' upper canine (i.e., with a regular convexity of the crown and root). In addition, the maxillary premolars showed a large buccal cusp and two well-separated roots on the distal side, joined by a connecting plate of dentine and cementum on the mesial aspect. This kind of morphology has been identified in other Neanderthal premolars, such as in El Salt 3 (Garralda et al., 2014a), Grotte Boccard (Maureille et al., 2008) or La Sima de los Huesos (Martino'n-Torres et al., 2012). Another important characteristic feature is the taurodontism of the molars, especially remarkable in the deciduous first molar M22.

Based on crown diameters, the well-preserved Marillac teeth are variable in terms of size and do not plot with the largest Ne- anderthals (see Figs. 10e12). It is of note that the partially digested teeth show reduced crown diameters in proportion to the intensity of the biocorrosion they underwent.

In terms of enamel thickness, the Marillac teeth show similar values to the comparative sample of Neanderthals. 
EDJ morphology of the LP3, LP4 and M19 LM3 is consistent with attribution to Ne- anderthals, acknowledging that the diminutive distal crown of the LM3 resembles a pattern seen in many modern humans.

The roots show different degrees of hypercementosis, also pre- sent in the deciduous teeth, and their dimensions are medium- sized in comparison to other Neanderthal teeth. This is found even in those that have not been altered by the partial digestion. Pulp cavities are generally large, probably in relation to the young estimated age of most individuals (Philippas, 1961). The Marillac pulp chambers are also clearly much larger than those of modern humans (see comparative data in Le Cabec et al., 2013 for perma- nent anterior teeth, and Kupczik and Hublin, 2010 for permanent lower molars). The pulp cavity of M20 is partially filled with a significant amount of secondary dentine, and shows what could be several pulp stones at the level of root furcation (SOM-S20:4). Both M13 premolars and M19 LM3 present concretions of similar density to dentine in the pulp cavity in the apical half of their root canals, probably of taphonomic origin (SOM-S12, S13, S19). M17 presents pulp calcifications, which are denser than the surrounding dentine (SOM-S17:4), though there is less extreme filling of the pulp cavity than what was observed in Combe-Grenal V (Garralda and Vandermeersch, 2000).

Little attention has been devoted to describing taurodontism in deciduous molars as the vast majority of classifications and publi- cations focus on permanent teeth. Yet, the literature shows evi- dence of this morphology in the primary dentition from previously described fossils (Patte, 1962). All the deciduous molars of Gibraltar 2 have hypertaurodontic roots (Garrod et al., 1928), as with La Quina H18 (Henri-Martin, 1926) and Combe-Grenal I (Legoux, 1966; Garralda and Vandermeersch, 2000) which also show a strong degree of taurodontism (similar to that described in M22). Oddly, these types of taurodontism are very different from those of the earlier Krapina juveniles (Kallay, 1963; Krikum et al., 1999) which have smaller pulp chambers.

Several authors have proposed that Neanderthal juveniles had faster dental development than recent modern humans (e.g., Smith et al., 2007, 2010). This would imply that estimating their age at death using calcification stages (Moorrees et al., 1963a, b) scored with modern human standards (as we did), could result in an overestimation. But variability in tooth formation and eruption for Pleistocene Homo has also been published (Guatelli-Steinberg et al., 2005; Macchiarelli et al., 2006; Reid et al., 2008; Guatelli-Steinberg, 2009, 2016; Compton and Stringer, 2012; Shackelford et al., 2012; Rosas et al., 2017). These authors document the variability in Neanderthal dental development showing that, to some extent, it is very likely that there is overlap with that of modern humans. This hinders more accurate estimation of age at death of extinct Homo based on modern humans.

Furthermore, dental development variability in extant pop- ulations has been extensively investigated (Goodman, 1998; Zadzin'ska et al., 2013; Hillson, 2014; Sharma, 2014; Al-Batayneh

et al., 2015; Mahoney et al., 2016), demonstrating that tooth for- mation and emergence times are influenced not only by genetic and environmental factors but also by sexual dimorphism, infant illnesses, and nutritional status. All of these factors are unknown for the Marillac individuals. Therefore, age estimations based on the calcification stages of isolated teeth (without any other age matu- ration markers) can be merely indicative, and thus must be considered with caution.

The MNI of the Marillac human assemblage is estimated to be nine. This paleodemographic reconstruction, based exclusively on the discovered teeth, is most likely biased. It involves six immature specimens and three adults of undetermined age (Table 1). Among the latter, M20 seems to represent an older individual. This paleodemographic profile is consistent with that estimated for other sites where a higher number of human remains has been found. In particular, the age distribution at Marillac is compatible to that observed on other sites, despite their high taphonomic and cultural heterogeneity (e.g., Krapina, Combe-Grenal, Grotte du Renne, Grotte du Bison, Le Fate, Cova Negra or Palomas; Wolpoff, 1979; Arsuaga et al., 1989, 2007; Garralda and Vandermeersch, 2000; Bailey and Hublin, 2006; Lumley and Giacobini, 2013; Tillier et al., 2013; Trinkaus and Walker, 2017).

In several Neanderthal-bearing sites (e.g., Combe-Grenal, Mar- illac or Le Fate), naturally shed deciduous teeth are absent. The two deciduous teeth described here, M21 and M22, do not have resorbed roots. Although randomness should not be excluded, this repeated absence may indicate short periods of human presence at the sites (e.g., Le Fate in Lumley and Giacobini, 2013). As explained before, Marillac is interpreted as an occasionally used hunting camp, not as a residential place. Consequently, the Neanderthal collection corresponds only to a partial cadaveric representation, further related and modified by anthropic and/or carnivore activities. 
The Marillac teeth also provide indirect information about the health conditions of these Neanderthal people (Fig. 14A, B, F). On six of the M13 teeth, we described hypoplastic defects involving linear, pitted, ovally depressed or punctuated hypoplasias. On the basis of their locations in the upper incisors and the canine (i.e., at the middle or in the cervical half of the crown), they may have formed during infancy, around $\sim 3$ e years (age estimation after Reid and Dean, 2006; Shackelford et al., 2012; Guatelli-Steinberg et al., 2014). In fact, the enamel hypoplasias observed in the two upper premolars of M13 were estimated to have formed at around 3.5e4.5 years of age by Ogilvie et al. (1989; note that they call the teeth 'Marillac 3' and 'Marillac 9'). Of the isolated teeth, only the M17 RI2 shows two lines developed at a similar age, i.e., around 3.5e4.5 years. Although there is uncertainty in pinpointing the age of the growth disturbances, similar ontogenetic timing has been estimated for other fossils from the Middle and Early Late Pleistocene (Molnar and Molnar, 1985; Ogilvie et al., 1989; Hutchinson et al., 1997; Cunha et al., 2004; Bilsbourough and Thompson, 2005; Hlusko et al., 2013). Several of them have suggested a possible relation to weaning, although this is still debated (Humphrey, 2008). As summarized by Hillson (2014, p. 197), "enamel hypoplasia can be related to the medical history of a child, including infectious disease and nutricional deficiencies, without forgetting other environmental stresses" (e.g., mistreat- ment, child abuse and neglect, low protection, hard labor, or hard living conditions).

The oval-shaped fossae, described on the upper mesial side of the labial face on both M13 I2s (Fig. 14C-D; SOMS9, S10) are worth mentioning. On the one hand, they have also been observed in several other Neanderthal teeth recovered from sites spanning a wide chronological range across Europe. On the other hand, they are absent in many other fossils (e.g., the two partially digested M15 and M17). The presence of those fossae on teeth showing other hypo- plastic defects (e.g., lines, small pits) in the same area makes it difficult to infer about other possible causes. They were observed in Pín ar 7 (García-Sa'nchez et al., 1994), Combe-Grenal X (Fig. 14E; Garralda and Vandermeersch, 2000), and seven of the Krapina I2s. Interestingly, this feature was visible both on the enamel outer surface and on the EDJ, in M13 (SOM-S9, S10) and in Abri Bourgeois- Delaunay 10 (M. D. G. and A. L. C., pers. obs.). As expected, when both a central and a lateral upper incisor are preserved from the same individual (e.g., M13, Pín ar 7), both teeth show hypoplasias that formed at a similar time ( $\sim$ e4 years). However, the central incisors consistently lack the fossa, while the lateral incisors may show such a depression. This observation implies that one cannot hypothesize a similar developmental causality for these traits as is commonly done for enamel hypoplasias. Although the described oval-shaped fossae must be thoroughly investigated, one may speculate that a mechanical stress occurring in the oral environment during crown calcification may have induced this defect. Future research will be needed to clarify the etiology of this potential Neanderthal apo- morphic trait (Rougier, 2003).

No other pathological lesions, nor traces of tartar deposits were found. It cannot be ruled out that they probably were lost during post-excavation processes to clean and consolidate the teeth. Only M20 LM2 presents an elliptical and concave mark at the distal cervical margin (SOM-S20). It could be attributed to a toothpick groove (stage 4 in Estalrrich et al., 2017), given its similarity to others published for numerous fossils (e.g., Frayer and Russell, 1987; Lalueza et al., 1993; Bermúdez de Castro et al., 1997; Lozano et al., 2013; Estalrrich et al., 2017; Frayer et al., 2017). Yet, because this tooth was partially digested, this depression does not show visible scratches running parallel to its long axis such as those identified in other toothpick grooves (Bouchneb and Maureille, 2004). M20 also shows a small alteration of the dentine in the cervical part of the mesial face, which is oval, diffuse, and wider than the distal sulcus (SOM-S20). It is difficult to diagnose, because this does not appear to correspond to any onset of caries (Nguyen et al., 2008; Hur et al., 2011) and is different from the general morphology (oval-elongated) of the toothpick marks. We cannot exclude biocorrosion (e.g., partial digestion) as a possible origin because of the numerous alterations suffered by the molar. Therefore, its etiology remains unclear. 


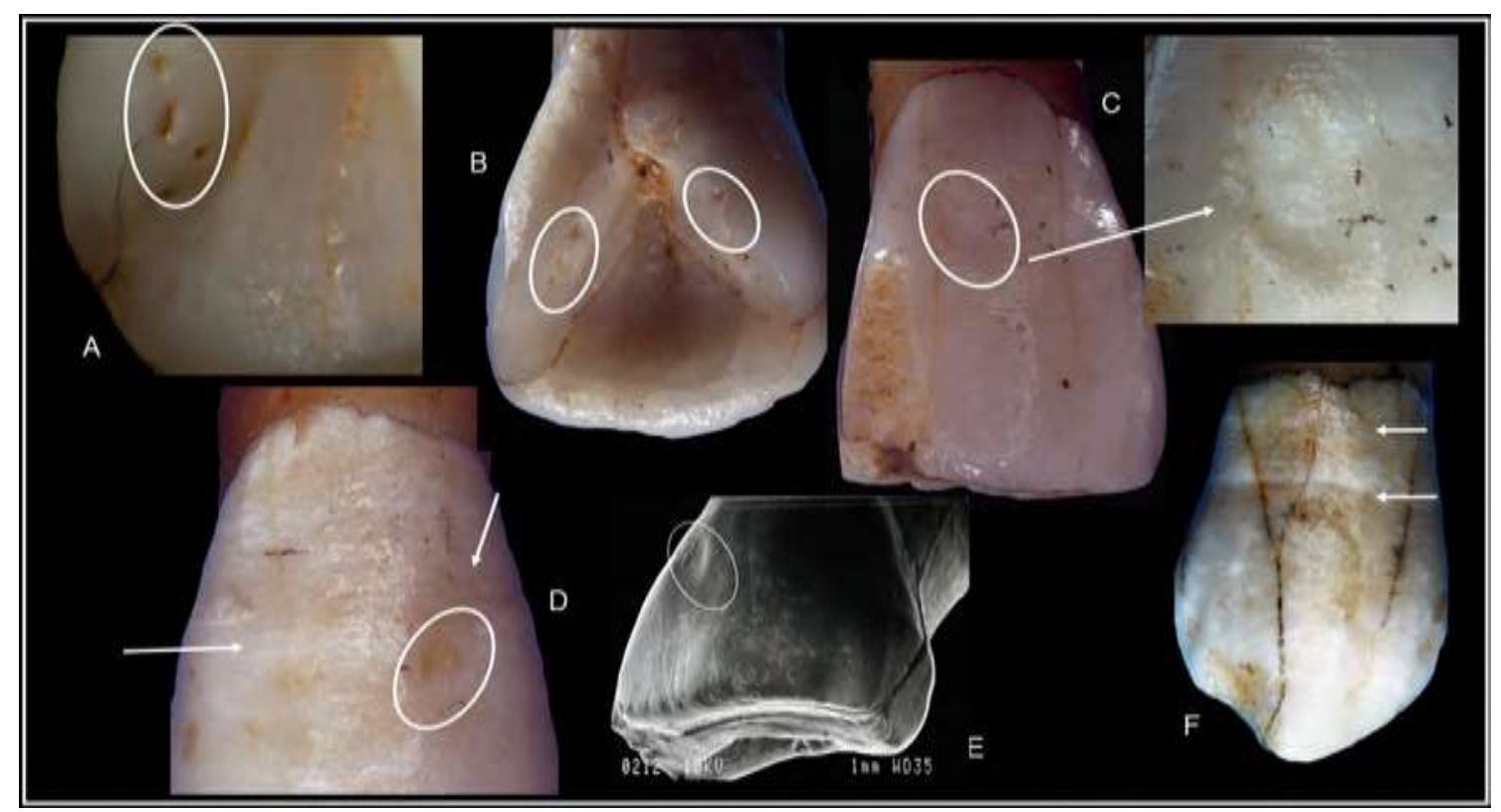

Figure 14. Enamel hypoplasias and fossae: (A) M13C, (B) M13D, (C) M13D, (D) M13C, (E) Combe-Grenal X, (F) M13E. Not to the same scale.

\section{Anterior tooth use and paramasticatory activities}

Five of the Marillac anterior teeth, belonging to individuals M13 and M17, present several microfractures on the occlusal border and the labial face that affect enamel or both enamel and dentine. These alterations are usually called dental chipping, which refers to antemortem fractures produced during a shock, pressure caused by the use of the teeth for para- and non-masticatory activities, or hard particles ingested with the food (Belcastro et al., 2004; Scott and Winn, 2011). The juvenile M13 shows small lesions on the RI1 and two more evident alterations on the LI1 and RC1. However, these lesions present edges with little erosion (Fig. 15 AeC) and are consequently interpreted as possible microtraumas suffered not long before the individual's death, similar to those published by Estalrrich and Rosas (2015) for other Neanderthals of different cultural contexts. They are very different to those observed on the mesial angle of M13D LI2 (Fig. 15D; SOM-S10 and on the isolated RI2 of the adult M17 (distal angle, Fig. 15E; SOM-S15). In both cases, a big inverted V-shaped enamel and dentine chip broke off and the edges are polished, especially in M17, due to the contact with saliva, lips and food. Both lesions are very similar to those described on the Combe-Grenal XI RI1 (Fig. 15F), also found in a Quina Mousterian context (Garralda and Vandermeersch, 2000), and reflect the poorly known complexity of the Neanderthal behavior.

The Marillac anterior teeth present an uneven distribution of hypercementosis on their root apices, also in the case of the de- ciduous incisor M21 (SOM-S21, and orange arrows on 2D sections of the fossils). This would not only be further evidence for the use of the anterior teeth for para- or non-masticatory activities (Le Cabec et al., 2013), but also for different oral and alveolar pathologies (d'Incau, 2012). 


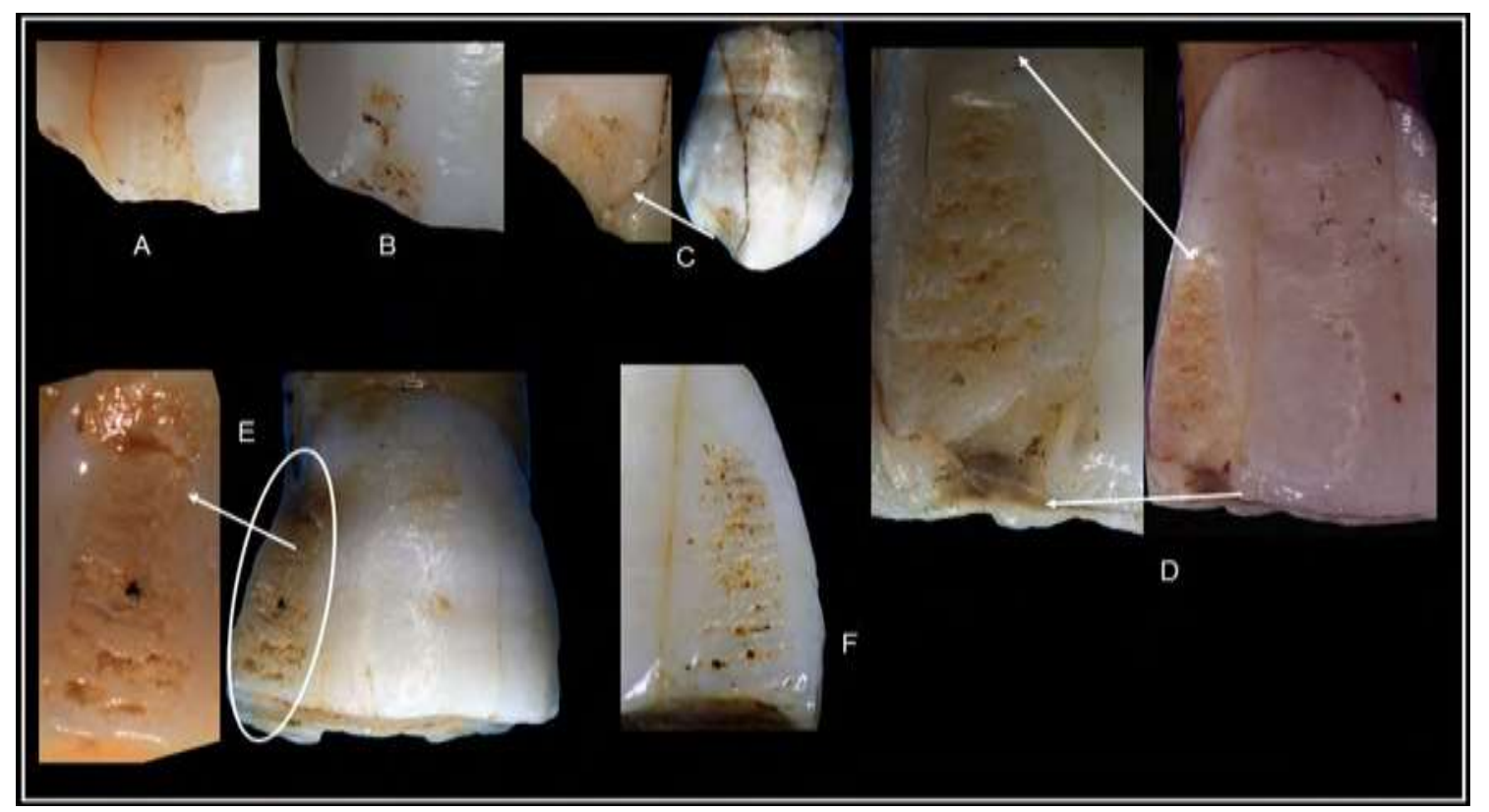

Figure 15. Dental chipping. (A) M13A, (B) M13B, (C) M13E, (D) M13D, (E) M17, (F) Combe-Grenal XI. Not to the same scale.

\section{Effect of digestion on the dental tissues at Marillac}

The alterations affecting both crown and root surfaces of six (five permanent and one deciduous) of the 16 teeth were produced by biocorrosion, such as that induced by the action of enzymes and stomach acids (Maureille et al., 2017). The teeth could have been ingested by one of the diverse carnivore species (mostly cave hy- enas) identified in the same lithostratigraphic unit that delivered the Neanderthal fossils. Those scavengers probably ate parts of the incomplete human corpses that the Neanderthals carried, manip-ulated, and finally abandoned in the sinkhole of Marillac.

From the anthropological material published so far, the M3 cranial fragment (Garralda et al., 2014b) and the diaphysis of the infantile femur M25 (Garralda et al., 2014c) have clear breaks produced by crushing and, in the second case, also by torsion. These kinds of manipulation were undoubtedly produced by the Nean- derthals, as for the cut-marks identified in other Marillac cranial (M2) and infracranial (M24 radius) human fragments (Garralda et al., 2005, 2014c). Both types of manipulation were also observed on the Marillac faunal remains (Costamagno et al., 2006), as well as in several other Middle Paleolithic European sites (e.g., Defleur et al., 1999; Frayer et al., 2006; Garralda and Vandermeersch, 2000; Rosas et al., 2006).

Attacks and/or scavenging events can be inferred from small and large carnivore tooth marks observed on European Pleistocene human fossils (e.g., White and Toth, 1991; Tournepiche et al., 1996; Andrews and Ferna'ndez-Jalvo, 1997; Defleur et al., 1999; Garralda and Vandermeersch, 2000; Ferna'ndez-Jalvo and Andrews, 2001; Beauval et al., 2005; Mann et al., 2007; Trinkaus et al., 2007; Camaro's et al., 2017). Although no animal tooth marks could be observed on any human bones discovered in Marillac (with the exception of a femoral fragment; Mussini, 2011), carnivore actions could yet be demonstrated by the partially digested and expelled teeth.

In some other sites, bone fragments of small-bodied animals (e.g., Gran Dolina; Saladie' et al., 2011) or teeth (Ferna'ndez-Jalvo and Andrews, 2016) were also shown to have been ingested and regurgitated/defecated. In Marillac, several partially digested bovid incisors, cervid or hyena teeth, and mammal bone fragments (i.e.,

reindeer petrous bones) have been identified in facies $2 \mathrm{a}$ and $4 \mathrm{~b}$. They document some active involvement of carnivores on the faunal and hominin remains, but they are scarce and clearly out-numbered by the unaltered remains (Maureille et al., 2017).

The key macroscopic features that we observed on the six partially digested Marillac teeth (Fig. 16) concern the shape of the anatomical cervix and, the irregular distribution of the enamel, or even its full disappearance as in M22. These taphonomic alterations also affect the root morphology, which could be: a) smoothed (on their whole surface area, with substantially reduced diameters), b) lacking cementum (present even in the unaltered 
deciduous M21), reduced dimensions in all directions, and d) with open apices. All of these features also appear in the bovid teeth found in the same stratigraphic unit of Marillac (see Figs. 5 and 6 in Maureille et al., 2017). As far as we know, regarding Neanderthals, only one LM3 from Grotte du Bison (Arcy-sur-Cure) has been reported as partially digested (Tillier et al., 2013).

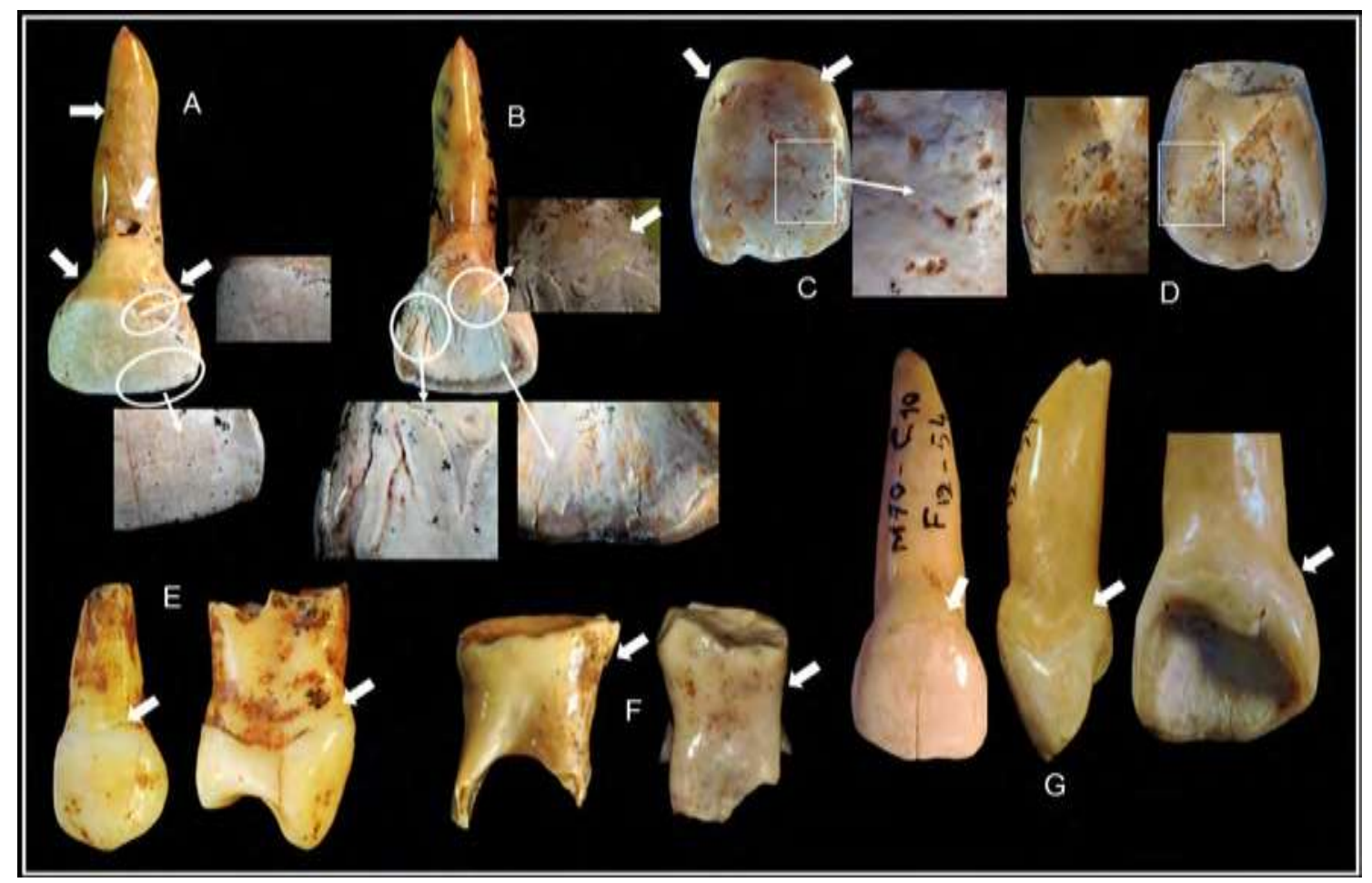

Figure 16. Partially digested teeth (enlarged). (A) Labial and (B) Lingual faces of M14. (C) Labial and (D) Lingual faces of M16. (E) Buccal and mesial faces of M18. (F) Buccal and distal faces of M22. (G) Labial, mesial and lingual sides of M15. Not to the same scale.

We assume that the occasional action of the carnivores on these cadaveric remains, specifically being torn apart and fragmented, must have occurred after human intervention (probably not as direct attacks). Given the absence of trunk remains in the Marillac's human fossil record, we suggest that the Neanderthals carried and manipulated only parts of the corpses of children and adults in the sinkhole (i.e., heads, and upper and lower limbs; Mussini, 2011; Garralda et al., 2014b, c). On the human bones, the conchoidal and torsion fractures, the crushing marks, and the sharp edges and grooves of the cut-marks, suggest that these alterations were induced peri-mortem (Garralda et al., 2005, 2014c; Garralda, 2008; Mussini, 2011). Yet, the time lag between death and manipulation is impossible to specify.

Ferna'ndez-Jalvo and Andrews (2016) demonstrated that enamel erosion is the principal effect of digestion on teeth, and that, in rodent teeth at least, enamel is more eroded than dentine. They also described five stages of partial digestion on rodent incisors: 1) Light (categories ' $a$ ' and ' $b$ '); 2) Moderate (cat. 'c'); 3): Heavy (cat. 'd'); and 4e5): Extreme (cat. 'e' and ' $\mathrm{f}$ ').

The Marillac teeth show similar degrees of enamel destruction (cat. ' $c$ ' to ' $f$ ') caused by partial digestion, with numerous pits and enamel partly destroyed or eliminated (almost completely as in M22, or more or less accentuated, as, by order, in M20, M14, M15, M16, and M18). In Homo, where enamel is thicker than in rodents (Rensberger and Krentz, 1988), the effect of the digestive process on the dentine (at the root) is more evident than on the enamel. This is reflected in the reduced dimensions of the Marillac roots, which were probably exposed to the enzymes and stomach acids for a longer time.

Based on the morphological descriptions, pictures and $\mathrm{mCT}$ data presented, these alterations, particularly those affecting the enamel, cannot be confused with cases of amelogenesis imperfecta. This very rare inherited genetic disease involves opacities and hypoplasia, and in many cases affects the whole of both the permanent and deciduous dentitions (Hillson, 1996, 2014; Slootweg, 2007; Scheid and Weiss, 2012; Wright, 2006). We also exclude any 
destruction of the enamel in the Marillac teeth caused by soil acidity. Moreover, since the sediments are represented by clast-supported limestone deposits associated to a clayey matrix (Maureille et al., 2010a; Frouin, 2014; Frouin et al., 2017), neither the human bone fragments nor the other 10 studied teeth display such kinds of damage.

Furthermore, the data included in this paper on both 2D and 3D enamel thickness components (Tables 3 and 4 ) demonstrate how reduced the values are for the partly digested teeth with respect to non-digested teeth, belonging to the Marillac individuals or to the Neanderthals and modern humans used for comparison. The 3D distribution of enamel thickness (Fig. 13) clearly reflects the dif- ferences between the normal and the partially digested teeth with their enamel alterations. M14, M15, M16, M18, and M20 display the enamel destruction (thinner enamel areas in green and blue on Fig. 13) starting from the apical part of the crown and presenting (exposed crown dentine in beige on Fig. 13) the tooth regions where it has nearly disappeared.

We propose that these teeth were ingested by any of the scav-enging carnivores documented at Marillac, probably together with parts of the individuals' faces (M16 and M18 were unerupted and protected in their alveoli) whose partial cadavers were abandoned there. Stomach acids, plus the enzymatic activity related to diges- tion, triggered the dramatic alterations and destruction of the enamel, shortening and thinning of the roots, and opening of the apex in addition to causing the hole above the crown in M14.

\section{Conclusions}

Although many sites bearing Neanderthal remains have been discovered in Western Europe, only a limited number of them are attributed to the end of MIS 4/beginning of MIS 3. The site of Marillac is of particular interest because of its well-documented chronostratigraphic and cultural contexts, its reliable dating, and its important collection of human fossils.

In the present study, we analyzed the sixteen Neanderthal teeth found in Marillac. They provided new data that enriches our knowledge of the morphology, biology and ethology of those nomadic hunter-gatherer groups in South-West France, as well as their relationships with their dead, prey, and local predators. These findings considerably extend the morphological and metric vari- ability of the Eurasian Neanderthals dentition.

We also show direct evidence of the ingestion of Neanderthal children and adult body parts by carnivores. To date, the Marillac site has delivered the highest number of human remains, specif- ically six permanent and deciduous teeth that present undeniable traces of biocorrosion. We illustrate, for the first time, how the partial digestion affected the 2D and 3D dental tissue proportions. This interaction with the carnivores may result from the function of the sinkhole as a place for processing parts of animal and human carcasses, some of which indeed show evidence of peri-mortem manipulations. These body fragments were later abandoned by the Neanderthals and then scavenged by carnivores.

This is the first comprehensive multidisciplinary research on the Marillac Neanderthal teeth discovered during Vandermeersch's excavations. This work investigates the paleobiology and behavior of the Neanderthal groups that used the Marillac sinkhole $60 \mathrm{ky}$ ago, and thus contributes to the clarification of several problems raised by such a complex site. Yet, many other questions remain subject to debate, such as the interpretation of the inferred behavior related to the treatment of the human bodies.

\section{Funding}

The archeological excavations conducted by B. Vandermeersch at Marillac site (1967e1980) were supported by the Universite' Paris VI 'Pierre et Marie Curie', the Universite' Bordeaux 1 and the French Ministry of Culture. Excavations at Marillac between 2001 and 2013 and archeological remainsresearchhas beensupportedby differentfundingsources: the Ministe`re de la Culture of France, the Service Re'gional de l'Arche'ologie (DRAC Poitou-Charentes), the Conseil Ge'ne'ral de la Charente, the Conseil Municipal de Marillac-le-Franc, Princeton University, the CNRS, University of Bordeaux, UMR5199 PACEA, the Research Program of the Aquitaine Region: Transitions, d'une socie'te' a ' l'autre processus d'adaptation et de peuplements (convention no 20051403003A), the Scientific Project: Ne'Mo of the LabEx Sciences Arche'ologiques de Bordeaux, support provided by the ANR - noANR-10-LABX-52/LaS- cArBx, the Research Program of the Nouvelle Aquitaine Region: Neanderthalenses Aquitanensis: Territoires, Chronologie, Humanite' convention no 2016-1R4020400007349-00007350.

M. D. G. received grants from the CNRS, the Universite' Bordeaux-1 and the Spanish Ministry of Science and Technology for three research periods at the PACEA-Laboratoire (Universite' de Bordeaux). This research has 
also been supported by the Max Planck Institute (Germany).

The analysis of the 2D and 3D enamel thickness of the teeth has received funding from the European Research Council (ERC) under the European Union's Horizon 2020 research and innovation pro- gramme (grant agreement No 724046 - SUCCESS); http:/ / www.erc- success.eu/

\section{Acknowledgements}

The authors gratefully acknowledge the curators and in- stitutions for providing access to original specimens, particularly to J.-J. Cleyet-Merle at the Muse'e National de Pre'histoire in Les Eyzies, H. de Lumley at the Institut de Pale'ontologie Humaine, R. Krus- zinsky and C. Stringer at the Natural History Museum in London, L. Bondioli at the Museo 'Luigi Pigorini' (Rome), G. Manzi at the Universita 'di Roma 'La Sapienza', A. G. Segre and E. Naldini-Segre at the Inst. Ital. de Paleontologia Umana (Rome) and J. Radov`ci'c at the Hrvatski Prirodoslovni Muzej in Zagreb. We also thank M. Bessou (ASI at the UMR-PACEA) for the X-ray plates, F. d'Errico, L. Bouchard for the photographs of the teeth, and L. Drak and E. Ruiz for their support with some of the figures.

We are also deeply grateful to H. Temming, A. Winzer, P. Scho€nefeld, T. Smith, A. Olejniczak, K. Kupczik, and D. Plotzki for mCT-scanning the Marillac teeth and comparative samples at MPI- EVA, and especially to D. Plotzki for his technical assistance with the segmentation of the teeth. We thank P. Gunz for helpful discussion and W. Plummer for contributing upper premolar EDJ comparative data and assistance with the GM analyses. We sincerely acknowledge C. Molenaar and M. Lui for careful proof- reading of the manuscript. Finally, the manuscript benefitted greatly from constructive reviews by the Editor, the Associated Editor and three anonymous reviewers.

\section{Supplementary Online Material}

Supplementary online material to this article can be found on- line at https:// doi.org/10.1016/j.jhevol.2019.102683.

\section{References}

AlQahtani, S.J., Hector, M.P., Liversidge, H.M., 2010. Brief communication: the Lon- don atlas of human tooth development and eruption. American Journal of Physical Anthropology 142, 481e490.

AlQahtani, S.J., Hector, M.P., Liversidge, H.M., 2014. Accuracy of dental age estima- tion charts: Schour and Massler, Ubelaker, and the London Atlas. American Journal of Physical Anthropolology 151, $70 \mathrm{e} 78$.

Al-Batayneh, O.B., Shaweesh, A.I., Alsoreeky, E.S., 2015. Timing and sequence of emergence of deciduous teeth in Jordanian children. Archives of Oral Biology 60(1), $126 \mathrm{e} 133$.

Andrews, P., Ferna'ndez-Jalvo, Y., 1997. Surface modifications of the Sima de los Huesos fossil humans. Journal of Human Evolution 33, $191 \mathrm{e} 217$.

Arsuaga, J.L., Gracia, A., Martínez, I., Bermúdez de Castro, J.M., Rosas, A., Villaverde, V., Fumanal, M.P., 1989. The human remains from Cova Negra (Valencia, Spain) and their place in European Pleistocene human evolution. Journal of Human Evolution 18, 55e92.

Arsuaga, J.L., Villaverde, V., Quam, R., Martínez, I., Carretero, J.M., Lorenzo, C., Gracia, A., 2007. New Neandertal remains from Cova Negra (Valencia, Spain). Journal of Human Evolution 52, 31 e58.

Bailey, S., 2002a. Neandertal dental morphology: Implications for modern human origins. Ph.D. Dissertation, Arizona State University.

Bailey, S., 2002b. A closer look at Neanderthal postcanine dental morphology: the mandibular dentition. Analytical Record 269, 148e156. 
Bailey, S., 2005. Diagnostic dental differences between Neandertals and Upper Paleolithic modern humans: getting to the root of the matter. In: Zadzinska, E. (Ed.), Current Trends in Dental Morphology Research. University of Lo€dz Press, Lo€dz, pp. 201e210.

Bailey, S.E., Lynch, J.M., 2005. Diagnostic differences in mandibular P4 shape be- tween Neandertals and anatomically modern humans. American Journal of Physical Anthropology 126, $268 \mathrm{e} 277$.

Bailey, S.E., Hublin, J.-J., 2006. Dental remains from the Grotte du Renne at Arcy-sur- Cure (Yonne). Journal of Human Evolution 126, 268e277.

Bayle, P., Braga, J., Mazurier, A., Macchiarelli, R., 2009. Dental developmental pattern of the Neanderthal child from Roc de Marsal: a high-resolution 3D analysis. Journal of Human Evolution 56(1), 66e75.

Bayle, P., Le Luyer, M., Robson-Brown, K., 2017. 9-The Palomas dental remains: enamel thickness and tissue proportions. In: Trinkaus, E., Walker, M.J. (Eds.), The People of Palomas: Neandertals from the Sima de Las Palomas Del Cabezo Gordo, Southeastern Spain, Texas A\&M University Anthropology Series. Texas A\&M University Press, College Station, pp. 115e137.

Beauval, C., Maureille, B., Lacrampe-Cuyaube`re, F., Serre, D., Persinotto, D., Bordes, J.G., Cochard, D., Couchoud, I., Dubrasquet, D., Laroulandie, V., Lenoble, A., Mallye, J.-B., Pasty, S., Primault, J., Rohland, N., Pa€€abo, S., Trinkaus, E., 2005. A late Neandertal femur from Les Rochers-de-Villeneuve, france. Proceedings of the National Academy Sciences USA 102(20), 7085e7090.

Been, E., Hovers, E., Ekshtain, R., Malinski-Buller, A., Agha, N., Barash, A., Bar-Yosef Mayer, D.E., Benazzi, S., Hublin, J.-J., Levin, L., Greenbaum, N., Mitki, N., Oxilia, G., Porat, N., Roskin, J., Soudack, M., Yeshurun, R., Shahack-Gross, R.,Nir, N., Stahlschmidt, M.C., Rak, Y., Barzilai, O., 2017. The first Neanderthal remains from an open-air Middle Palaeolithic site in the Levant. Scientific Reports 7, 2958.

Belcastro, M.-G., Mariotti, V., Facchini, F., Bonfiglioli, B., 2004. Proposal of a data collection form to record dentoalveolar features-application to two Roman skeletal samples from Italy. Collegium Antropologicum 28(1), $161 \mathrm{e} 177$.

Benazzi, S., Panetta, D., Fornai, C., Toussaint, M., Gruppioni, G., Hublin, J.-J., 2014a. Guidelines for the digital computation of 2D and 3D enamel thickness. Amer- ican Journal of Physical Anthropolology 153, $305 \mathrm{e} 313$.

Benazzi, S., Toussaint, M., Hublin, J.-J., 2014b. Enamel thickness in the ScladinaNeandertal teeth. In: Toussaint, M., Bonjean, D. (Eds.), The Scladina I-4A Juvenile Neandertal. E'tudes et Recherches Arche'ologiques de l'Universite' de Lie`ge, 134, pp. 307e314.

Benazzi, S., Slon, S., Talamo, S., Negrino, F., Peresani, M., Bailey, S.E., Sawyer, S., Panetta, D., Vicino, G., Starnini, E., Mannino, M.A., Salvadori, P.A., Meyer, M., Pa€€abo, S., Hublin, J.-J., 2015. The makers of the Protoaurignacian and implica- tions for Neandertal extinction. Science 348, 793 e796.

Bermúdez de Castro, J.M., Arsuaga, J.L., Pe'rez, P.J., 1997. Interproximal grooving inthe Atapuerca-SH hominid dentitions. American Journal of Physical Anthro- polology 102, 369e376.

Bilsbourough, A., Thompson, J.L., 2005. Dentition of Le Moustier 1 Neanderthal. In: Ullrich, H. (Ed.), The Neandertal Adolescent Le Moustier 1. New aspects, New Results. Staatliche Museum zu Berlin, Berlin, pp. $157 \mathrm{e} 186$.

Bookstein, F.L., 1997. Landmark methods for forms without landmarks: Morpho- metrics of group differences in outline shape. Medical Image Analysis 1, 225e243.

Bouchneb, L., Maureille, B., 2004. Sillons d'usure interproximaux : reproduction expe'rimentale, analyse et application des re'sultats aux observations sur la ligne'e ne'andertalienne. Bulletin et Me'moires de la Socie'te' d'Anthropologie de Paris 16, 37 e48. 
Burnett, S.E., 1998. Maxillary premolar accesory ridges (Mxpar): Woldwide occur- rence and utility in Population differentiation. MA Thesis, Arizona State Uni- versity, Tempe.

Buti, L., Le Cabec, A., Panetta, D., Tripodi, M., Salvadori, P.A., Hublin, J.-J., Feeney, R.N.M., Benazzi, S., 2017. 3D enamel thickness in Neandertal and modern human permanent canines. Journal of Human Evolution 111, $162 \mathrm{e} 172$.

Camaro's, E., Cueto, M., Rosell, J., Díez, J.C., Blasco, R., Duhig, C., Darlas, A., Harvati, K., Jorda', J., Montes, L., Villaverde, V., Rivals, F., 2017. Hunted or scavenged Neanderthals? Taphonomic approach to hominin fossils with carnivore damage. International Journal of Osteoarchaeology 27(4), 606e620.

Compton, T., Stringer, C., 2012. The Human remains. In: Aldhouse-Green, S., Peterson, R., Walker, E.A. (Eds.), Neanderthals in Wales. Pontnewydd and the Elwy Valley Caves. Oxbow Books, Oxford, pp. 118e230.

Condemi, S., 2001. Les Ne’andertaliens de La Chaise. CTHS, Paris, 178p.

Costamagno, S., Meignen, L., Vandermeersch, B., Maureille, B., 2006. Les Pradelles (Marillac-le-Franc, France): a Mousterian reindeer hunting camp? Journal of Archaeological Science 25, 466e484.

Couture, C., Tournepiche, J.-F., 1997. Les restes humains de la grotte de Rochelot (Charente). Anthropologie et Pré'histoire 108, 99e108.

Crevecoeur, I., Bayle, P., Rougier, H., Maureille, B., Higham, T., van der Plicht, J., De Clerck, N., Semal, P., 2010. The Spy VI child: A newly discovered Neandertal infant. Journal of Human Evolution 59, 641e656.

Crummett, T., 1994. The evolution of shovel-shaping: Regional and temporal vari- ation in human incisor morphology. Ph.D. Dissertation, University of Michigan, Ann Arbor. Univ. Microfilms.

Cunha, E., Ramirez Rozzi, F., Bermúdez de Castro, J.M., Martinón-Torres, M.,Wasterlain, S.N., Sarmiento, S., 2004. Enamel hypoplasias and physiological stress in the Sima de los Huesos Middle Pleistocene Hominins. American Journal of Physical Anthropolology 125, $220 \mathrm{e} 231$.

David, P., 1935. Les fouilles de l'abri-repaire de Marillac, pre`s La Rochefoucault. Bulletin et Me'moires de la Societe’ des Archives Historiques de la Charente 89e90 anne’e 1934.

Debe'nath, A., 1974. Recherches sur les terrains quaternaires charentais et les in- dustries qui leur sont associe'es. Doctorat d'État. Universite' de Bordeaux I, Fac.des Sciences t. 1, 359-377, and 578-598.

Nouvelles fouilles a` La Quina (Charente). Re’sultats pre'liminaires. In: Debe'nath, A., Jelinek, A.J. (Eds.), Gallia Pre’’histoire 40, 29e74.

Delagnes, A., Rendu, W., 2011. Shifts in Neandertal mobility, technology and sub- sistence strategies in western France. Journal of Archaeological Science 38, 1771e1783.

Defleur, A., White, T., Valensi, P., Slimak, L., Cre'gut-Bonnoure, E’., 1999. Neandertal cannibalism at Moula-Guercy, Arde`che, France. Science 286, 128e131.

D'Incau, E., 2012. Hyperce'mentose : Définition, classification et fréquence. Apport des re'sultats a' la ligne'e Ne'andertalienne. Ph.D. Dissertation, Universite’ Bordeaux 1.

D'Incau, E., Couture, C., Cre'peau, N., Chenal, F., Beauval, C., Vanderstraete, Maureille, B., 2015. Determination and validation of criteria to define hyper-cementosis in two medieval samples from France (Sains-en-Gohelle, AD 7th-17th c.; Jau-Dignac-et-Loirac, AD 7th-8th c.). Archives of Oral Pathology 60, 293 e303. Estalrrich, A., Rosas, A., 2015. Division of labor by sex and age in Neandertals: an approach through the study of activity-related dental wear. Journal of Human Evolution 80, 51e63.

Estalrrich, A., Alarcón, J.A., Rosas, A., 2017. Evidence of toothpick groove formation in Neandertal anterior and 
posterior teeth. American Journal of Physical Anthropolology 162, 747e756.

Ferna'ndez-Jalvo, Y., Andrews, P., 2001. Atapuerca, le conte de deux sites.

L'Anthropologie 105, 223e236.

Ferna'ndez-Jalvo, Y., Andrews, P., 2016. Atlas of Taphonomic Identifications. Springer, pp. 235e276. Chapter 8.

Frayer, D.W., Russell, M.D., 1987. Artificial grooves on the Krapina Neanderthal teeth. American Journal of Physical Anthropolology 74, 393e405.

Frayer, D.W., Orschied, J., Cook, J., Russell, M.D., Radov`ci`c, J., 2006. Krapina 3: Cut marks and ritual behavior? Periodicum Biologorum 108(4), 519e524.

Frayer, D.W., Gatti, J., Monge, J., Radov`cic, D., 2017. Prehistoric dentistry? P4 rotation, partial M3 impaction, toothpick grooves and other signs of manipulation in Krapina Dental Person 20. Bulletin of the International Association of Paleo- dontology 11(1), 1e10.

Frouin, M., 2014. Les Feldspaths comme support pour la datation par luminescence de gisements arche'ologiques et de se'quences quaternaires d'Aquitaine. Ph.D. Dissertation, Universite' de BordeauxMontaigne.

Frouin, M., Lahaye, C., Mercier, N., Guibert, P., Couchoud, I., Texier, J.-P., Royer, A., Costamagno, S., Beauval, C., Bourguignon, L., Meignen, L., Bordes, J.-G., Seguin, G., Bocherens, H., Lacrampe-Cuyaube`re, F., Grün, R., Garralda, M.-D., Vandermeersch, B., Mann, A.E., Maureille, B., 2017. Les Pradelles (Marillac-le- Franc, Charente) : chronologie d'un site moustérien de type Quina. PALEO 28, 117e136.

García Sa'nchez, M., Tillier, A.-M., Garralda, M.D., Vega, G., 1994. Dents d'enfant Moustériennes de la Cueva de La Carihuela (Grenade, Espagne). PALEO 6, 79e88.

Garralda, M.D., Vandermeersch, B., 2000. Les Ne’andertaliens de Combe-Grenal. PALEO 12, 213 e259.

Garralda, M.D., Maureille, B., Rigaud, J.-P., Vandermeersch, B., 2004. La molaire ne'andertalienne de la grotte Vaufrey (Dordogne, France). Bulletin et Me'moires de la Societe' d'Anthropologie de Paris 16(3e4), $189 \mathrm{e} 200$.

Garralda, M.D., Giacobini, G., Vandermeersch, B., 2005. Cutmarks on the Combe- Grenal and Marillac Neandertals. A SEM analysis. Anthropologie XLIII, 251e271. Garralda, M.D., 2008. Les Ne'andertaliens : d'autres gestes envers les de'funts. In: Vandermeersch, B., Cleyet-Merle, J.J., Jaubert, J., Maureille, B., Turq, A. (Eds.), Premie`re Humanite', Gestes Fune'raires des Ne'andertaliens. Re'union des Muse'es Nationaux, Paris, pp. 42e51.

Garralda, M.D., Maureille, B., Pautrat, Y., Vandermeersch, B., 2008. La molaire d'enfant ne'andertalien de Genay (Co^te-d’Or, France). Re’flexions sur la varia- bilite’ dentaire des Ne’andertaliens. PALEO 20, 89e100.

Garralda, M.D., Galv’an, B., Herna’ndez, C.B., Mallol, C., Go'mez, J.A., Maureille, B., 2014a. Neanderthals from El Salt (Alcoy, Spain) in the context of the latest Middle Palaeolithic populations from the Southeast of the Iberian Peninsula. Journal of Human Evolution 75, 1 e15.

Garralda, M.D., Maureille, B., Vandermeersch, B., 2014b. Hyperostosis frontalis interna in a Neandertal from Marillac (Charente, France). Journal of Human Evolution 67, 76e84.

Garralda, M.D., Maureille, B., Vandermeersch, B., 2014c. Neanderthal Infant and Adult Infracranial Remains from Marillac (Charente, France). American Journal of Physical Anthropolology 155, 99e113.

Garrod, D.A.E., Buxton, L.H.D., Elliot Smith, G., Bate, M.A., 1928. Excavation of a Mousterian rock-shelter at Devil's Tower, Gibraltar. Journal of the Royal Anthropological Institute 58, 37e48.

Gorjanovi'c-Kramberger, D., 1906. Der diluviale Mensch von Krapina in Kroatien ein Beitrag zur Palaeoanthropologie. C. W. Kreidel Verlag, Wiesbaden, 277p. 
Goodman, A., 1998. Variation in time of tooth formation and eruption. In: Ulijaszek, S.J., Johnston, F.E., Preece, M.A. (Eds.), The Cambridge Encyclopedia of Human growth and Development. Cambridge Univ. Press, pp. $209 \mathrm{e} 211$.

Guatelli-Steinberg, D., 2009. Recent studies of dental development in Neandertals: Implications for Neandertal life histories. Evolutionary Anthropology 18, 9e20. Guatelli-Steinberg, D., 2016. What Teeth Reveal About Human Evolution. Cambridge Universiy Press, 287 pages.

Guatelli-Steinberg, D., Reid, D.J., Bishop, T.A., Larsen, C.S., 2005. Anterior tooth growth periods in Neandertals were comparable to those of modern humans. Proceedings of the National Academy Sciences USA 102(40), $14197 \mathrm{e} 14202$.

Guatelli-Steinberg, D., Stinespring-Harris, A., Reid, D.J., Larsen, C.S., Hutchinson, D.L., Smith, T., 2014. Chronology of linear enamel hypoplasia formation in the Kra- pina Neanderthals. PaleoAnthropology 2014, $431 \mathrm{e} 445$.

Gunz, P., Mitteroecker, P., Bookstein, F.L., 2005. Semilandmarks in three dimensions. In: Slice, D. (Ed.), Recent Modern Morphometrics in Physical Anthropology. Kluwer Academic/Plenum Publishers, New York, pp. $73 \mathrm{e} 98$.

Gunz, P., Mitteroecker, P., 2013. Semilandmarks: A method for quantifying curves and surfaces. International Journal of Mammalian Biology 24, 103e109.

Gustafson, G., Koch, G., 1974. Age estimation up to 16 years of age based on dental development. Odontologisk Revy 25, 297e306.

Henri-Martin, L.H., 1926. Recherches sur l'évolution du Moustérien dans le gisement de La Quina (Charente). T. 4 : L'enfant fossile de La Quina, Angoule^${ }^{\wedge}$ me. Me'moires de la Socie'te’ Arche'ologique et Historique de la Charente 14, 158 p.

Hillson, S., 1996. Dental Anthropology. Cambridge University Press, Cambridge. Hillson, S., 2014. Tooth Development in Human Evolution and Bioarchaeolgy. Cambridge Univ. Press.

Hillson, S., FitzGerald, C., Flinn, H., 2005. Alternative dental measurements: Pro- posals and relationships with other measurements. American Journal of Phys- ical Anthropolology 126, 413e426.

Hlusko, L.J., Carlson, J.P., Guatelli-Steinberg, D., Krueger, K.L., Mersey, B., Ungar, P.S., Defleur, A., 2013. Neanderthal teeth from Moula-Guercy, Arde`che, France. American Journal of Physical Anthropolology $151,477 \mathrm{e} 491$.

Hublin, J.-J., Talamo, S., Julien, M., David, F., Connet, N., Bodu, P., Vandermeersch, B., Richards, M.P., 2012. Radiocarbon dates from the Grotte du Renne and Saint- Ce'saire support a Neandertal origin for the $\mathrm{Cha}^{\wedge}$ telperronian. Proceedings of the National Academy Sciences USA 109, 18743e18748.

Humphrey, L., 2008. Enamel traces of early lifetime events. In: Schutkowski, H. (Ed.), Between Biology and Culture. Cambridge University Press, New York, pp. 186e286.

Hur, B., Kim, H.C., Park, J.P., Versluis, A., 2011. Characteristics of non-carious cervical lesions. An ex-vivo study using micro computed tomography. Journal of Oral rehabilitation 38, 469e474.

Hutchinson, D.L., Larsen, C.S., Choi, I., 1997. Stressed to the max? Physiological perturbation in the Krapina Neandertals. Currrent Anthropology 38, 904e914.

Jaubert, J., Hublin, J.-J., McPherron, S.P., Soressi, M., Bordes, J.-G., Claud, E., Cochard, D., Delagnes, A., Mallye, J.-B., Michel, A., Niclot, M., Niven, L., Park, S.-J., Rendu, W., Richards, M., Richter, D., Roussel, M., 
Steele, T.E., Texier, J.-P., Thie'baut, C., 2008. Pale'olithique moyen recent et Pale'olithique supe'rieur ancient 'a Jonzac (Charente-Maritime) : premiers re’sultats des campagnes 2004-2006. In: Jaubert, J., Bordes, J.-G., Ortega, I. (Eds.), Les Socie'te's du Pale'olithique du Grand Sud-Ouest de la France : Nouveaux Gisements, Nou-veaux Re'sultats, Nouvelles Me'thodes. Me'moire XLVII de la Socie'te' Pre'historique Française, pp. $203 \mathrm{e} 243$.

Keene, H.J., 1966. A morphologic and biometric study of taurodontism in a contemporary population. American Journal of Physical Anthropolology 25, $208 \mathrm{e} 209$.

Kallay, J., 1963. A radiographic study of the Neanderthal teeth from Krapina, Croatia. In: Brothwell, D.R. (Ed.), Dental Anthopology. Pergamon Press, Oxford, pp. 75e86.

Kono, R., 2004. Molar enamel thickness and distribution patternsin extant great apes and humans: new insights based on a 3-dimensional whole crown perspective. Anthropological Sciences 112, $121 \mathrm{e} 146$.

Krikum, M., Monge, J., Mann, A., Finkel, G., Lampl, M., Radov`cíc, J., 1999. The Krapina Hominids. A radiographic Atlas of the Skeletal Collection. Croatian Nat. History Museum, Zagreb.

Kupczik, K., Hublin, J.-J., 2010. Mandibular molar root morphology in Neanderthals and Late Pleistocene and recent Homo sapiens. Journal of Human Evolution 59, 525e541.

Kuwahara, M., Hachimura, K., Ehiu, S., Kinoshita, M., 1976. Processing of ri- angiocardiographic images. In: Preston, K., Onoe, M. (Eds.), Digital Processing of Biomedical Images. Plenum Press, pp. 187e203.

Lalueza, C., Pe'rez-Pe'rez, A., Chimenos, E., Maroto, J., Turbo'n, D., 1993. Estudi radi- ogra`fic i micro`spic de la mandíbula de Banyoles: patologies i estat de con- servacio’. In: Maroto, J. (Ed.), La Mandíbula de Banyoles en el Context dels Fossils Humans del Pleistoce`, 13. Centre d'Investigacions Arqueolo`giques de Girona Se`rie Monogra`fica, pp. 135e144.

Le Cabec, A., Gunz, P., Kupczik, K., Braga, J., Hublin, J.-J., 2013. Anterior tooth root morphology and size in Neanderthals: Taxonomic and functional implications. Journal of Human Evolution 64, 169e193.

Le Cabec, A., Tang, N., Tafforeau, P., 2015. Accessing developmental information of fossil hominin teeth using new synchrotron microtomography-based visu- alization techniques of dental surfaces and interfaces. PLoS One 10(4), e0123019.

Le Mort, F., 1987. Incisions volontaires sur un arrie`re-cra^ne de $\mathrm{Ne}^{\wedge}$ andertalien de Marillac (Charente). In: Actes du 111e Congre`s National des Socie'te’s Savantes, Pre'- et Protohistoire; Pre'histoires de PoitouCharentes, Proble`mes actuels. E’d. du C.T.H.S, Paris, pp. $151 \mathrm{e} 156$.

Legoux, P., 1966. De’termination de l’a^ge dentaire de fossiles de la lignée humaine. Librairie Maloine S. A., Paris.

Liversidge, H.M., Molleson, T., 2004. Variation in crown and root formation and eruption of human deciduous teeth. American Journal of Physical Anthro- polology 123(2), 172e180.

Lozano, M., Subir`a, M.E., Aparico, J., Lorenzo, C., Go'mez-Merino, G., 2013. Tooth- picking and periodontal disease in a Neanderthal from Cova Forada`site (Valencia, Spain). PLoS One 8(10), e76852.

Lumley, M.A. de, Giacobini, G., 2013. Les ne’andertaliens de la Caverna delle Fate (Finale Ligure, Italie). II - Les dents. L'Anthropologie 117(3), 305e344.

Macchiarelli, R., Bondioli, L., Debe'nath, A., Mazurier, A., Tournepiche, J.F., Birch, W., Dean, C., 2006. How Neanderthal molar teeth grew. Nature 444, 748e751.

Madre-Dupouy, M., 1992. L'Enfant du Roc du Marsal: étude analytique et compar- ative. Cahiers de Pale'oanthropologie. Editions du CNRS, Paris, France. 
Mahoney, P., Miskiewicz, J.J., Pitfield, R., Schlecht, S.H., Deter, C., Guatelli- Steinberg, D., 2016. Biorythms, deciduous enamel thickness, and primery bone grow: a test of the Havers-Halberg Oscillation hypothesis. Journal of Anatomy. Doi:10.111/joa.1250.

Mann, A., Vandermeersch, B., Delagnes, A., Tournepiche, J.-F., 2007. Human fossils from the Mousterian levels of Artenac (Charente). Comptes Rendus Palevol 6, 581e589.

Martin, R., Saller, K., 1957. Lehrbuch der Anthropologie. Gustav Fisher Verlag, Stuggart.

Martin, L.B., 1983. Relationships of the later Miocene Hominoidea, PhD Dissertation.

University College London.

Martin, L.B., 1985. Significance of enemel thickness in hominoid evolution. Nature 314, $260 \mathrm{e} 263$.

Martin, R.M.G., Hublin, J.-J., Gunz, P., Skinner, M.M., 2017. The morphology of the enamel-dentine junction in Neanderthal molars: Gross morphology, non- metric traits, and temporal trends. Journal of Human Evolution $103,20 \mathrm{e} 44$.

Martinón-Torres, M., Bermúdez de Castro, J.M., Gómez-Robles, A., Prado-Simo’nn, L., Arsuaga, J.L., 2012. Morphological description and comparison of the dental remains from Atapuerca-Sima de los Huesos site (Spain). Journal of Human Evolution 62, 7e58.

Maureille, B., 2001. Variabilite' dans le genre Homo : les mensurations des couronnes dentaires de'ciduales et permanentes. Synthe`se de l'activite' scientifique pour l'obtention de l'habilitation a'diriger des recherches. UMR 5809. Laboratoire d'Anthropologie des Populations du Passe', Universite' Bordeaux. 1, 168 pp.

Maureille, B., Rougier, H., Houet, F., Vandermeersch, B., 2001. Les dents infe'rieures du Ne'andertalien Regourdou 1 (site de Regourdou, commune de Montignac, Dordogne): Analyses mé'triques et comparatives. PALEO 13, 183e200.

Maureille, B., 2018. La ligne'e ne'andertalienne : apport des fossiles mis au jour en France. In: Djinjan, F. (Ed.), La Pre'histoire de la France. Hermann Eds, Paris, pp. 181e205.

Maureille, B., Djinjan, F., Garralda, M.D., Mann, A., Vandermeersch, B., 2008. Les dents Mouste'riennes de la Grotte Boccard, lieu-dit Bas-de-Morant (C. de Cre'ancey, Co^te-d'Or, Bourgogne, France). Bulletin et Me'moires de la Societe' d'Anthropologie de Paris 20(1e2), 59e77.

Maureille, B., Mann, A., Beauval, C., Bordes, J.-G., Bourguignon, L., Costamagno, S., Couchoud, I., Fauquignon, J., Garralda, M.D., Geigl, E.-M., Grün, R., Guibert, P., Lacrampe-Cuyaube`re, F., Laroulandie, V., Marquet, J.-Cl, Meignen, L., Mussini, C., Rendu, W., Royer, A., Seguin, G., Texier, J.-P., 2010a. Les Pradelles `a Marillac-leFranc (Charente). Fouilles 2001e2007 : nouveaux re'sultats et synthe`se. In: Buisson-Catil, J., Primault, J. (Eds.), Pre'histoire Entre Vienne et Charente. Hommes et Socie'te's du Pale'olithique. Association des Publications Chauvin- oises, Me'm. XXXVIII. APC, Chauvigny, pp. 145e162.

Maureille, B., Garralda, M.D., Madelaine, S., Turq, A., Vandermeersch, B., 2010b. Le plus ancien enfant d'Aquitaine : Combe-Grenal 31 (Domme, France). PALEO 21, 189e202.

Maureille, M., Costamagno, S., Beauval, C., Mann, A.E., Garralda, M.D., Mussini, C., Laroulandie, V., Rendu, W., Royer, A., Seguin, G., Vandermeersch, B., 2017. The challenges of identifying partially digested human teeth: first description of Neandertal remains from the Mousterian site of Marillac (Marillac-le-Franc, Charente) and implications for Palaeoanthropological research. PALEO 28, $201 \mathrm{e} 212$.

Meignen, L., Vandermeersch, B., 1987. Le gisement mouste'rien de Marillac (Char- ente) couches 9 et 10. Caractéristiques des outillages. E'conomie des matie`res premie`res. In: Pre’histoire de Poitou-Charentes. Proble`mes Actuels. Actes III Congre`s Nat. des Socie’te’s Savantes, Poitiers, 1986. CTHS E`d., Paris, pp. $135 \mathrm{e} 144$. 
Meignen, L., Costamagno, S., Beauval, C., Bourguignon, L., Vandermeersch, B., Maureille, B., 2007. Gestion des ressources lithiques au Pale'olithique moyen dans une halte de chasse spe'cialise'e sur le renne : Les Pradelles (Marillac-le- Franc, Charente). In: Moncel, M.H., Moigne, A.-M., Arzarello, M., Peretto, C. (Eds.), Aires d'approvisionnement en matie`res premie`res et aires d'approvi- sionnement en ressources alimentaires, approches inte'gre'es de comporte- ments. UISPP, Actes XV Cong., Lisbonne, 4-9 septembre 2006. BAR Int. Series. 1725, Oxford, pp. 127e139.

Meignen, L., Costamagno, S., Bourguignon, L., Beauval, C., Maureille, B., 2010. Approche interdisciplinaire d'une halte de chasse au Pale'olithique moyen. In: Buisson-Catil, J., Primault, J. (Eds.), Préhistoire Entre Vienne et Charente. Hommes et Socie'te's du Paléolithique. Association des Publications Chauvinoises, Me'm. XXXVIII. Chauvigny, APC, pp. $163 \mathrm{e} 166$.

Molnar, S., 1971. Human tooth wear, tooth function and cultural variability. Amer- ican Journal of Physical Anthropolology 34, 175e190.

Molnar, S., Molnar, J.M., 1985. The incidence of enamel hypoplasia among the Krapina Neandertals. American Anthropologist 55, 443e450.

Moorrees, C.F.A., Fanning, E.A., Hunt, E.E., 1963a. Formation and resorption of three deciduous teeth in children. American Journal of Physical Anthropolology 19, 99e108.

Moorrees, C.F.A., Fanning, E.A., Hunt, E.E., 1963b. Age variation of formation stages for ten permanent teeth. Journal of Dental Research 42, 1490e1502.

Mussini, C., 2011. Les restes humains mouste'riens des Pradelles (Marillac-le-Franc, Charente, France). E'tude morphométrique et re'flexions sur un aspect com- portemental des Ne'andertaliens. Ph.D. Dissertation, Universite' Bordeaux 1.

Nguyen, C., Ranjitkar, S., Kaidonis, J.A., Towsend, G.C., 2008. A qualitative assess- ment of non-carious cervical lesions in extracted human teeth. Australian Dental Journal 53, 46e51.

Ogilvie, M.D., Curran, B.K., Trinkaus, E., 1989. Incidence and patterning of dental enamel hypoplasia among the Neandertals. Journal of Human Evolution 79, 25e41.

Olejniczak, A.J., Smith, T.M., Feeney, R.N.M., Macchiarelli, R., Mazurier, A., Bondioli, L., Rosas, A., Fortea, J., de la Rasilla, M., Garcia-Tabernero, A., Radovcî́c, J., Skinner, M.M., Toussaint, M., Hublin, J.J., 2008. Molar tissue pro- portions and enamel thickness distinguish Neanderthals from modern humans. Journal of Human Evolution 55, 12e23.

Patte, $E^{\prime} .$, 1962. La dentition des Néanderthaliens. Masson \& Cie, Paris, 307p.

Philippas, G.G., 1961. Influence of occlusal wear and age on formation of dentin and size of pulp chamber. Journal of Dental Research 40,1186e1198.

Piveteau, J., 1957. Marillac. Traite' de Pale'ontologie, vol. VII. Masson et Cie., Paris, pp. $473 \mathrm{e} 474$.

Piveteau, J., 1970. Les grottes de La Chaise (Charente). L'homme de l'abri Suard. Annales de Pale'ontologie (Verte’bre's) LVI 2, 167e225.

Reid, D.J., Dean, M.C., 2006. Variation in modern human enamel formation times. Journal of Human Evolution $50,329 \mathrm{e} 346$.

Reid, D.J., Guatelli-Steinberg, D., Walton, P., 2008. Variation in modern human premolar enamel formation times: Implications for Neandertals. Journal of Human Evolution 54(2), 225e235.

Rensberger, J.M., Krentz, H.B., 1988. Microscopic effects of predator digestion on the surfaces of bones and teeth. 
Scanning Microscopy 2, 1541e2155.

Rosas, A., Martínez-Maza, C., Bastir, M., García-Tabernero, A., Lalueza-Fox, C., Huguet, R., Ortiz, J.E., Julia`, R., Soler, V., de Torres, T., Martínez, E., Can averas, J.C., Sa’nchez-Moral, S., Cuezva, S., Lariol, J., Santamaría, D., de la Rasilla, M., Fortea, J., 2006. Paleobiology and comparative morphology of a late Neandertal sample from El Sidro'n, Asturias, Spain. Proceedings of the National Academy of Sci-ences USA 103(5), $19266 \mathrm{e} 19271$.

Rosas, A., Ríos, L., Estalrrich, A., Liversidge, H., García-Tabernero, A., Huguet, R., Cardoso, H., Bastir, M., Lalueza-Fox, C., de la Rasilla, M., Dean, C., 2017. The growth patern of neandertals, reconstructed from a juvenile skeleton from El Sidro'n (Spain). Science 357.

Rougier, H., 2003. E'tude descriptive et comparative de Biache-Saint-Vaast 1 (Biache-Saint-Vaast, Pas-de-Calais, France). Ph.D. Dissertation, Universite' Bordeaux 1, France.

Royer, A., Le'cuyer, C., Montuire, S., Escarguel, G., Fourel, F., Mann, A., Maureille, B., 2013. Late Pleistocene (MIS 3e4) climate inferred from micromammal com- munities and d18O of rodents from Les Pradelles, France. Quaternary Research 80, 113e124.

Saladie', P., Huguet, R., Rodríguez-Hidalgo, A., Díez, C., Martín-Rodríguez, P., Carbonell, E., 2011. Carcass transport decisions in Homo antecessor subsistence strategies. Journal of Human Evolution 61, $425 \mathrm{e} 446$.

Scolan, H., Santos, F., Tillier, A.-M., Maureille, B., Quintard, A., 2012. Des nouveaux vestiges ne'anderthaliens a`Las Pe'lénos (Monsempron-Libos, Lot-et-Garonne, France). Bulletin et Me'moires de la Socie'te' d'Anthropologie de Paris 24,69e95.

Scott, G.R., Winn, J.R., 2011. Dental chipping: contrasting patterns of microtrauma in Inuit and European populations. International Journal of Osteoarchaeology 21, 723e731.

Scott, G.R., Irish, J.D., 2017. Human Tooth Crown and Root Morphology. Cambridge University Press, 332 p.

Scheid, R.C., Weiss, G., 2012. Woelfel. Anatomía Dental, 8 Ed. Wollters Kluwer/ Lippincott Williams \& Wilkins, Barcelona.

Schulze, M.A., Pearce, J.A., 1994. A morphology-based filter structure for edge- enhancing smoothing. Proceedings of the 1994 IEEE International Conference on Image Processing (ICIP-94) 530e534.

Se'ronie-Vivien, M.-R., Tillier, A.-m, 2002. La dent humaine de Pradayrol (Caniac-du-Cause, Lot) dans son contexte stratigraphique at paleontologique. PALEO 14, 257e264.

Shackelford, L.L., Harris, A.E.S., Konigsberg, L.W., 2012. Estimating the distribution of probable age-at-death from dental remains of immature human fossils. American Journal of Physical Anthropolology 147, 227 e253.

Sharma, K., 2014. Genetic determinants and dynamics of permanent teeth emer- gence in Northwest Indian twins: a chronogenetic study. Homo 65(6), $450 \mathrm{e} 463$.

Siffre, A., 1911. Note sur une usure spéciale des molaires de La Quina. Bulletin de la Societe' Pre'historique Française 8, 741e743.

Skinner, M.M., 2008. Enamel-dentine junction morphology of extant hominoid and fossil hominin mandibular molars. Ph.D. Dissertation, The George Washington University.

Skinner, M.M., Wood, B.A., Boesch, C., Olejniczak, A.J., Rosas, A., Smith, T.M., Hublin, J.-J., 2008. Dental trait expression at the enamel-dentine junction of mandibular molars in extant and fossil hominoids. Journal of Human Evolution 54, 173e186.

Skinner, M.M., Gunz, P., Wood, B.A., Hublin, J.J., 2009. Discrimination of extant Pan species and subspecies using the enamel-dentine junction morphology of mandibular molars. American Journal of Physical 
Anthropolology 140, 234e243.

Skinner, M.M., Gunz, P., 2010. The presence of accessory cusps in chimpanzee mandibular molars is consistent with a patterning cascade model of develop- ment. Journal of Anatomy 217, 245e253.

Slootweg, P., 2007. Dental Pathology. Springer, Germany.

Smith, T.M., Toussaint, M., Reid, D.J., Olejniczak, A.J., Hublin, J.-J., 2007. Rapid dental development in a Middle Paleolithic Belgian Neanderthal. Proceedings of the National Academy of Sciences USA 104, 20220e20225.

Smith, T.M., Tafforeau, P., Reid, D.J., Pouech, J., Lazzari, V., Zermeno, J.P., Guatelli- Steinberg, D., Olejniczak, A.J., Hoffmann, A., Radov`ci'c, J., 2010. Dental evidence for ontogenetic differences between modern humans and and Neanderthals. Proceedings of the National Academy of Sciences USA 107, 20923 e20928.

Smith, T.M., Olejniczak, A.J., Zermeno, J.P., Tafforeau, P., Skinner, M.M., Hoffmann, A., Radov`ci`c, J., Toussaint, M., Kruszynski, R., Menter, C., Moggi-Cecchi, J., Glasmacher, U.A., Kullmer, O., Schrenk, F., Stringer, C., Hublin, J.-J., 2012. Vari- ation in enamel thickness within the genus Homo. Journal of Human Evolution 62, 395e411.

Tillier, A.-m, 1979. The dentition of the Mousterian child Chateauneuf 2 from Hauteroche (Charente). L'Anthropologie 83(3), 417e438.

Tillier, A.-M., Sansilbano-Collilieux, M., David, F., Enloe, J.G., Girard, M., Hardy, M., D'iatchenko, V., RoblinJouve, A., Tolmie, C., 2013. Les vestiges ne'andertaliens provenant des niveaux mouste'riens I et J de la Grotte du Bison a' Arcy-sur-Cure (Yonne) : bilan actuel. Bulletin et Mémoires de la Socie'te' d'Anthropologie de Paris 25, 39e54.

Tournepiche, J.F., Couture, C., Guadelli, J.L., Michel, P., 1996. Neandertal remains of Rochelot Cave Hyena-den. Comptes Rendus de l'Academie des Sciences de Paris, sérieII 322(5), 429e435.

Trinkaus, E., Maki, J., Zilhao, J., 2007. Middle Paleolithic human remains from the Gruta da Oliveira (Torres Novas), Portugal. American Journal of Physical Anthropolology 134, 263e273.

Trinkaus, E., 2017. The people of Palomas. In: Trinkaus, E., Walker, M.J. (Eds.), The People of Palomas. Neandertals from the Sima de las Palomas del Cabezo Gordo, Southeastern Spain. Texas A\&M Univ. Anthropology Series, pp. $245 \mathrm{e} 247$.

Trinkaus, E., Walker, M.J. (Eds.), 2017. The People of Palomas. Neandertals from the Sima de las Palomas del Cabezo Gordo, Southeastern Spain. Texas A\&M Univ. Anthropology Series.

Turner II, C.G., Nichol, C., Scott, G., 1991. Scoring procedures for key morphological traits of the permanent dentition. The Arizona State University Dental An- thropology System. In: Kelley, M., Larsen, C.S. (Eds.), Advances in Dental An- thropology. Wiley-Liss, New York, pp. 13e31.

Vandermeersch, B., 1980. Marillac-le-Franc. Gallia Pre’histoire 23(2), 302e303.

Vandermeersch, B., 1986. Le peuplement du Poitou-Charentes au Pale'olithique infe'rieur et moyen. Actes du 111e Congre`s des Socie'te's Savantes, Pre'histoire de Poitou-Charentes. Proble`mes Actuels, Poitiers 1986. du CTHS, Paris, pp.7e15.

Verna, C., 2006. Les restes humains mouste'riens de la Station Amont de La Quina (Charente, France). Ph.D. Dissertation, Universite' Bordeaux 1.

White, T.D., Toth, N., 1991. The question of ritual cannibalism at Grotta Guattari.

Currrent Anthropology 32(2), $118 \mathrm{e} 138$.

Willman, J.C., Maki, J., Bayle, P., Trinkaus, E., Zilhao, J., 2012. Middle Paleolithic human remains from the Gruta 
da Oliveira (Torres Novas), Portugal. American Journal of Physical Anthropolology 149, 39e51.

Wolpoff, M., 1979. Krapina teeth. American Journal of Physical Anthropology 50, 67e114.

Wright, J.T., 2006. The molecular etiologies and associated phenotypes of amelo- genesis imperfecta. American Journal of Medical Genetics A 140, 2547 e2555.

Wright, T., 2007. The molecular control of and clinical variations in root formation. Cells Tissues Organs 186, $86 \mathrm{e} 93$.

Zapata, J., Bayle, P., Lombardi, V., Pe'rez-Pe'rez, A., Trinkaus, E., 2017. The Palomas dental remains: Preservation, Wear and Morphology. In: Trinkaus, E., Walker, M.J. (Eds.), The People of Palomas. Texas A\&M University Press, Texas, pp. 52e88.

Zadzin’ska, E., Nieczuja-Dwojacka, J., Borowska-Sturgin'ska, B., 2013. Primary tooth emergence in Polish children: timing, sequence and the relation between morphological and dental maturity in males and females. Anthropologischer Anzeiger 70(1), 1 e13. 
The Neanderthal teeth from Marillac (Charente, Southwestern France): Morphology, comparisons and paleobiology

María Dolores Garralda, Bruno Maureille, Adeline Le Cabec, Gregorio Oxilia, Stefano Benazzi, Matthew M. Skinner, Jean-Jacques Hublin, Bernard Vandermeersch

\section{Legends for Supplementary Online Materials}

SOM Figure S1. In situ position of five permanent anterior teeth (stars) found in close proximity which allowed their attribution to a single individual, Marillac 13 (square F12, layer 10, B. Vandermeersch excavations in 1971).

SOM Table S2. Technical parameters for the $\mu \mathrm{CT}$ acquisitions.

SOM Table S3. List of sites and references used for Figs. 11-13.

SOM S4. Protocol for analyzing 2D and 3D enamel thickness of the Marillac teeth.

SOM Figure S5. Quantification of the EDJ shape of the M13F LP3, M13G LP4 and M19 LM3, compared to Neanderthals and modern humans.

SOM Table S6. Root morphometrics of the Marillac teeth and comparative samples.

SOM Figure S7. Marillac 13A. (Enamel, dentine and pulp were segmented by region growing in Avizo 6.3 from the filtered $\mu \mathrm{CT}$ scans acquired MPI-EVA, and following the protocol described in Le Cabec et al. (2013, JHE, 64[3]: 169- 193). The images contained in the slides showing the whole tooth, the dentine and the pulp cavity were rendered in Avizo, while those in the slides showing the 2D sections were rendered in VGStudio MAX 3.0 from the unfiltered $\mu \mathrm{CT}$ scans. The plates were designed in Adobe Photoshop CC 2015. Also applicable to SOM Figs S8 to S22).

SOM Figure S8. Marillac 13B.

SOM Figure S9. Marillac 13C.

SOM Figure S10. Marillac 13D.

SOM Figure S11. Marillac 13E.

SOM Figure S12. Marillac 13F.

SOM Figure S13. Marillac 13G.

SOM Figure S14. Marillac 14.

SOM Figure S15. Marillac 15.

SOM Figure S16. Marillac 16.

SOM Figure S17. Marillac 17.

SOM Figure S18. Marillac 18.

SOM Figure S19. Marillac 19.

SOM Figure S20. Marillac 20.

SOM Figure S21. Marillac 21.

SOM Figure S22. Marillac 22.

SOM Table S23. 2D (A) and 3D (B) components of crown tissue proportions and enamel thickness indices of the Marillac teeth. 


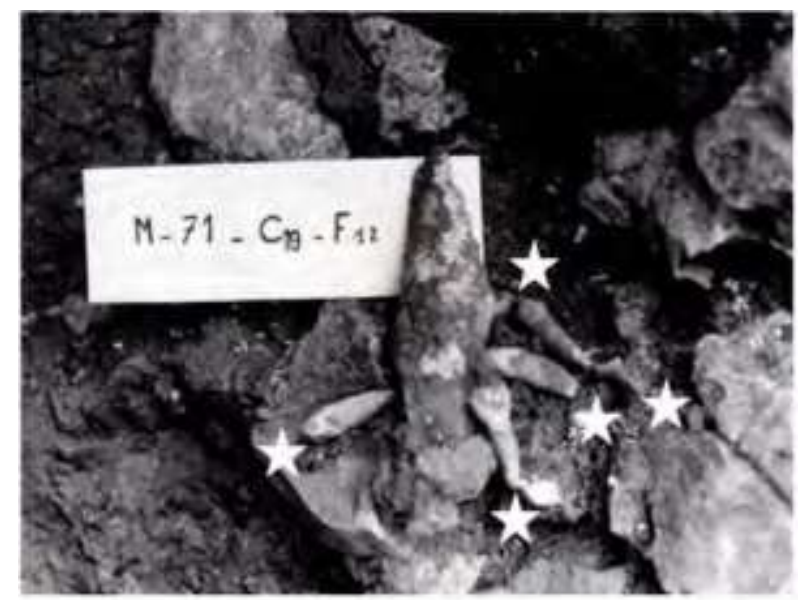

SOM Figure \$1.

In situ position of five permanent anterior teeth (stars) found in close proximity which allowed their attribution to a single individual, Marillac 13 (square F12, layer 10, B. Vandermeersch excavations in 1971). 
Table S2. Technical parameters for the micro-CT scan acquisitions of the Marillac teeth performed at the MPI-EVA.

\begin{tabular}{|c|c|c|c|c|c|c|c|c|c|c|}
\hline Specimen & Tooth & $\begin{array}{c}\text { Initial } \\
\text { resolution } \\
{[\mu \mathrm{m}]}\end{array}$ & Scan date & $\begin{array}{c}\mu \mathrm{CT} \\
\text { operator }\end{array}$ & $\mu C T$ facility & Voltage, current & $\begin{array}{c}\text { Filters (thickness, } \\
\text { material) }\end{array}$ & $\begin{array}{l}\text { Number of } \\
\text { projections, } \\
\text { frame } \\
\text { averaging }\end{array}$ & Resampling & Segmentation \\
\hline Marillac $13 \mathrm{~A}$ & $\mathrm{RI}^{1}$ & 27.49 & 23-May-07 & TS & Sk. 1172 & $100 \mathrm{kV}, 0.1 \mathrm{~mA}$ & $0.5 \mathrm{~mm} \mathrm{Al}, 0.04 \mathrm{~mm} \mathrm{Cu}$ & 1440,2 & - & ALC \\
\hline Marillac 13 B & $\mathrm{LI}^{1}$ & 27.49 & 23-May-07 & TS & Sk. 1172 & $100 \mathrm{kV}, 0.1 \mathrm{~mA}$ & $0.5 \mathrm{~mm} \mathrm{Al}, 0.04 \mathrm{~mm} \mathrm{Cu}$ & 1440,2 & - & $\mathrm{ALC}$ \\
\hline Marillac $13 \mathrm{C}$ & $\mathrm{RI}^{2}$ & 27.49 & 23-May-07 & TS & Sk. 1172 & $100 \mathrm{kV}, 0.1 \mathrm{~mA}$ & $0.5 \mathrm{~mm} \mathrm{Al}, 0.04 \mathrm{~mm} \mathrm{Cu}$ & 1440,2 & - & $\mathrm{ALC}$ \\
\hline Marillac 13 D & $\mathrm{LI}^{2}$ & 17.39 & 14-May-08 & AJO & Sk. 1172 & $100 \mathrm{kV}, 0.1 \mathrm{~mA}$ & $0.5 \mathrm{~mm} \mathrm{Al}, 0.04 \mathrm{~mm} \mathrm{Cu}$ & 3000,2 & y & DP \\
\hline Marillac $13 \mathrm{E}$ & $\mathrm{RC}^{1}$ & 27.49 & 22-May-07 & TS & Sk. 1172 & $100 \mathrm{kV}, 0.1 \mathrm{~mA}$ & $0.5 \mathrm{~mm} \mathrm{Al}, 0.04 \mathrm{~mm} \mathrm{Cu}$ & 1800,2 & - & $\mathrm{ALC}$ \\
\hline Marillac 13 F & $\mathrm{LP}^{3}$ & 13.74 & 23-May-07 & TS & Sk. 1172 & $100 \mathrm{kV}, 0.1 \mathrm{~mA}$ & $0.5 \mathrm{~mm} \mathrm{Al}, 0.04 \mathrm{~mm} \mathrm{Cu}$ & 3000,2 & - & DP \\
\hline Marillac $13 \mathrm{G}$ & $\mathrm{LP}^{4}$ & 13.74 & 23-May-07 & TS & Sk. 1172 & $100 \mathrm{kV}, 0.1 \mathrm{~mA}$ & $0.5 \mathrm{~mm} \mathrm{Al}, 0.04 \mathrm{~mm} \mathrm{Cu}$ & 3000,2 & y & DP \\
\hline Marillac $14^{*}$ & $\mathrm{RI}^{1}$ & 12.87 & 16-Sep-15 & DP & Sk. 1173 & $100 \mathrm{kV}, 0.062 \mathrm{~mA}$ & $1.0 \mathrm{~mm} \mathrm{Al}$ & 2400,4 & y & ALC \\
\hline Marillac $15^{*}$ & $\mathrm{RI}^{2}$ & 12.87 & 16-Sep-15 & DP & Sk. 1173 & $100 \mathrm{kV}, 0.062 \mathrm{~mA}$ & $1.0 \mathrm{~mm} \mathrm{Al}$ & 2400,4 & y & $\mathrm{ALC}$ \\
\hline Marillac $16^{*}$ & $\mathrm{LI}^{2}$ & 12.87 & 15-Sep-15 & DP & Sk. 1173 & $100 \mathrm{kV}, 0.062 \mathrm{~mA}$ & $1.0 \mathrm{~mm} \mathrm{Al}$ & 2400,4 & y & DP \\
\hline Marillac 17 & $\mathrm{RI}^{2}$ & 12.87 & 15-Sep-15 & DP & Sk. 1173 & $100 \mathrm{kV}, 0.062 \mathrm{~mA}$ & $1.0 \mathrm{~mm} \mathrm{Al}$ & 2400,4 & y & ALC \\
\hline Marillac $18^{*}$ & $\mathrm{LP}^{3}$ & 12.87 & 15-Sep-15 & DP & Sk. 1173 & $100 \mathrm{kV}, 0.062 \mathrm{~mA}$ & $1.0 \mathrm{~mm} \mathrm{Al}$ & 2400,4 & y & DP \\
\hline Marillac 19 & $\mathrm{LM}^{3}$ & 13.74 & 22-May-07 & TS & Sk. 1172 & $100 \mathrm{kV}, 0.1 \mathrm{~mA}$ & $0.5 \mathrm{~mm} \mathrm{Al}, 0.04 \mathrm{~mm} \mathrm{Cu}$ & 3000,2 & y & $\mathrm{DP}$ \\
\hline Marillac 20* & $\mathrm{LM}_{2}$ & 12.87 & 15-Sep-15 & DP & Sk. 1173 & $100 \mathrm{kV}, 0.062 \mathrm{~mA}$ & $1.0 \mathrm{~mm} \mathrm{Al}$ & 2400,4 & y & DP, ALC \\
\hline Marillac 21 & $\mathrm{Rdl}_{2}$ & 12.87 & 16-Sep-15 & DP & Sk. 1173 & $100 \mathrm{kV}, 0.062 \mathrm{~mA}$ & $1.0 \mathrm{~mm} \mathrm{Al}$ & 2400,4 & y & $\mathrm{ALC}$ \\
\hline Marillac $22^{*}$ & $\mathrm{Ldm}_{1}$ & 12.87 & 16-Sep-15 & DP & Sk. 1173 & $100 \mathrm{kV}, 0.062 \mathrm{~mA}$ & $1.0 \mathrm{~mm} \mathrm{Al}$ & 2400,4 & y & ALC \\
\hline
\end{tabular}

Abbreviations are as follows:

for names: TS: Tanya Smith, AJO: Anthony J. Olejniczak; DP: David Plotzki, ALC: Adeline Le Cabec.

for $\mu$ CT-scanners: Sk. 1172: SkyScan 1172 SN041; Sk. 1173: SkyScan 1173 SN11D05016. 


\begin{tabular}{|c|c|}
\hline \multicolumn{2}{|c|}{ TEETH USED FOR COMPARISONS: SITES AND REFERENCES } \\
\hline Amud 1 & Suzuki \& Takai, 1970 \\
\hline Angles sur I'anglin & Patte, 1960 \\
\hline Arcy sur Cure NN6 (B9 & Leroi-Gourhan, 1958; Bailey \& Hublin, 2006 \\
\hline B. Moula Guercy & Hlusko et al., 2013 \\
\hline Bacho Kiro 1124 & Glen E. \& Kaczanowski K., 1982 \\
\hline Bau de L'Aubesier & Lebel et al., 2001 \\
\hline Carihuela (Píñar 7) & García-Sánchez et al., 1994 \\
\hline Chateauneuf 2 & Tillier, 1979a \\
\hline Combe Grenal & Garralda \& Vandermeersch, 2000 \\
\hline Cotencher & Bay, 1984, 1981 \\
\hline Cova Negra 7856 & Arsuaga J. L. et al., 1989 \\
\hline Devil's Tower & Tillier, 1979 \\
\hline El Castillo & Garralda (obs. pers.) \\
\hline El Salt & Garralda et al., 2014 \\
\hline Figueira Brava & Antunes \& Santinho Cunha, 1992 \\
\hline Fossellone 1 & Manzi \&Passarello, 1995; Mallegni, 1992 \\
\hline Genay 1 & Lumley de., 1987 \\
\hline Grotte Boccard & Maureille et al., 2008 \\
\hline Guattari III & Sergi S. \& Ascenzi A., 1955 \\
\hline Hortus & de Lumley, 1973 \\
\hline Kalamakia & Harvati et al., 2013 \\
\hline Kébara 1 & Smith \& Arensburg, 1977; Tillier 1999 \\
\hline Kébara 2 & Tillier, 1991 \\
\hline Kebara 27, 4 & Tillier et al., 2003 \\
\hline Krapina & Radovcic et al., 1988 \& Wolpoff 1979 \\
\hline Kulna & Frayer D., 1978 \\
\hline La Chaise Bourgeois D. & Condemi, 1992 \\
\hline La Chaise Suard & Genet-Varcin, 1975 \\
\hline La Cote S.-Brelade & Keith A. \& Knowles H. S., 1912 \\
\hline La Ferrassie 8 & Heim, 1976 \\
\hline La Payre 0 à X & Moncel \& Condemi, 1996 \\
\hline La Quina H5 & Martin, 1923; Tillier, 1979; Verna, 1999 \\
\hline Le Fate 12 & Vacca \& Alciati, 2000 \\
\hline Le Fate 2 & Glen E. \& Kaczanowski K., 1982 \\
\hline Le Fate 8 & Giacobini et al., 1985; Giacobini \& de Lumley, 1988 \\
\hline Le Moustier 1 & Obs. pers. \\
\hline Le Portel & Gruselle, 1993 \\
\hline Macassargues 2 & de Lumley, 1973 \\
\hline Monsempron & Obs. pers. \\
\hline Ochoz 1 & Vlcek E., 1969 \\
\hline Pech-de-l'Azé & Tillier, 1979 \\
\hline Petit-Puymoyen & Obs. pers. \\
\hline Regourdou & Maureille et al., 2001 \\
\hline Rescoundudou & Jaubert \& Maureille, 2008 \\
\hline Roc-de-Marsal & Madre-Dupouy, 1992 \\
\hline Rochelot 1 & Obs. pers. \\
\hline Saccopastore & Condemi, 1992 \\
\hline Saint-Brais II & Koby, 1956 \\
\hline Saint-Césaire 1 & Mann comm. pers. \\
\hline
\end{tabular}




\begin{tabular}{|l|l|}
\hline San Bernardino 5 & Vacca \& Alciati, 2000 \\
\hline Shanidar & Trinkaus, 1983 \\
\hline Soulabé & Maureille et al., 1999 \\
\hline Spy 1, 2 & Obs. pers. \\
\hline Subalyuk 1 & Pap et al., 1996 \\
\hline Teshik Tash & Tillier, 1979 \\
\hline Valdegoba & Quam et al., 2001 \\
\hline Vindija 231 & Wolpoff et al., 1985 \\
\hline Zafarraya & Barroso Ruiz et al., 2006 \\
\hline
\end{tabular}

\section{REFERENCES}

Antunes, M. T., Santinho Cunha, A., 1992. Neanderthalian remains from Figueria Brava Cave, Portugal. Geobios, n 25, fasc. 5: 681-692.

Arsuaga, J.-L., Gracia, A., Martinez, I., Bermúdez de Castro, J. M., Rosas, A., Villaverde, V., Fumanal, M. P., 1989. The human remains from Cova Negra (Valencia, Spain) and their place in European Pleistocene Human Evolution. J. Hum. Evol., 18: 55-92.

Bailey, S., Hublin, J.-J., 2016. Dental remains from the Grotte du Renne at Arcy-sur-Cure. Journal of Human Evolution, 50: 485-508.

Barroso Ruiz, C., de Lumley, M.-A., Caparrós, M., Verdú Bermejo, L., 2006. Les restes humains néandertaliens et Homo sapiens de la grotte du Boquete de Zafarraya. In, (Barroso Ruiz C. \& de Lumley H, eds). La grotte du Boquete de Zafarraya, Málaga, Andalousie. T. III Junta de Andalucía, pp. 1167-1396.

Bay, R., 1981. Der menschliche Oberkiefer aus der Grotte de Cotencher (Rochefort, Neuchâtel, Suisse). Arch. Suisses d'Anthrop. Gén., 45, 1: 57-101.

Bay, R., 1984. The human maxilla from grotte de Contencher (Rochefort, Neuchâtel, Switzerland). J. Hum. Evol., 13, 4: 301-305.

Condemi, S., 1992. Les Neandertaliens de la Chaise (abri Bourgeois-Delaunay). Paris: Editions du Comite des travaux historiques et scientifiques, $178 \mathrm{p}$.

García-Sanchez, M., Tillier, A.-M., Garralda, M. D., Vega-Toscano, G., 1994. Les dents d'enfant des niveaux moustériens de la grotte de Carihuela (Grenade, Espagne). Paleo, 6: 79-88.

Garralda, M. D., Vandermeersch, B., 2000. Les Néandertaliens de Combe-Grenal. Paleo 12, 213-259.

Garralda M. D., Galván B., Hernández C. M., Mallol C., Gómez J. A., Maureille B., 2014. Neanderthals from El Salt (Alcoy, Spain) in the Context of the Latest Middle Palaeolithic Populations from the Southeast of the Iberian Peninsula, J. Hum. Evol., 75: 1-15

Genet-Varcin, E., 1975. Étude de dents humaines isolées provenant de la Chaise de Vouthon (Charente). Bull. et Mém. Soc. Anthrop., t. 2, sér. XIII: 277-286.

Genet-Varcin, E., 1976. Étude de dents humaines isolées provenant de la Chaise de Vouthon (Charente). Bull. et Mém. Soc. Anthrop., t. 3, sér. XIII: 243-259. 
Giacobini G., de Lumley, M.-A., Yokoyama, Y., Nguyen, H.-V., 1984. Neanderthal child and adult remains from a Mousterian deposit in Northern Italy (Caverna delle Fate, Finale Ligure). J. Hum. Evol., 13, 8: 687-707.

Giacobini, G., de Lumley, M.-A., Venturino, M., 1985. Les restes humains néandertaliens de la "Caverna delle Fate" (Finale, Ligurie italienne). Riv. di Studi Liguri, ann. XLVIII, nº 14: 49-74.

Glen, E, Kaczanowski, K., 1982. Human remains. In: J. K. Kozłowski (Ed.): Excavation in the Temnata Cave, Final Report. PWN, Warszawa, pp. 75-80.

Gruselle, J.-L., 1993 (inédit). Les restes humains moustériens de La Grotte du Portel, entrée Ouest, Loubens, Ariège. Mémoire de DEA, Muséum d'Histoire Naturelle, Institut de Paléontologie Humaine, 76 p.

Frayer, D. W., 1978. The evolution of the dentition in Upper Palaeolithic and Mesolithic Europe. University of Kansas publications in Anthropology number 10. Laurens: Univ. of Kansas, 201 p.

Harvati, K., 2013. New Neanderthal remains from Mani península, Southern Greece: the Kalamakia Middle Paleolithic cave site. Journal of Human Evolution, 64: 486-499.

Heim, J.-L., 1976. Les hommes fossiles de La Ferrassie. T. 1, le gisement, les squelettes adultes (crâne et squelette du tronc). Arch. Inst. Paléont. Humaine, mém. 35. Paris: Masson, 331 p.

Hlusko, L. J., Carlson, J. P., Guatelli-Steinberg, D., Krueger, K. L., Merset, B., Ungar, P. S., Defleur, A., 2013. Neanderthal teeth from Moula-Guercy, Ardèche, France. Am. J. of Physical Anthropology, 151: 477-491.

Keith, A., Knowles, H. S., 1912. A description of teeth of Palaeolithic man from Jersey. Journ. Anat. Physiol. London, vol. 64: 12-27.

Koby, F. E., 1956. Une incisive néandertalienne trouvée en Suisse. Verh. Naturf. Ges. Basel, B. $67, \mathrm{n}^{\circ} 1: 1-74$.

Jaubert, J., Maureille, B., 2008. Les dents humaines moustériennes du Rescoundudou (Sébazac-Concourès, Aveyron). Bull. Soc. Préhist. Française. t. 105, nº 4: 677-690.

Lebel, S., Trinkaus, E., Faure, M., Fernandez, Ph., Guérin, Cl., Richter, D., Mercier, N., Valladas, H., Wagner, G. A., 2001. Comparative morphology and paleobiology of Middle Pleistocene human remain from Bau de l'Aubesier, Vaucluse, France. Proceedings of National Academic Science USA, vol. 98: 11097-11102.

Leroi-Gourhan, A., 1958. Etudes des restes humains fossiles provenant des grottes d'Arcy-surCure. Annales de Paléontologie, t. 60: 87-148.

Lumley de, M.-A., 1973. Anténéandertaliens et néandertaliens du bassin méditerranéen occidental européen. Études quaternaire - 2. Marseille : Ed. du CNRS et de l'IPH, 626 .

Lumley de, M.-A., 1987. Les restes humains néandertaliens de la brèche de Genay, Côte-d'Or, France. L'Anthropologie (Paris), t. 91, nº 1: 119-162.

Patte, E., 1960. Découverte d'un Néandertalien dans la vienne. L'Anthropologie, t. 64, n 5-6: 512-517. 
Madre-Dupouy, M. 1992. L'Enfant de Roc de Marsal. Cahiers de Paleoanthropologie. Paris: Editions du CNRS, Paris, 300 p.

Mallegni, F., 1992. Human remains (Fossellone 3, ex Circeo 4) referable to Homo s. neanderthalensis from Fossellone Cave (Monte Circeo, Latium, Italy). Riv. di Antropologia (Roma), vol. LXX: 217-227.

Manzi, G., Passarello, P., 1995. At the archaic /modern boundary of the genus Homo: the Neandertals from Grotta Breuil. Current Anthropology, vol. 36 n²: 355-366.

Martin, H., 1923. Recherches sur l'Évolution du Moustérien dans le Gisement de La Quina. Tome 3. L'Homme fossile de La Quina. Archives de Morphologie générale et expérimentale, vol. 15. Paris: Doin, 264 p.

Maureille, B., Mann, A., Semal, P., Pales, L., 1999. Les dents humaines du Pléistocène supérieur de Soulabé-las-Maretas (Montseron, Ariège). Inventaire - présentation préliminaire. C. R. Acad. Sc. Paris, sér. IIa., t. 328, n 12: 853-858.

Maureille, B., Rougier, H., Houët, F., Vandermeersch, B., 2001. Les dents inférieures du Néandertalien Regourdou 1 (commune de Montignac, Dordogne): analyses métriques et comparatives. Paleo, vol. 13: 183-200.

Maureille, B., Djindjian, Fr., Mann, A., Garralda, M. D., Vandermeersch, B., 2008. Les dents moustériennes de la grotte Boccard, lieu-dit Bas-de-Morant. (Commune de Créancey, Côted'Or, Bourgogne). Bull. Mém. Soc. Anthrop. Paris., 20, 1-2: 59-78.

Moncel, M.-H., Condemi, S., 1996. Découverte de dents humaines dans le site Paléolithique moyen de Payre (Ardèche, France). C. R. Acad. Sci. Paris, t. 322, sér. Ila: 251-257.

Pap, I., Tillier, A.-M., Arensburg, B., Chech, M., 1996. The Subalyuk Neanderthal remains (Hungary): a re-examination. Ann. Historico-naturales Musei Nationalis Hungarici, vol. 88: 233- 270.

Quam, R. M., Arsuaga, J.-L., Bermúdez de Castro, J.-M., Carlos Diez, J., Lorenzo, C., Carretero, J. M., García, N., Ortega, A. I., 2001. Human remains from Valdegoba Cave (Huérmeces, Burgos, Spain). J. Hum. Evol., 41: 386-435.

Sergi, S., Ascenzi, A., 1955. La mandibola neandertaliana Circeo III. Rivista di Antropologia: 337402.

Radovčić, J., Smith, F. H., Trinkaus, E., Wolpoff, M. H., 1988. The Krapina hominids. An illustrated catalog of skeletal collection. Zagreb: Maldost et CNHM, 119 p.

Smith, P., Arensburg, B., 1977. A Mousterian skeleton from Kebara cave. In Arensburg, B. et Bar-Yosef, O. (eds), Moshe Stekelis, memorial volume. Eretz-Israel, vol. 13: 164-176

Suzuki, H., Takai, F., 1970. The Amud Man and his Cave Site. Tokyo: Academic Press of Japan, $439 \mathrm{p}$.

Tillier, A.-M., 1979. La dentition de l'enfant moustérien Chateauneuf 2 découvert à l'abri de hauteroche (Charente). L'Anthropologie, t. 83, nº 3: 417-438.

Tillier, A.-M., 1991. La mandibule et les dents. In, Bar Yosef, O. et Vandermeersch, B. (Éds), Le squelette moustérien de Kébara 2. Cahiers de Paléoanthropologie. Paris: éditions du CNRS, pp. 97-112. 
Tillier, A.-M., 1999. Les enfants moustériens de Qafzeh. Paris: CNRS éditions, 239 p.

Tillier, A.-M., Arensburg, B., Vandermeersch, B., Chech, M., 2003. New Human remains from Kebara Cave (Mount Carmel). The place of the Kebara hominids in the Levantine Mousterian fossil record. Paléorient, 29, 2: 33-62.

Trinkaus, E., 1983. The Shanidar neandertals. New York: Academic press, 502 p.

Vacca, E., Alciati, G., 2000. Observations anatomiques sur quelques restes humains du dépôt de la grotte de San Bernardino (Vénétie, Italie). L'Anthropologie (Paris), 104: 121-130.

Verna, C., 1999 (inédit). Les restes humains moustériens de la station Amont de La Quina (Charente, France). Contexte archéologique et constitution de l'assemblage. Étude morphologique et métrique des restes crânio-faciaux. Apport à l'étude de la variation néandertalienne. Thèse de l'Univeristé Bordeaux 1, spécialité Anthropologie biologique, 629 p.

Vlcek, E., 1969. Neandertaler der Tschechoslowakei. Prague: Verlag der Tschechoslowakische Akademie des Wissenschaften, 276 p.

Wolpoff, M., 1979. The Krapina Dental Remains. Am. J. Physical Anthropology, 50, 1: 67-113.

Wolpoff, M. H., Smith, F. H., Malez, M., Radovčić, J., Rukaniva, D., 1981. Upper Pleistocene human remains from Vindija cave, Croatia, Yugoslavia. Am. J.l of Physical Anthropology, 54: 499-545. 


\section{$\underline{\text { SOM S4 }}$}

Page 1 of 2

\section{D AND 3D ENAMEL THICKNESS:}

Briefly, for the 2D enamel thickness of the anterior teeth (Figure 1) we used a digital section passing through the widest labio-lingual bi-cervical diameter and either the central mamelon (for incisors) or the dentine horn tip (for the canine). For the posterior dentition (premolars and the molar) we used a virtual section of the tooth perpendicular to the cervical line that passed through the mesial cusps (paracone and protocone). Accordingly, we measured the enamel surface $(\mathrm{mm} 2)$, the dentine surface (also including the surface of the crown pulp chamber; $\mathrm{mm} 2$ ), and the length of the enamel-dentine junction (EDJ; $\mathrm{mm}$ ) in order to compute both the average enamel thickness index (2D AET = surface of enamel divided by the EDJ length; index in millimeters) and the relative enamel thickness index (2D RET $=$ AET divided by the square root of dentine surface; scale-free index).

For the 3D enamel thickness (Figure 1), the coronal dentine was separated from the root dentine using the curve digitized along the cervical line, which was then interpolated with a smooth surface to seal the bottom of the dentine core (Benazzi et al., 2014). We measured: the enamel volume (mm3), the coronal dentine volume, which includes the volume of the crown pulp chamber (mm3), and the enameldentine junction (EDJ) surface ( $\mathrm{mm} 2$ ). These measurements were used for the computation of both 3D average enamel thickness $(3 \mathrm{D}$ AET $=$ volume of enamel divided by the EDJ surface; in $\mathrm{mm}$ ) and the $3 \mathrm{D}$ relative enamel thickness (3D RET $=$ 3D AET divided by the cubic root of dentine volume; scale-free) index. The 2D AET and 2D RET values computed for the Marillac teeth were compared to Neanderthal, fossil and recent $H$. sapiens mean values published by Smith et al. (2012). Since the authors did not provided neither data for each single specimen, nor the standard deviation, comparisons was undertaken directly with the mean values. Unfortunately, there is no comprehensive comparative data for the $3 \mathrm{D}$ enamel thickness of the upper permanent dentition. The few published data are represented by 4 Neanderthal and 15 recent H. sapiens M3s (Olejniczak et al., 2008), plus two Scladina teeth, one $\mathrm{C}^{\prime}$ (Scla 4A-16) and one P3 (Scla 4A-

2) (Benazzi et al., 2014b). 


\section{$\underline{\text { SOM S4 }}$}

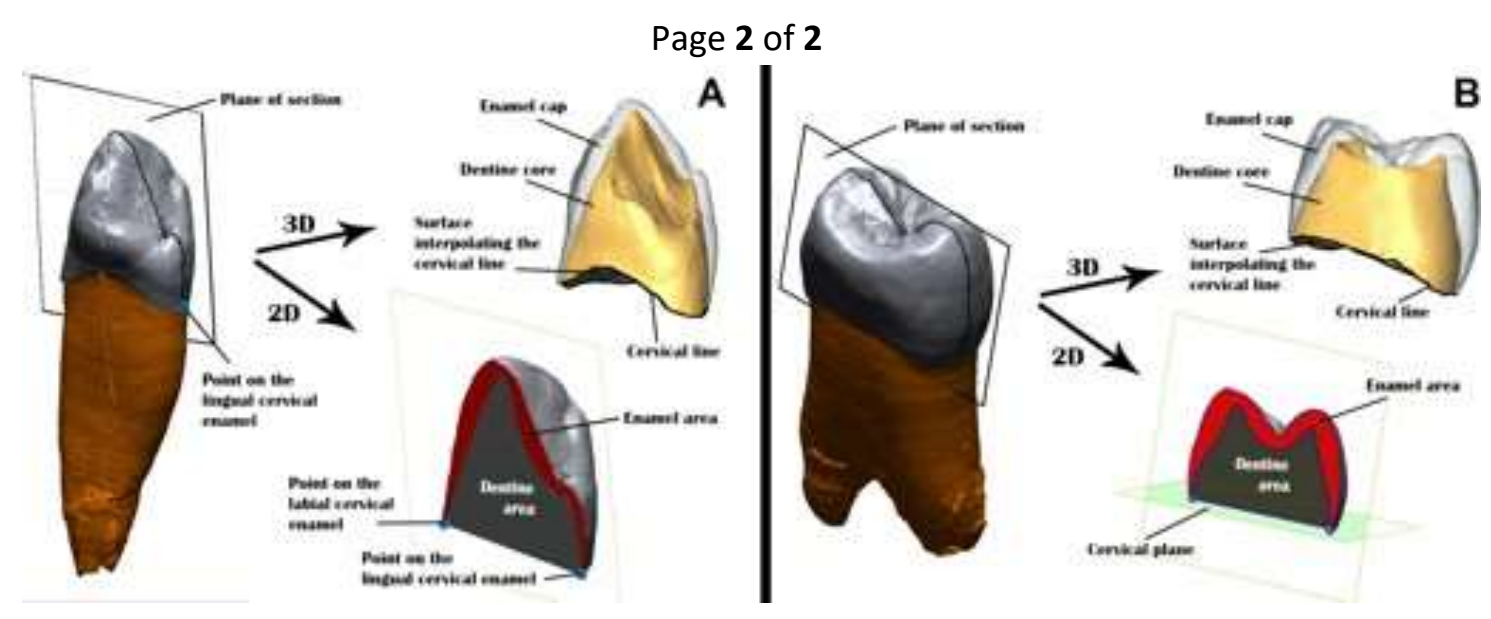

Figure 1.- For the 2D enamel thickness of the $C^{\prime}$ M13E (A), the plane of section passes through two points digitized on the widest labiolingual bi-cervical diameter and one point digitized on the dentine horn tip. For that of the P4 M13G (B) the plane of section is perpendicular to the cervical line and passes through the mesial cusps (paracone and metacone).For 3D enamel thickness, the coronal dentine was separated from the root dentine based on the cervical line, which was then interpolated by a smooth surface to seal the bottom of the dentine core.

\section{REFERENCES}

Benazzi, S., Panetta, D., Fornai, C., Toussaint, M., Gruppioni, G., Hublin, J-J., 2014. Guidelines for the digital computation of 2D and 3D enamel thickness. Am. J. Phys. Anthropol. 153, 305313.

Benazzi, S., Toussaint, M., Hublin, J-J., 2014b. Enamel thickness in the Scladina Neandertal teeth. In: Toussaint M, \& Bonjean D (Eds.), The Scladina I-4A Juvenile Neandertal. Études et Recherches Archéologiques del'Université de Liège, 134, pp. 307-314.

Olejniczak, A.J., Smith, T.M., Feeney, R.N. M., Macchiarelli, R., Mazurier, A., Bondioli, L., Rosas, A., Fortea, J., de la Rasilla, M., García-Tabernero, A., Radovčić, J., Skinner, M.M., Toussaint, M., Hublin, J.-J., 2008. Dental tissue proportions and enamel thickness in Neandertal and modern human molars. J. Hum. Evol. 55, 12-23.

Smith, T.M., Olejniczak, A.J., Zermeno, J.P., Tafforeau, P., Skinner, M.M., Hoffmann, A., Radovčić, J., Toussaint, M., Kruszynski, R., Menter, C., Moggi-Cecchi, J., Glasmacher, U.A., Kullmer, O., Schrenk, F., Stringer, C., Hublin, J.-J., 2012. Variation in enamel thickness within the genus Homo. J. Hum. Evol. 62, 395-411. 


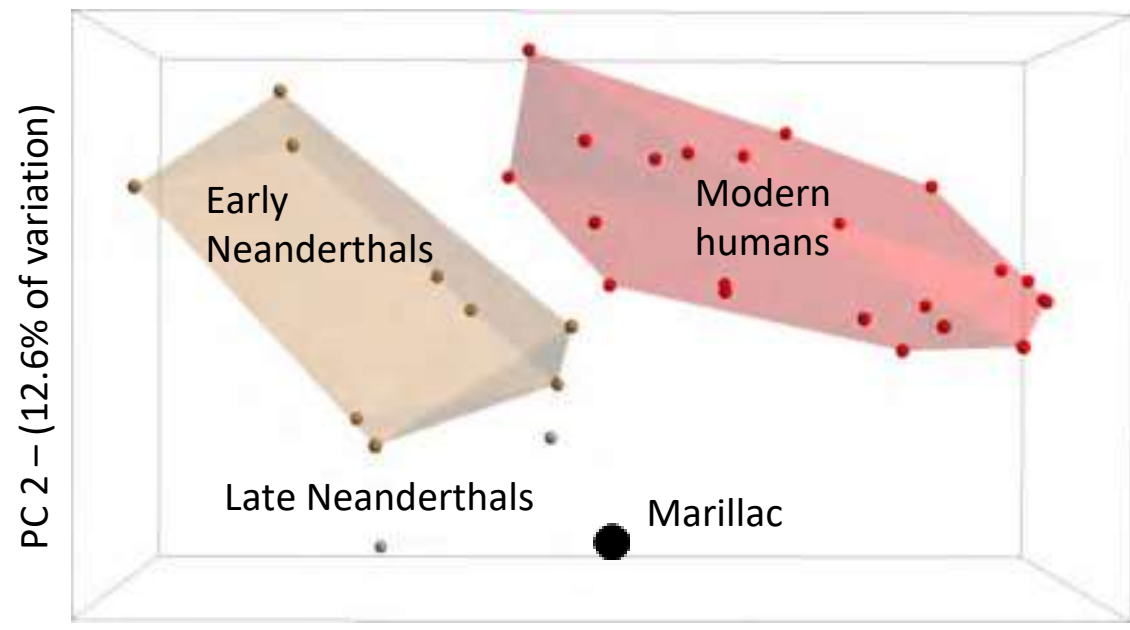

PC $1-(47.2 \%$ of variation $)$

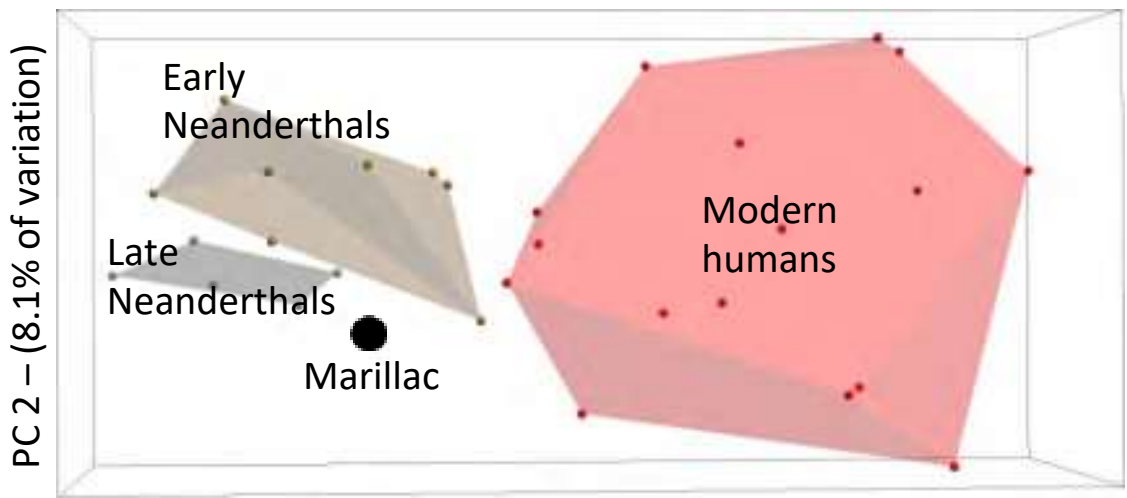

PC $1-(54.0 \%$ of variation)

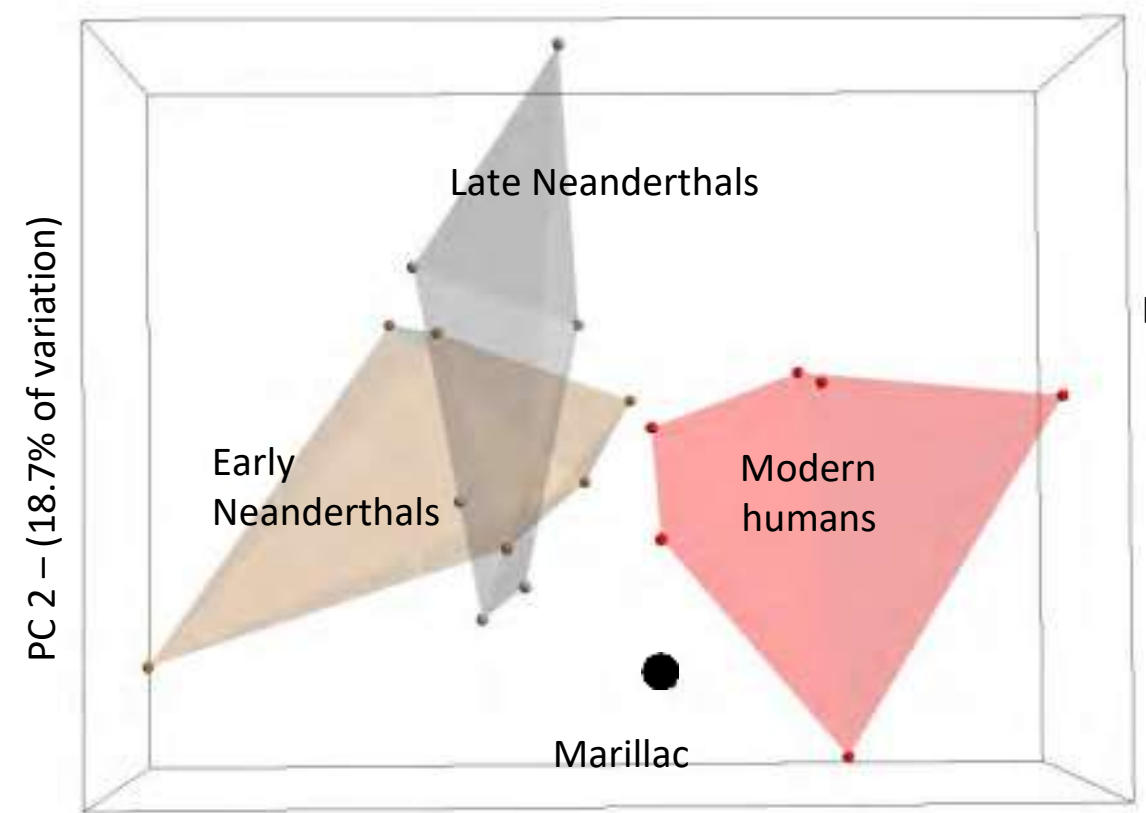

PC $1-(27.5 \%$ of variation $)$
P3

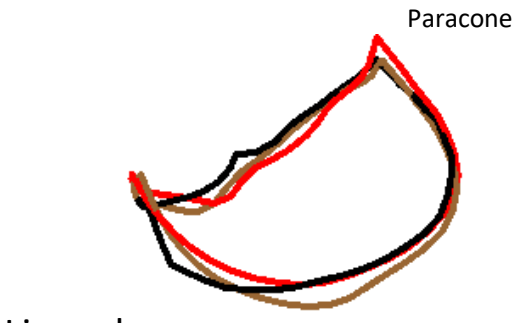

Buccal

Lingual

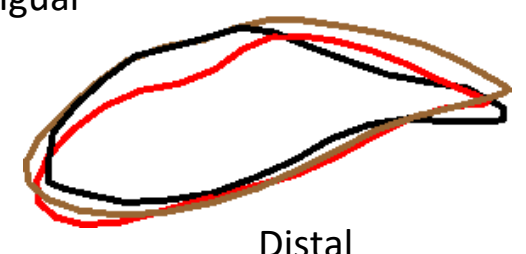

Distal

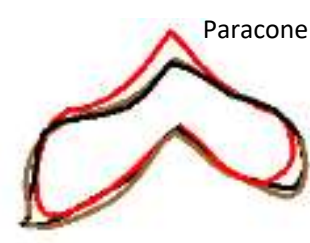

Distal

Mesial

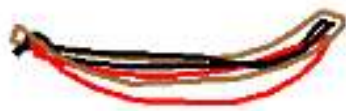

Lingual

$M^{3}$

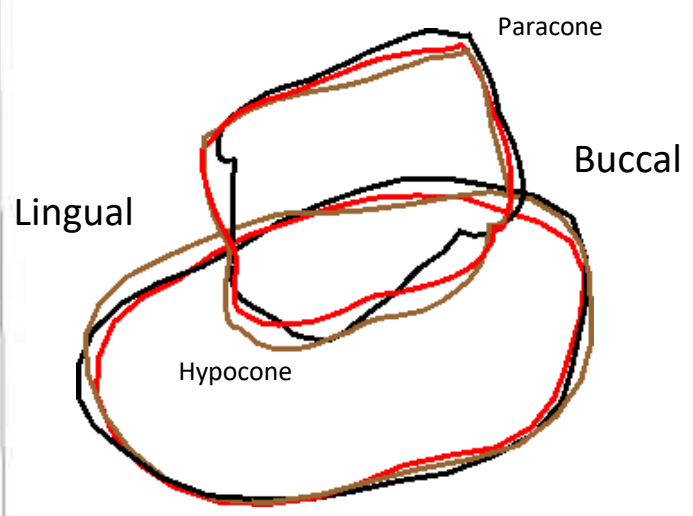

Distal

Average modern human shape Average Neanderthal shape Marillac shape

Supplementary Figure S5. Principal component analyses of EDJ shape (left ) and overlain wireframe models (right) of the average modern human, Neanderthal and the relevant Marillac specimen for the $\mathrm{P}^{3}, \mathrm{P}^{4}$ and $\mathrm{M}^{1}$, respectively. Comparative samples: $\mathrm{P}^{3}$ (modern humans = 22 ; early Neanderthals: Krapina 46, 48 ,49, D39, D43, D52, D53, D110, D112 ; late Neanderthals: El Sidrón 566, Le Moustier 1 ), P4 (modern humans = 16; early 
Neanderthals: Krapina 46, 47, 48, 49, D41, D42, D44, D115 ; late Neanderthals: El Sidrón 50, 411, 1106, Le Moustier 1, Scladina 4A-2 ), M³ (modern humans = 6; early Neanderthals: Abri Bourgeois-Delaunay 8, Krapina 97, 163, 170, 173, 180; late Neanderthals: Le Moustier 1, Scladina 4A-8, El Sidrón 332, 621, 1164, Saint-Césaire). 


\section{SOM 6 - Tab1 (Comparative samples for root) Neanderthal comparative sample for root measurements}

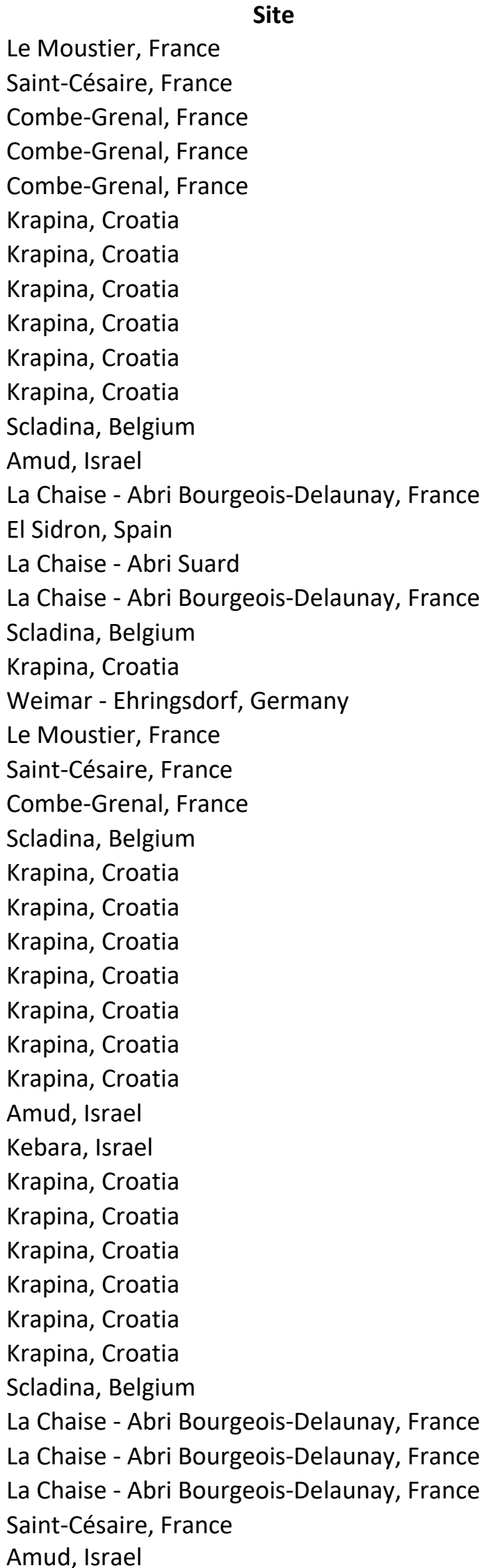

\begin{tabular}{|c|c|c|}
\hline Specimen & Tooth type & Side \\
\hline Le Moustier 1 & UI1 & $\mathrm{L}$ \\
\hline Saint-Césaire 1 & UI1 & $R$ \\
\hline Combe-Grenal V & UI1 & $\mathrm{L}$ \\
\hline Combe-Grenal 27 & UI1 & $\mathrm{R}$ \\
\hline Combe-Grenal XI & UI1 & $\mathrm{R}$ \\
\hline Krapina 49 / Maxilla E & UI1 & $\mathrm{L}$ \\
\hline Krapina 50 / Maxilla F & UI1 & $\mathrm{R}$ \\
\hline krp_123 & UI1 & $\mathrm{L}$ \\
\hline krp_126 & UI1 & $\mathrm{R}$ \\
\hline krp_157 & UI1 & $\mathrm{R}$ \\
\hline krp_158 & UI1 & $\mathrm{L}$ \\
\hline scla-4a-11 & UI1 & $\mathrm{R}$ \\
\hline Amud1 & UI1 & $\mathrm{R}$ \\
\hline BD12 & UI1 & $\mathrm{L}$ \\
\hline SD_331_ab & UI1 & $\mathrm{R}$ \\
\hline S33 & UI2 & $\mathrm{R}$ \\
\hline BD10 & UI2 & $\mathrm{L}$ \\
\hline scla-4a-14 & UI2 & $\mathrm{R}$ \\
\hline Krapina 50 / Maxilla F & UI2 & $\mathrm{R}$ \\
\hline 1012/69_Ehringsdorf_G & UI2 & $\mathrm{L}$ \\
\hline Le Moustier 1 & U12 & $\mathrm{L}$ \\
\hline Saint-Césaire 1 & UI2 & $\mathrm{R}$ \\
\hline Combe-Grenal X & UI2 & $\mathrm{L}$ \\
\hline scla-4a-17 & UI2 & $\mathrm{L}$ \\
\hline krp_122 & UI2 & $\mathrm{L}$ \\
\hline krp_125 & UI2 & $\mathrm{L}$ \\
\hline krp_127 & UI2 & $\mathrm{R}$ \\
\hline krp_156 & UI2 & $\mathrm{L}$ \\
\hline krp_159 & UI2 & $\mathrm{R}$ \\
\hline krp_160 & UI2 & $\mathrm{L}$ \\
\hline Krapina 49 / Maxilla E & UI2 & $\mathrm{L}$ \\
\hline Amud1 & UI2 & $\mathrm{R}$ \\
\hline KMH27 & UI2 & $\mathrm{L}$ \\
\hline Krp_d37 & UC & $\mathrm{L}$ \\
\hline Krp_d36 & UC & $\mathrm{R}$ \\
\hline Krp_d56 & UC & $\mathrm{R}$ \\
\hline Krp_d76 & UC & $\mathrm{R}$ \\
\hline Krapina 50 / Maxilla F & UC & $\mathrm{R}$ \\
\hline Krapina 49 / Maxilla E & UC & $\mathrm{L}$ \\
\hline scla-4a-16 & UC & $\mathrm{R}$ \\
\hline BD11 & UC & $\mathrm{L}$ \\
\hline BD15 & UC & $\mathrm{R}$ \\
\hline BD16 & UC & $\mathrm{R}$ \\
\hline Saint-Césaire 1 & UC & $\mathrm{R}$ \\
\hline Amud1 & UC & $\mathrm{R}$ \\
\hline
\end{tabular}


DEcIDUOUS

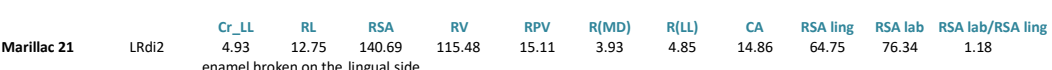
Crevecoeur et a I (2010) JHE Spy IV (Spy 594a)
Neand.

$$
\begin{array}{lccc}
\text { Ldi2 } & 5.06 & 154.19 & 42.36 \\
\text { mean } & 4.85 & 13.67 & 17.72 \\
\text { N } & 15 & 1 \\
\text { SD } & 0.25 & \text { Roc de Mars Roc de Marsal 1 } \\
\text { M21 } & 0.15 & & \\
\text { Spy IV } & 0.39 & &
\end{array}
$$

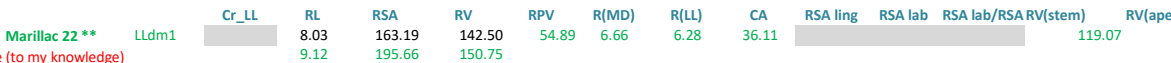

Missing root calculation
Hiag ar

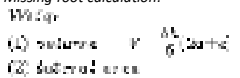

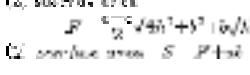

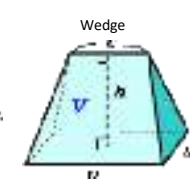

$b=1.64 \mathrm{~mm}$
$c=3.99 \mathrm{~mm}$
$h=1.09 \mathrm{~mm}$

$v=\quad 5.08 \mathrm{~mm}^{3}$

Distal root:
a=s.4.41 mm
$b=1.30 \mathrm{~mm}$
$c=3.51 \mathrm{~mm}$
$\mathrm{~h}=1.02 \mathrm{~m}$

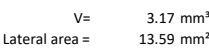

PERMANENT

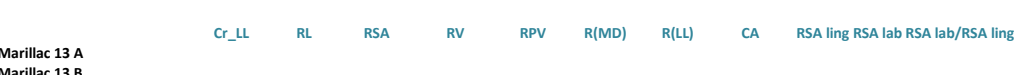

\section{Marillac $13 \mathrm{~A}$
Mariliac $13 \mathrm{~B}$}

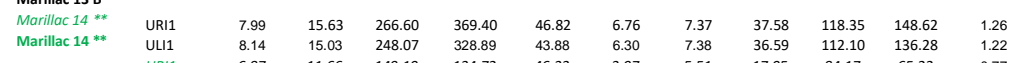

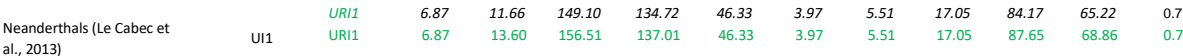

$$
\begin{aligned}
& \begin{array}{clccccccccccc} 
& \text { N } & 15 & 15 & 15 & 15 & 15 & 15 & 15 & 15 & 15 & 15 & 15 \\
\text { A25 } & \text { mean } & 8.5 & 17.2 & 321.4 & 465.2 & 36.2 & 7.1 & 7.6 & 42.5 & 137.4 & 184.5 & 1.4 \\
\text { SD } & 0.6 & 2.5 & 60.7 & 125.1 & 21.9 & 1.1 & 0.5 & 8.3 & 27.3 & 39.5 & 0.2
\end{array}
\end{aligned}
$$

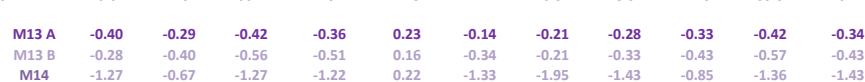

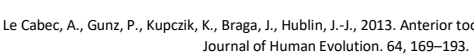

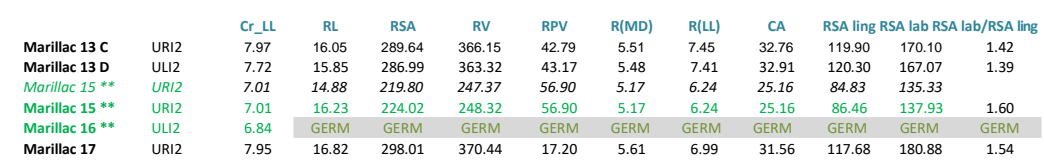

Neanderthals (Le Cabec et

al, 2013)

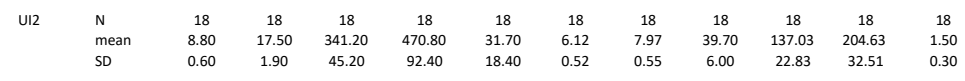

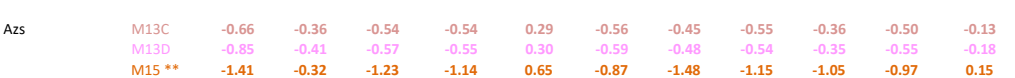

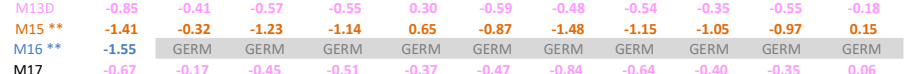

Maxillary canines

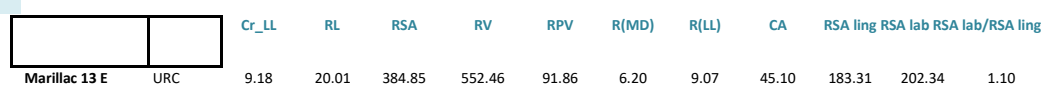

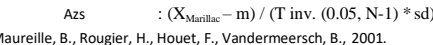

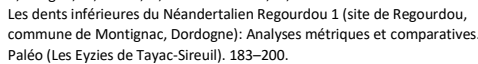

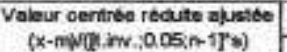

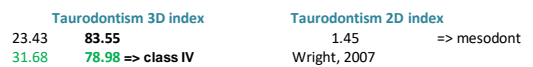

Total missing root estimation:
$V=$
$\begin{aligned} V .25 \mathrm{~mm}^{3} \\ \text { lateral surface }\end{aligned}=$
$32.47 \mathrm{~mm}^{2}$

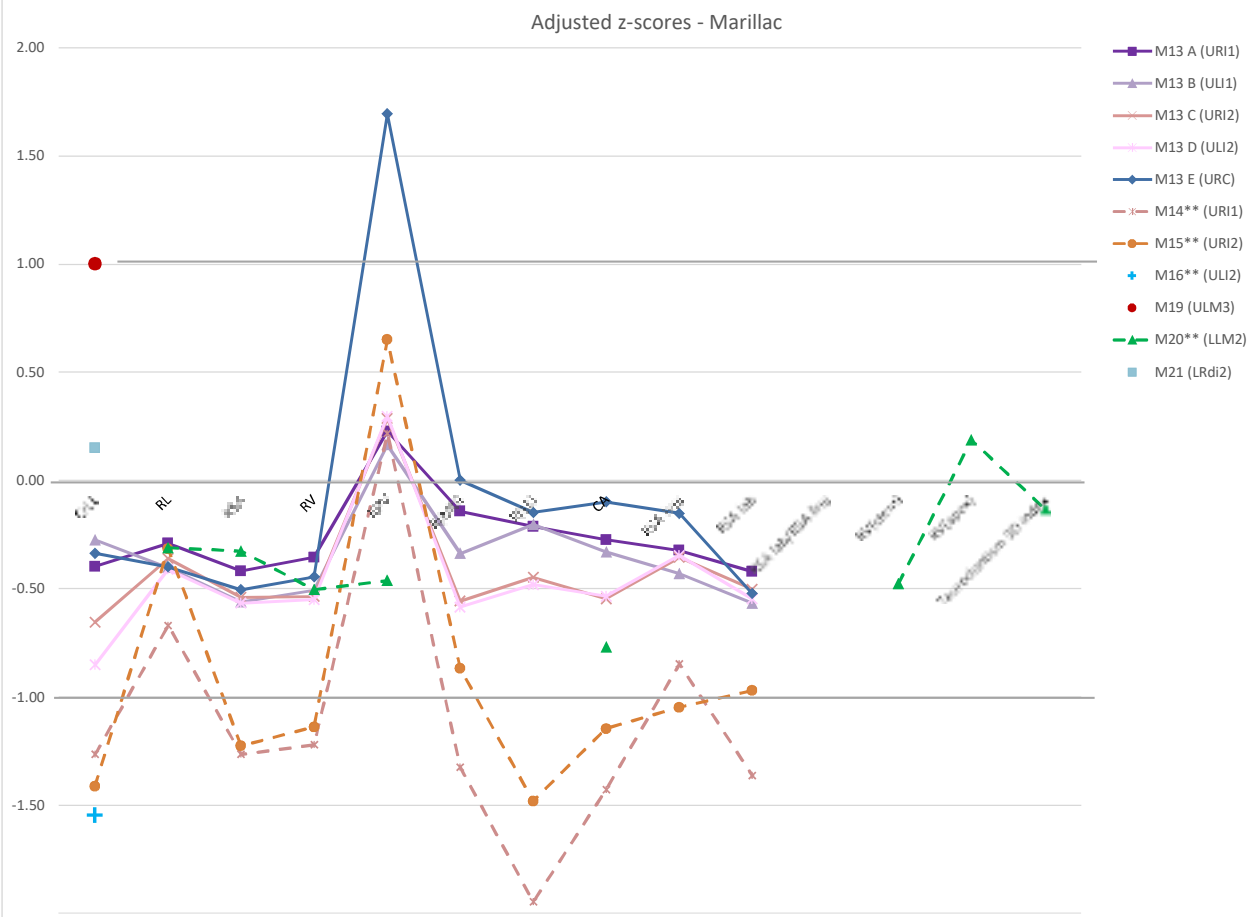




\begin{tabular}{|c|c|c|c|c|c|c|c|c|c|c|c|c|c|c|}
\hline & Marillac 19 & ULM3 & crlt & $\begin{array}{r}\text { RL } \\
12.99 \\
15.36\end{array}$ & $\begin{array}{r}\text { RSA } \\
442.34 \\
511.75\end{array}$ & $\begin{array}{c}\text { RV } \\
531.53 \\
568.68\end{array}$ & $\begin{array}{r}\text { RPV } \\
112.01 \\
112.01\end{array}$ & $\begin{array}{l}\text { R(MD } \\
7.93 \\
7.93\end{array}$ & $\begin{array}{l}\mathrm{R}(\mathrm{LI}) \\
12 \\
12\end{array}$ & $\begin{array}{c}\text { CA } \\
78.74 \\
78.74\end{array}$ & RSA ling & RSA lab RSA lab/RSA & $\begin{array}{r}\text { vistem) } \\
367.11 \\
367.11\end{array}$ & \\
\hline & & \multirow[t]{2}{*}{ Broken] root lengths: } & & & & & groot tips: & & lingual root & $\begin{array}{l}\mathrm{h}=3.34 \mathrm{~mm} \\
r=2.28 \mathrm{~mm} \\
r=2.37 \mathrm{~mm}\end{array}$ & & $\begin{array}{l}v= \\
\text { Lateral surface area }\end{array}$ & & $\begin{array}{l}8.90 \mathrm{~mm}^{3} \\
9.72 \mathrm{~mm}^{2}\end{array}$ \\
\hline & & & $\mathrm{DB}: 1$ & & $\mathrm{~mm}$ & & & & MB root: & $\begin{array}{l}\mathrm{h}=1.98 \mathrm{~mm} \\
r=1=67 \mathrm{~mm} \\
r=2.99 \mathrm{~mm}\end{array}$ & & $\begin{aligned} v= \\
\text { Lateral surface area }\end{aligned}$ & & $\begin{array}{l}0.35 \mathrm{~mm}^{3} \\
1.66 \mathrm{~mm}^{2}\end{array}$ \\
\hline Bailey (2005) & Neand. & $\begin{array}{l}\text { N } \\
\text { mean } \\
\text { SD }\end{array}$ & & $\begin{array}{c}5.5 \\
15.2 \\
1.38 \\
0.04\end{array}$ & & & & & DB root: & $\begin{array}{l}\mathrm{h}=1.81 \mathrm{~mm} \\
r=2=.69 \mathrm{~mm} \\
\mathrm{r} 2=1.55 \mathrm{~mm}\end{array}$ & & $\begin{aligned} & v= v= \\
& \text { Lateral surface area }\end{aligned}$ & & $\begin{array}{l}7.90 \mathrm{~mm}^{3} \\
88.03 \mathrm{~mm}^{2}\end{array}$ \\
\hline
\end{tabular}

$\begin{array}{lll} & \text { A25 } & 0.04 \\ \text { Mandibular molar } & & \end{array}$

\begin{tabular}{|c|c|c|c|c|c|c|c|c|c|c|}
\hline $\begin{array}{l}\text { Neanderthals (Kupczik and } \\
\text { Hublin, 2010) }\end{array}$ & LM & $\begin{array}{l}\text { Nean } \\
\text { SD }\end{array}$ & $\begin{array}{c}14 \\
16.24 \\
2.04\end{array}$ & $\begin{array}{c}15 \\
528.92 \\
81.99\end{array}$ & $\begin{array}{c}14 \\
821.18 \\
188.13\end{array}$ & $\begin{array}{c}12 \\
75.58 \\
3.5517\end{array}$ & $\begin{array}{c}14 \\
93.03 \\
1.158\end{array}$ & $\begin{array}{c}14 \\
610.79 \\
624.95\end{array}$ & $\begin{array}{c}14 \\
211.06 \\
14.92\end{array}$ & $\begin{array}{l}14 \\
74.32 \\
62.58\end{array}$ \\
\hline & & ${ }^{M 20}$ & -0.31 & -0.33 & -0.51 & -0.46 & -0.77 & -0.48 & 0.19 & -0.13 \\
\hline
\end{tabular}

\section{CLASSIFICATION OF TAURODONTISM}

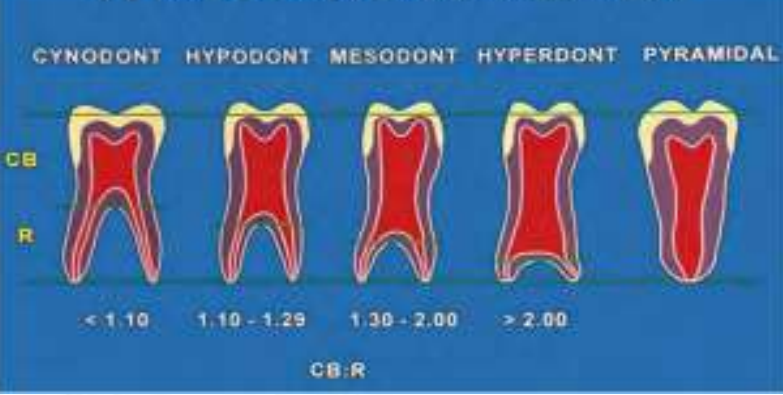

Fig. 1. Tuarudontism ranges in severity.

becoming increasingly serere with in.

thetiat roon deach The degree of taur.

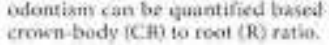

Wrieht T. 2007 The Molecular Control of and Clinical Variations in Root Formation. Cells Tissues Organs. 186, 86-98

\section{D Taurodontism index (Kupczik et Hublin, 2010)}

Following from this,

we computed a volumetric bifurcation index (in \%) as [root stem

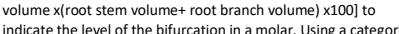
indicate the level of the bifurcation in a molar. Using a categor
scheme siminiar to that of theene (1966), molars were classified into four groups: : : $0-24.9 \%$, il: 25-49.9\%, Ill: $50-74.9 \%$ and
IV. $75-100 \%$.

\begin{tabular}{|c|c|}
\hline 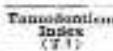 & resestis \\
\hline$a-249$ & 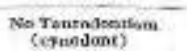 \\
\hline $25.0+9.9$ & 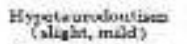 \\
\hline $500-745$ & 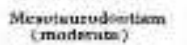 \\
\hline $75.0-100.0$ & Itypertumerodunism \\
\hline
\end{tabular}

Keene (1966)
Taurodontism 2 index
1.07 cynodont, bu

$$
\begin{aligned}
& 1.07 \text { cynn } \\
& \text { Wright, } 2007
\end{aligned}
$$




\section{M13A - URI1}

Apical
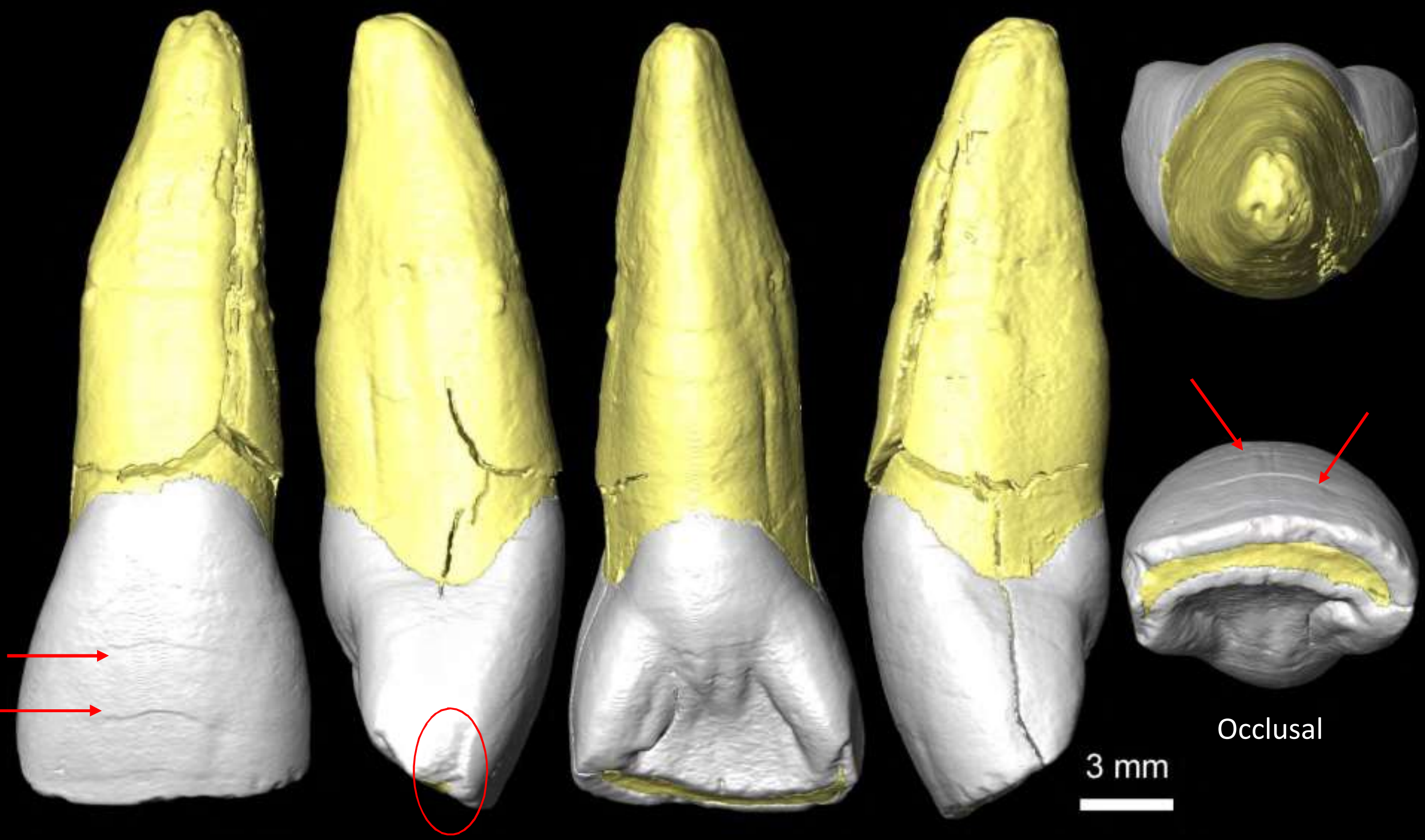


$$
\text { M13A - URI1 - EDJ }
$$

Buccal

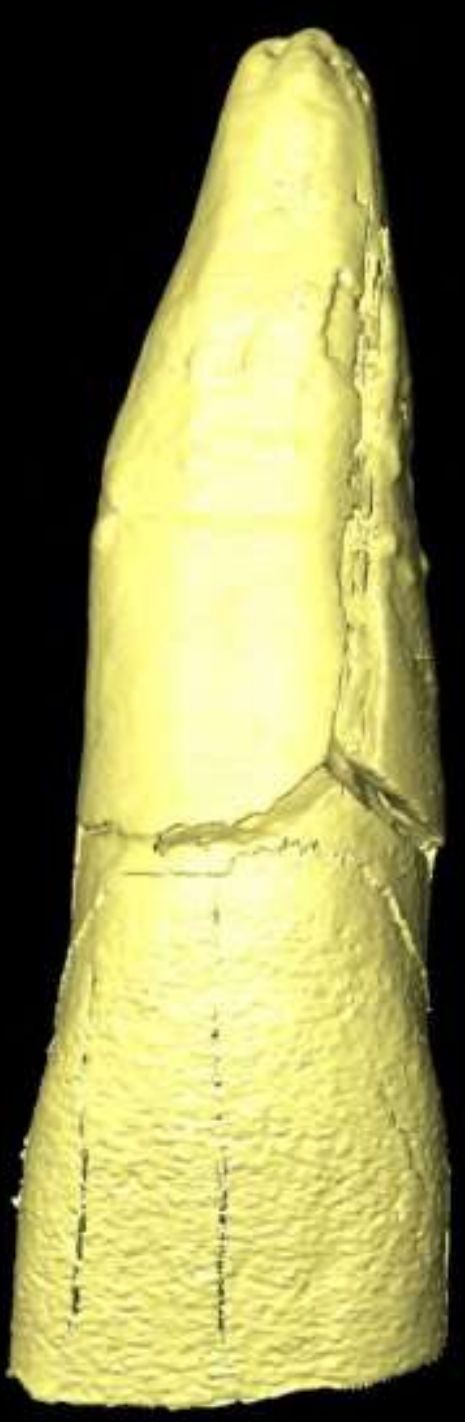

Distal

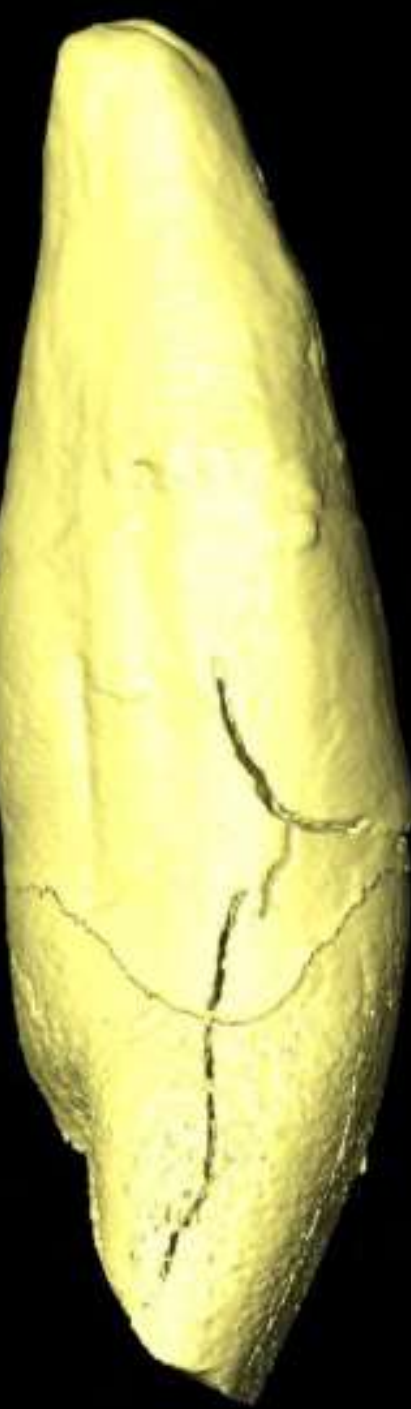

Mesial

Lingual

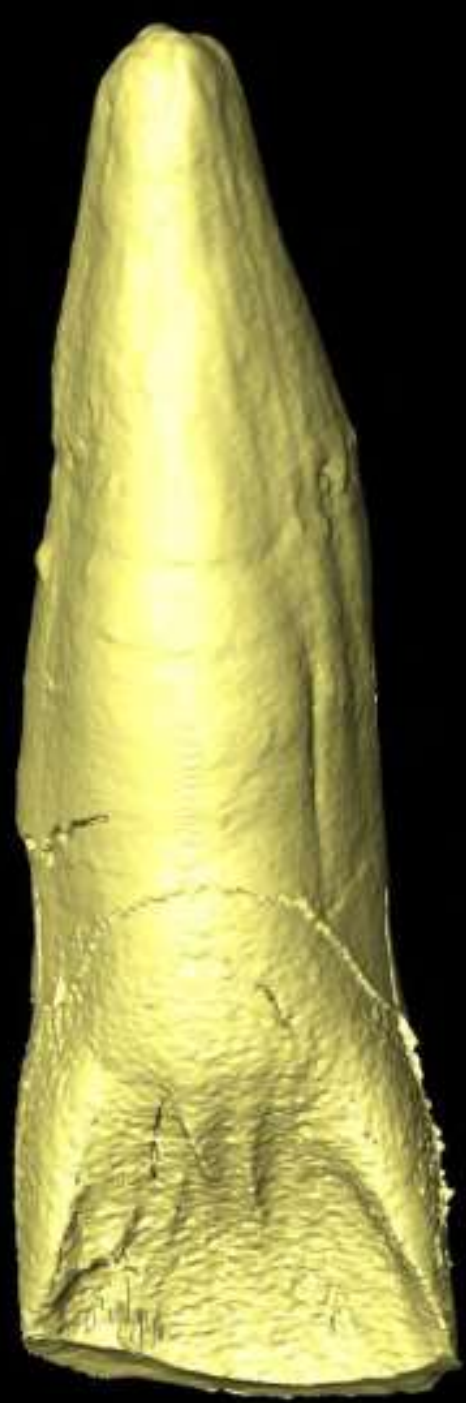

Apical

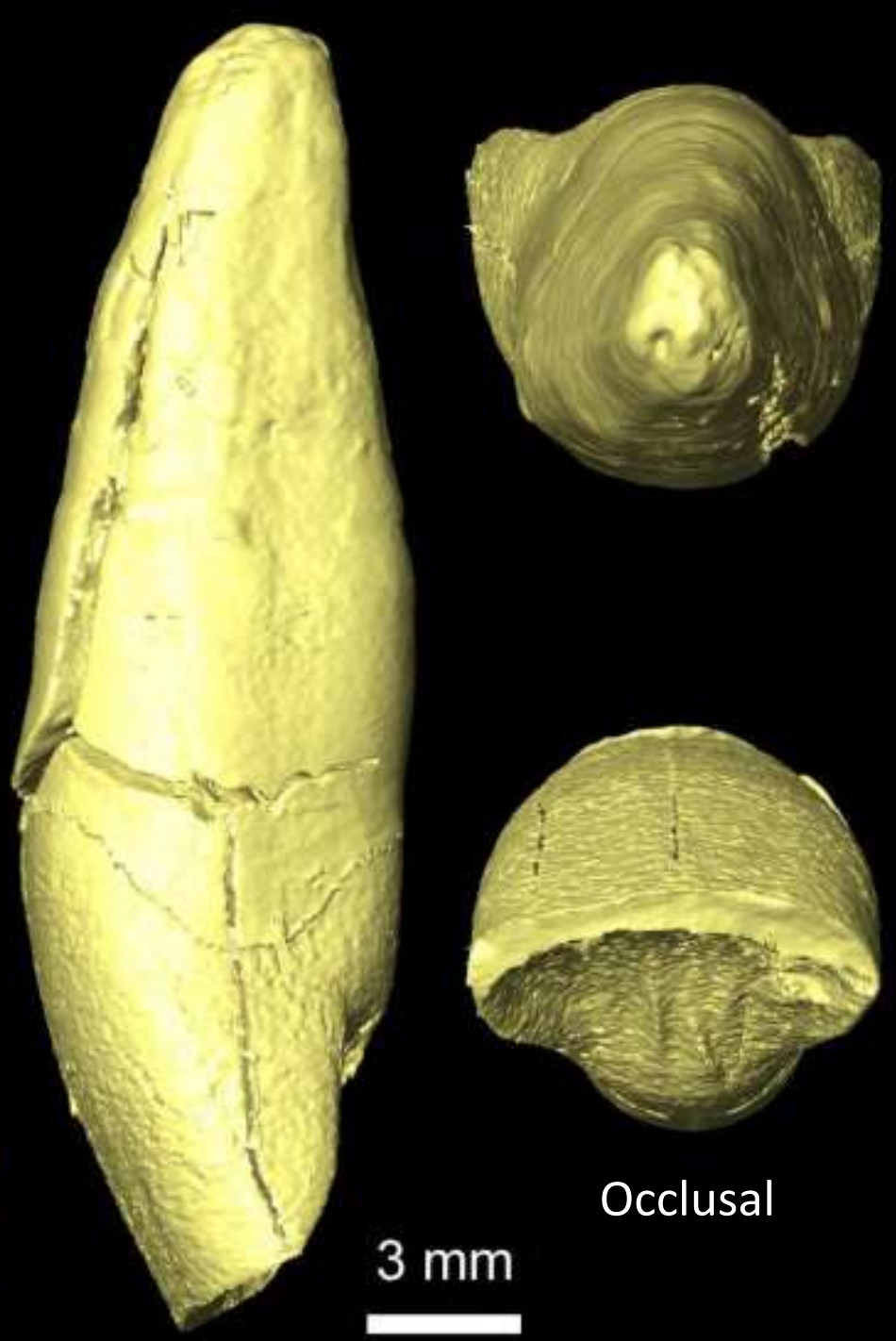



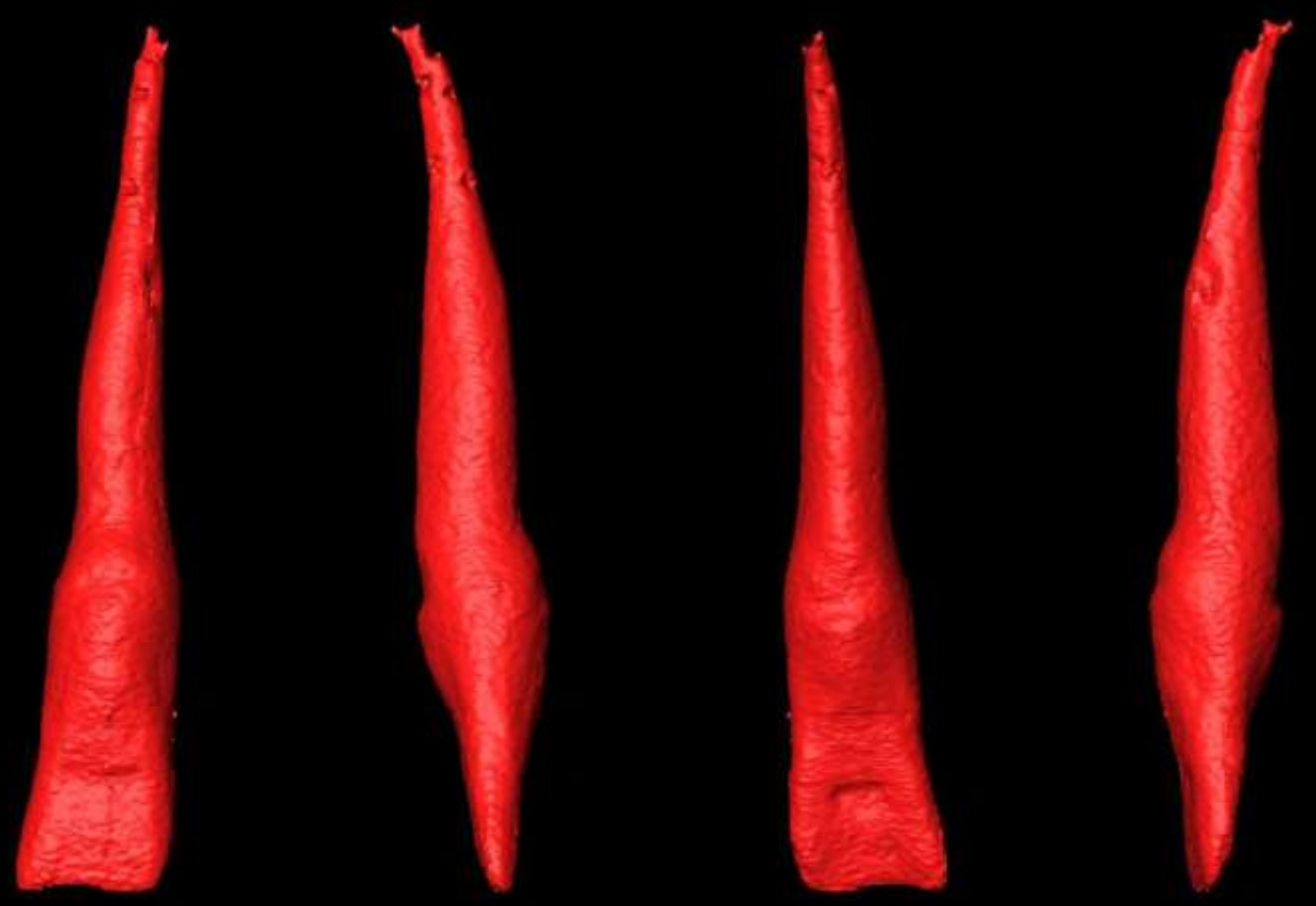


\section{M13A - URI1 - 2D sections}

Slices optimized for visualizing crown development
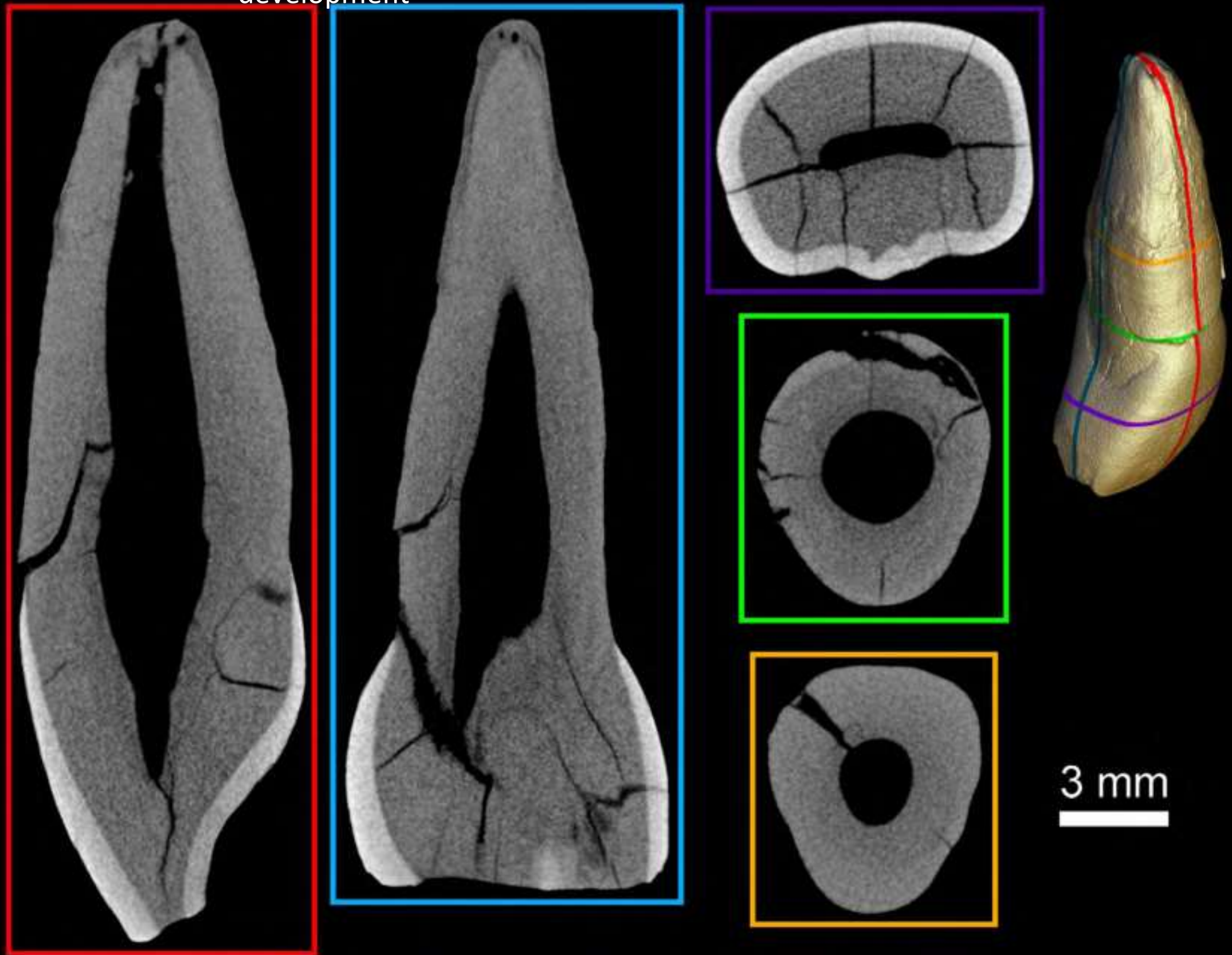

$3 \mathrm{~mm}$ 


\section{M13A - URI1 - Hypercementosis}
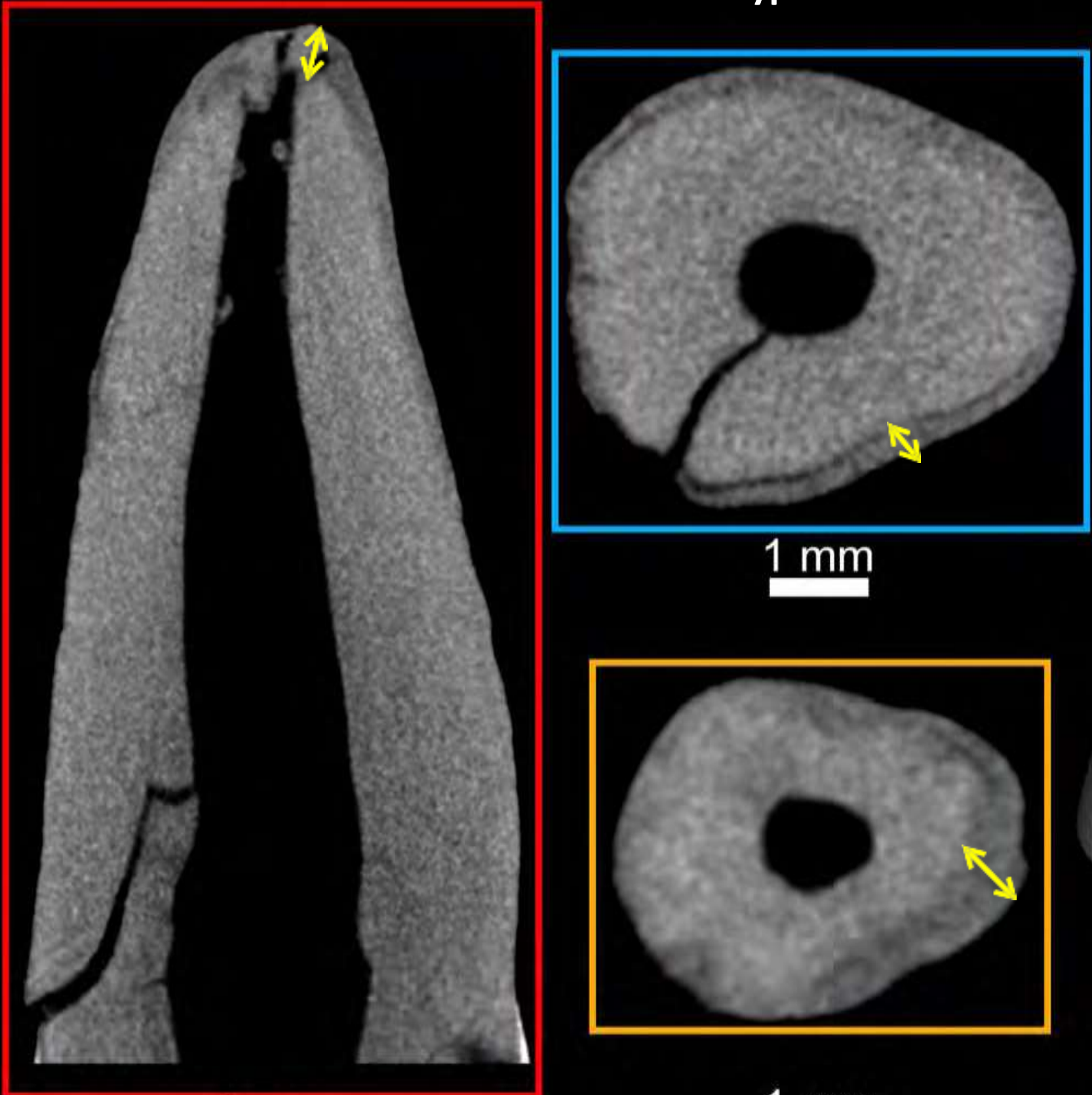

$1 \mathrm{~mm}$

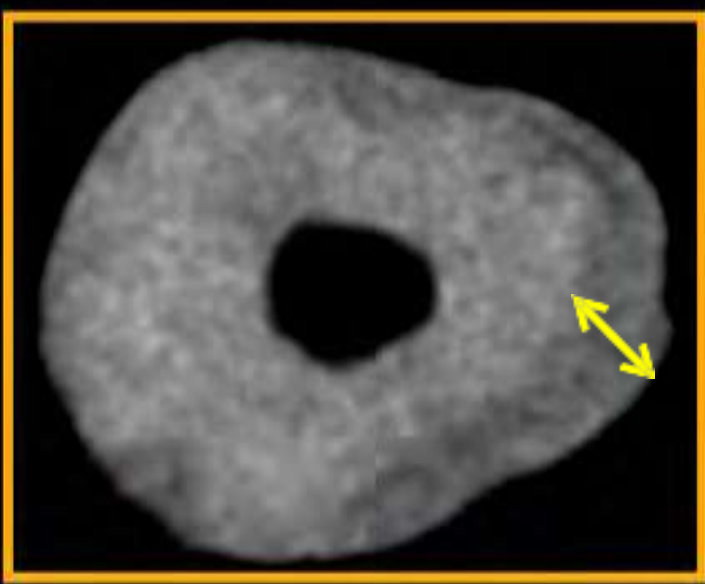

$\uparrow$
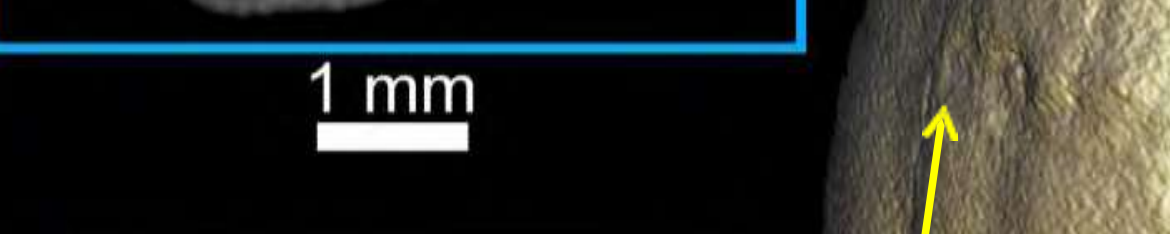

$\mathrm{mm}$ 
Apical

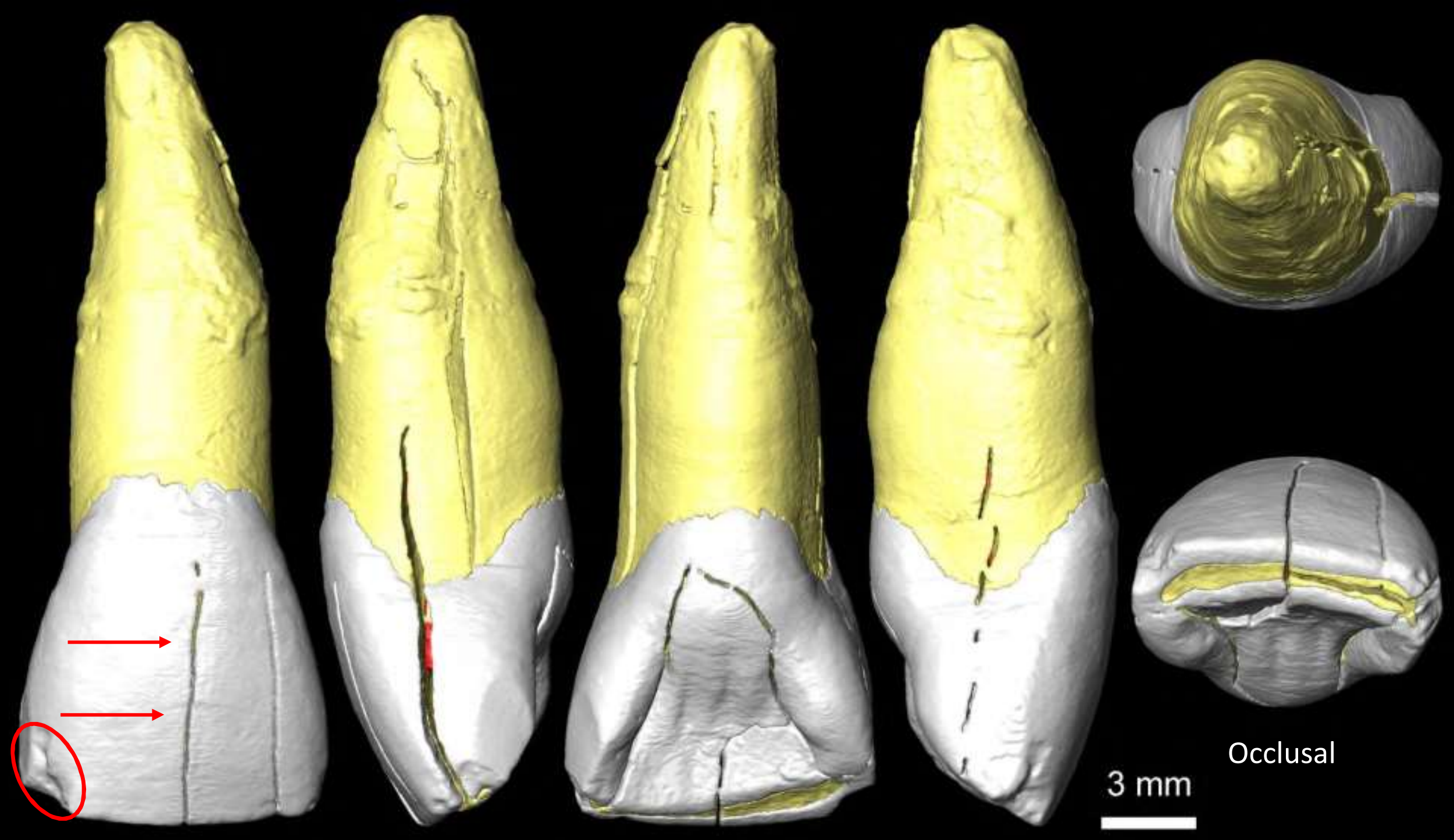




$$
\text { M13B - ULI1 - EDJ }
$$

Buccal

Distal

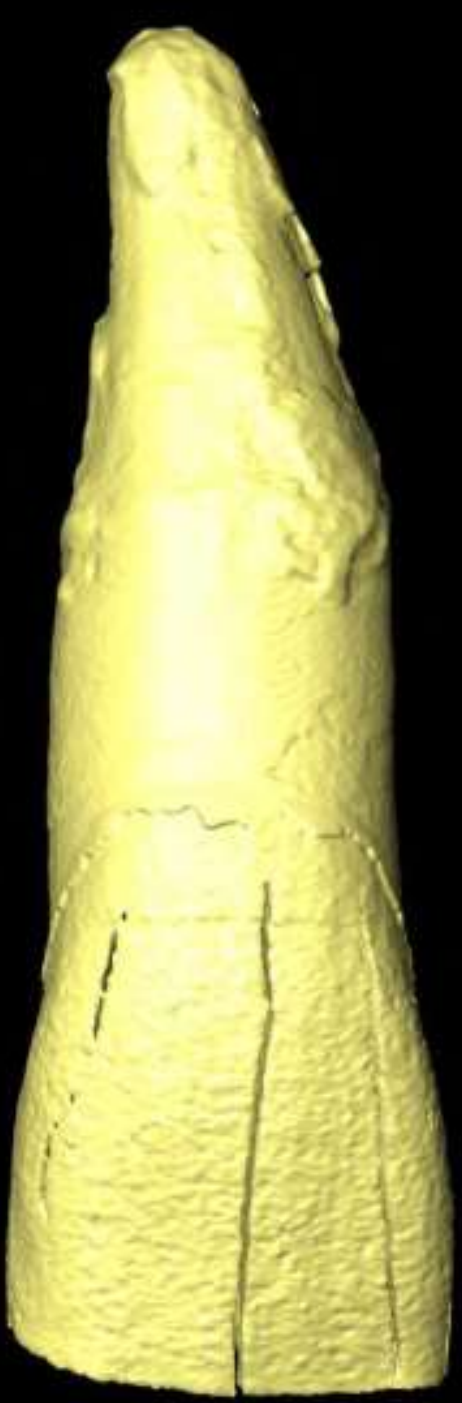

Lingual

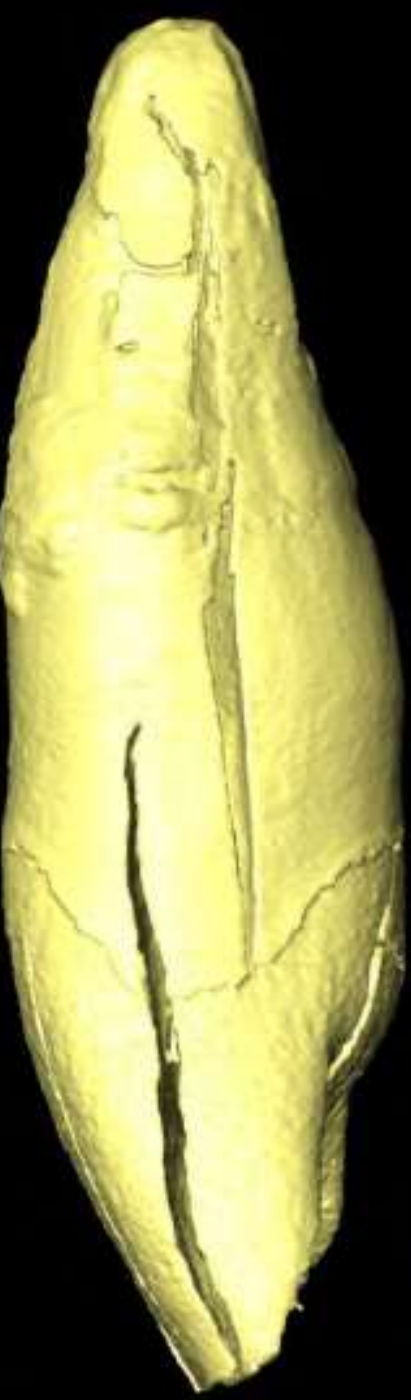

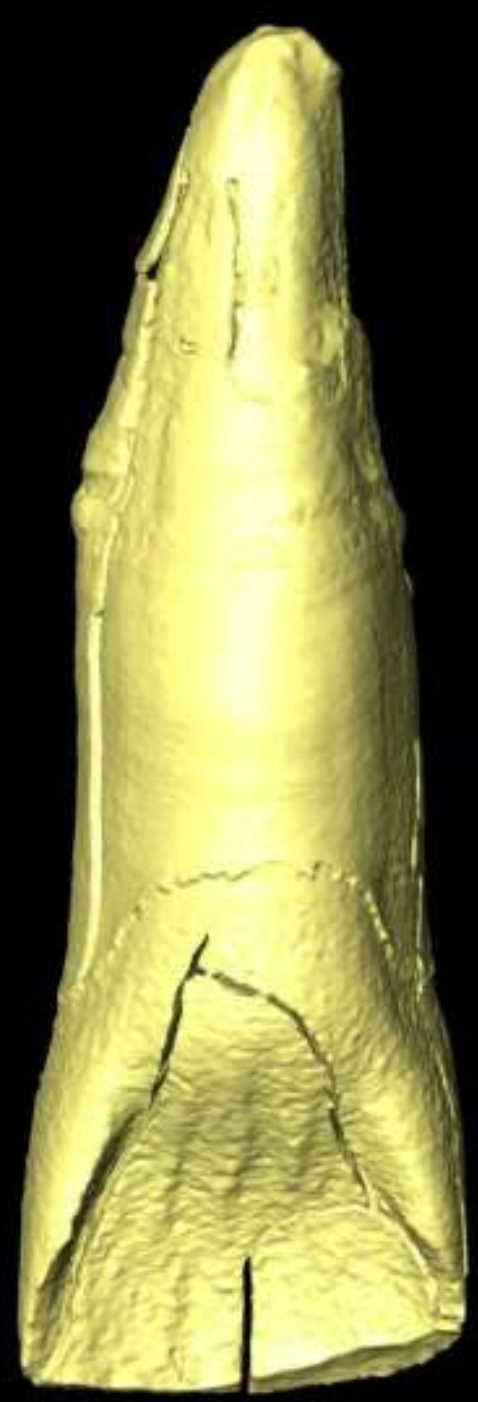

Mesial

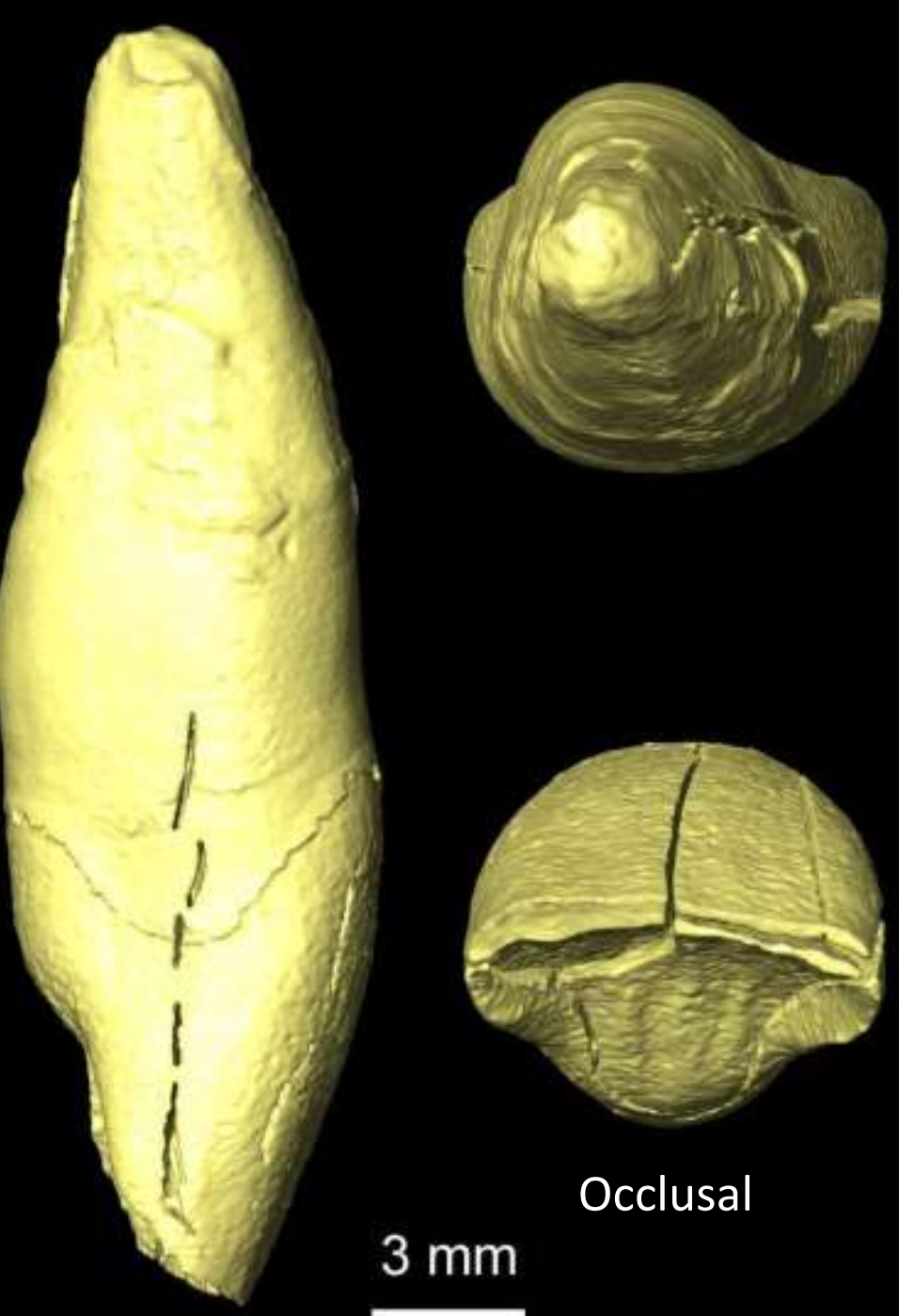

Apical 
M13B - ULI1 - Pulp

Buccal

Distal

Lingual

Mesial

Apical
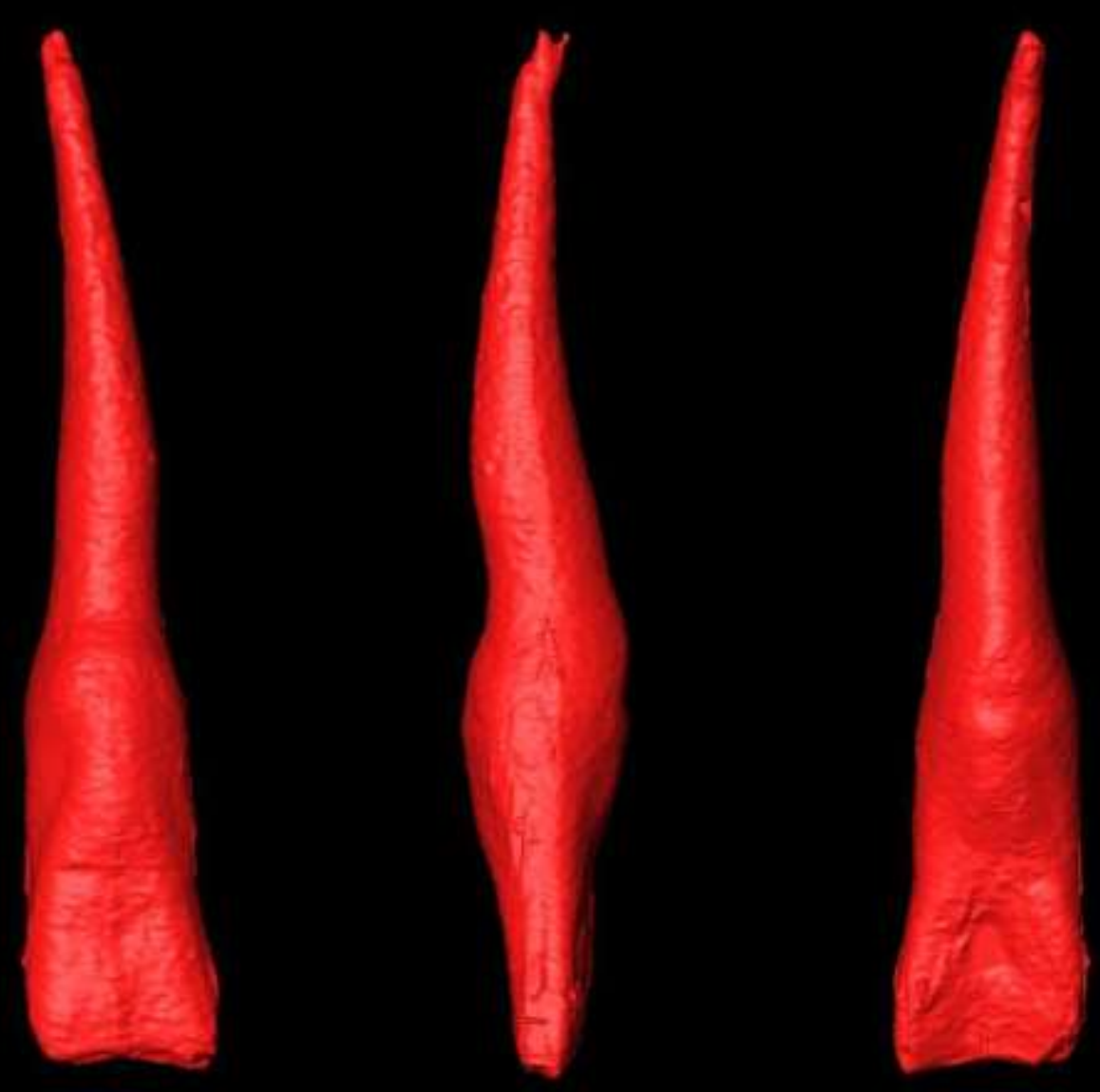

Occlusal 


\section{M13B - ULI1 - 2D sections}
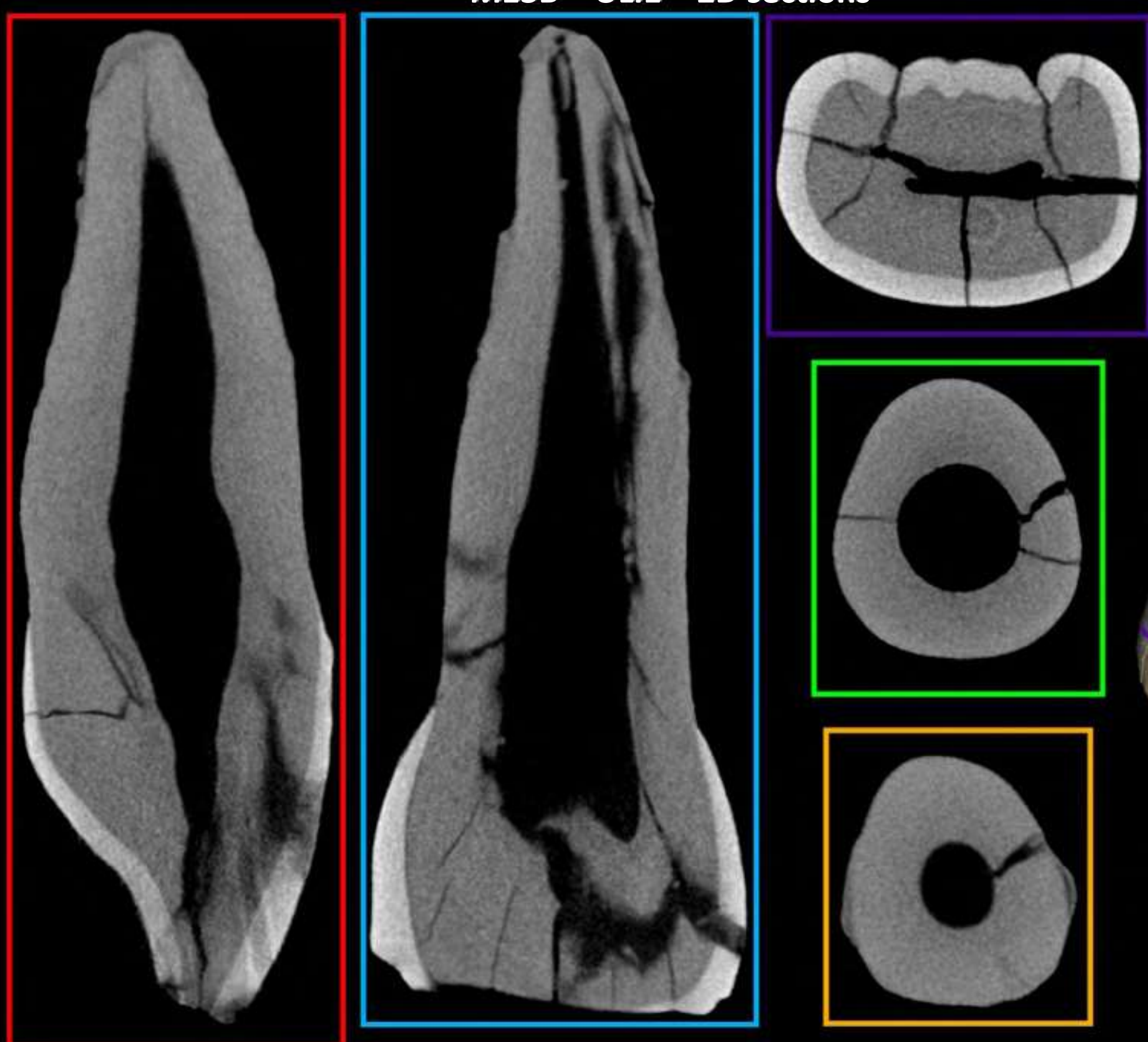

$3 \mathrm{~mm}$ 


\section{M13B - ULI1 - Hypercementosis}
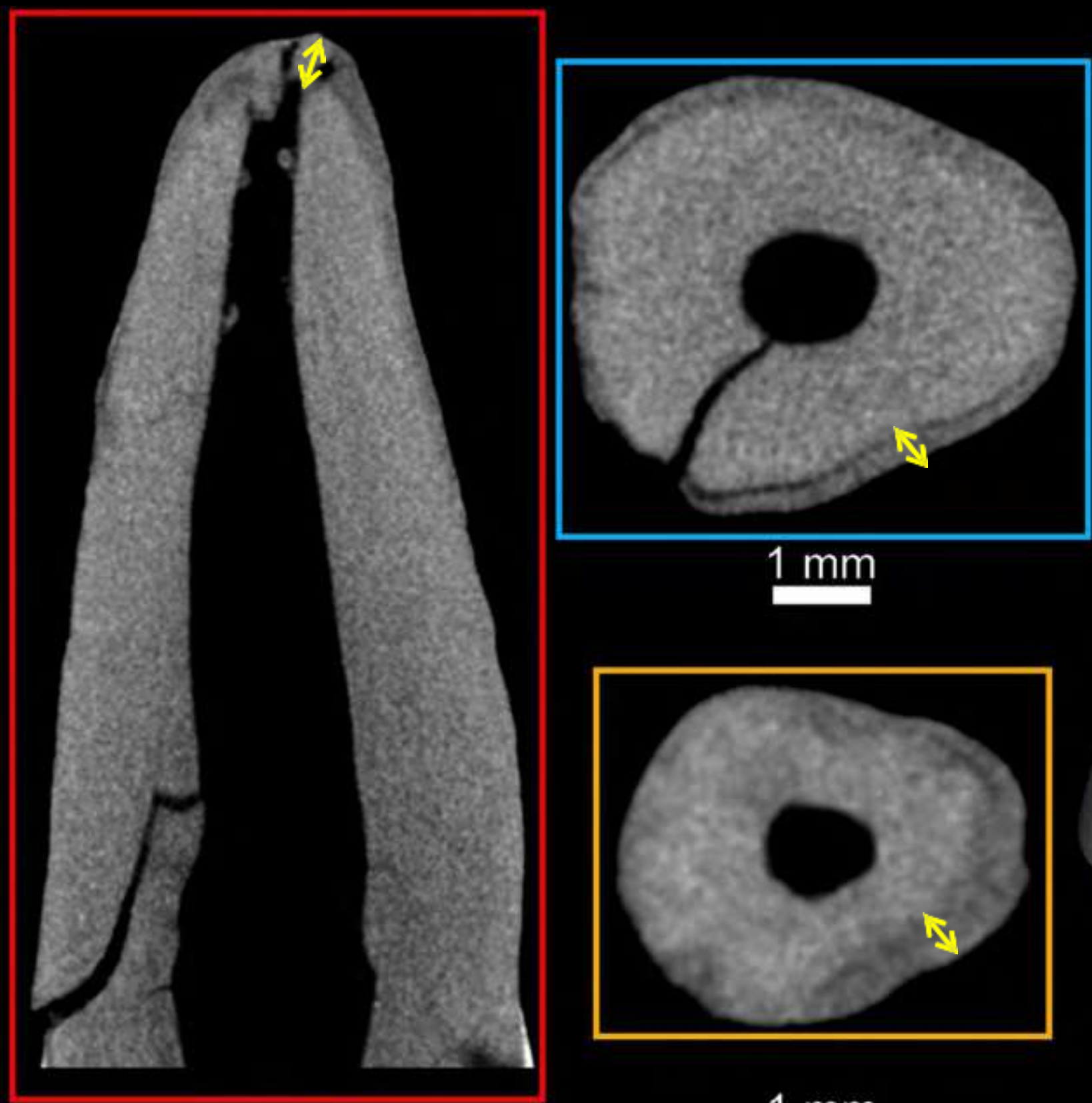

$1 \mathrm{~mm}$
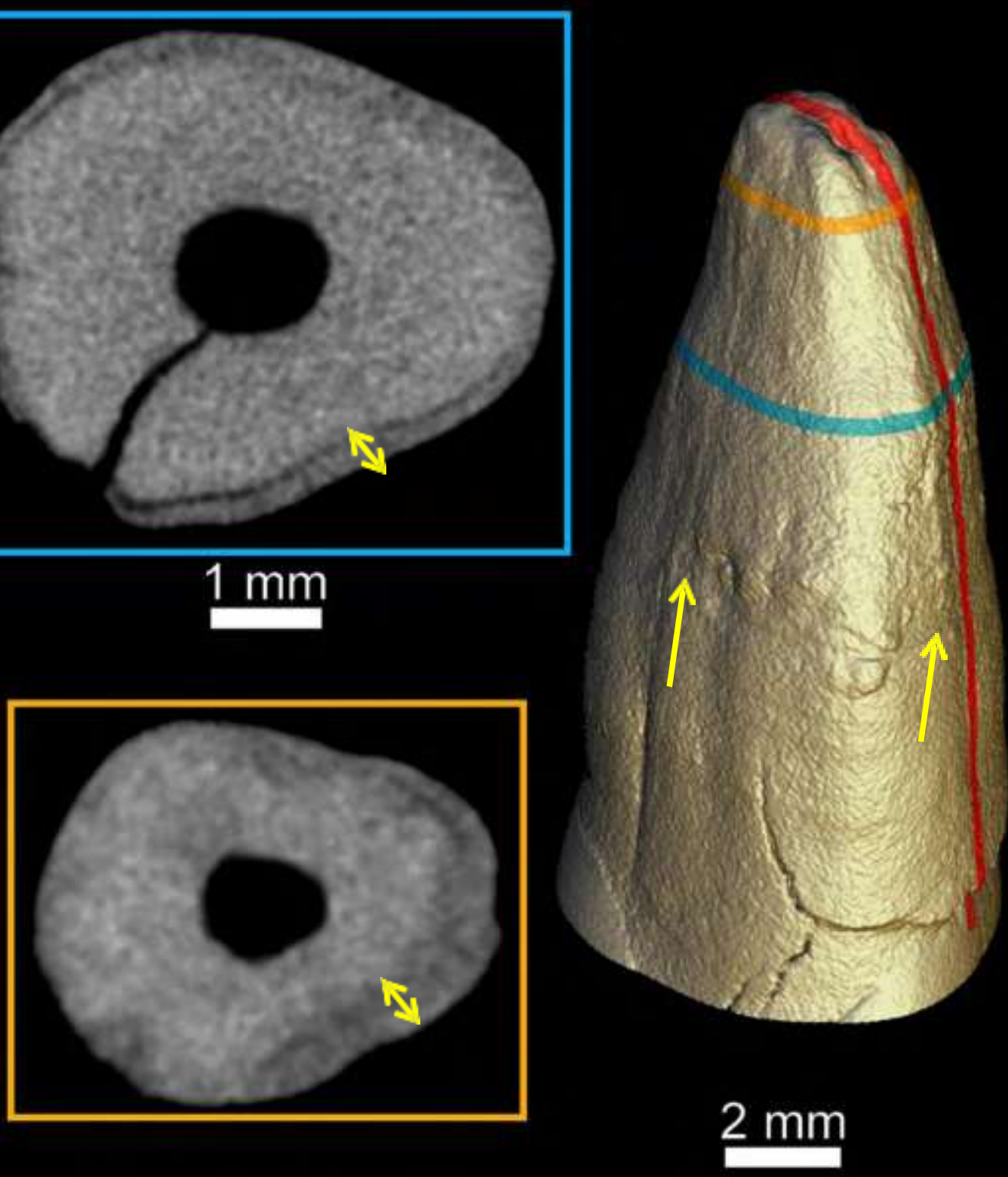

$2 \mathrm{~mm}$ 


\section{M13C - URI2}

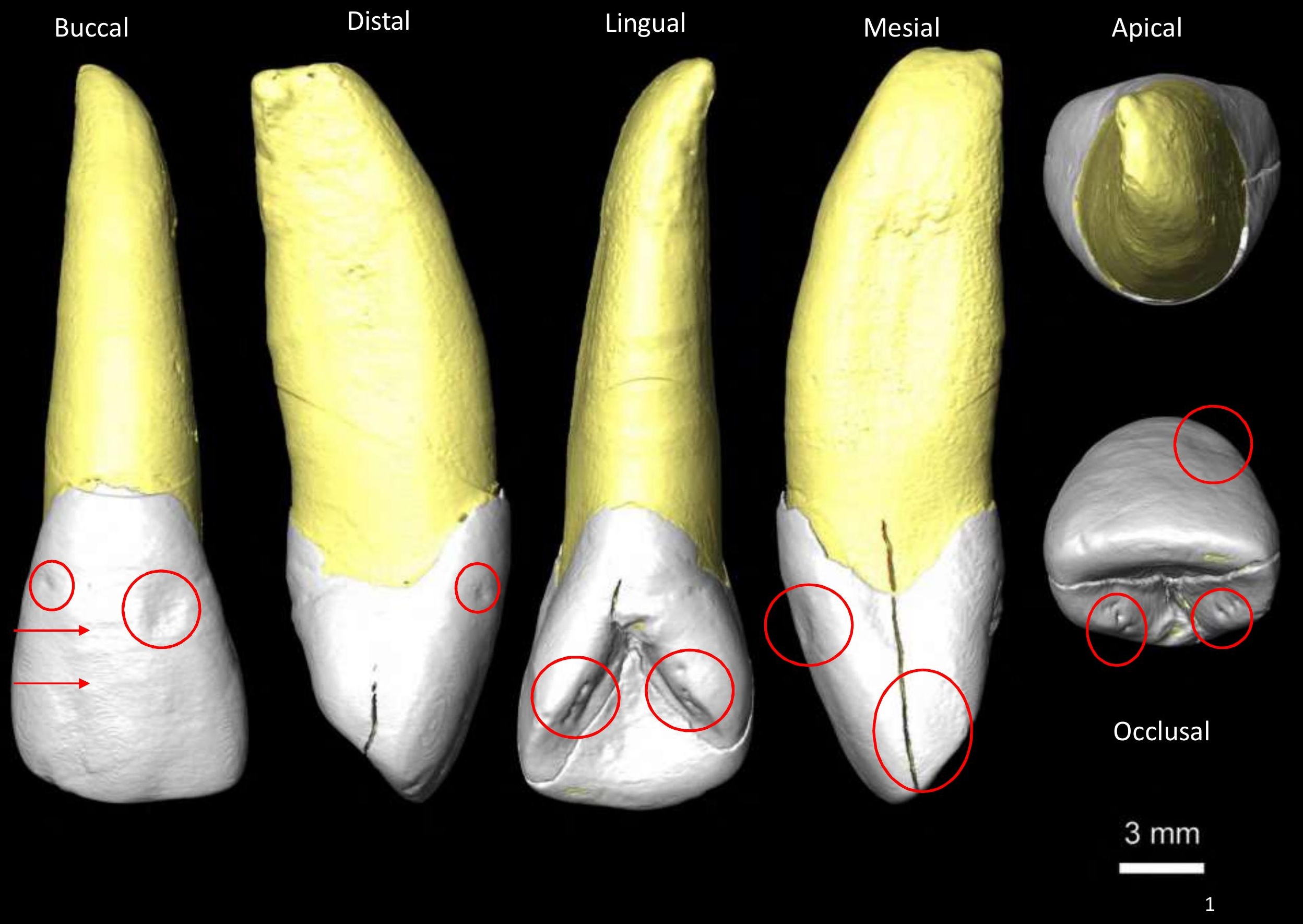




\section{M13C - URI2 - EDJ}

Buccal

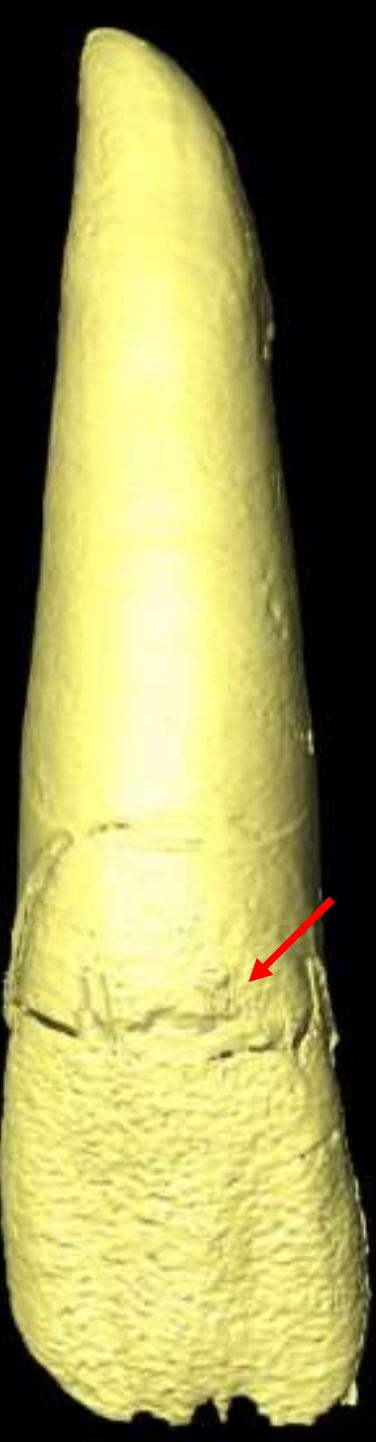

Distal

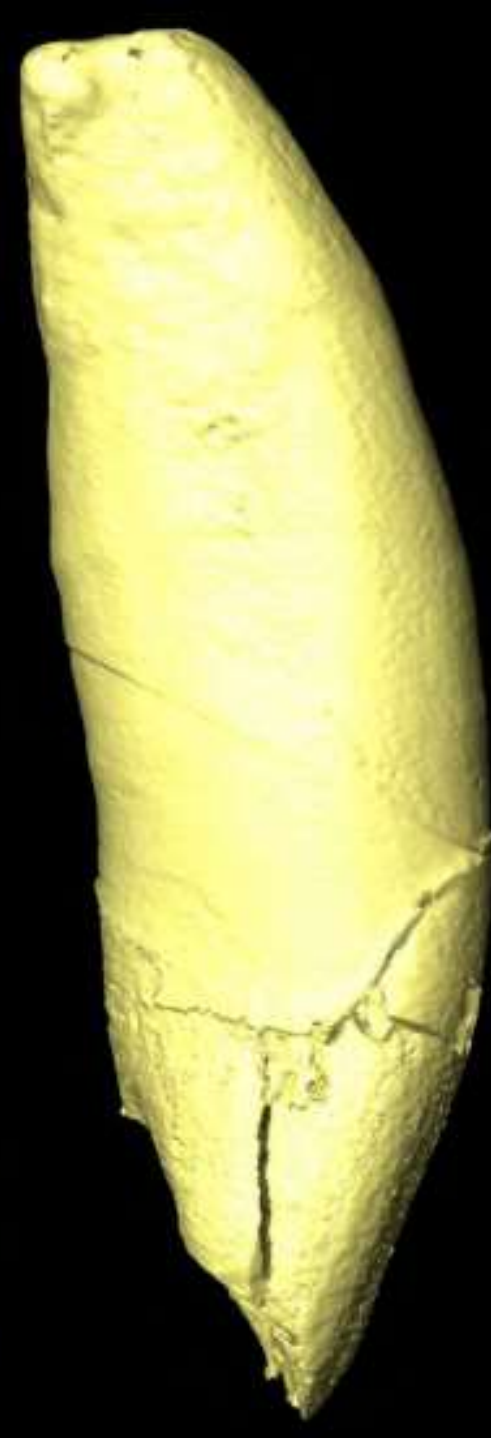

Lingual

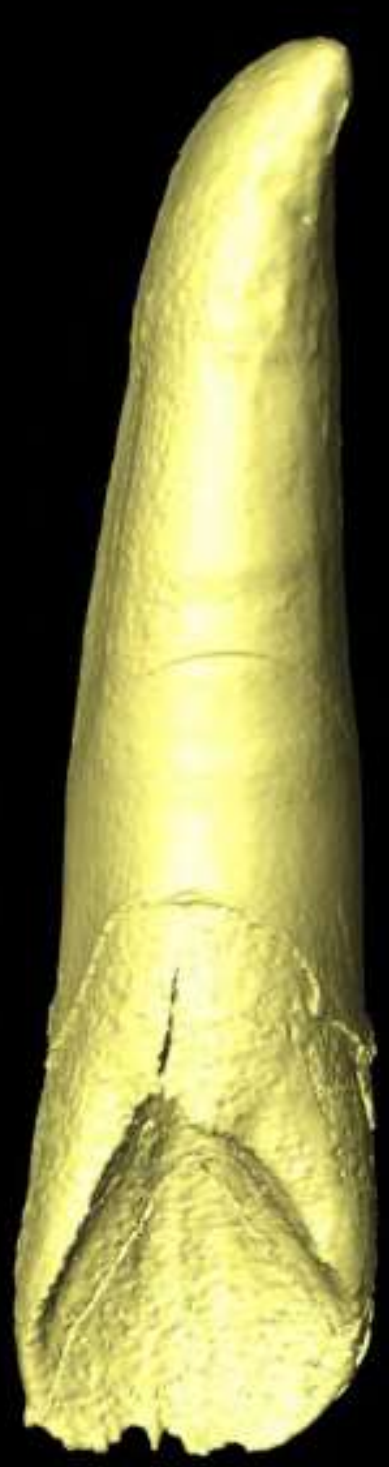

Mesial

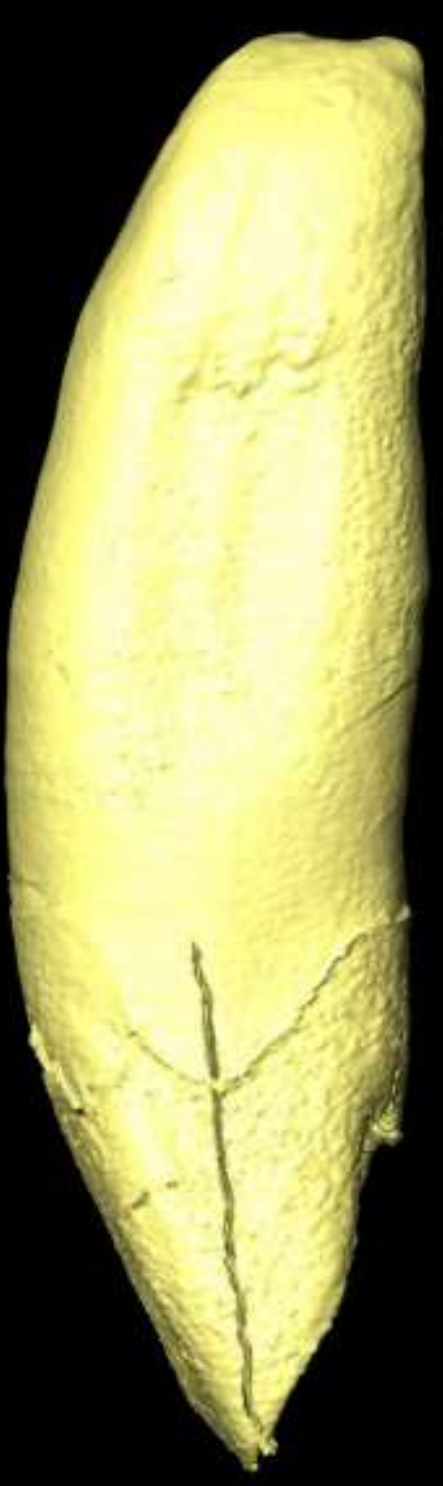

Apical
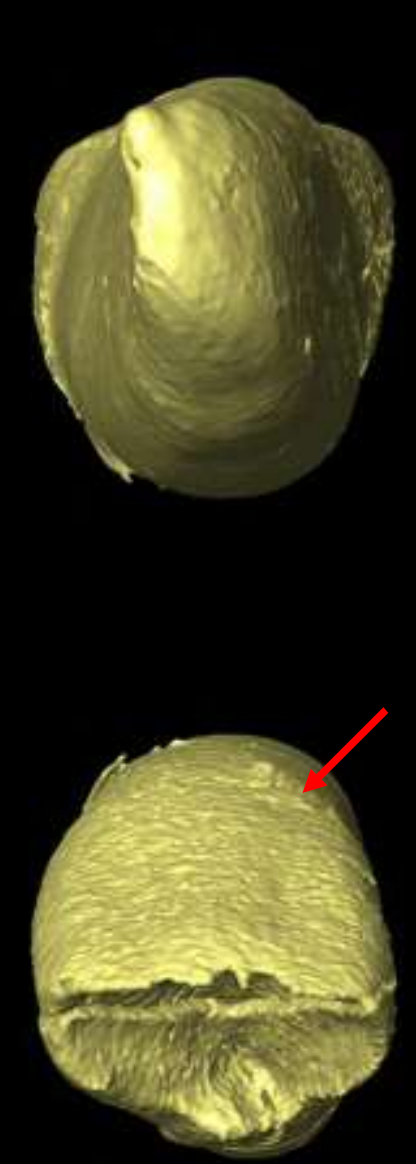

Occlusal

$3 \mathrm{~mm}$ 


$$
\text { M13C - URI2 - Pulp }
$$

Buccal

Distal

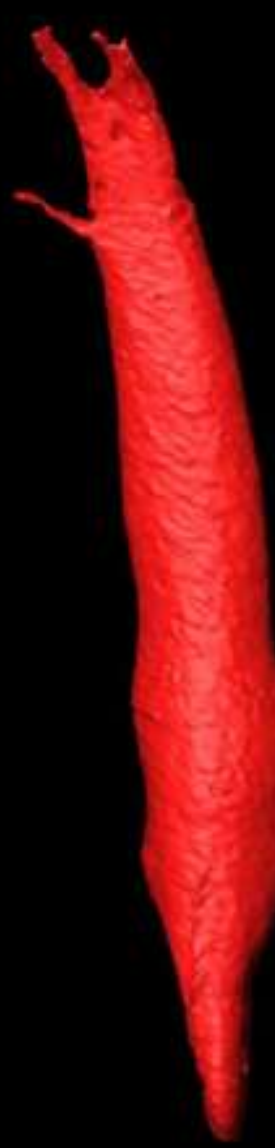

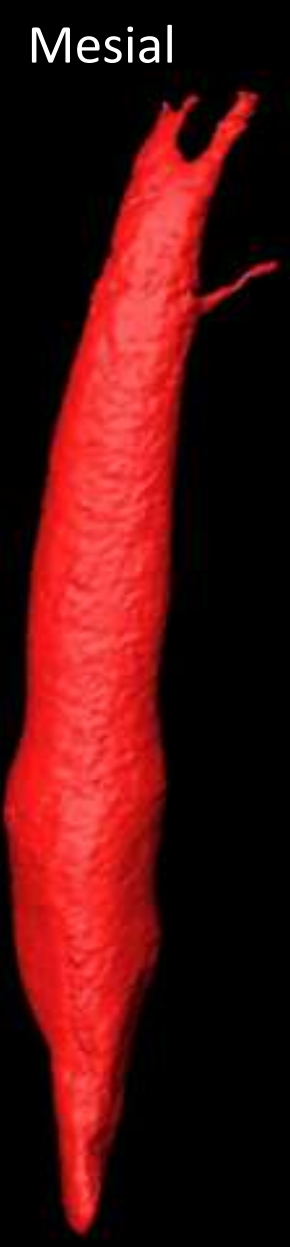

Apical

Lingual

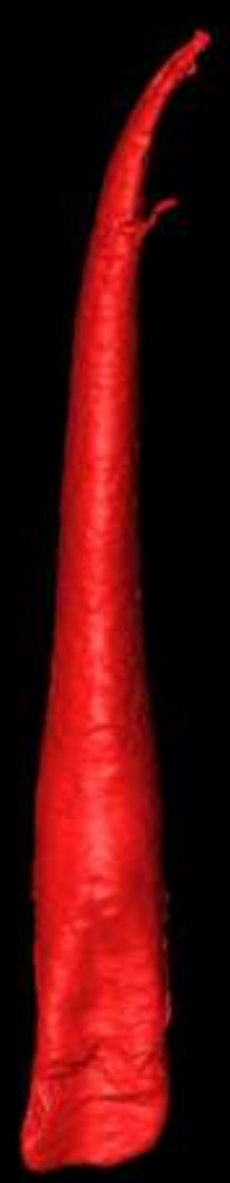

Occlusal

$3 \mathrm{~mm}$ 
M13C - URI2 - 2D sections
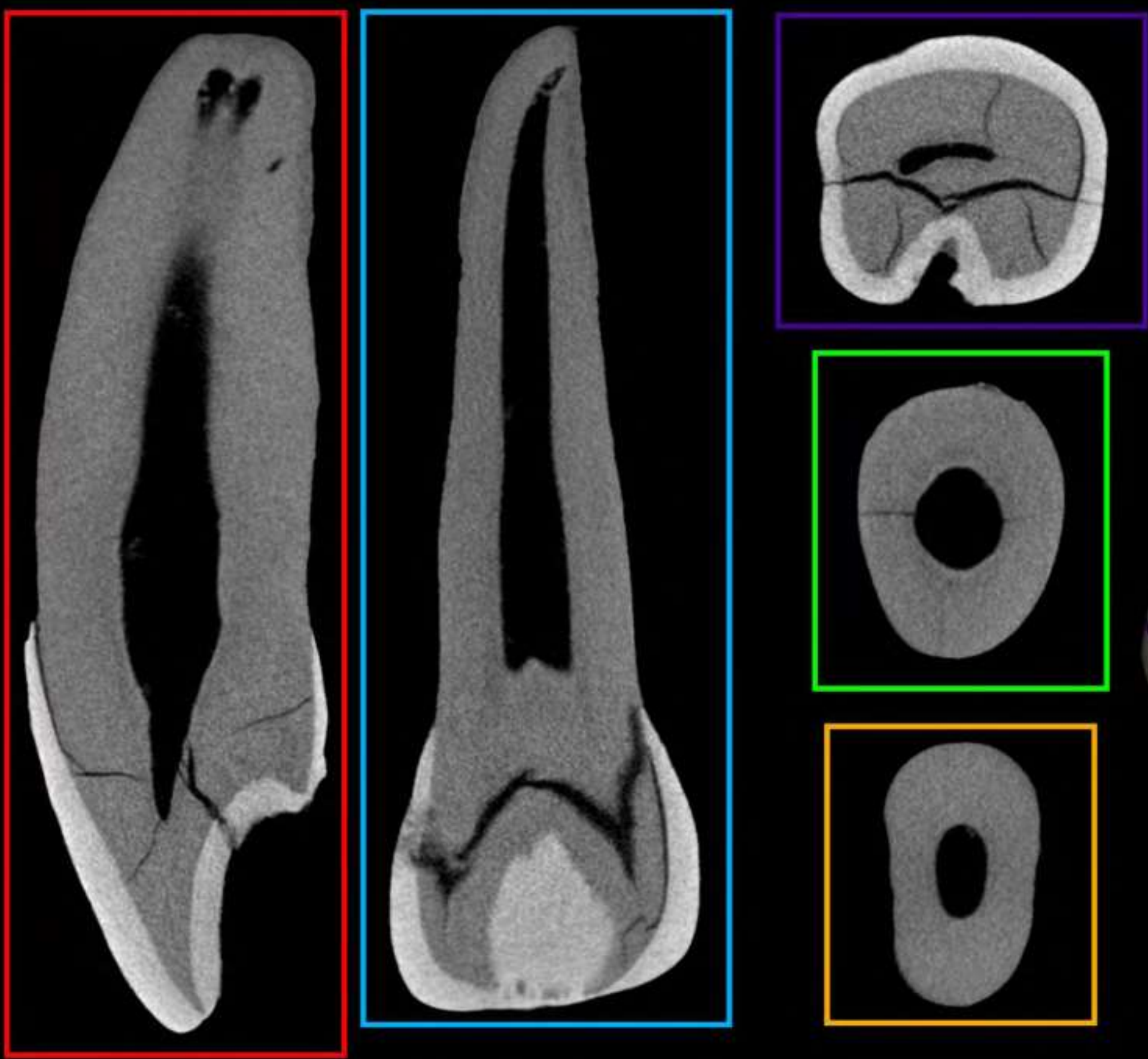

$3 \mathrm{~mm}$ 


\section{M13C - URI2 - Hypercementosis}
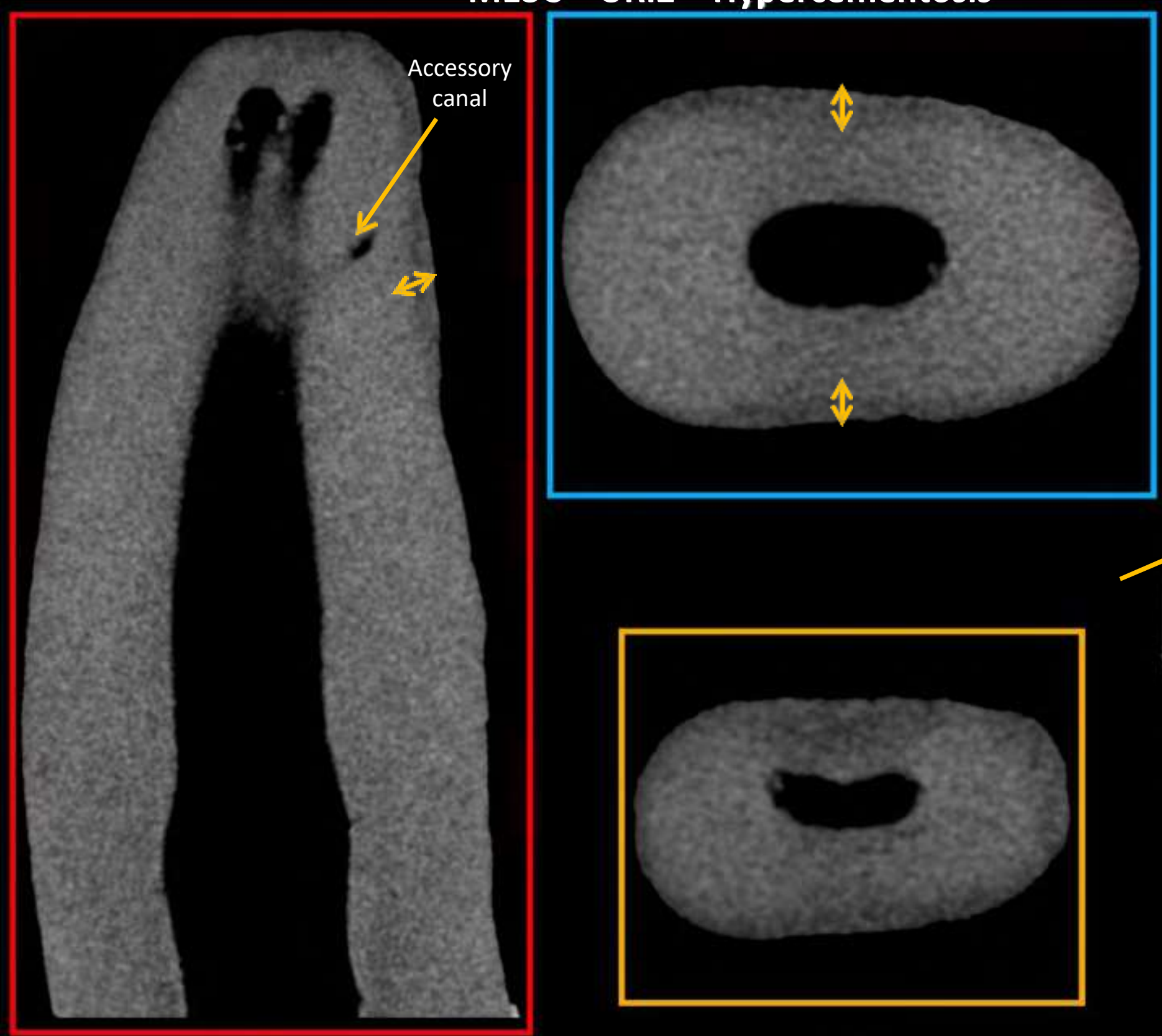

$1 \mathrm{~mm}$ 


\section{M13D - ULI2}

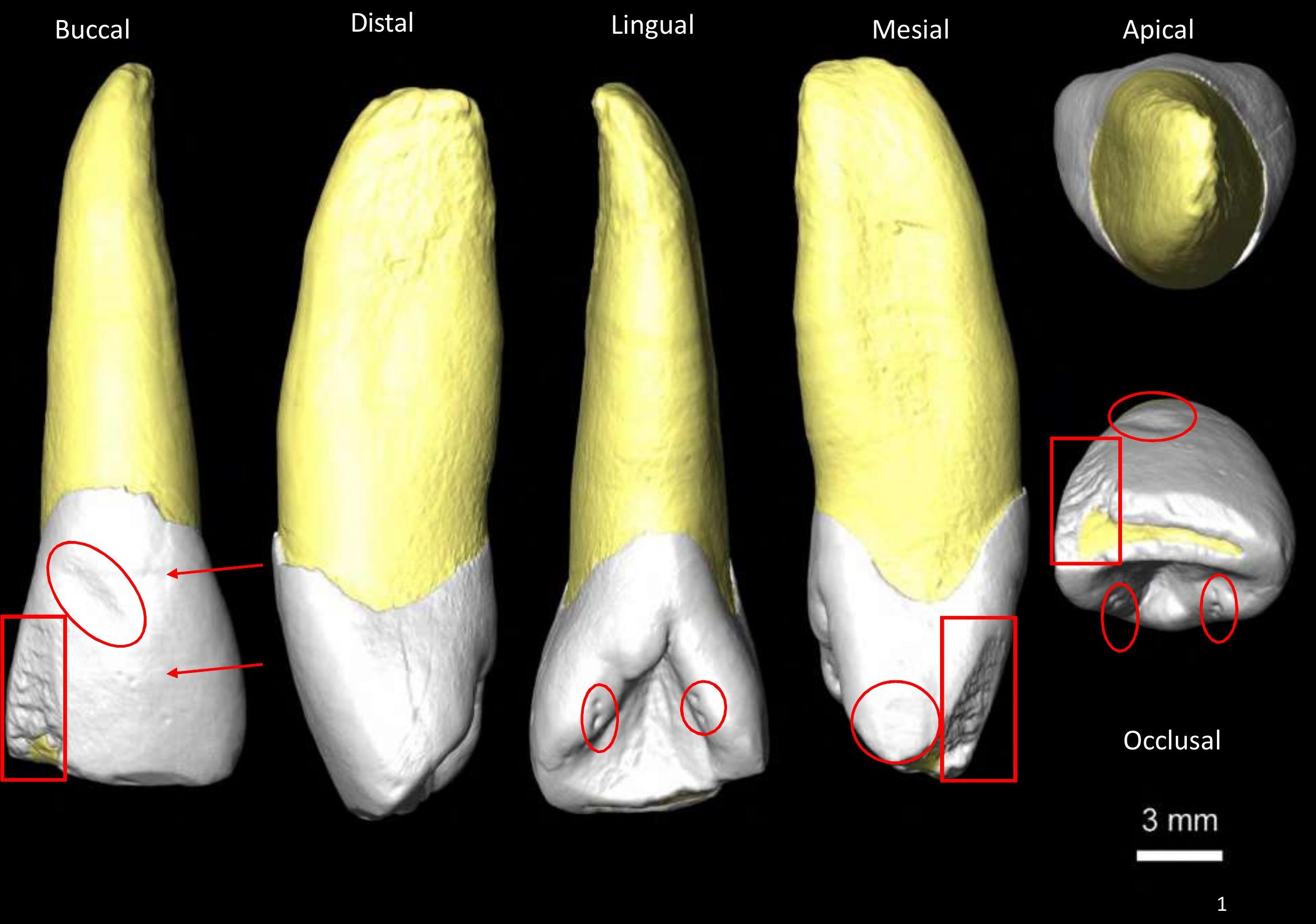




$$
\text { M13D - ULI2 - EDJ }
$$
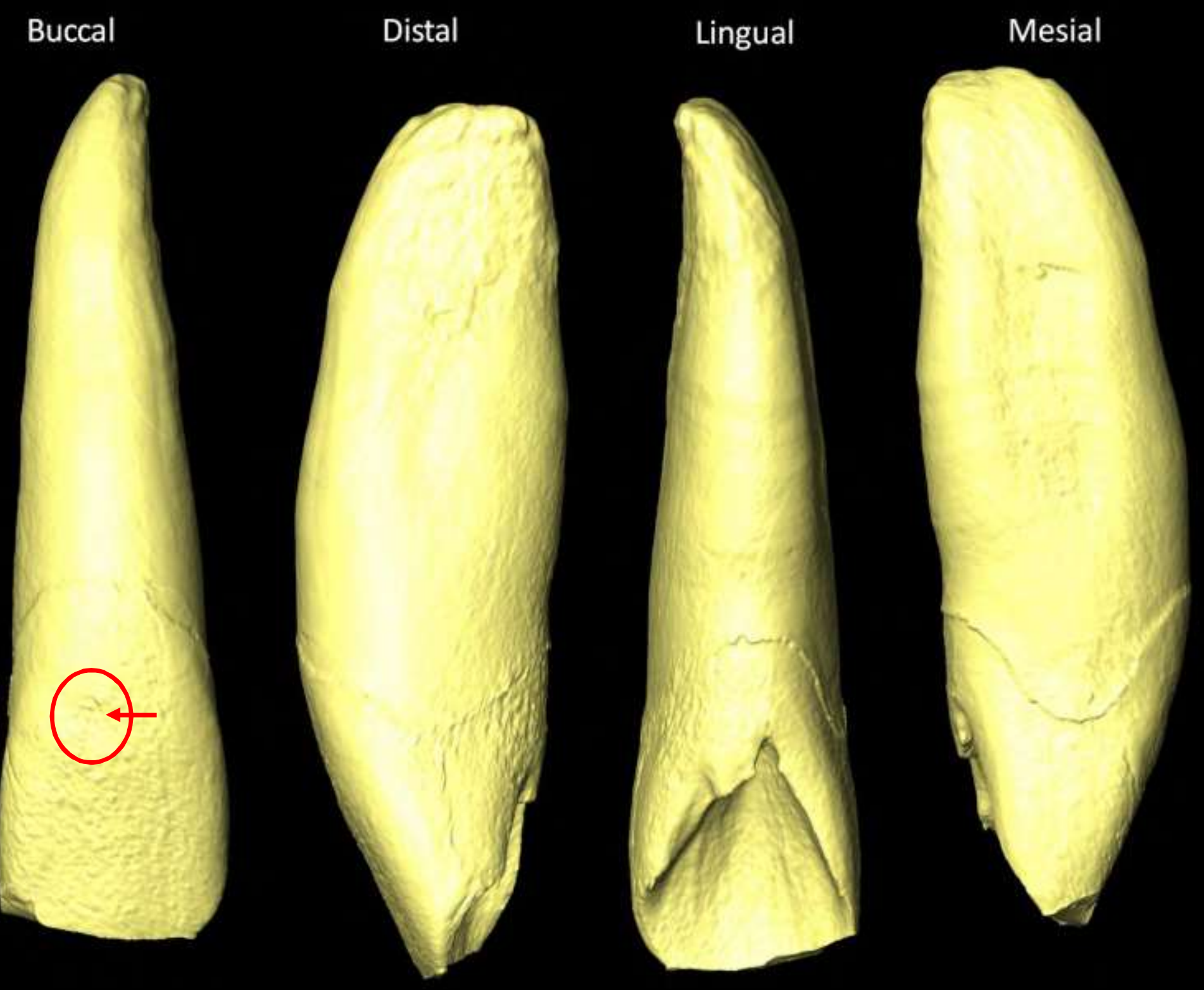

Apical
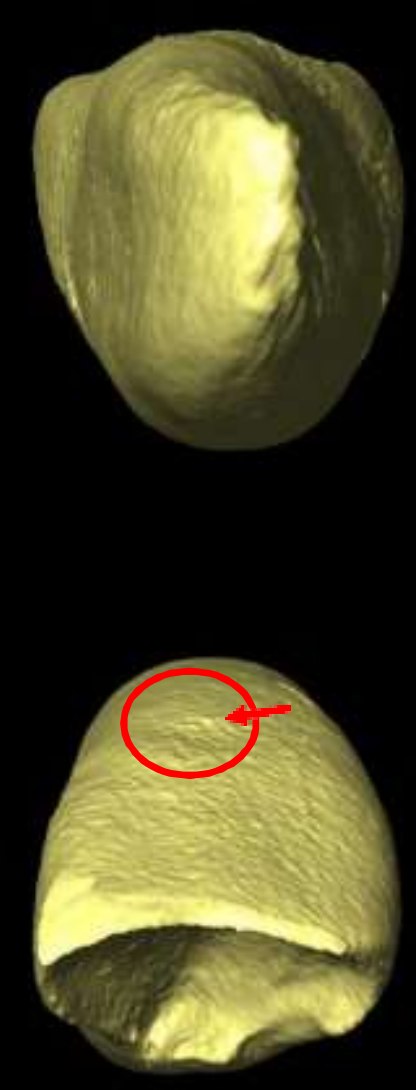

Occlusal

$3 \mathrm{~mm}$

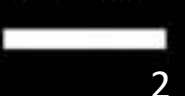




\section{M13D - ULI2 - Pulp}

Buccal

Distal

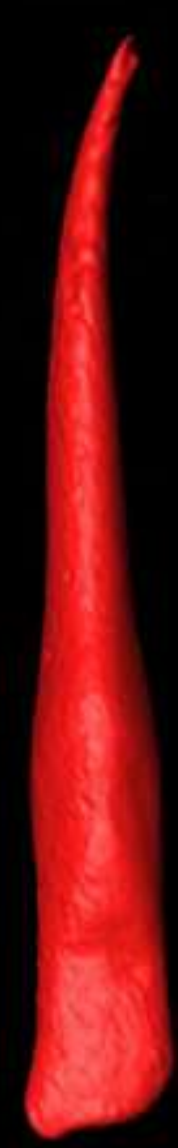

Lingual

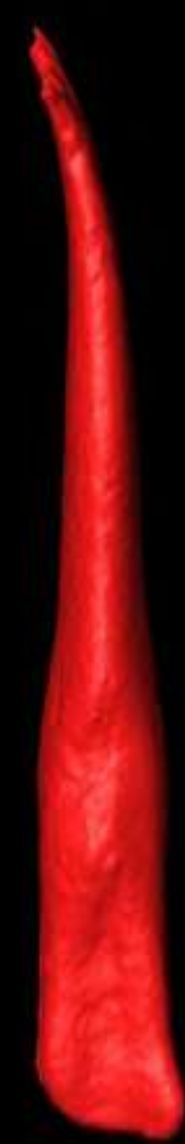

Mesial

Apical

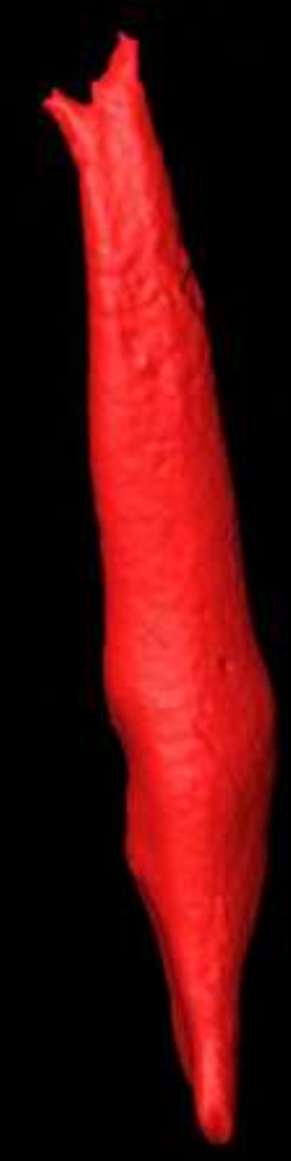

Occlusal

$3 \mathrm{~mm}$ 


\section{M13D - ULI2 - 2D sections}
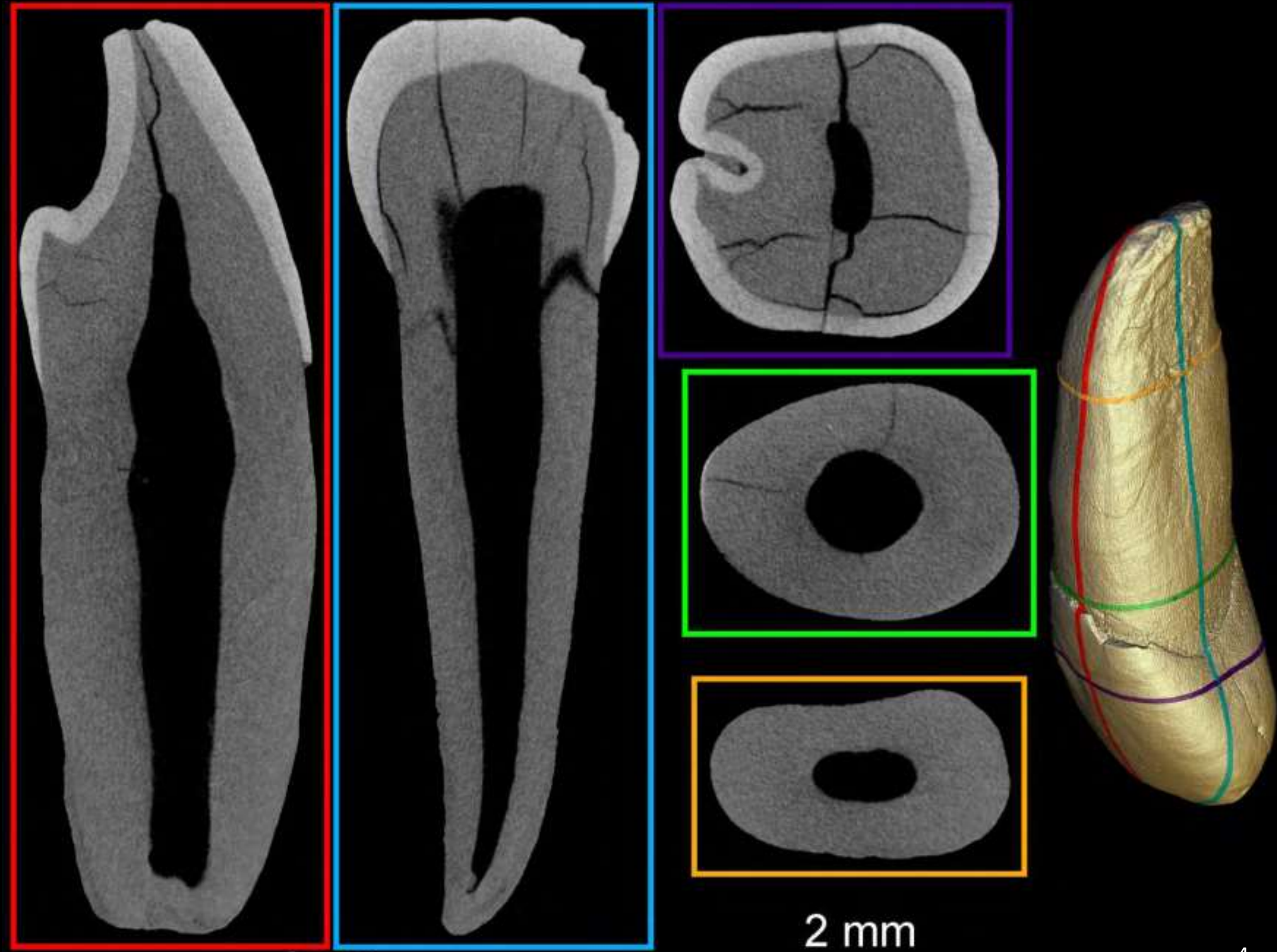


\section{M13D - UU2 - Hypercementosis}
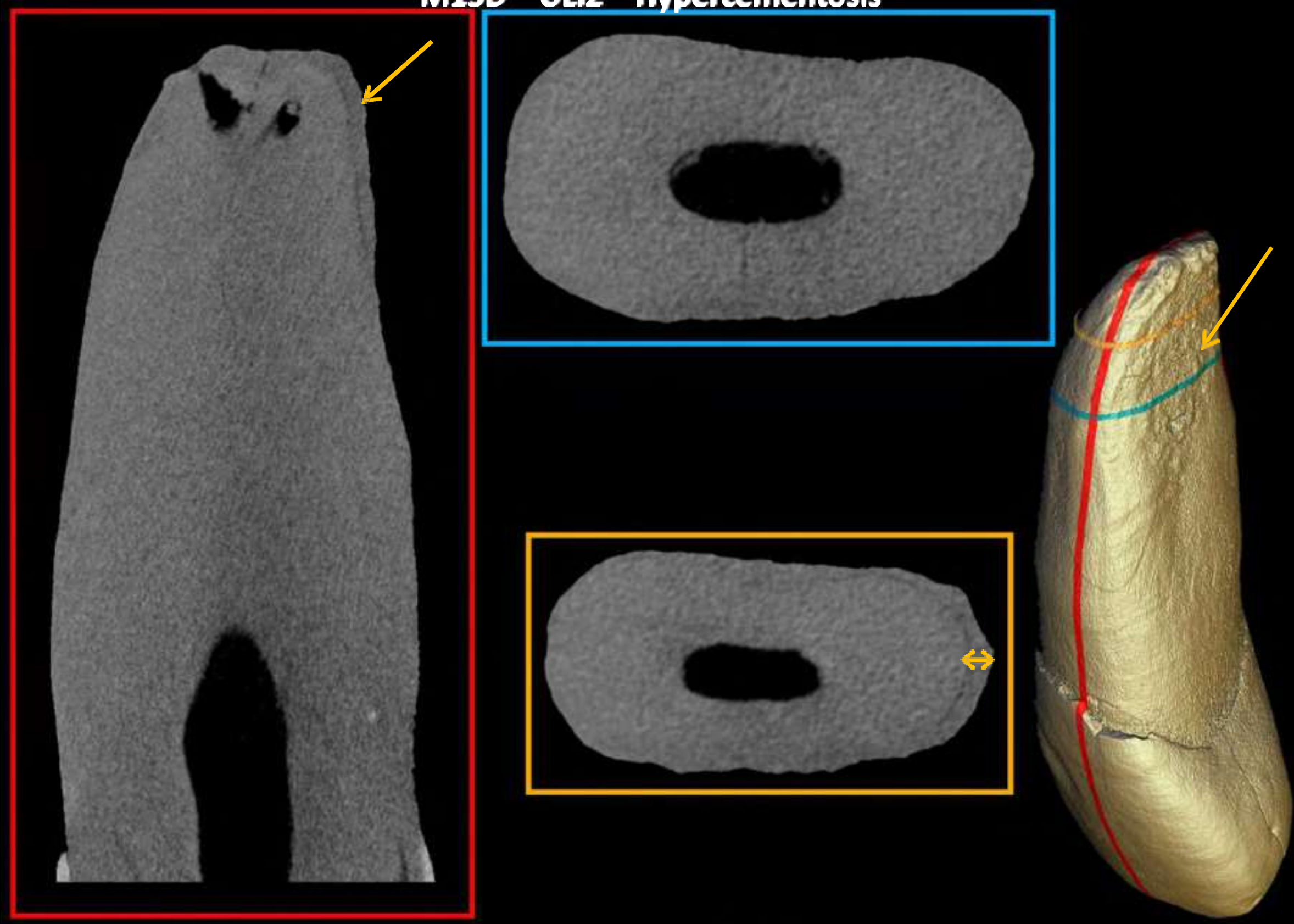

$2 \mathrm{~mm}$ 


\section{M13E - URC}

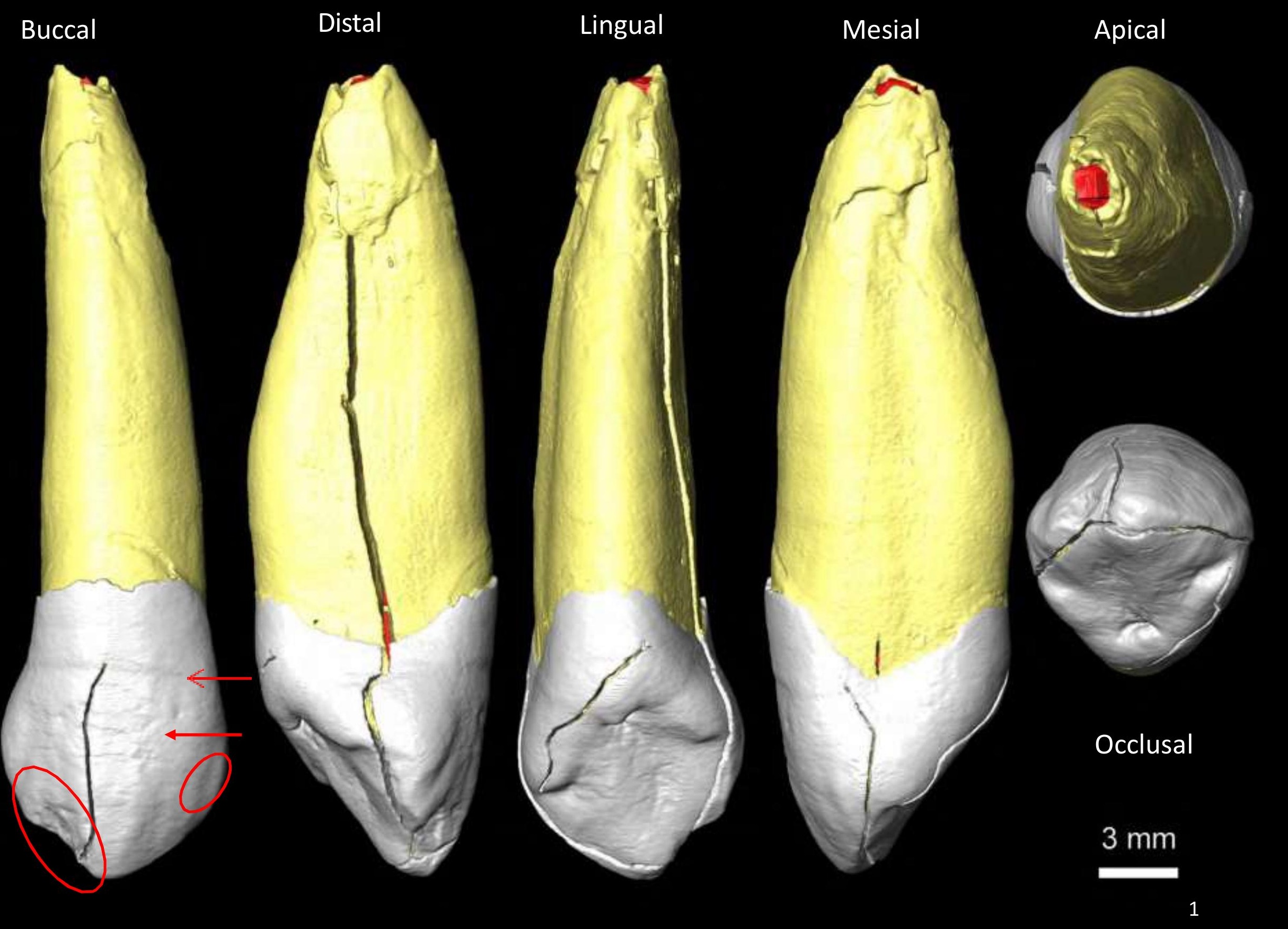


M13E - URC - EDJ

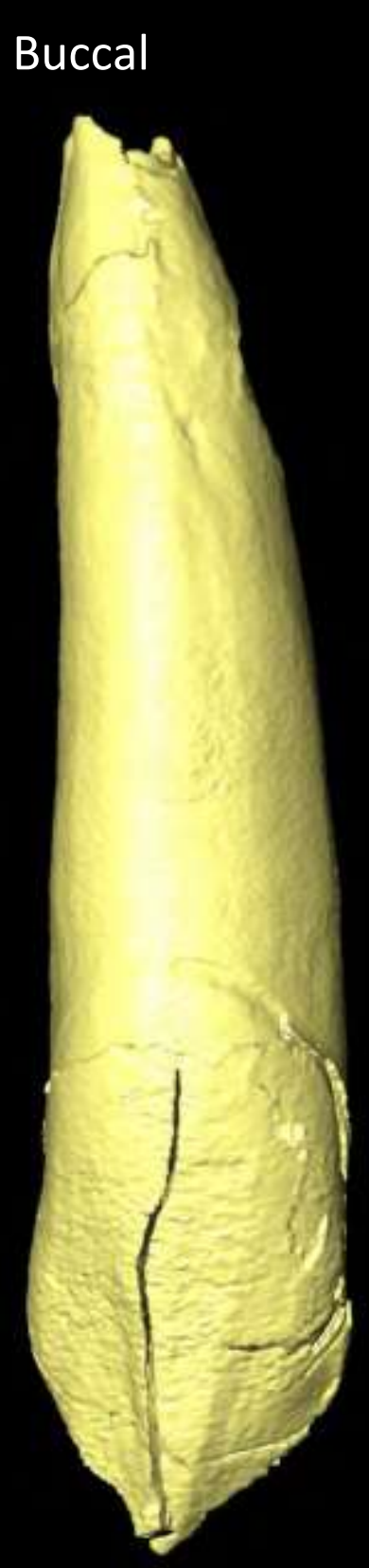

Distal

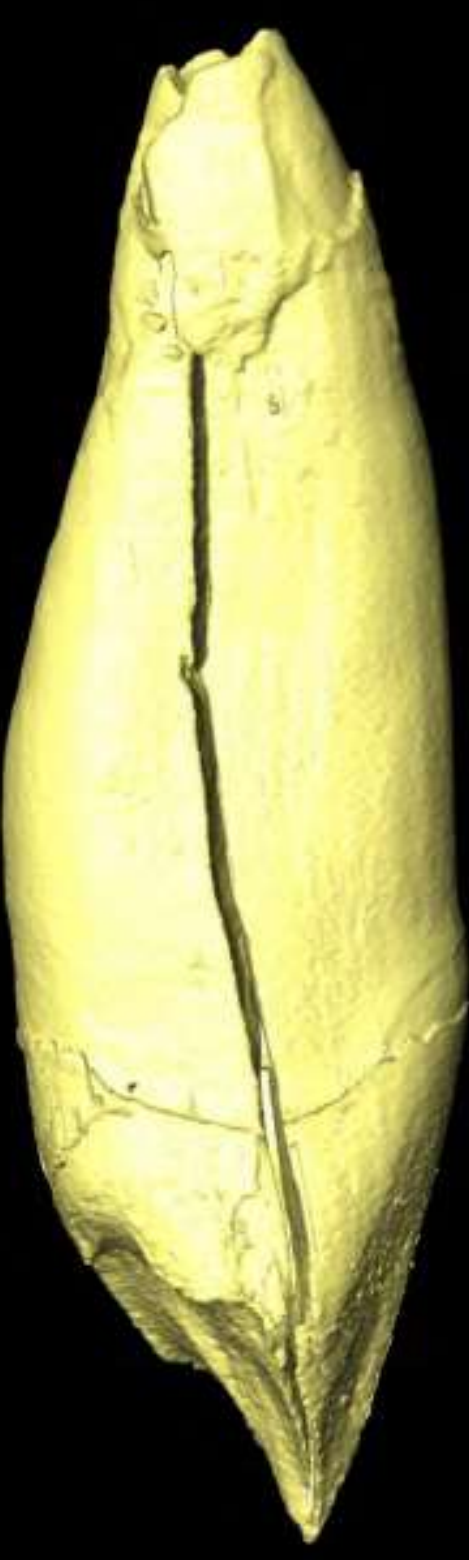

Lingual

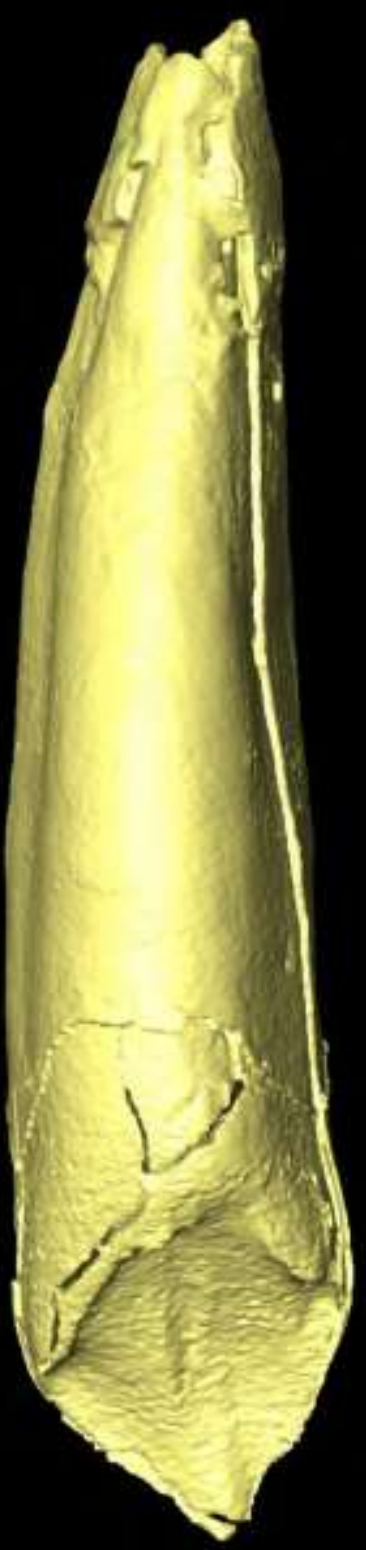

Mesial

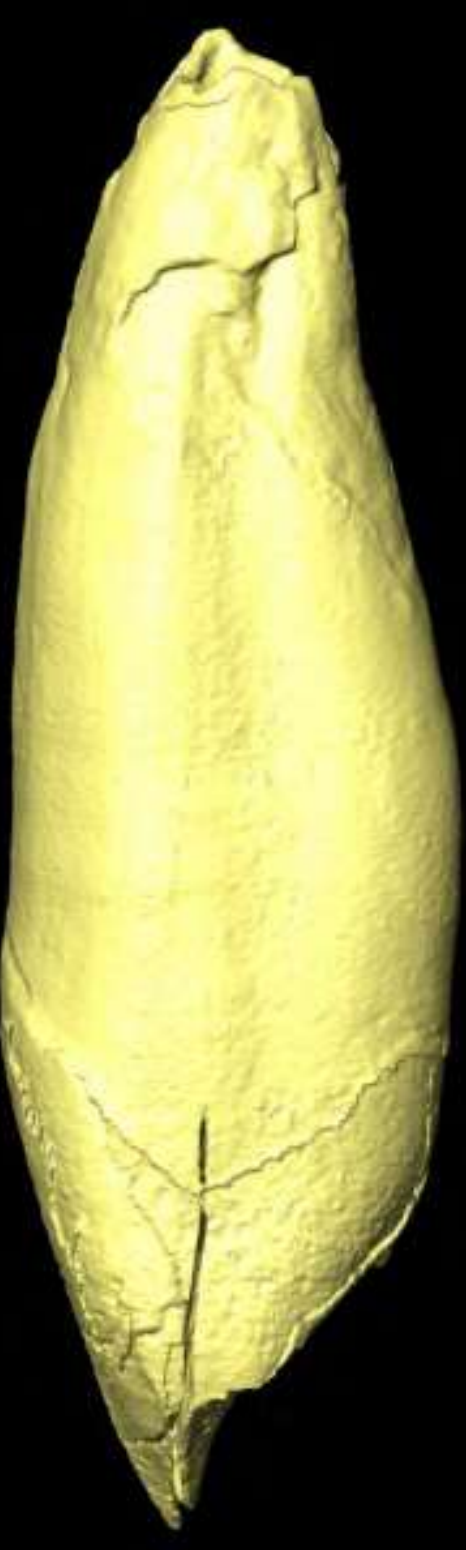

Apical
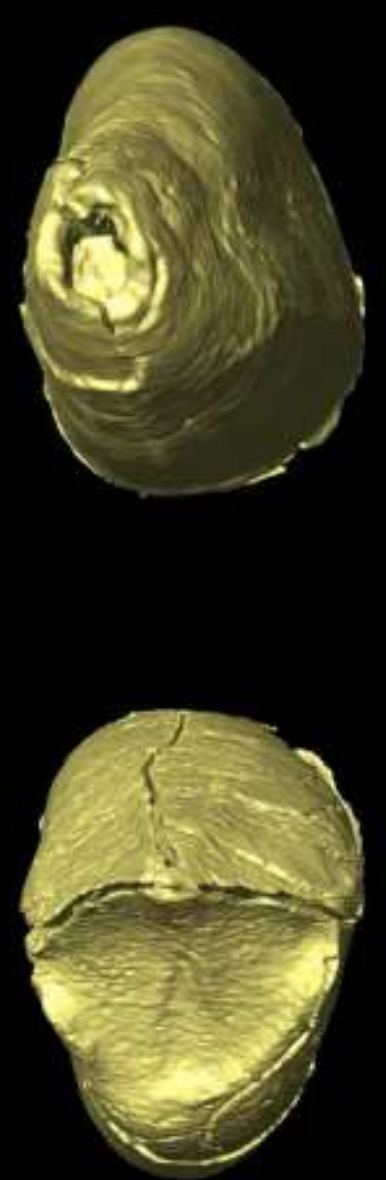

Occlusal

$3 \mathrm{~mm}$ 


\section{M13E - URC - Pulp}

Buccal

Distal

Lingual

Mesial

Apical
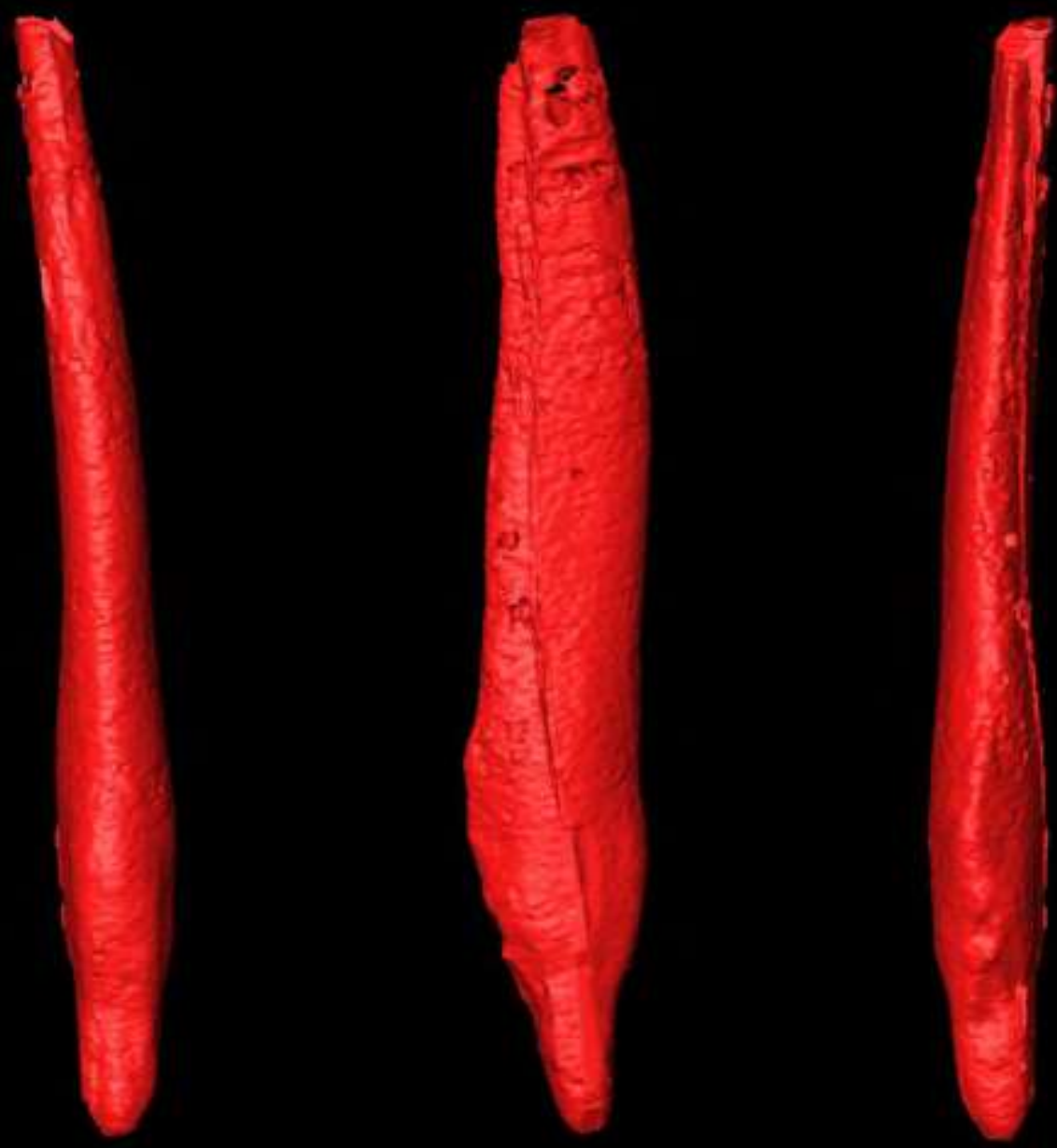

Occlusal

$3 \mathrm{~mm}$ 

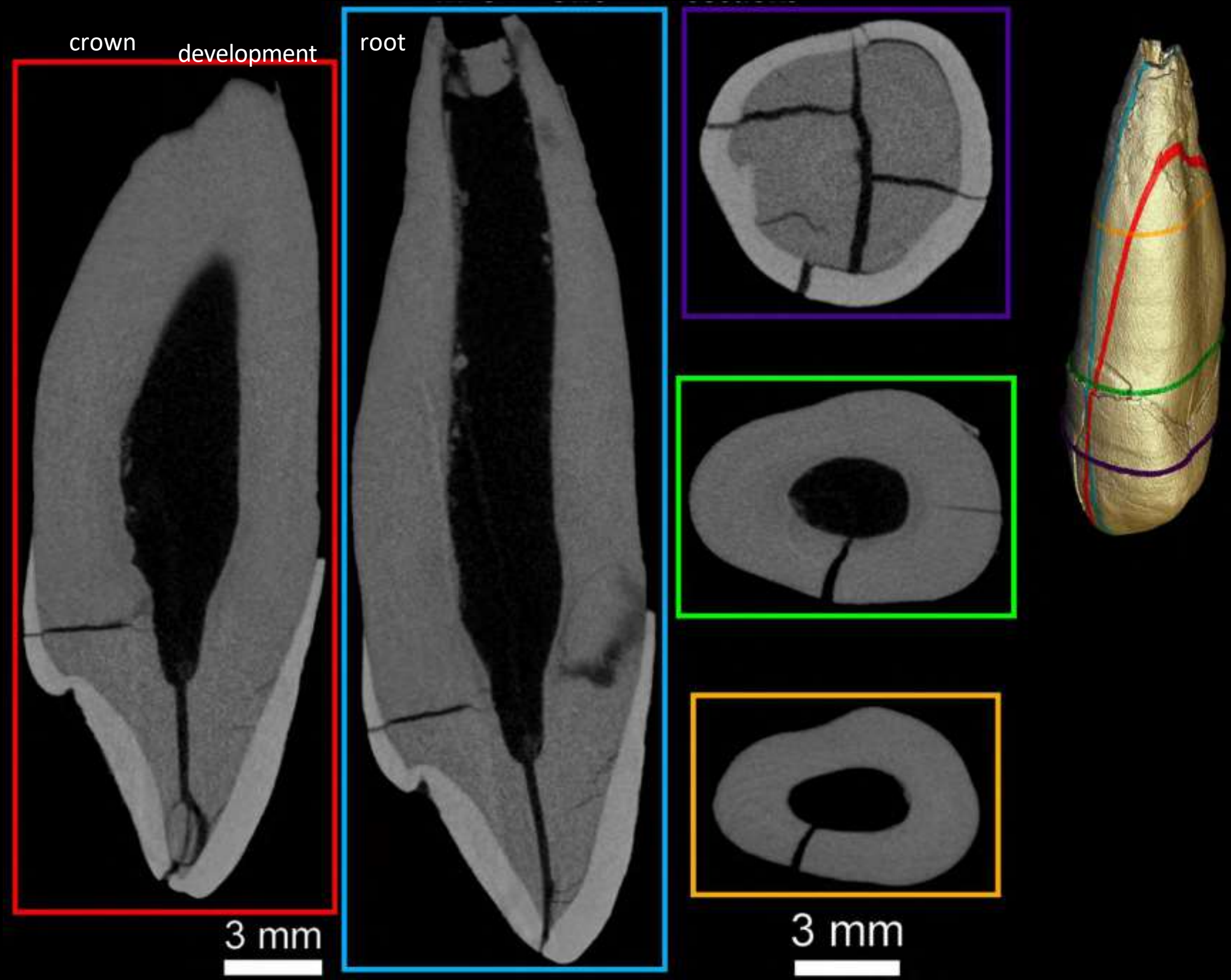

$3 \mathrm{~mm}$
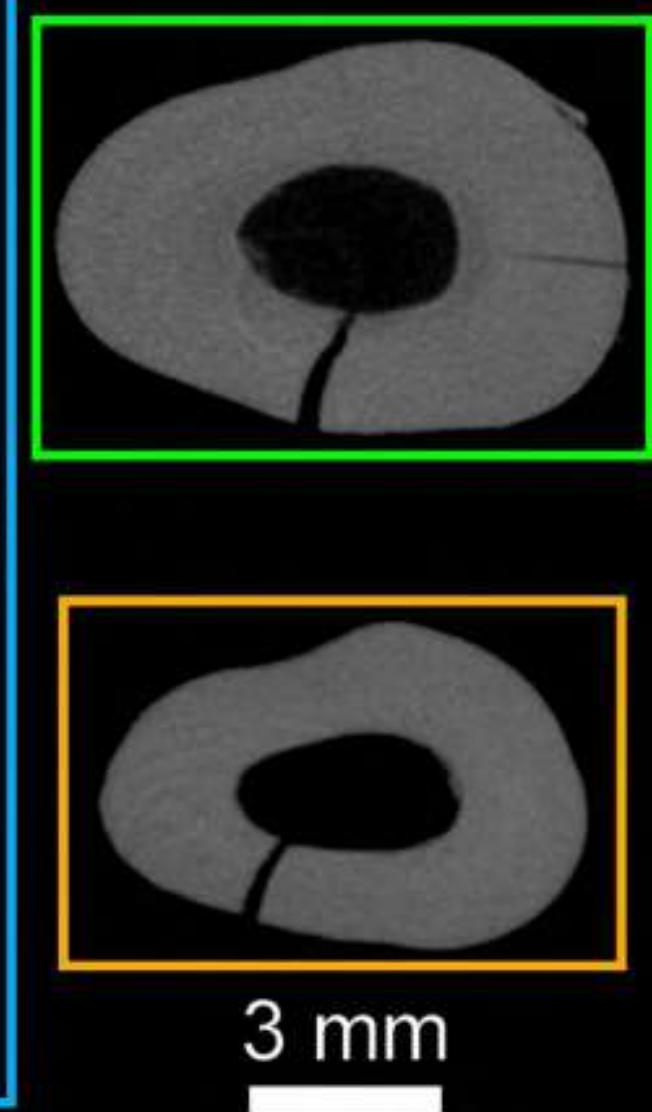



\section{M13E - URC - Hypercementosis}
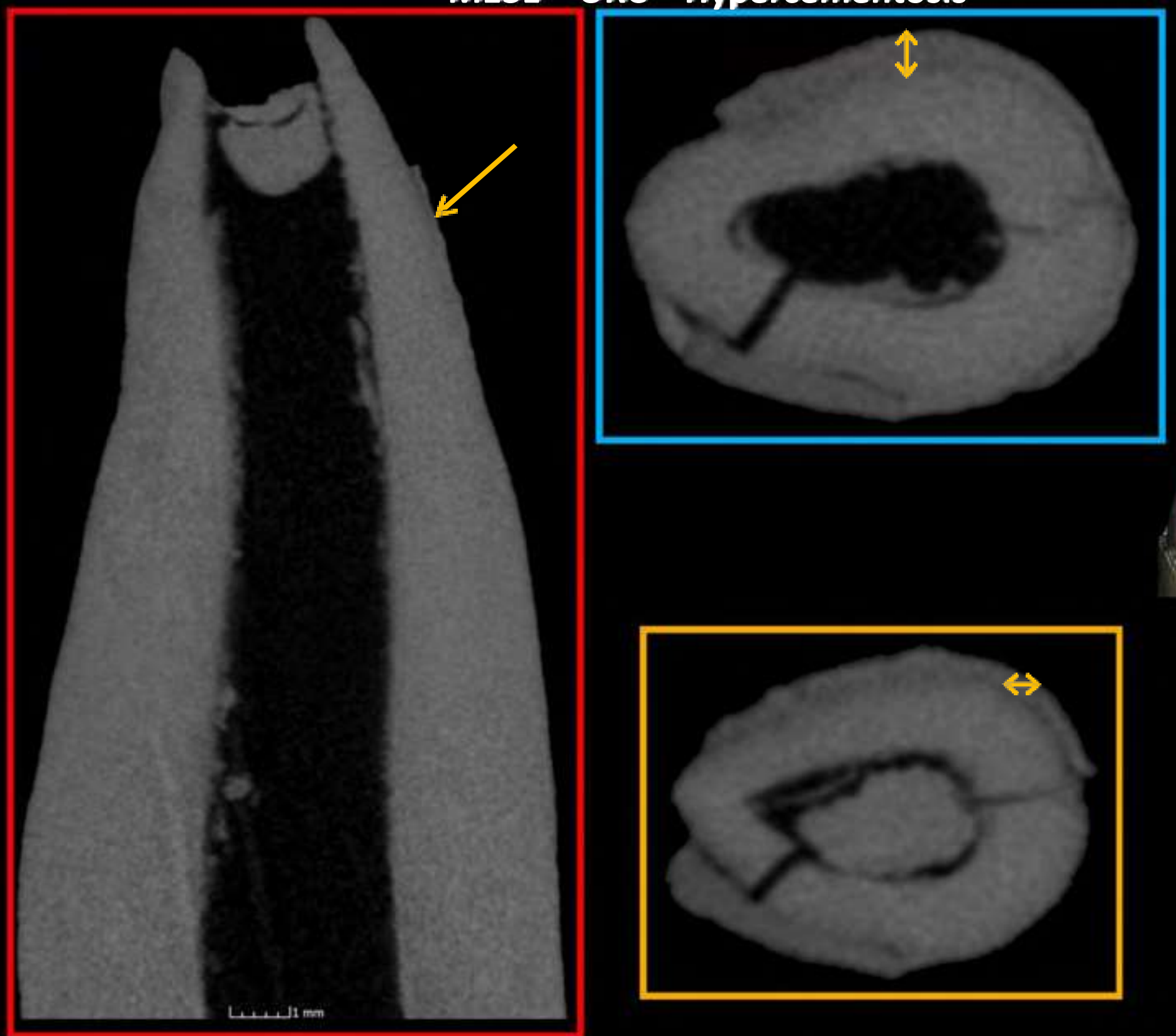

$2 \mathrm{~mm}$

$1 \mathrm{~mm}$ 
M13F - ULP3

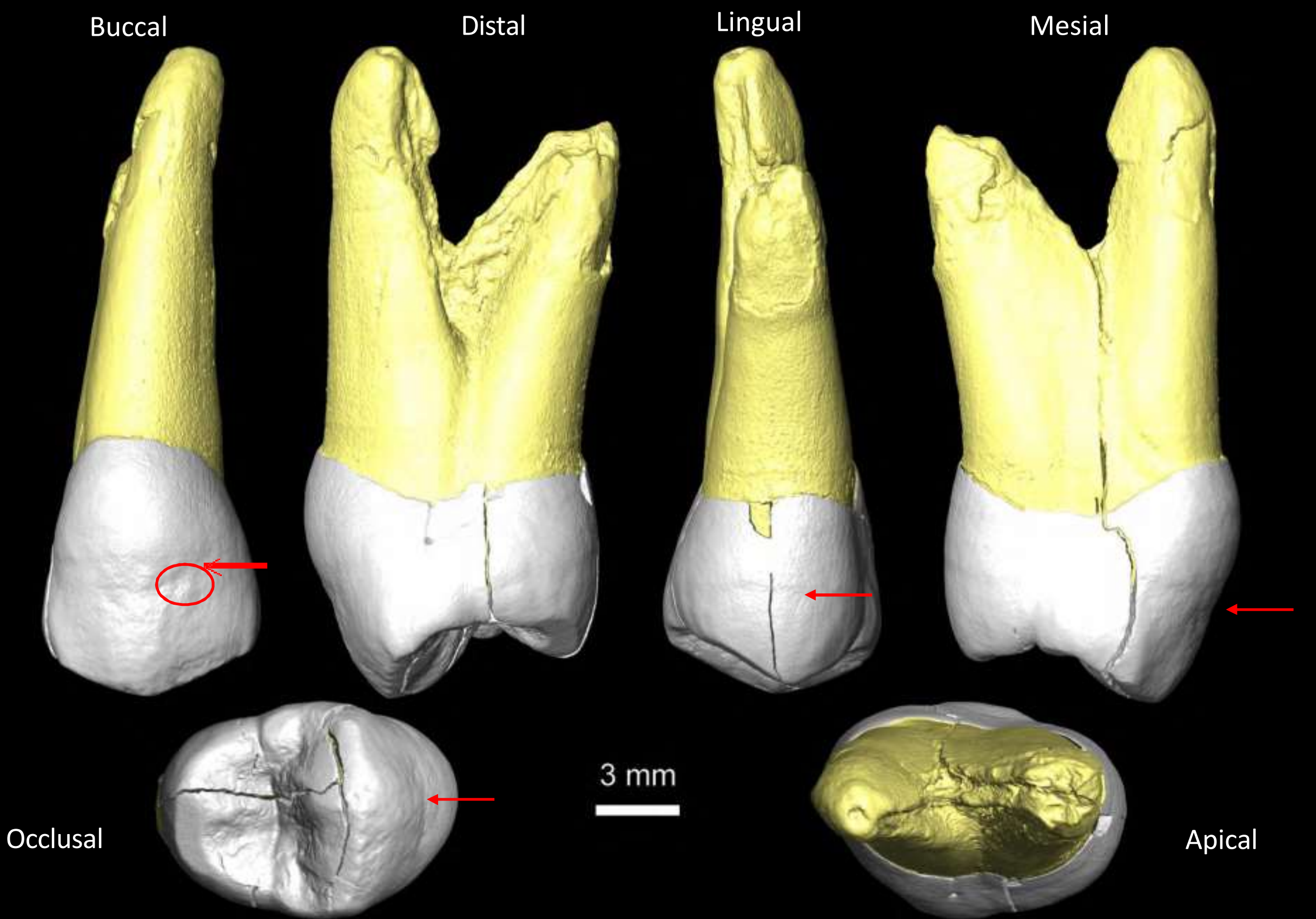




\section{M13F - ULP3 - EDJ}
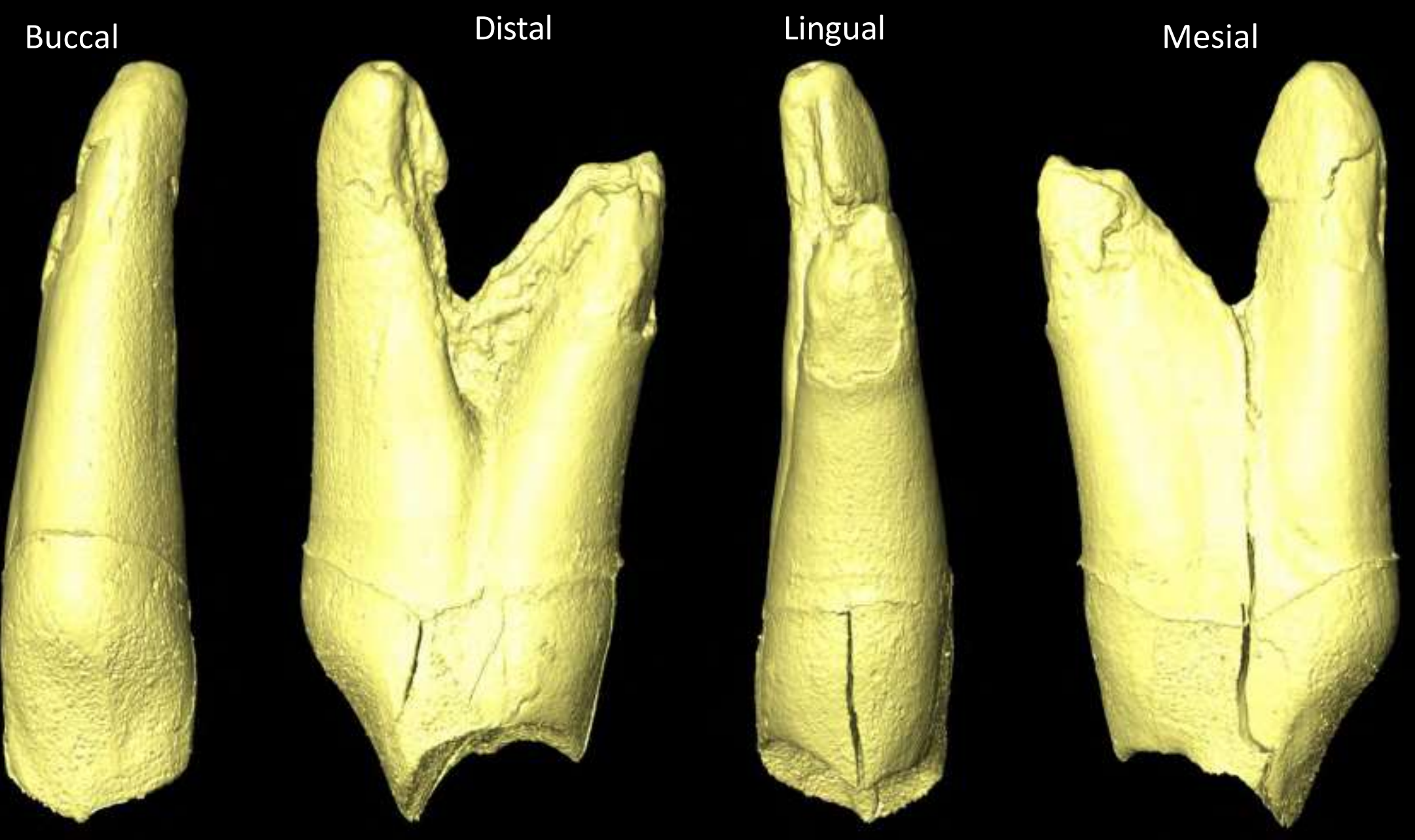

Occlusal

$3 \mathrm{~mm}$
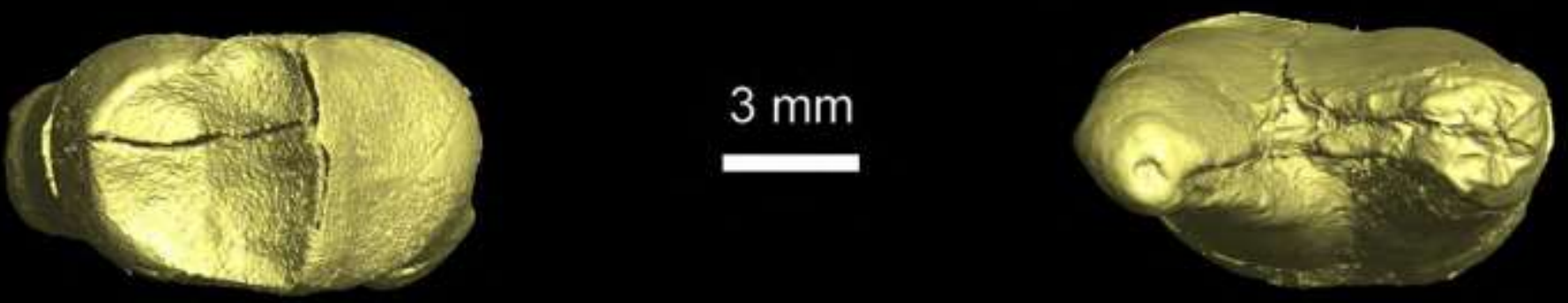

Apical 



\section{M13F - ULP3 - Pulp}

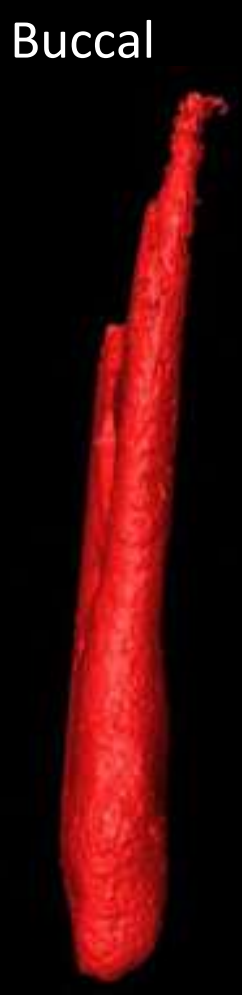

Buccal

Distal

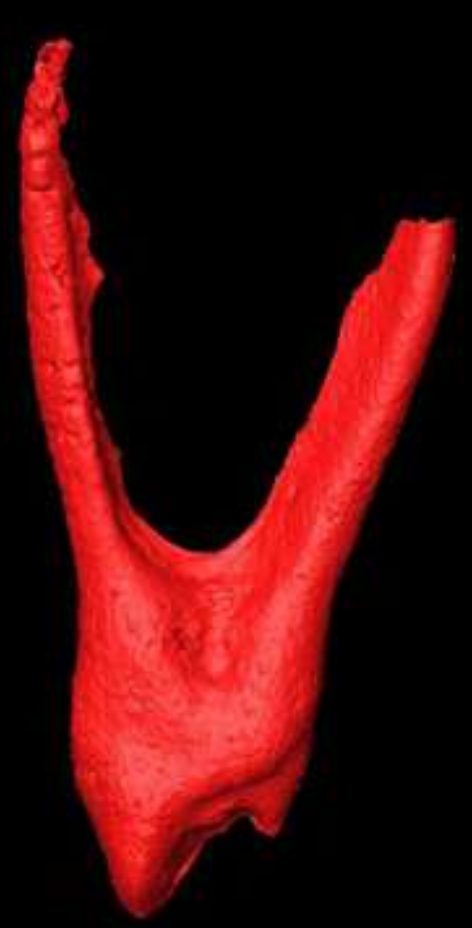

$3 \mathrm{~mm}$

Occlusal

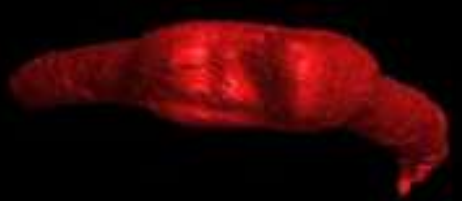

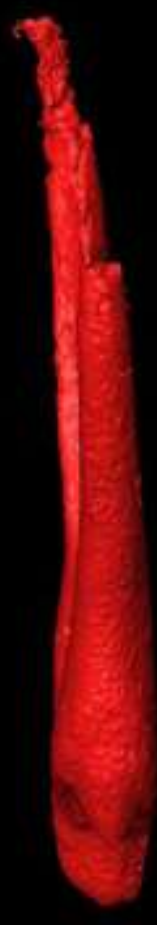

Mesial

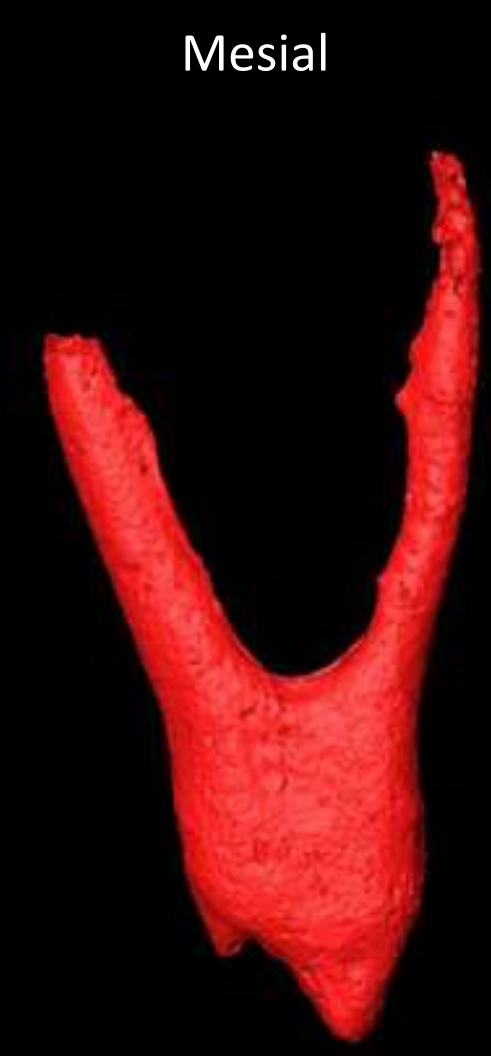




\section{M13F - ULP3 - 2D sections}

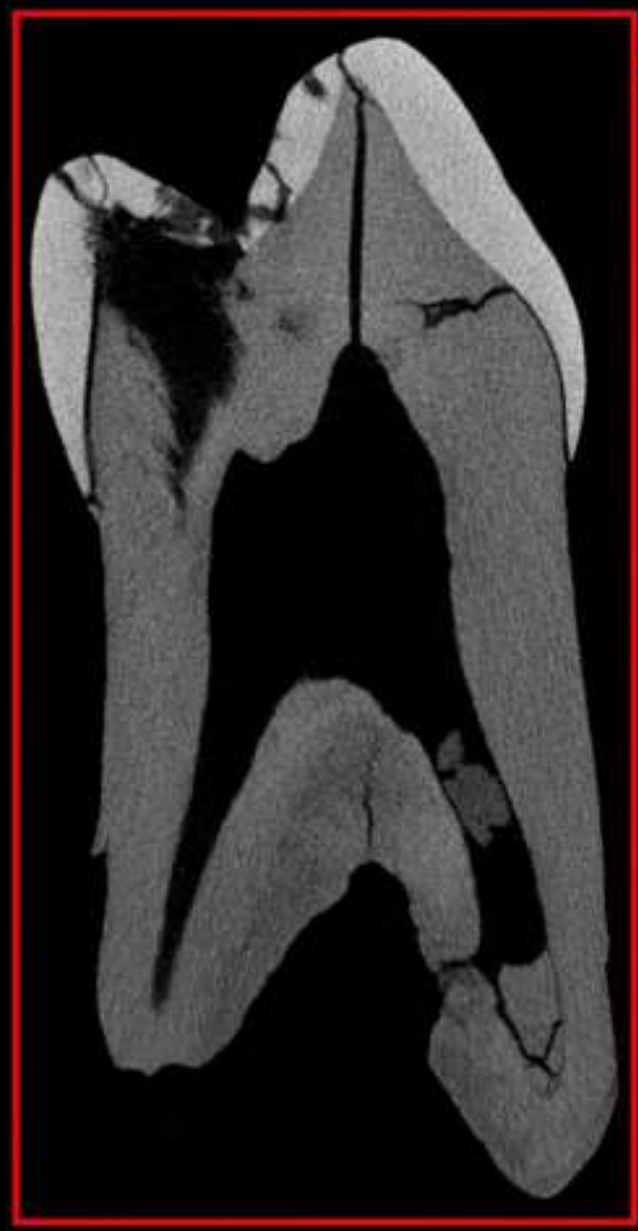

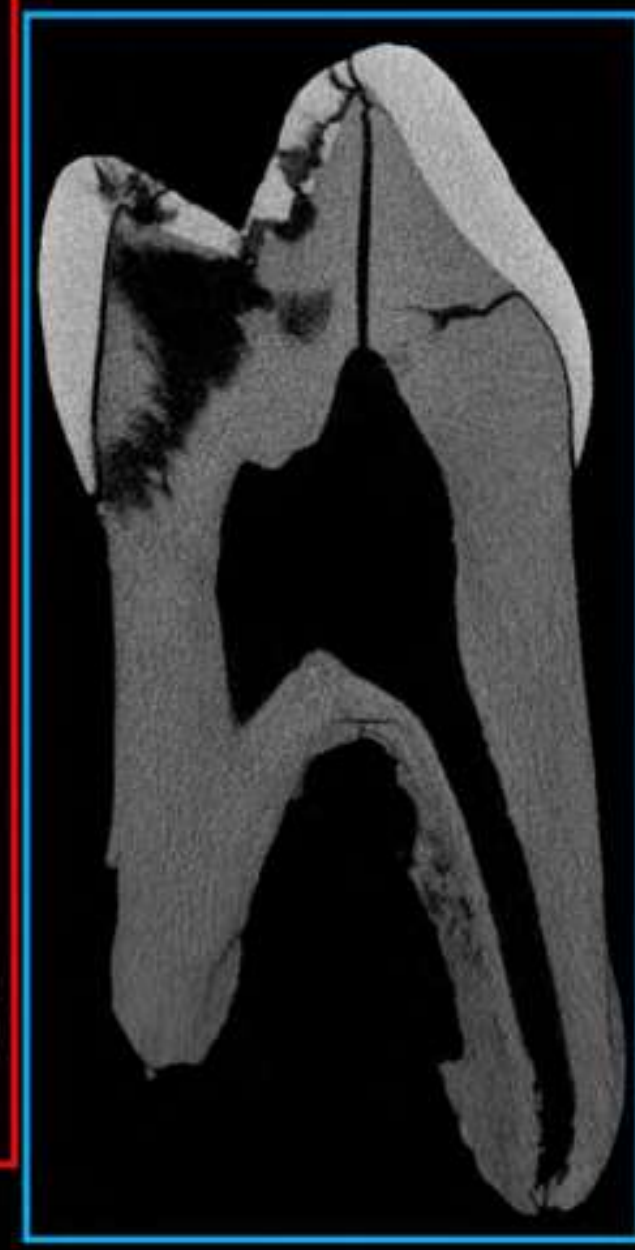

$3 \mathrm{~mm}$
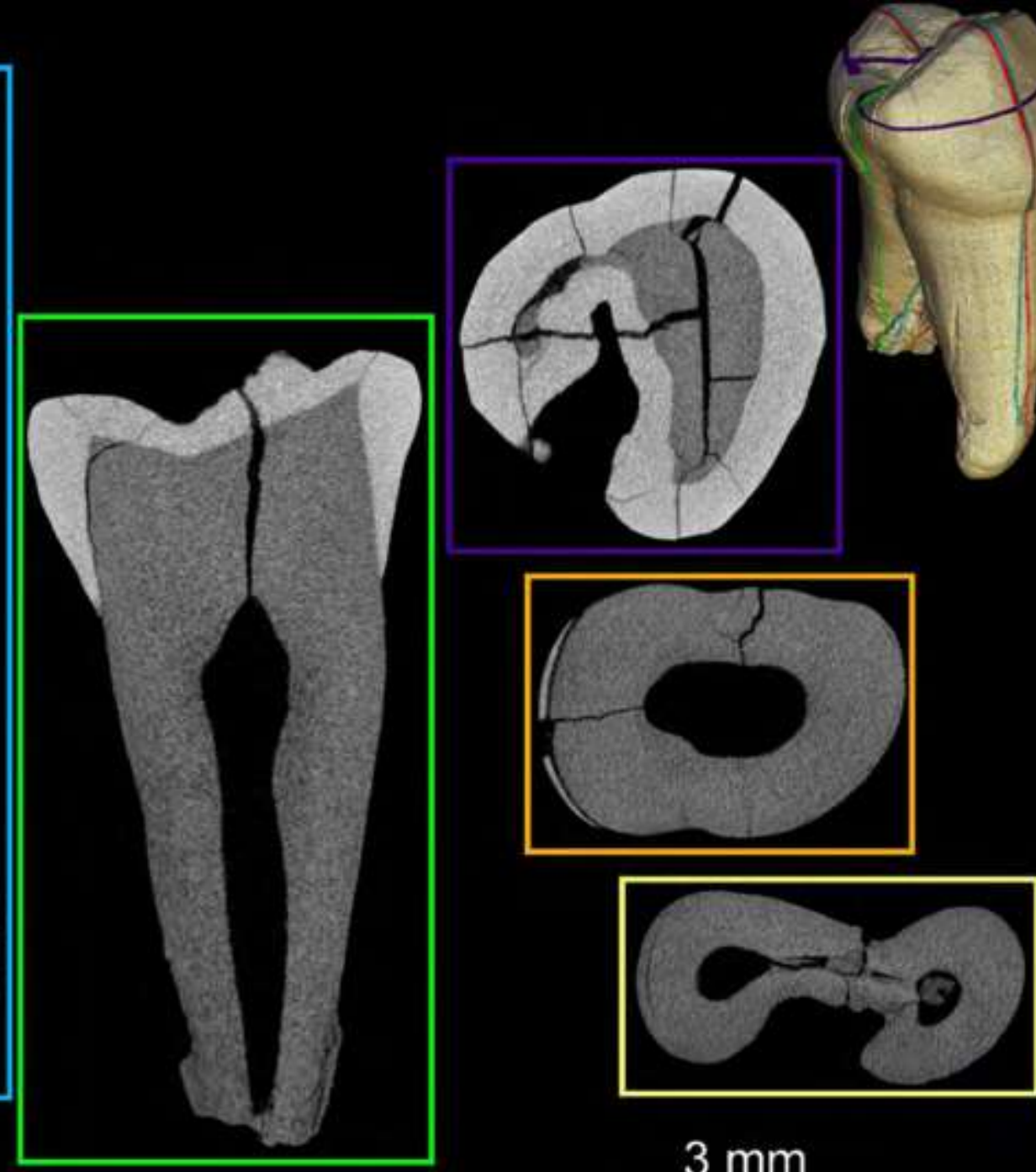

$3 \mathrm{~mm}$ 


\section{M13G - ULP4}
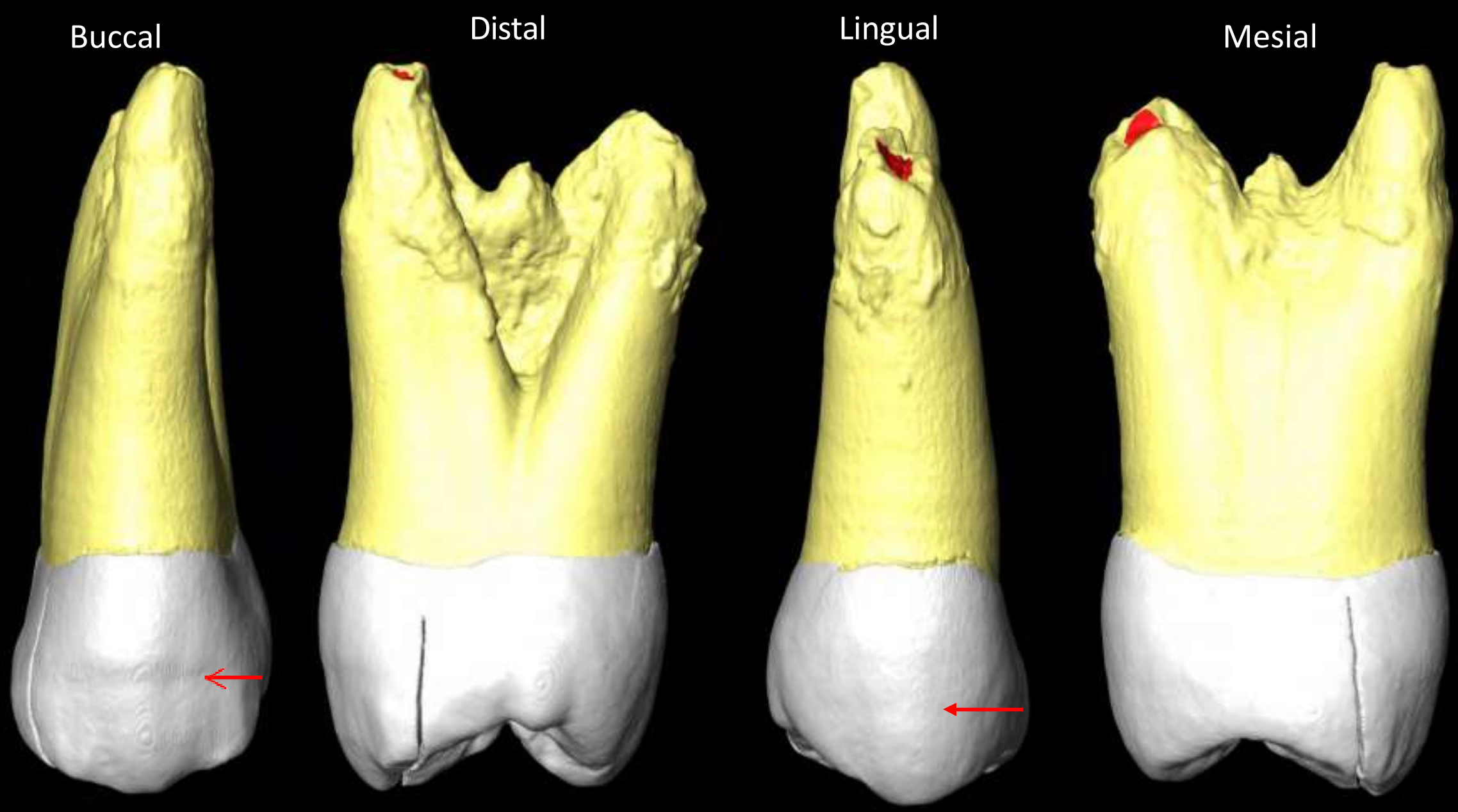

Occlusal

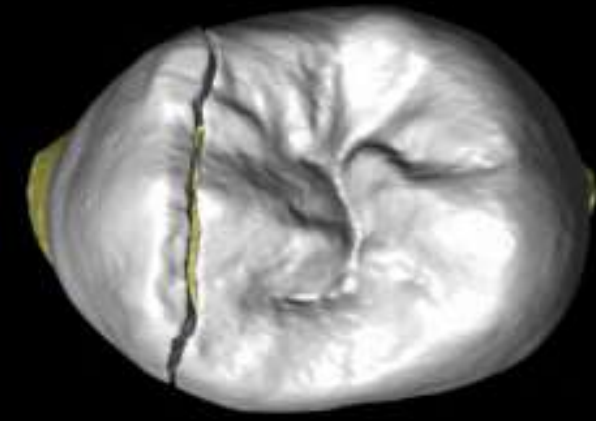

$3 \mathrm{~mm}$

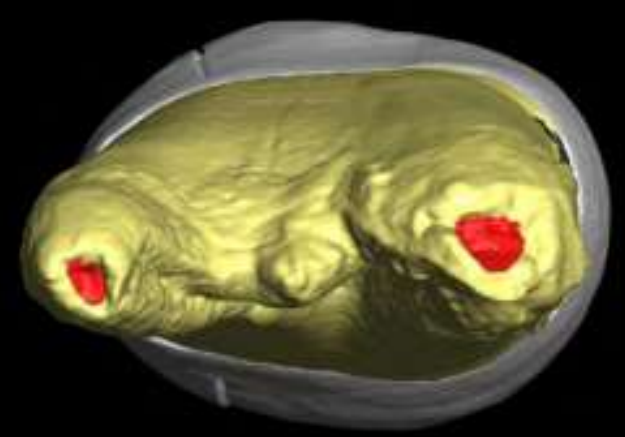

Apical 
M13G - ULP4 - EDJ

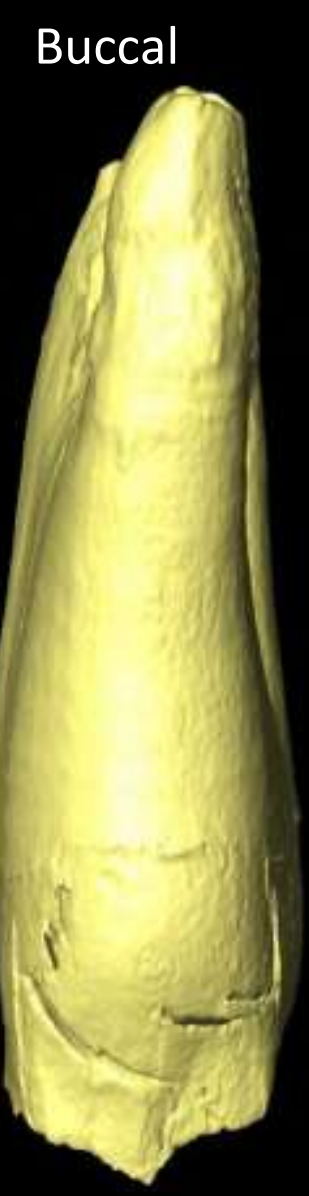

Distal

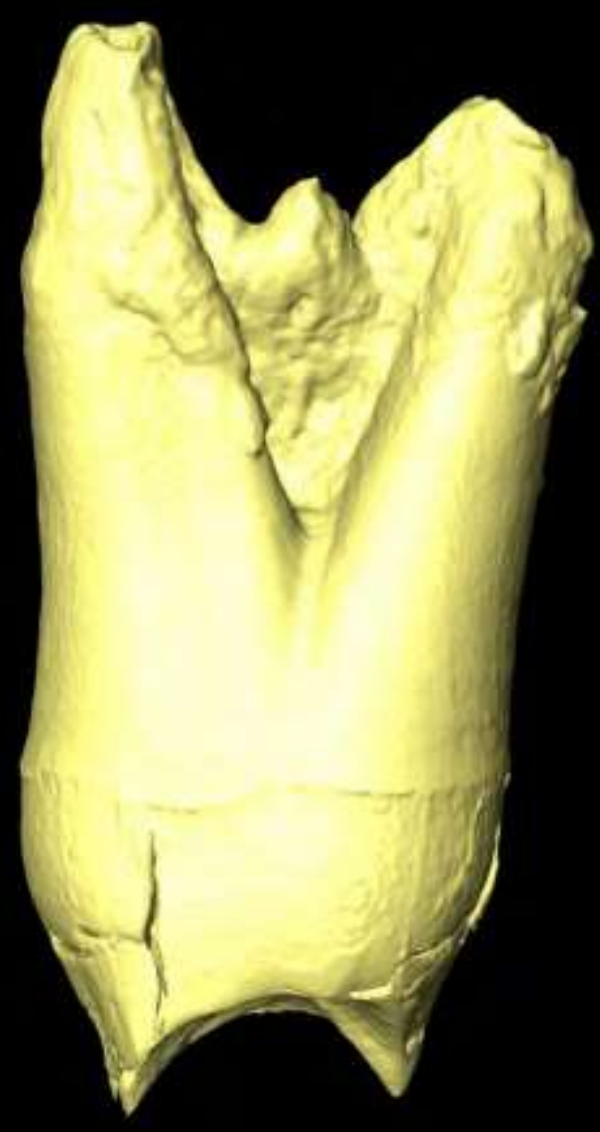

Lingual

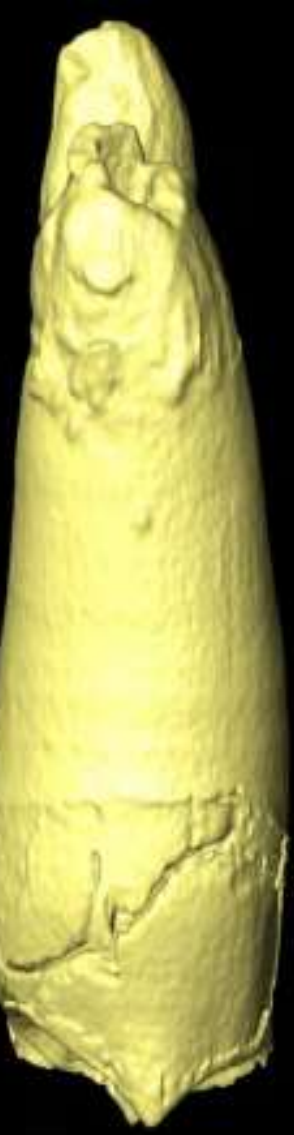

Mesial

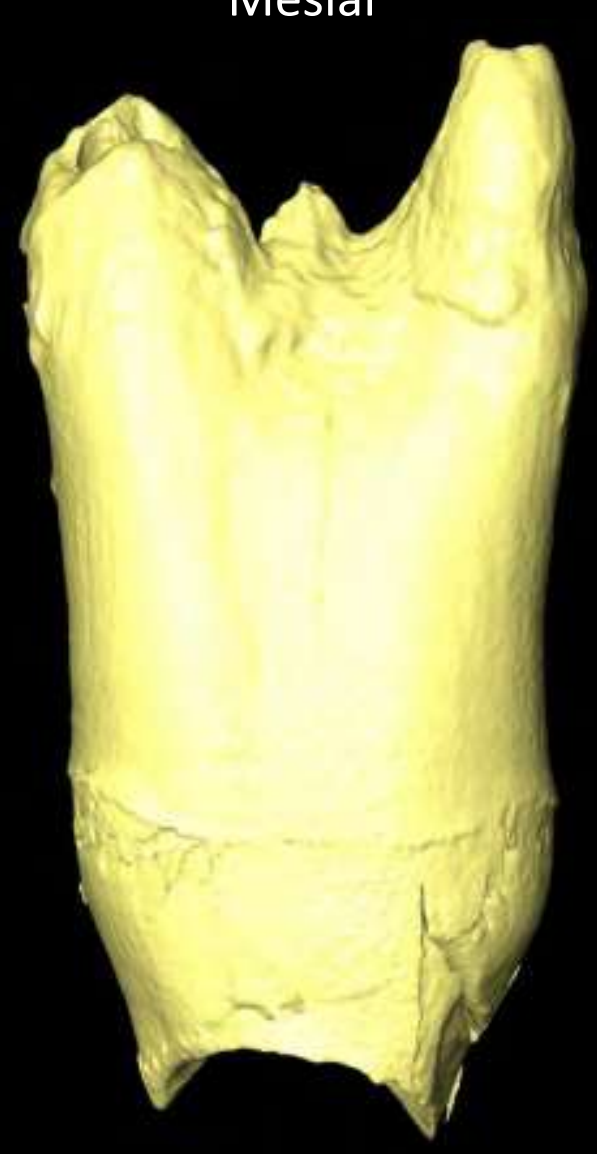

Occlusal

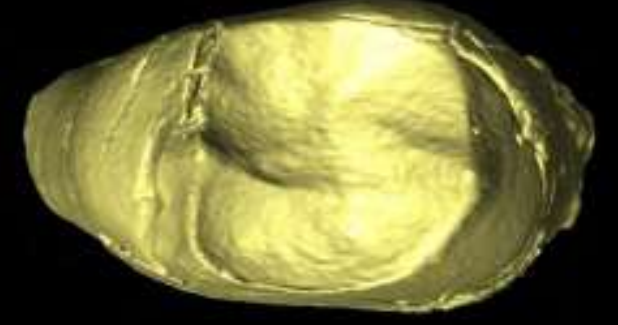

$3 \mathrm{~mm}$

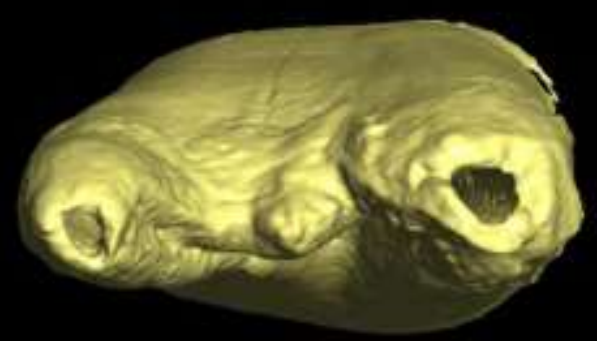

Apical 


\section{M13G - ULP4 - Pulp}

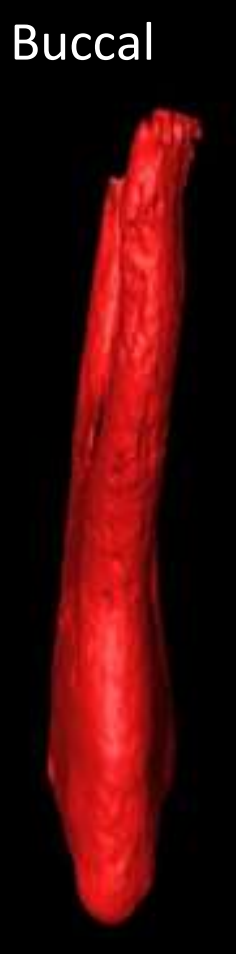

Distal

Lingual

Mesial
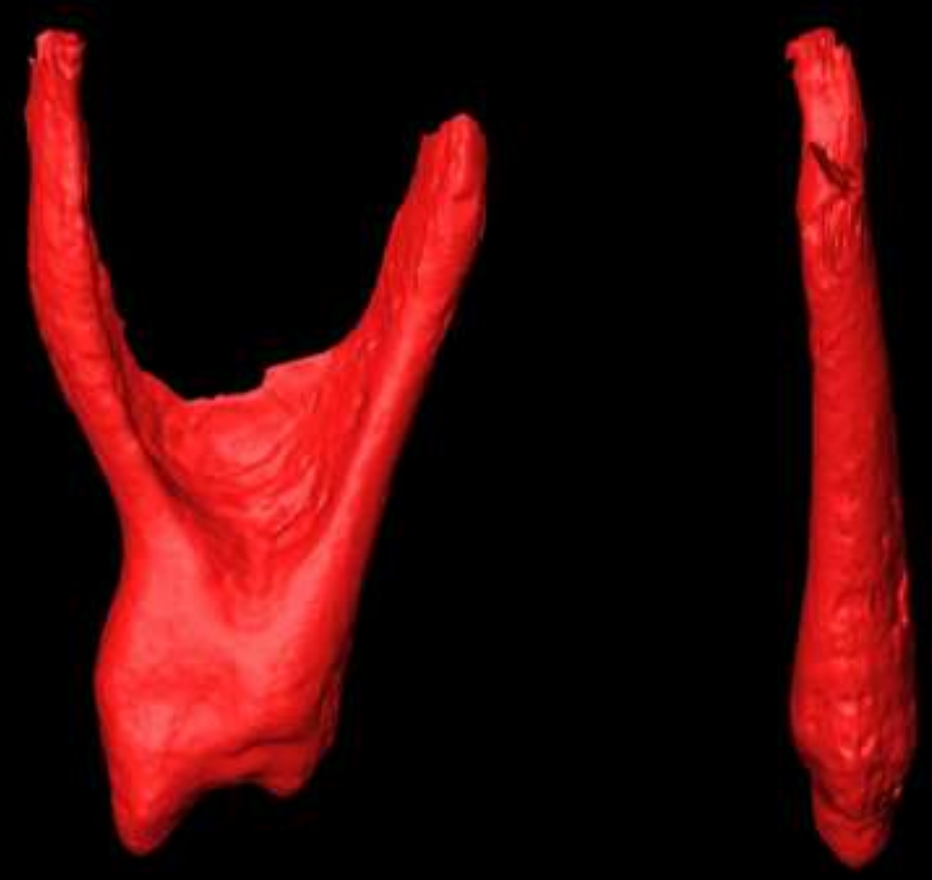

Occlusal 


\section{M13G - ULP4 - 2D sections}

Slices optimized for visualizing crown development

root
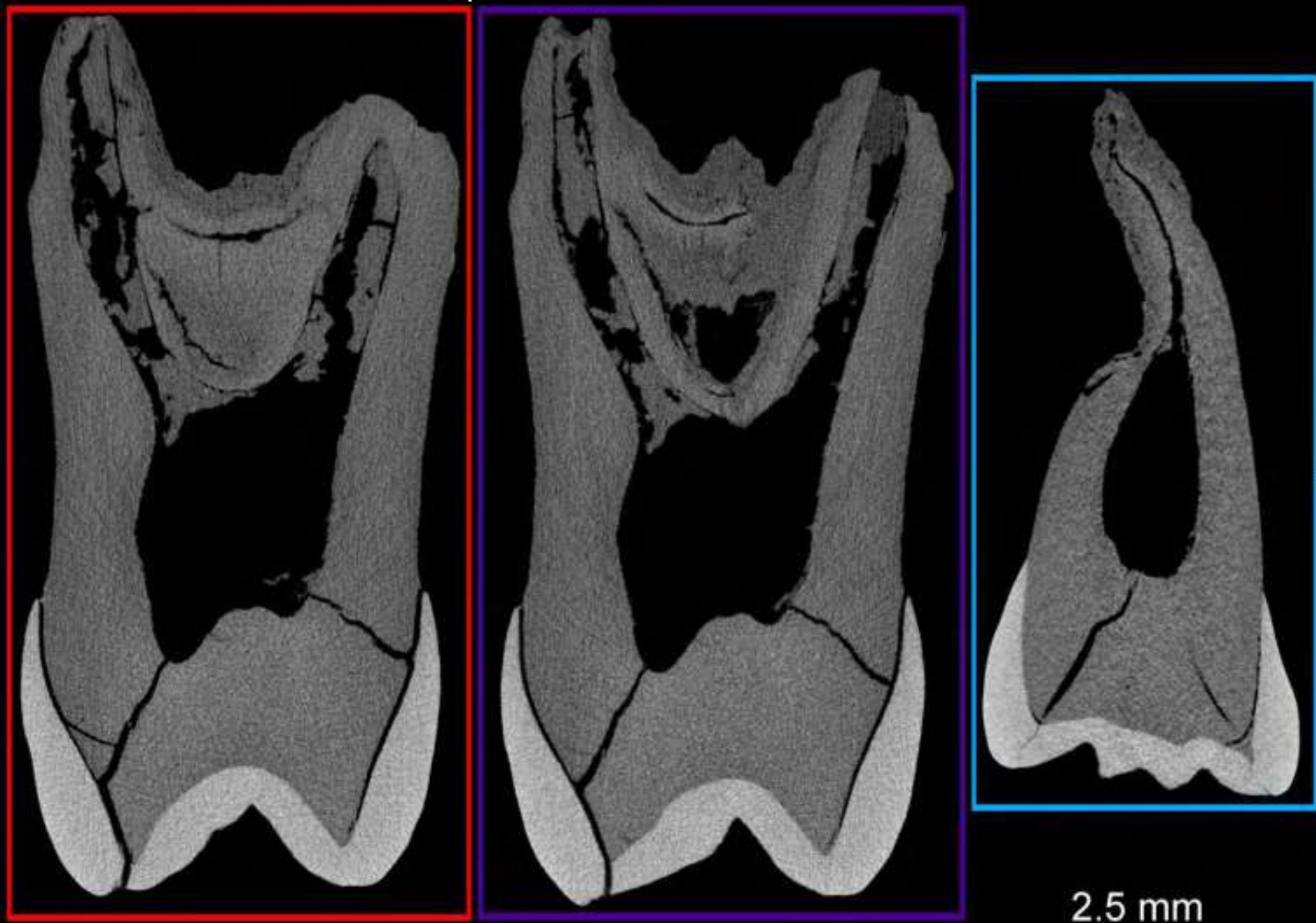

$2.5 \mathrm{~mm}$

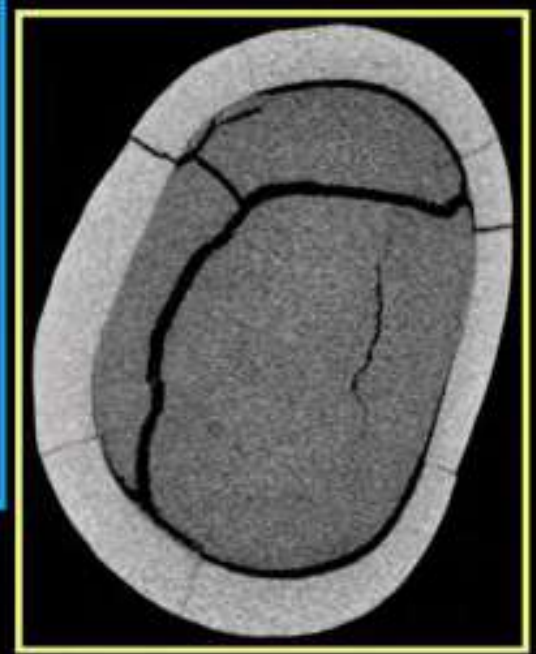




\section{M13G - ULP4 - Hypercementosis}
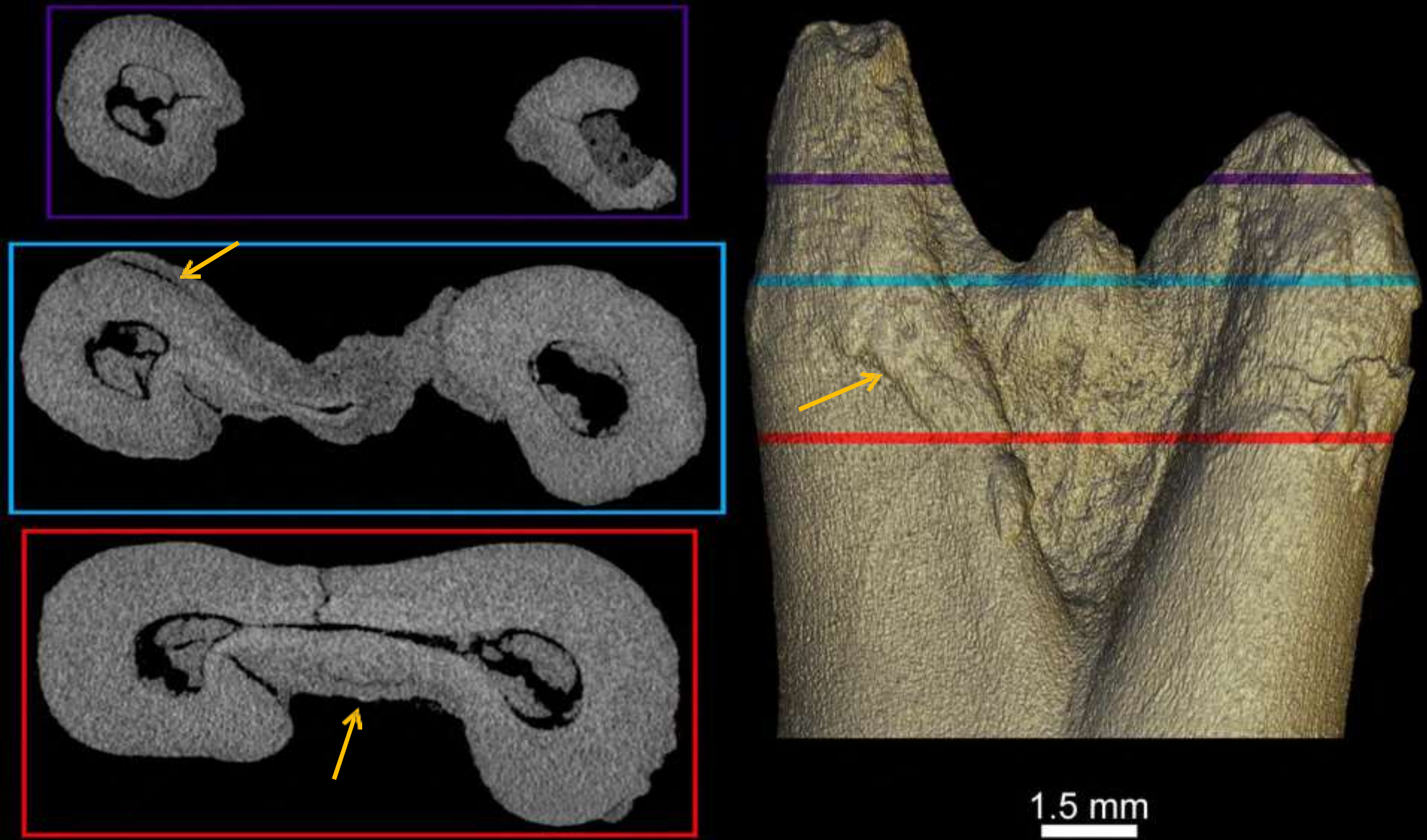

$1.5 \mathrm{~mm}$ 
Buccal

Distal

Lingual

Mesial
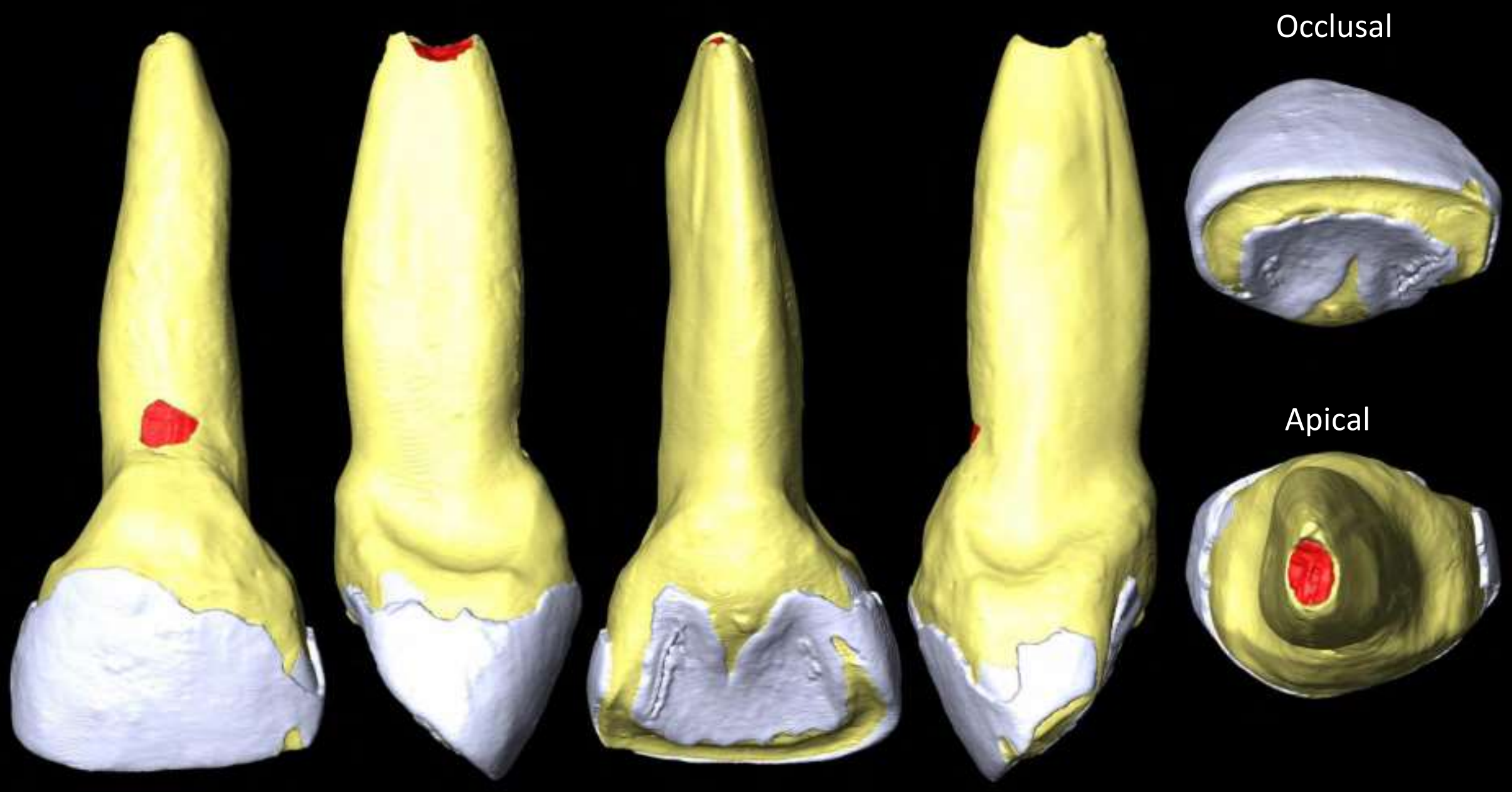


$$
\text { M14 - URI1 - EDJ }
$$

Buccal

Distal

Lingual
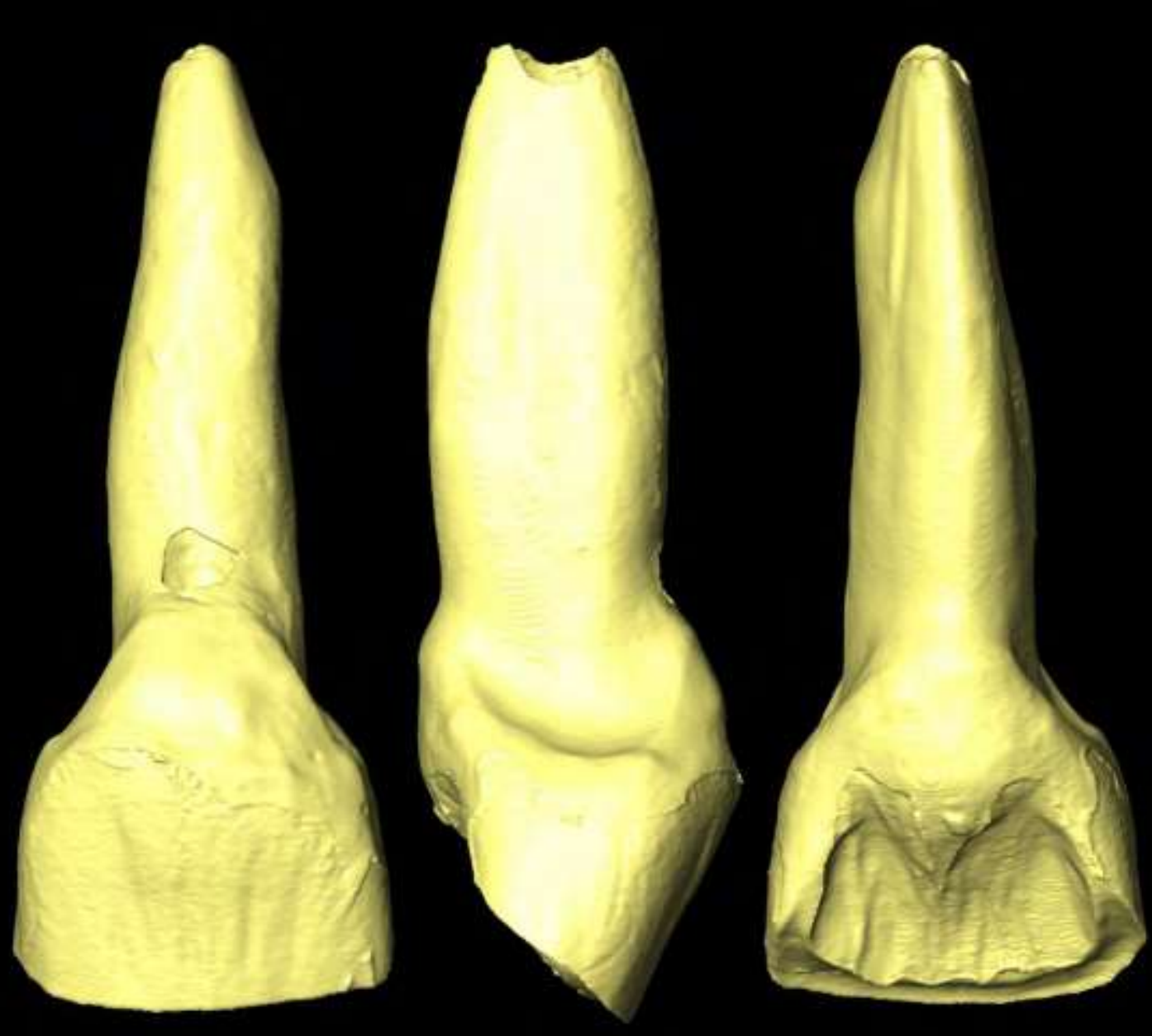

Mesial
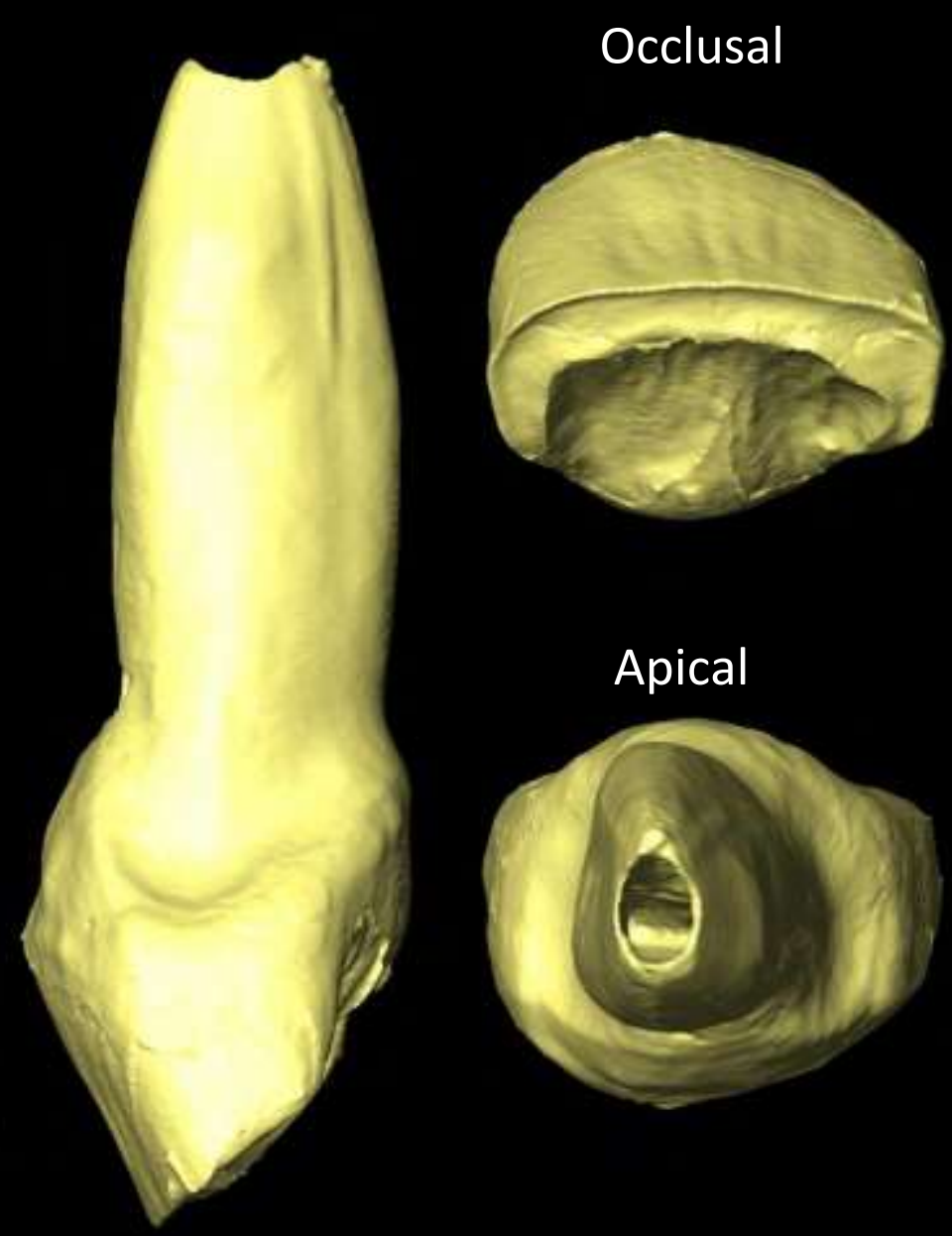


$$
\text { M14 - URI1 - Pulp }
$$

Buccal

Distal

Lingual

Mesial

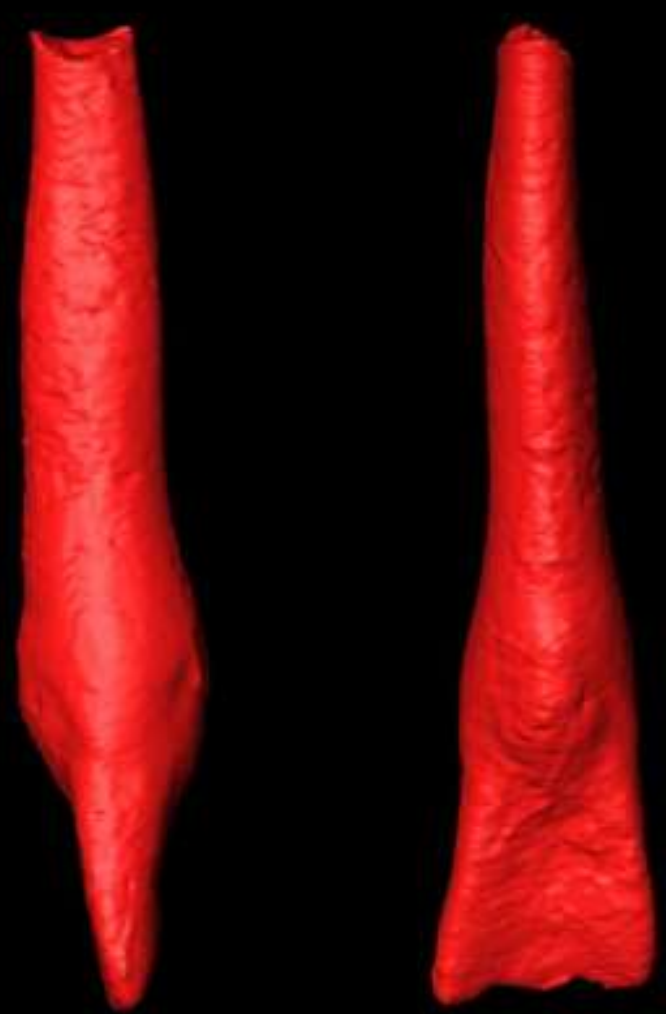

Occlusal

Apical

$3 \mathrm{~mm}$ 

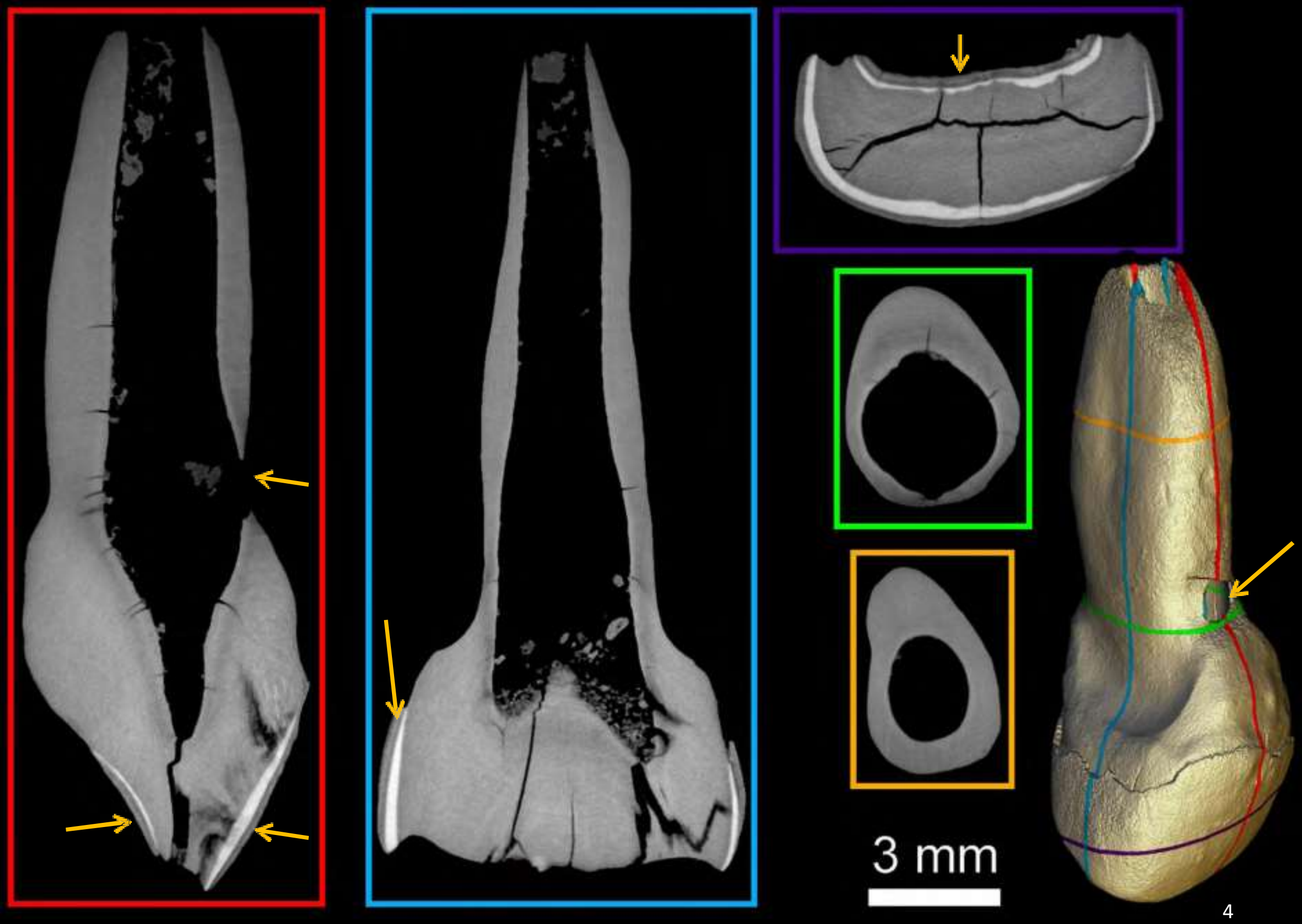

$3 \mathrm{~mm}$ 


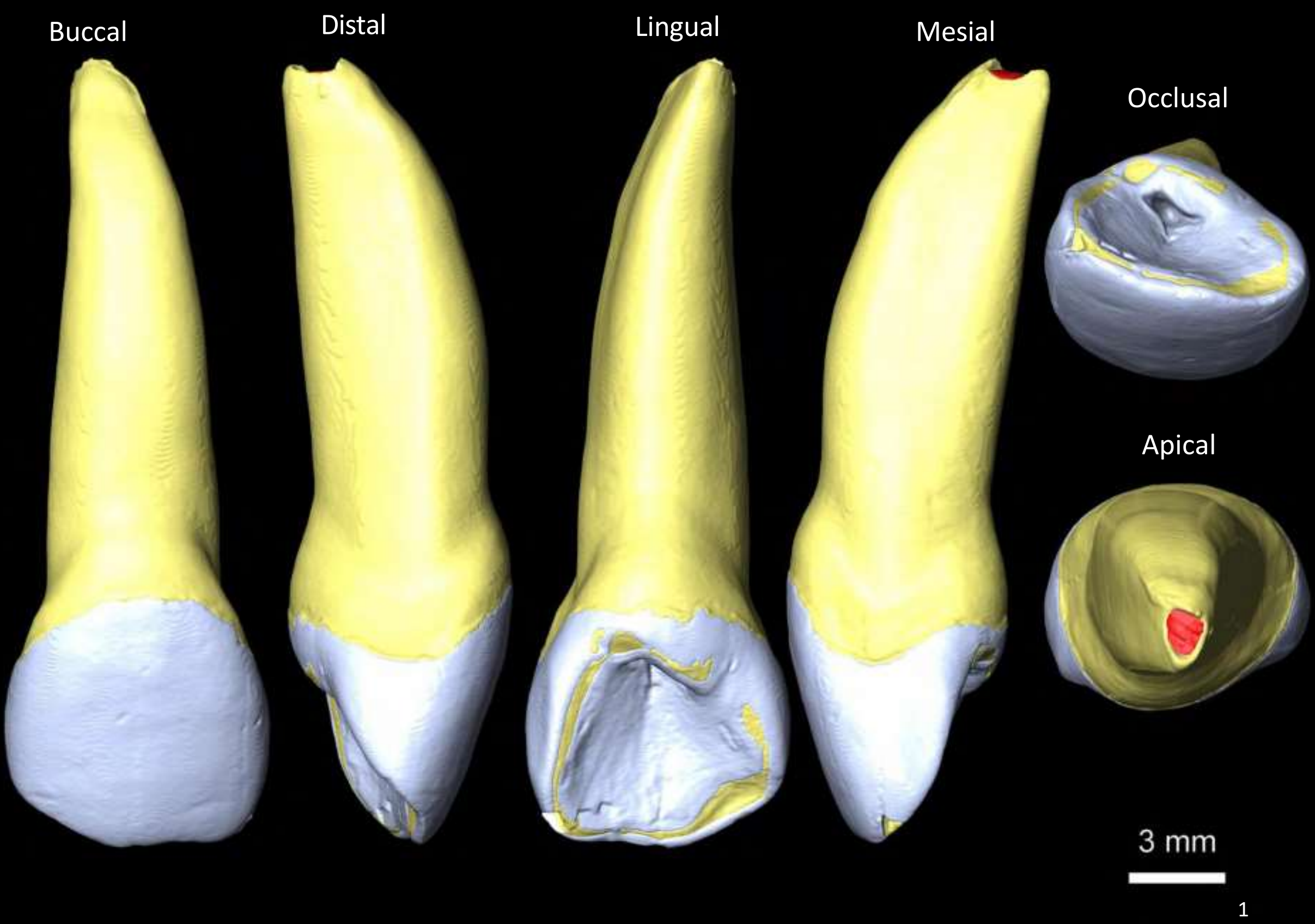




$$
\text { M15 - URI2 - EDJ }
$$
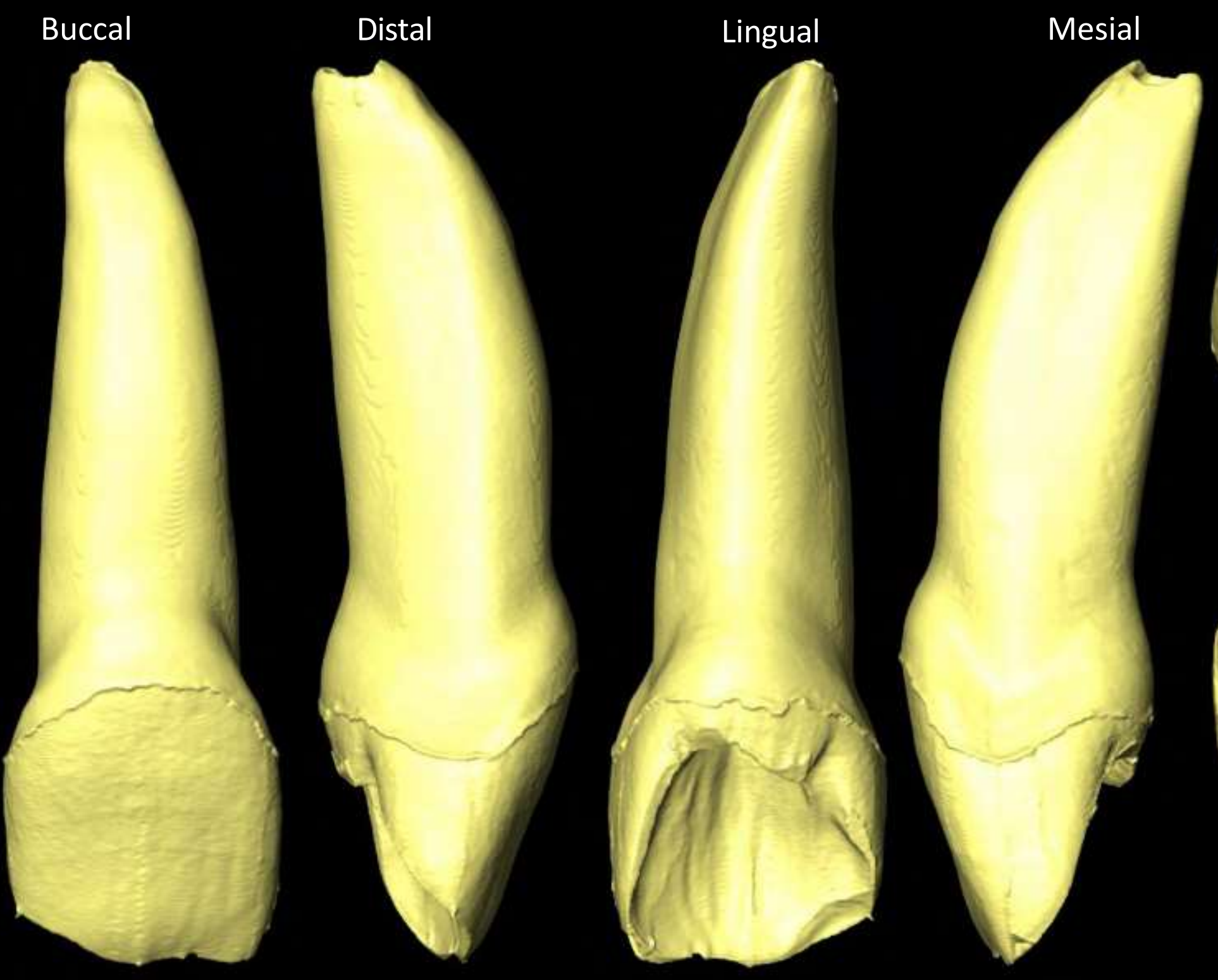

Occlusal

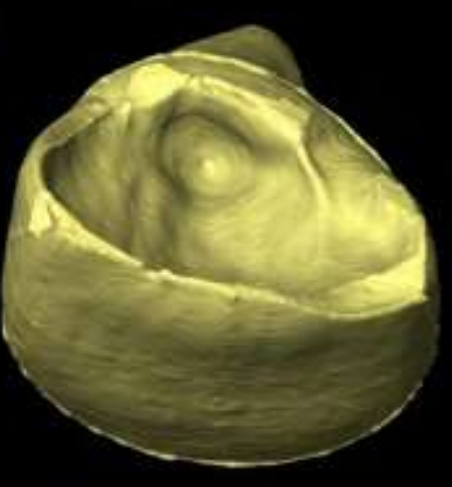

Apical

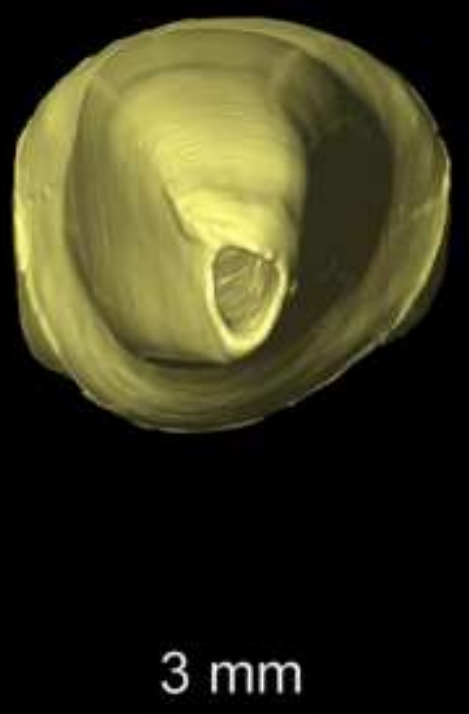




\section{M15 - URI2 - Pulp}

Buccal

Distal

Lingual
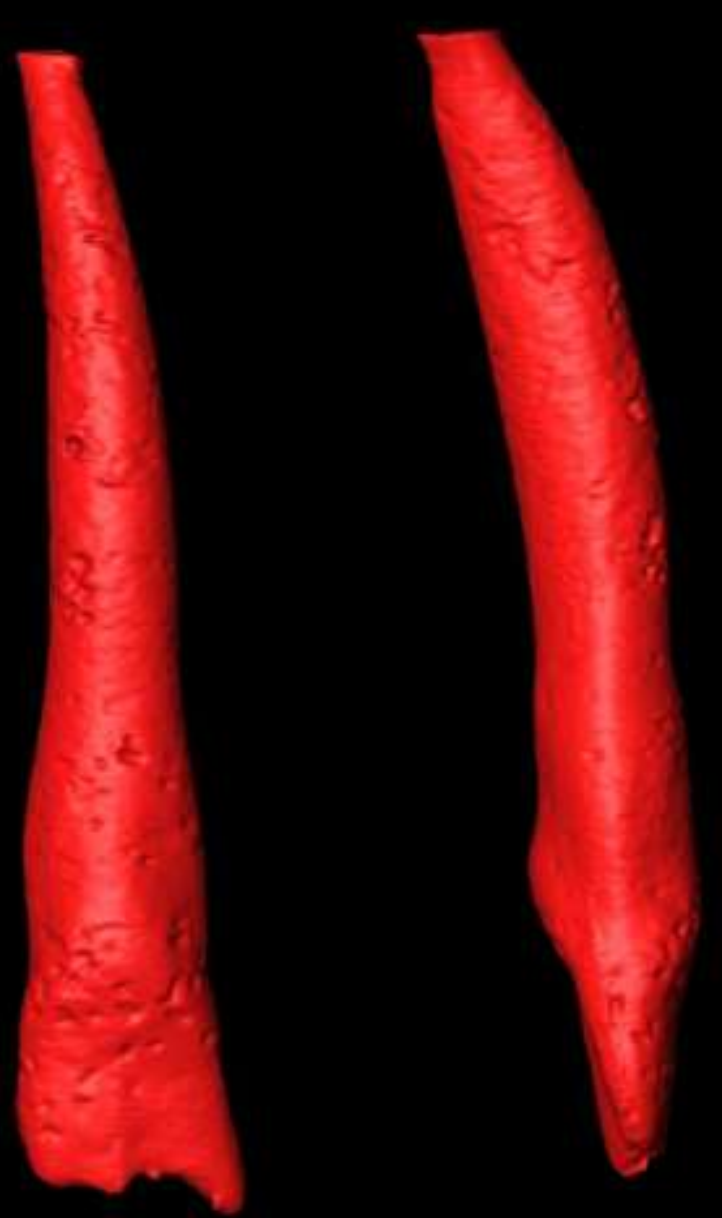

PARTIALLY DIGESTED

\section{Mesial}

Occlusal

Apical

$3 \mathrm{~mm}$ 


\section{M16 - ULI2}
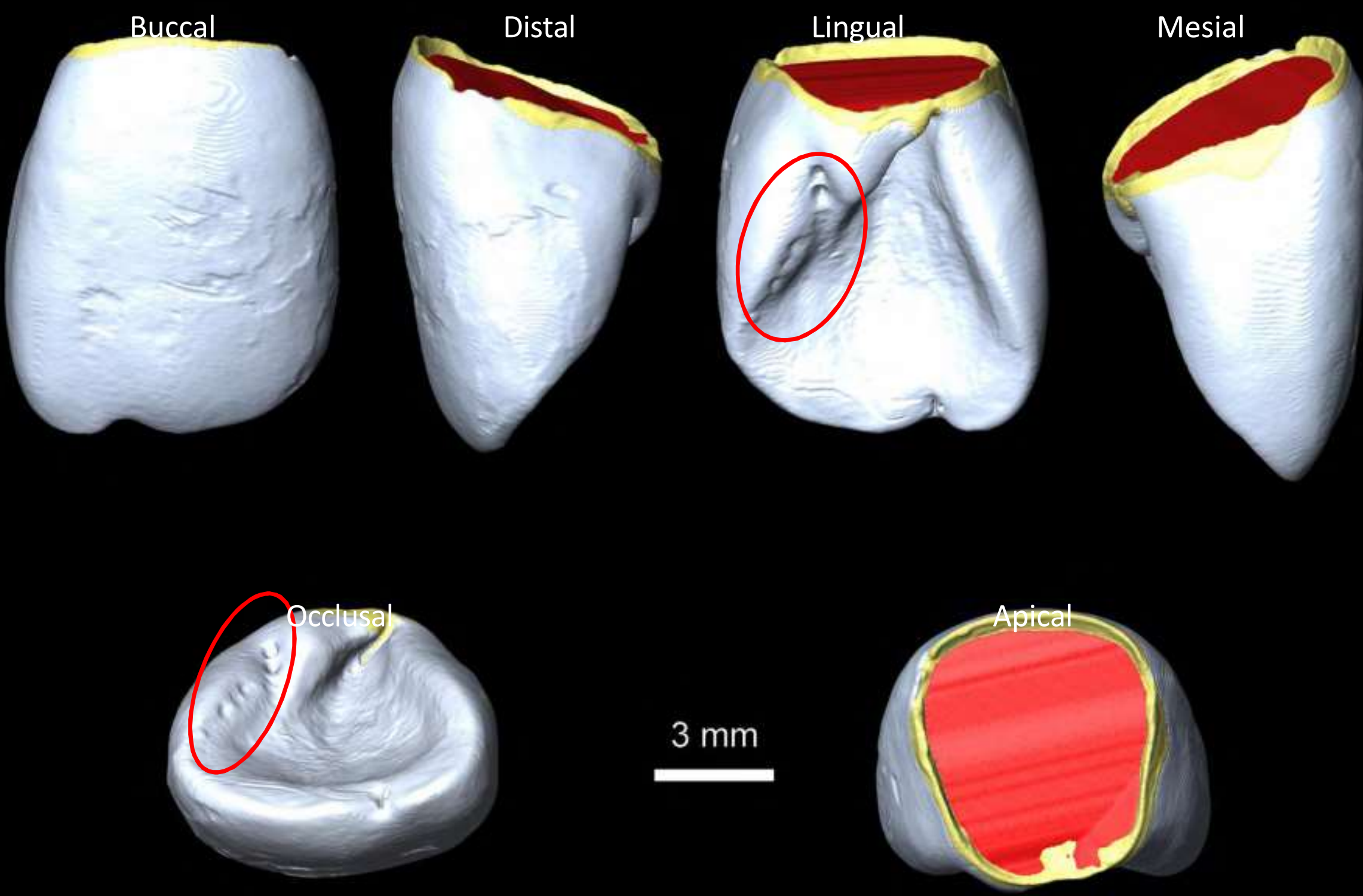



\section{M16 - ULI2 - EDJ}

Buccal

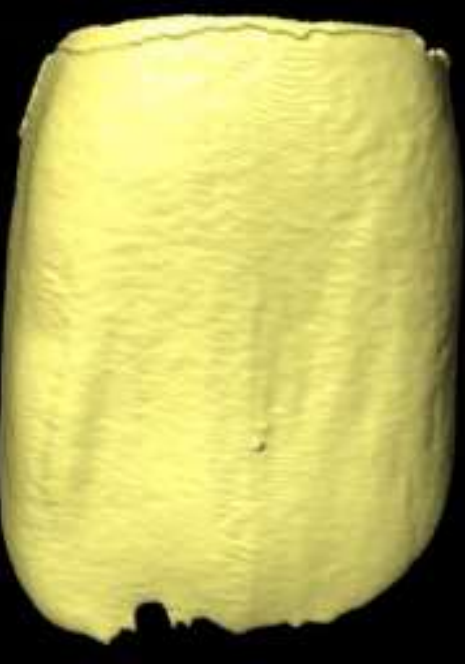

Distal

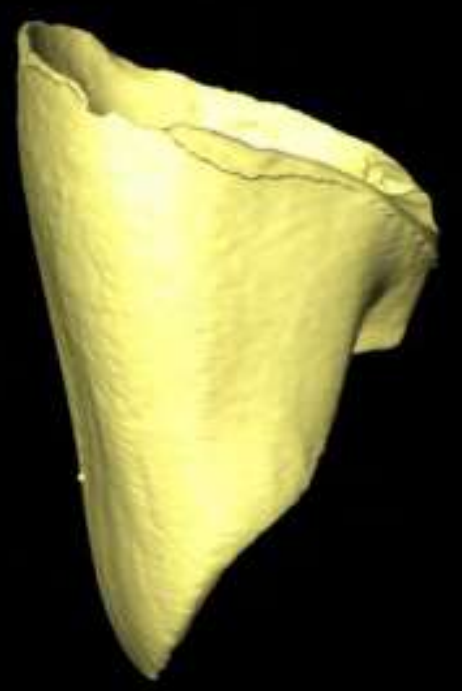

Lingual

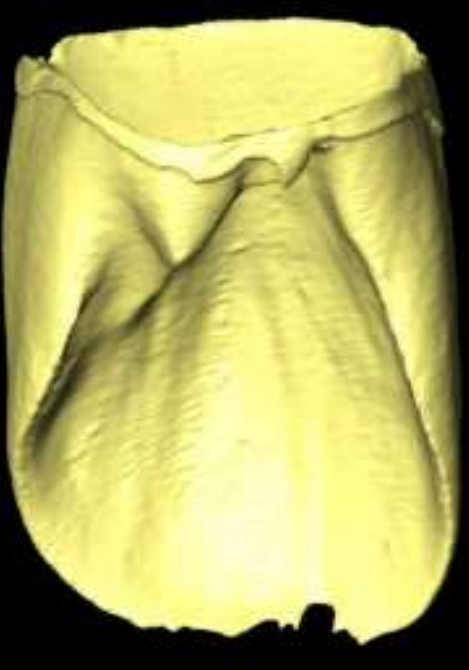

PARTIALLY DIGESTED

Mesial

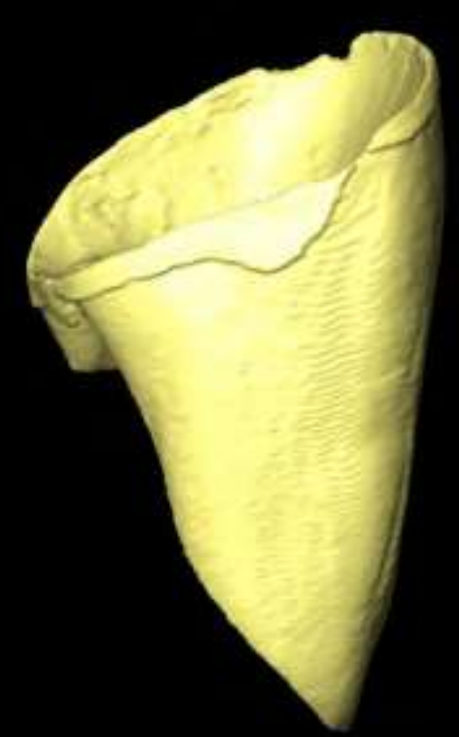

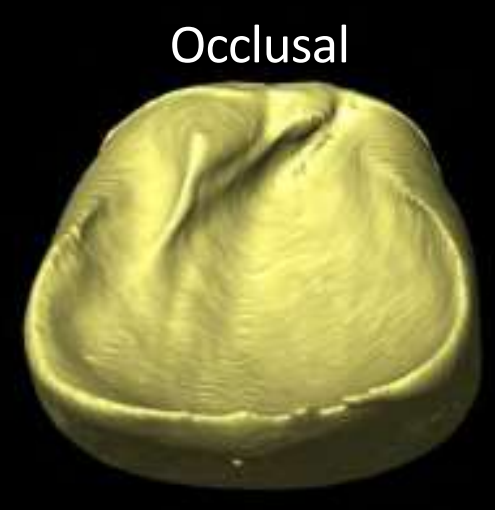

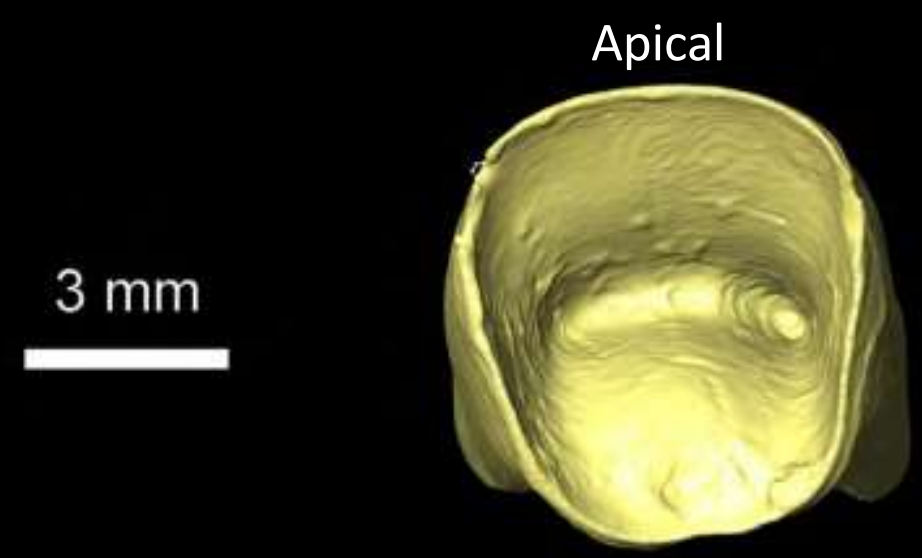


M16 - ULI2 - Pulp

Buccal

Distal

Lingual

Mesial

Occlusal

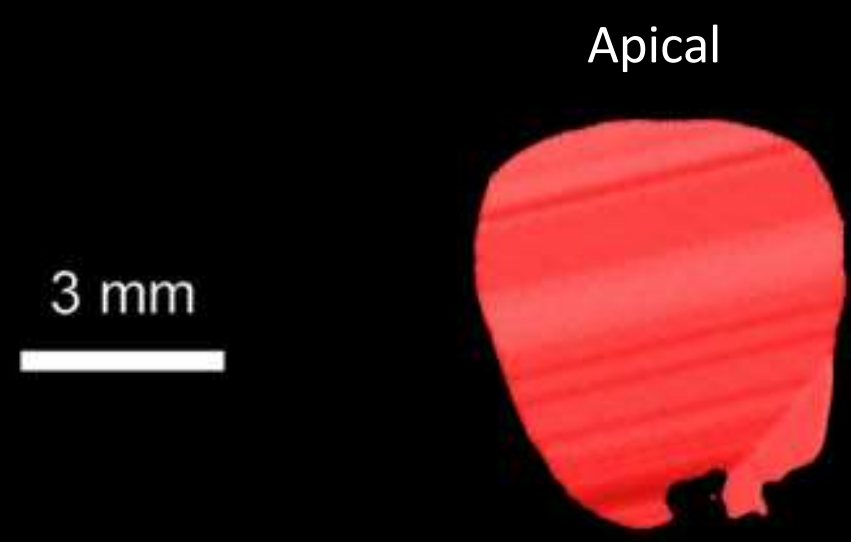




$$
\text { M16 - ULI2 - 2D sections }
$$
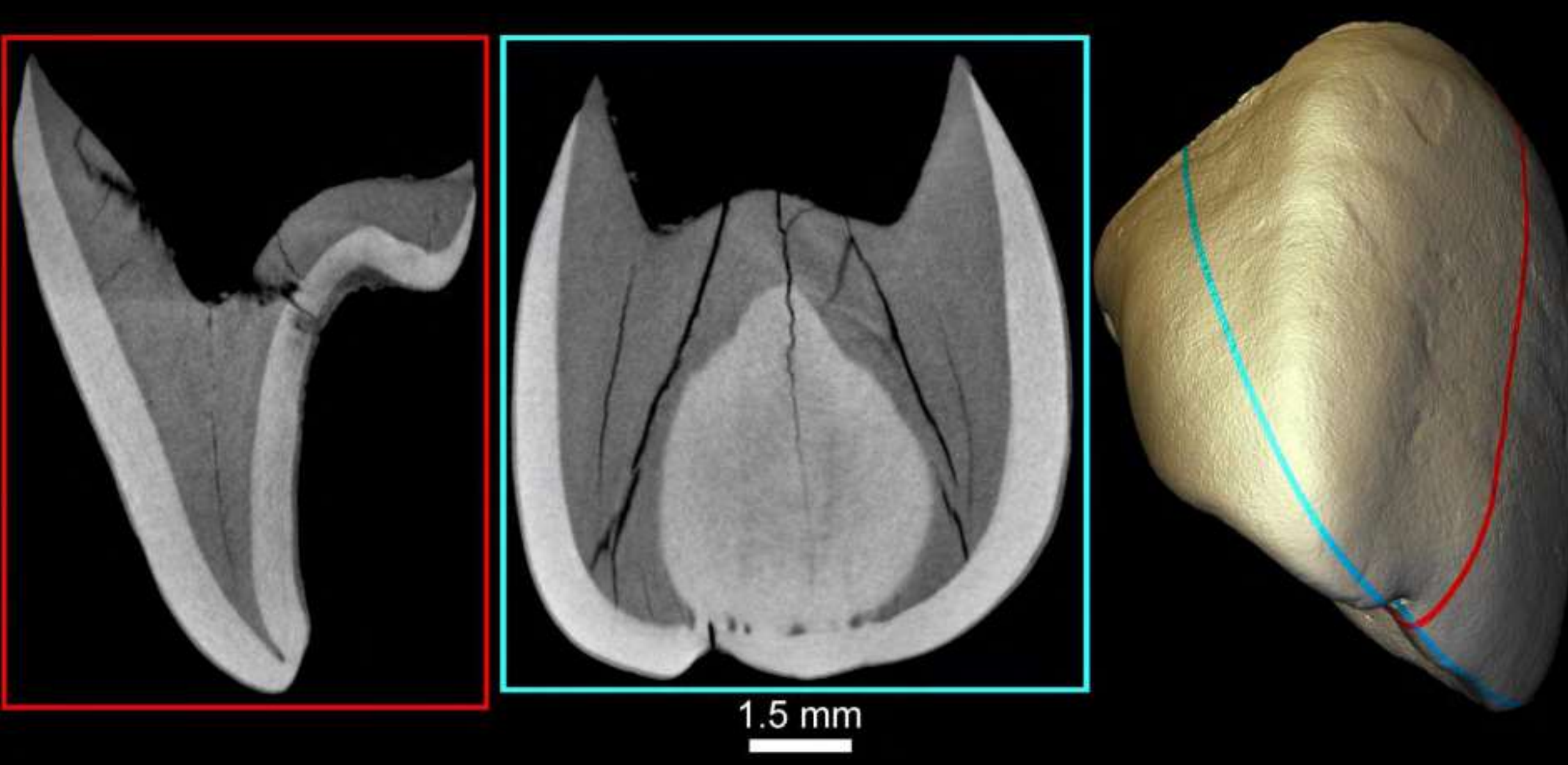


\section{M17 - URI2}

Buccal

Distal

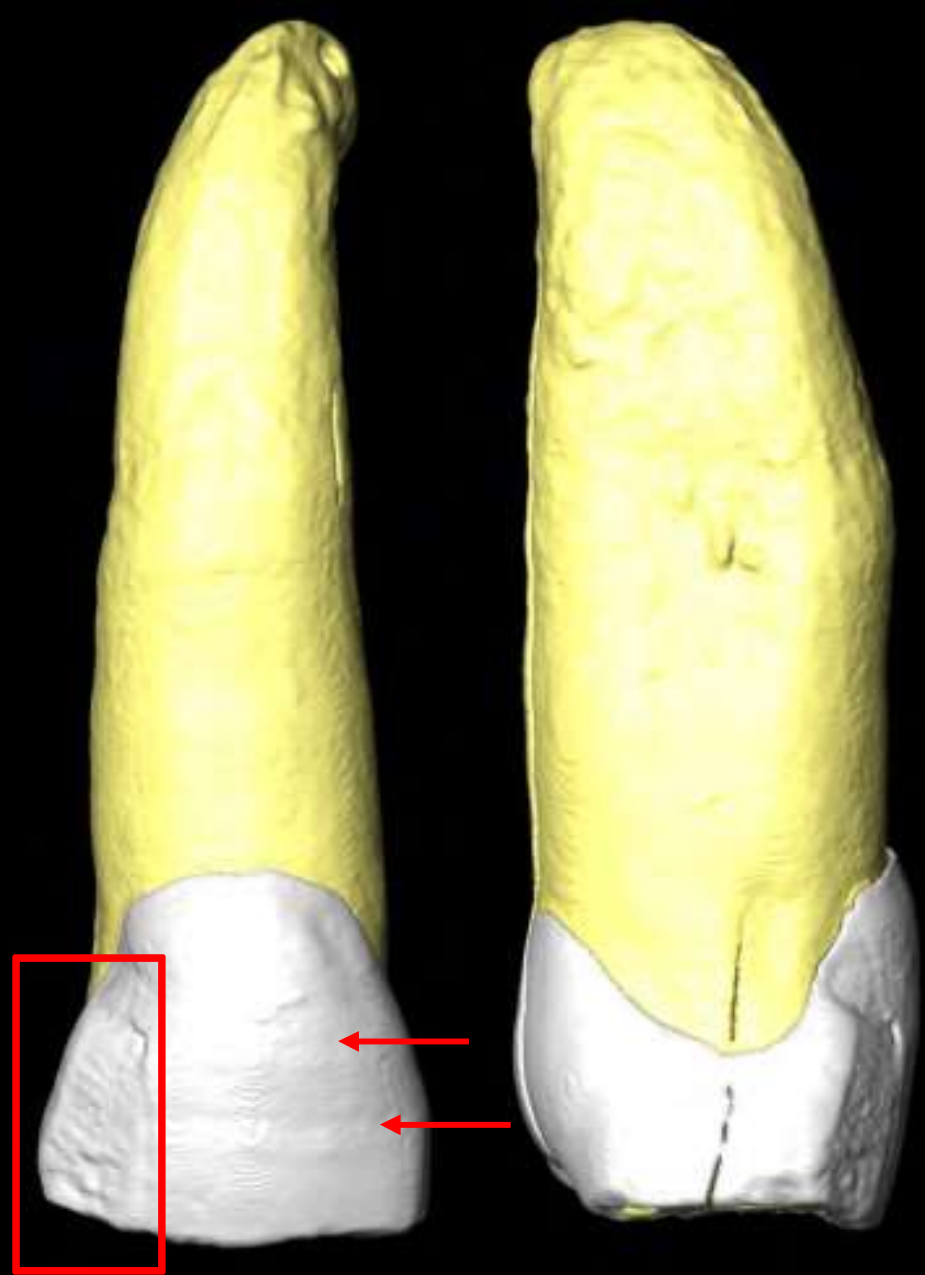

Lingual

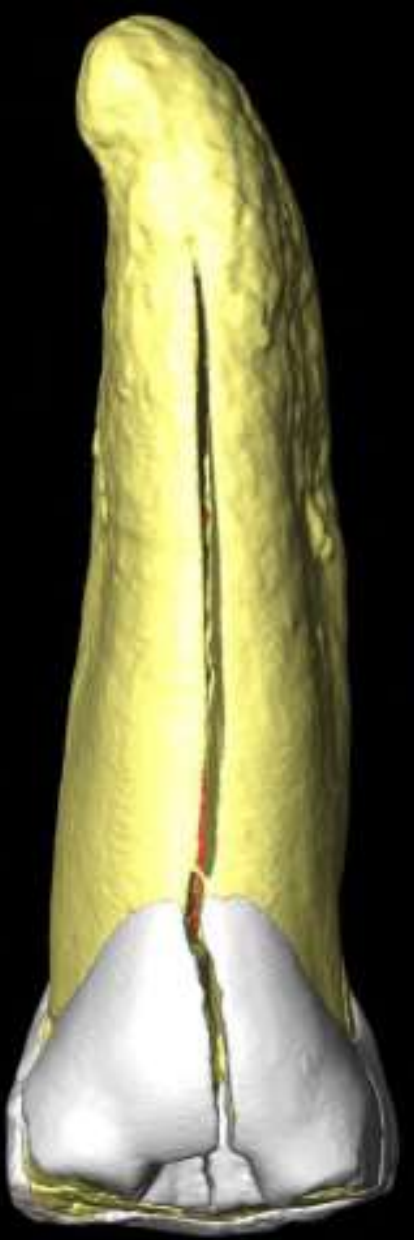

Mesial

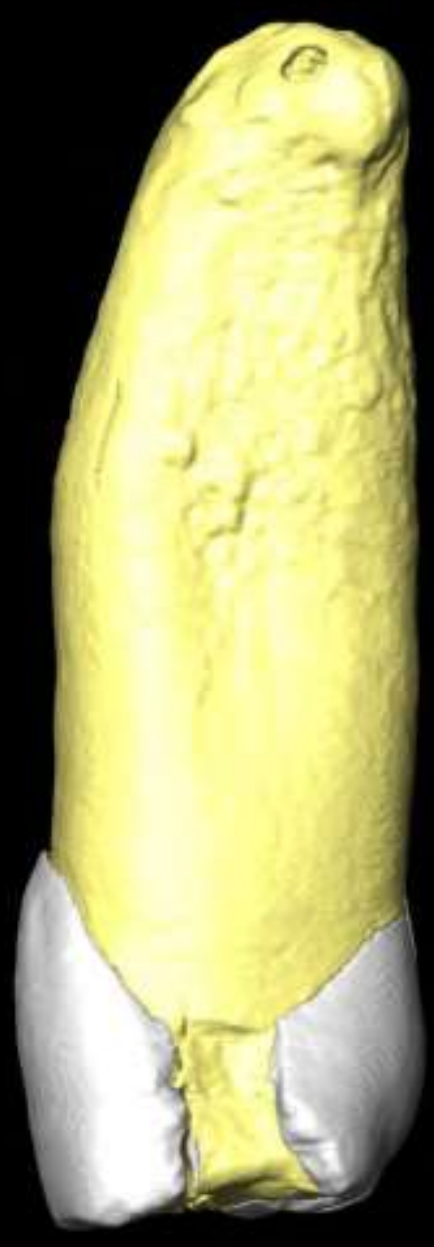

Apical

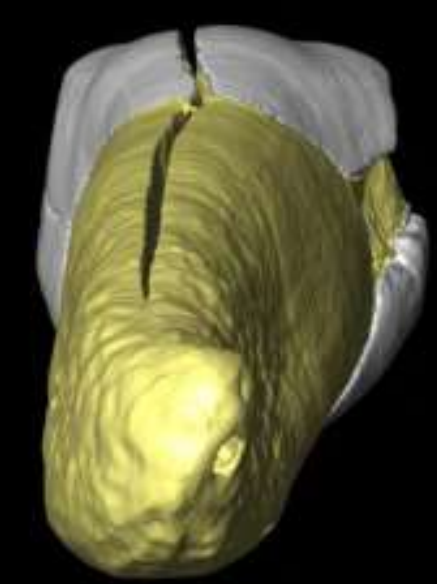

$3 \mathrm{~mm}$

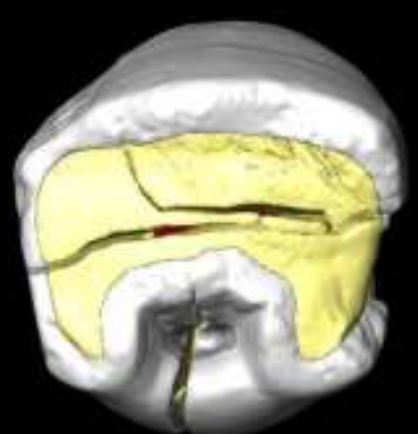

Occlusal 


\section{M17 - URI2 - EDJ}

Buccal

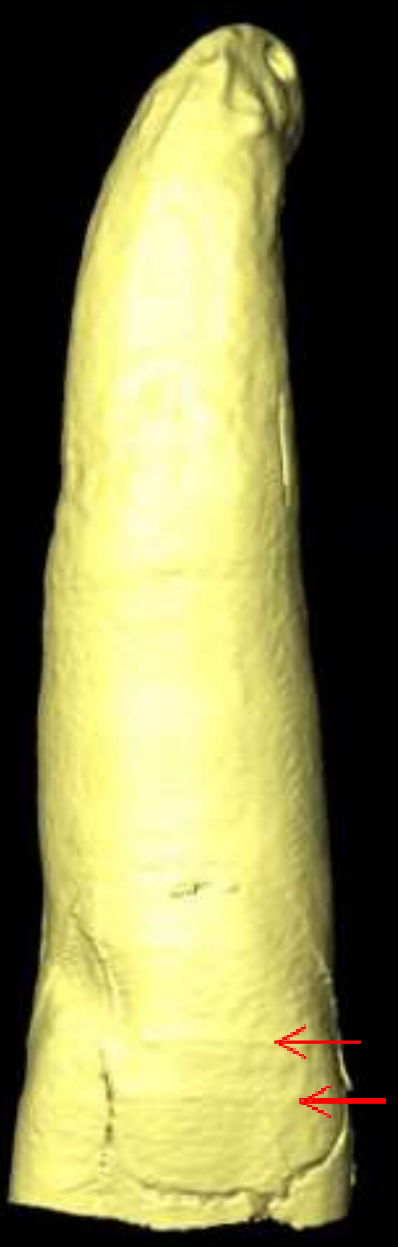

Distal

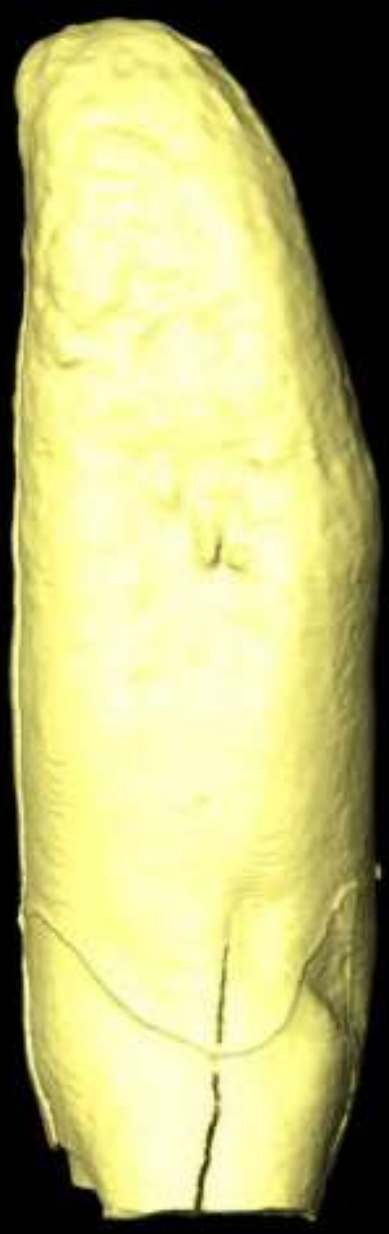

Lingual

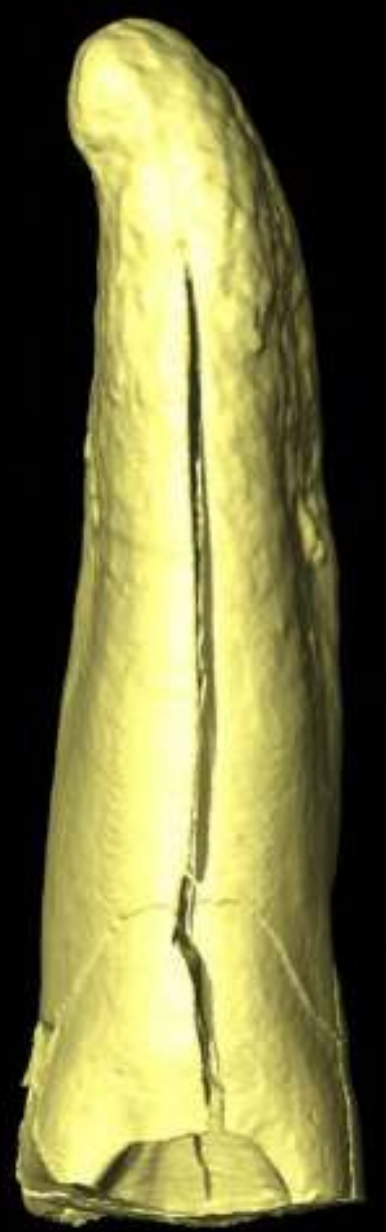

Mesial

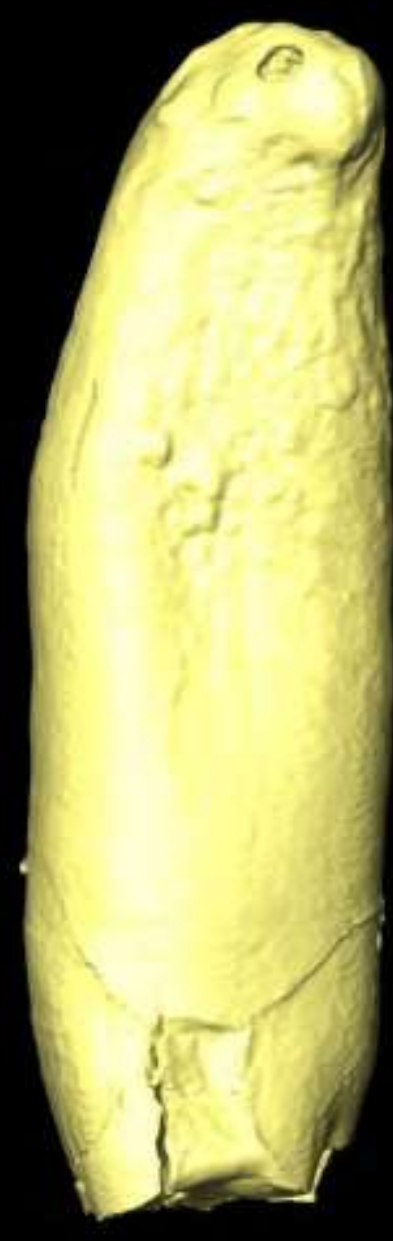

Apical

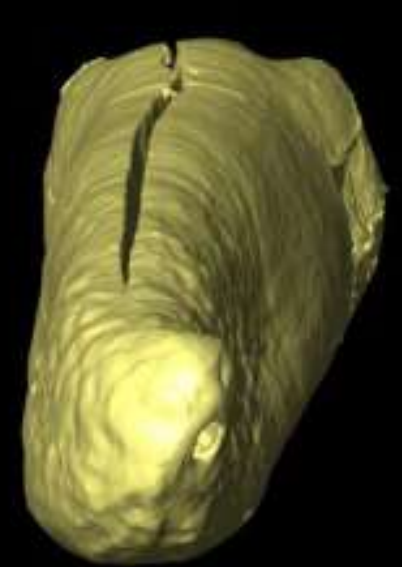

$3 \mathrm{~mm}$

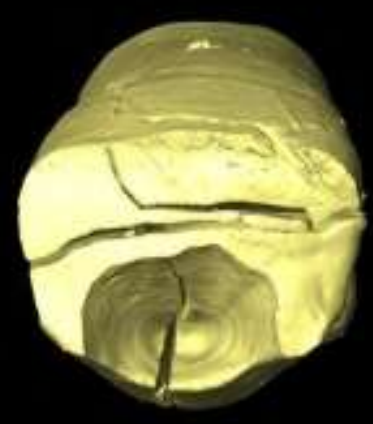

Occlusal 


\section{M17 - URI2 - Pulp}

Buccal

Distal

Lingual

Mesial

Apical
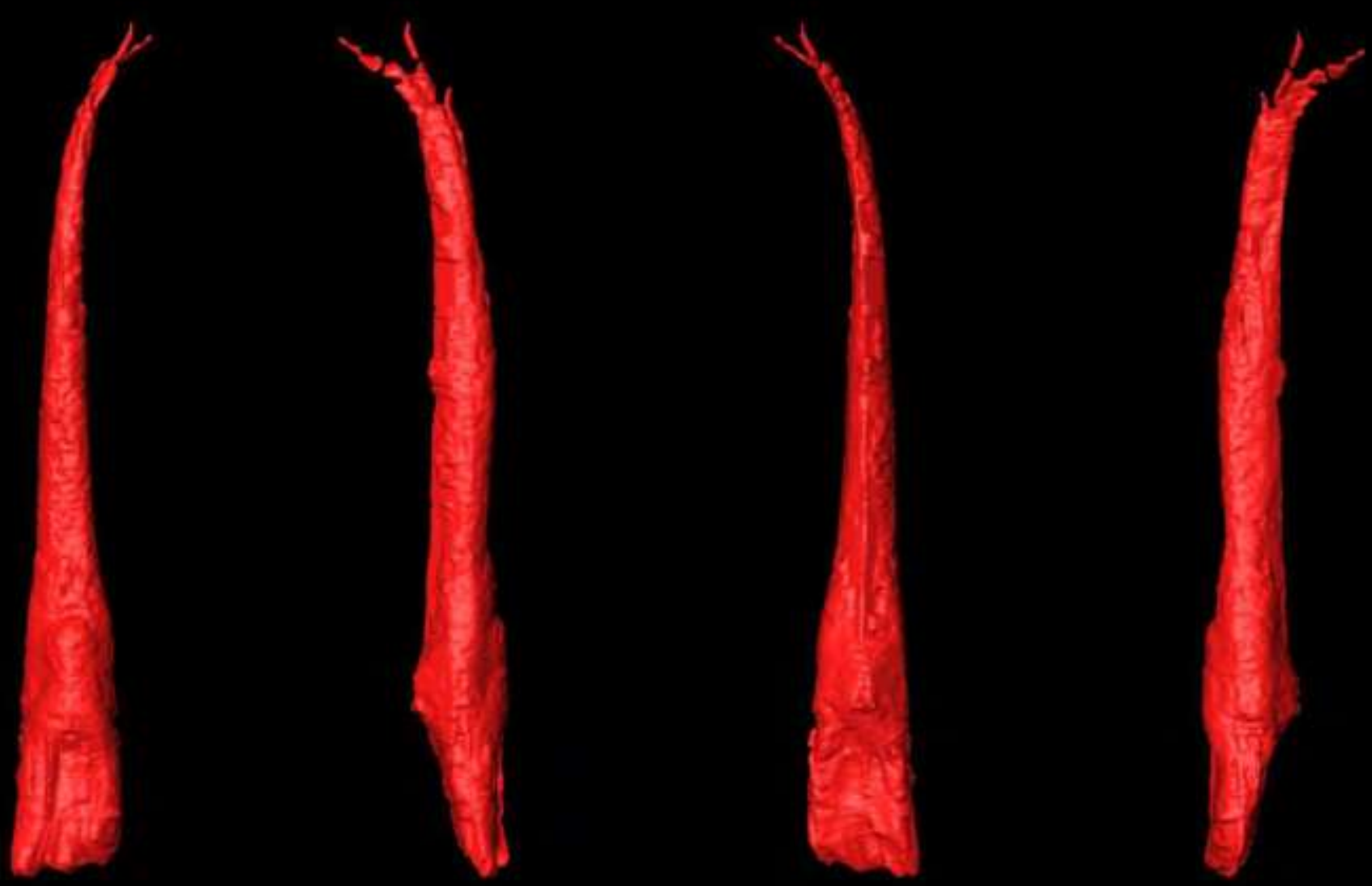

$3 \mathrm{~mm}$

Occlusal 

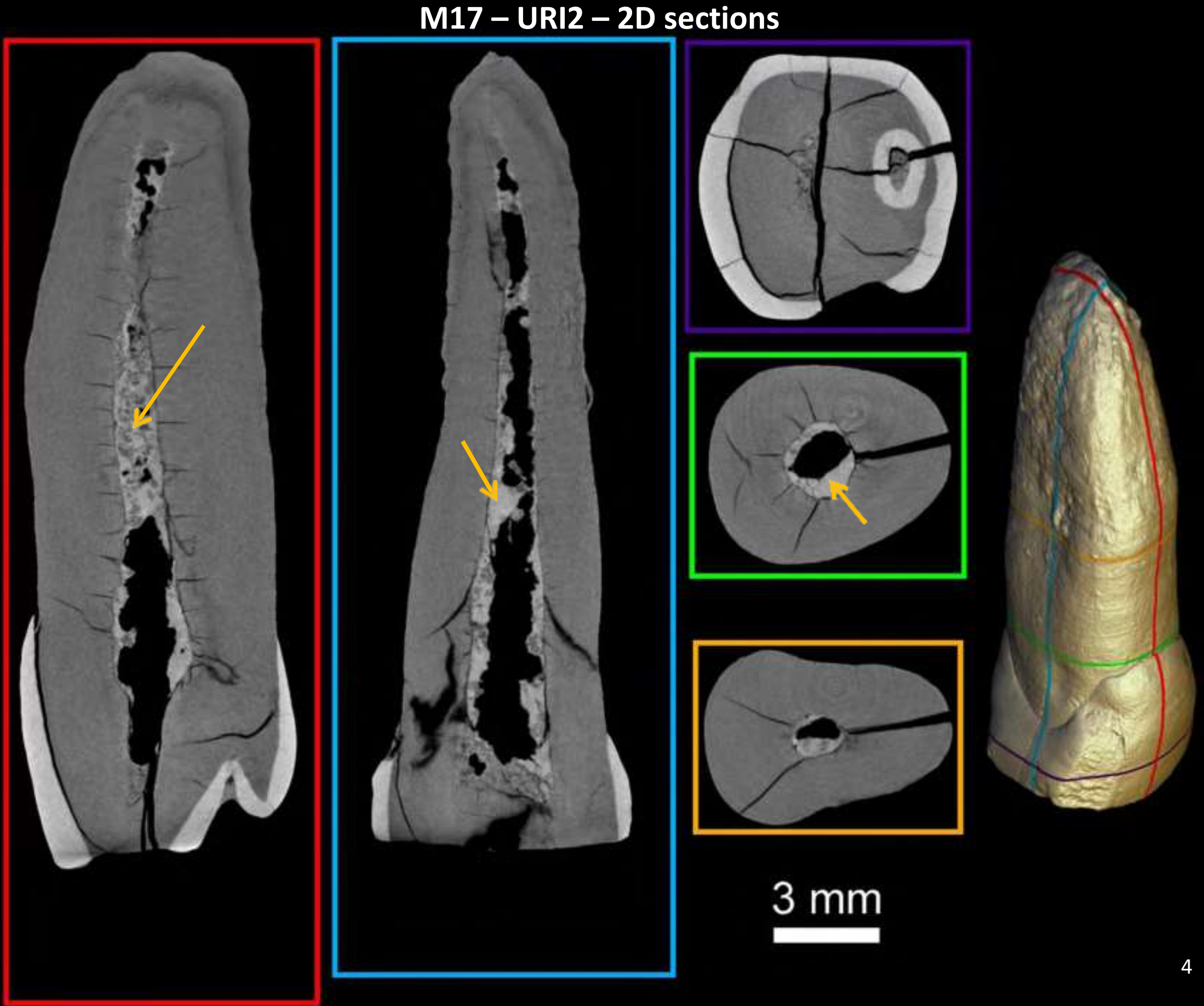

$3 \mathrm{~mm}$ 


\section{M17 - URI2 - Hypercementosis}
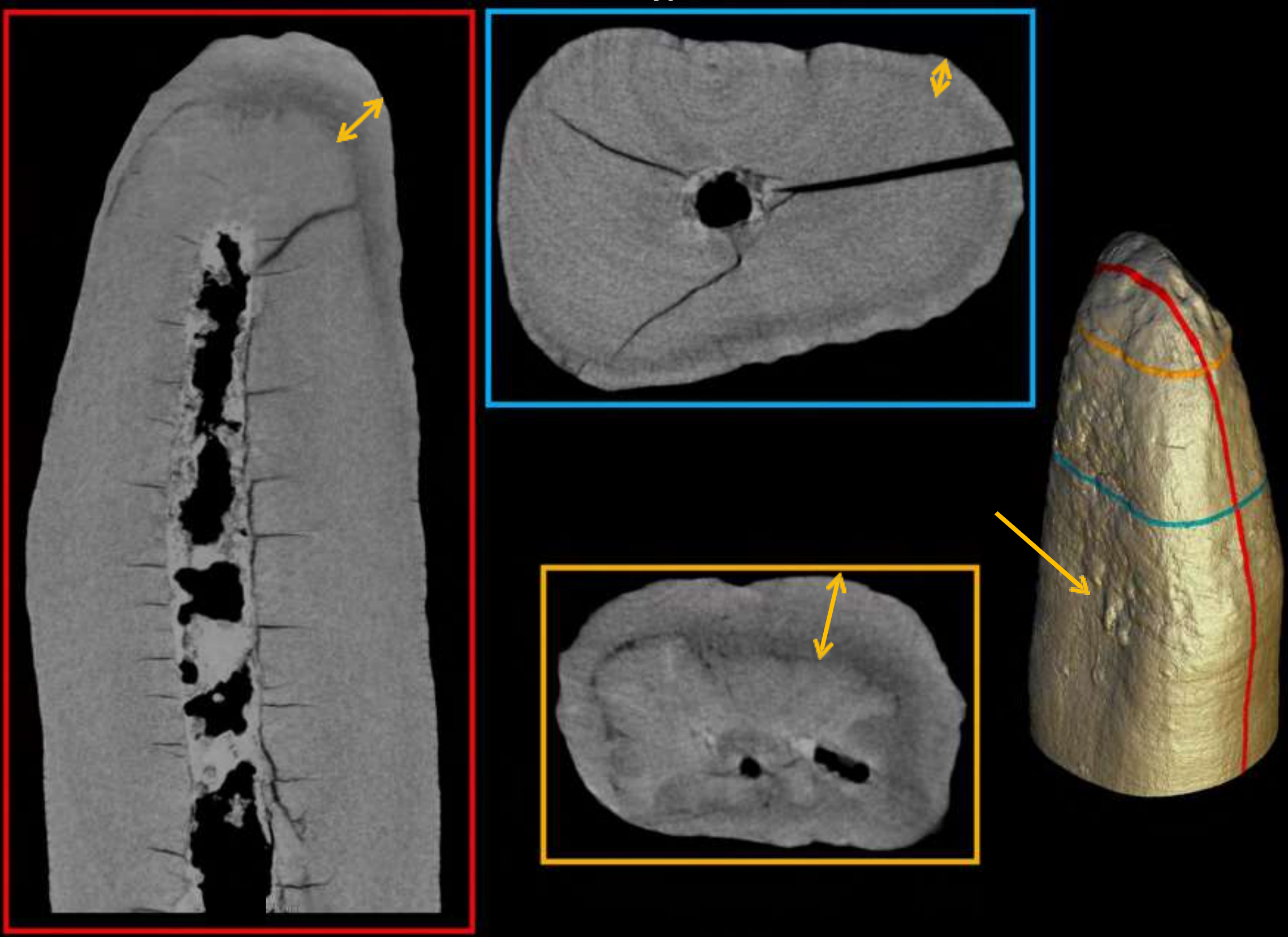

$2 \mathrm{~mm}$ 
M18 - ULP3

\section{Buccal}

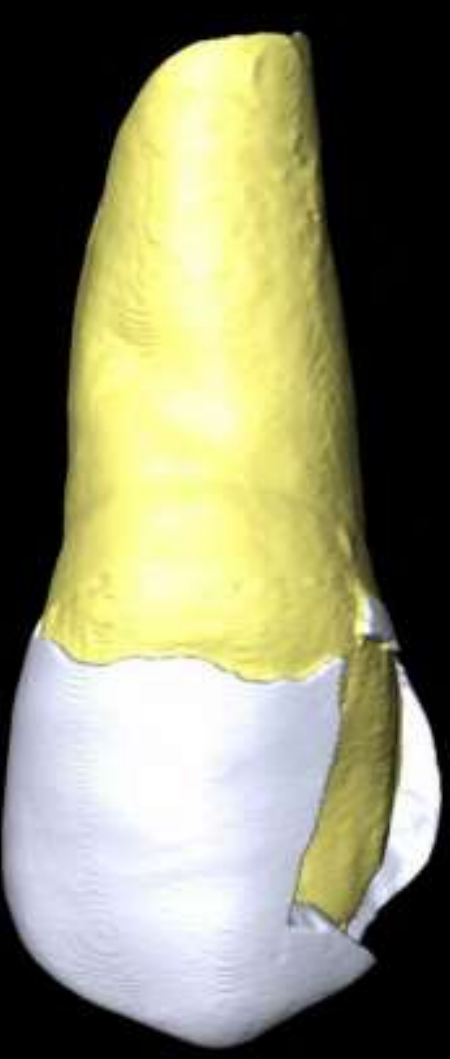

Distal

Lingual

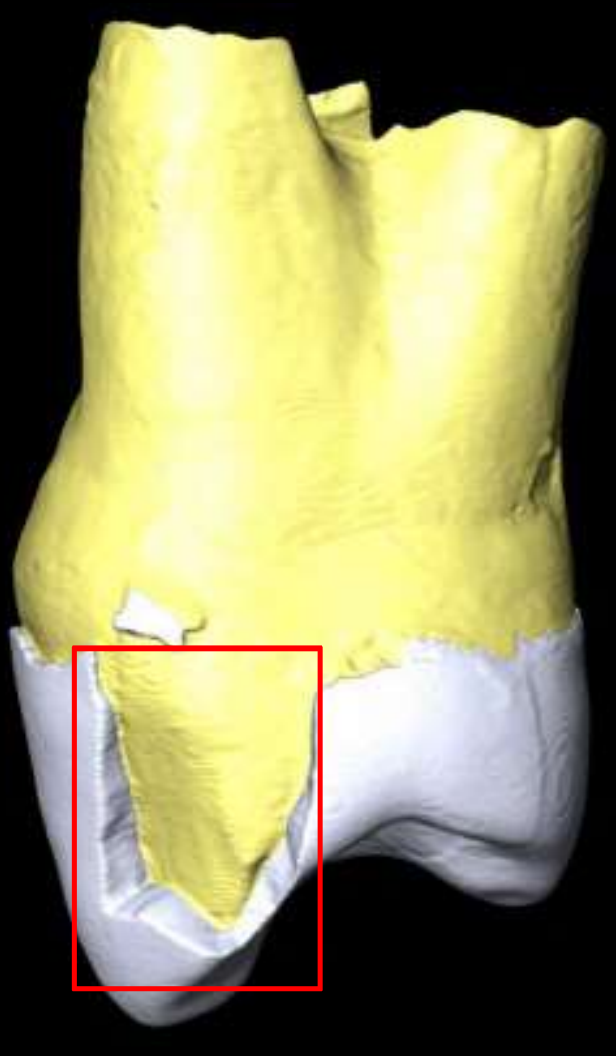

PARTIALLY DIGESTED

Mesial
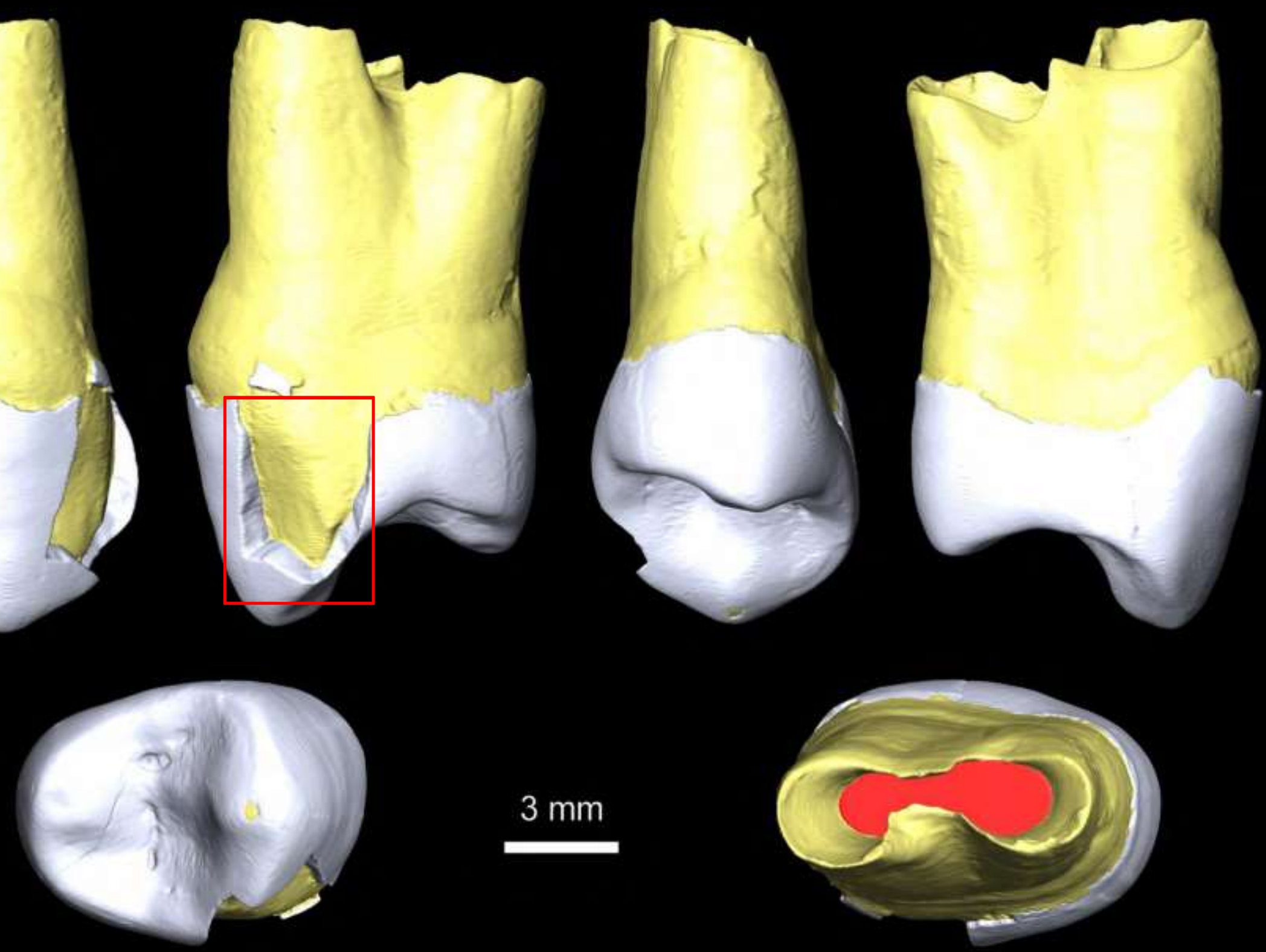

\section{$3 \mathrm{~mm}$}

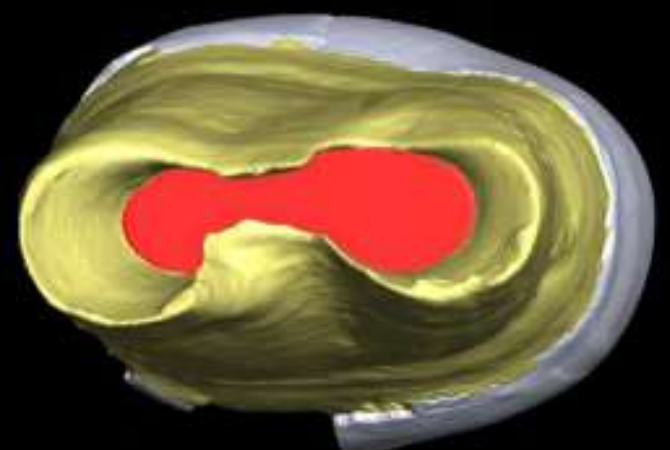





$$
\text { M18 - ULP3 - EDJ }
$$

Buccal

Distal
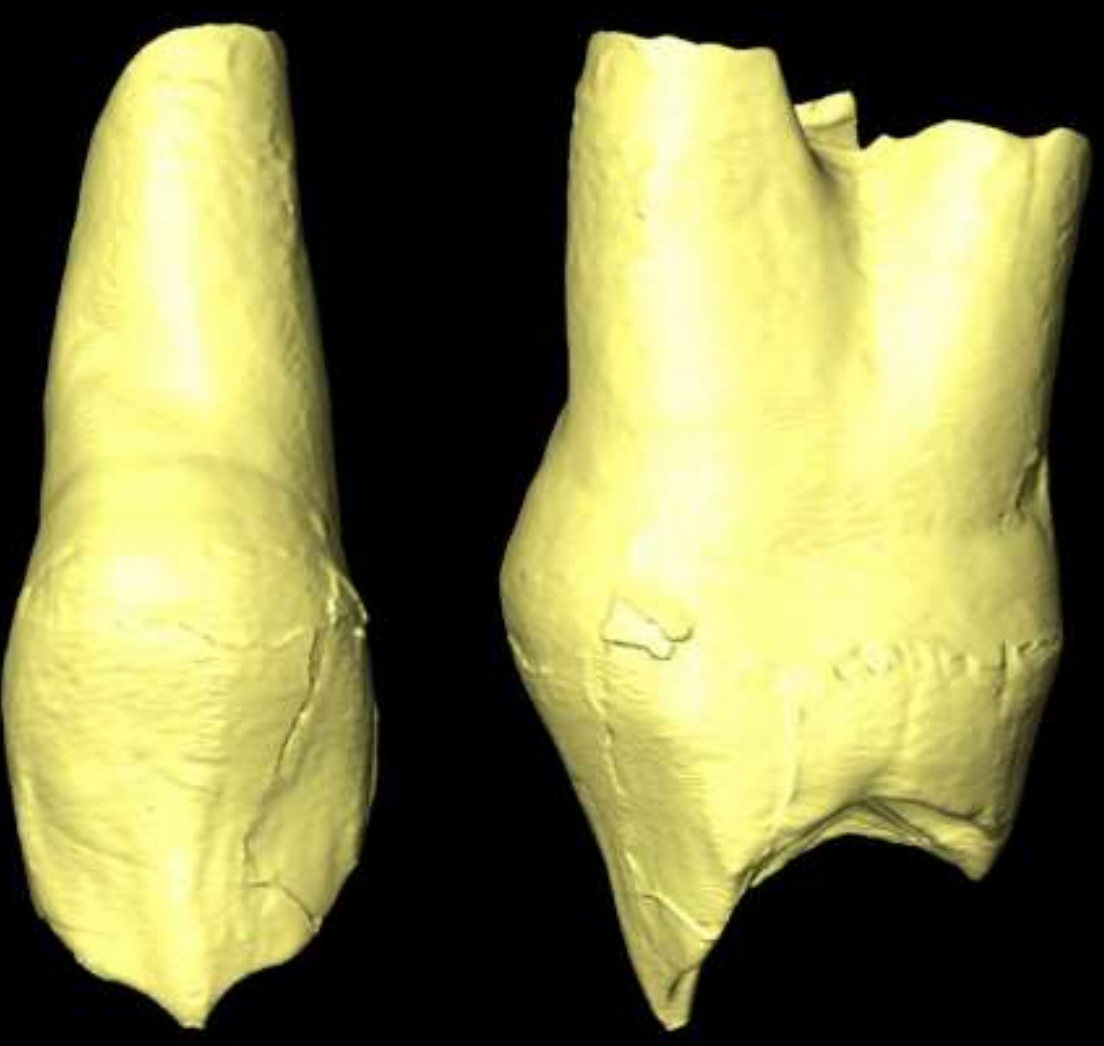

Lingual

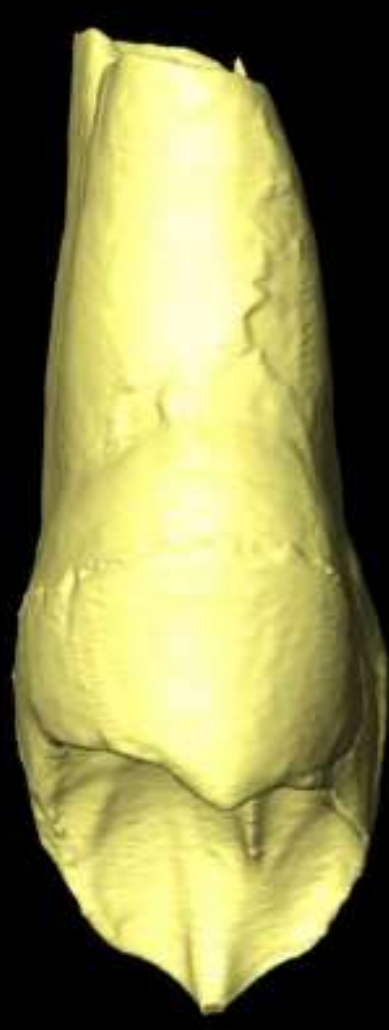

PARTIALLY DIGESTED

Mesial

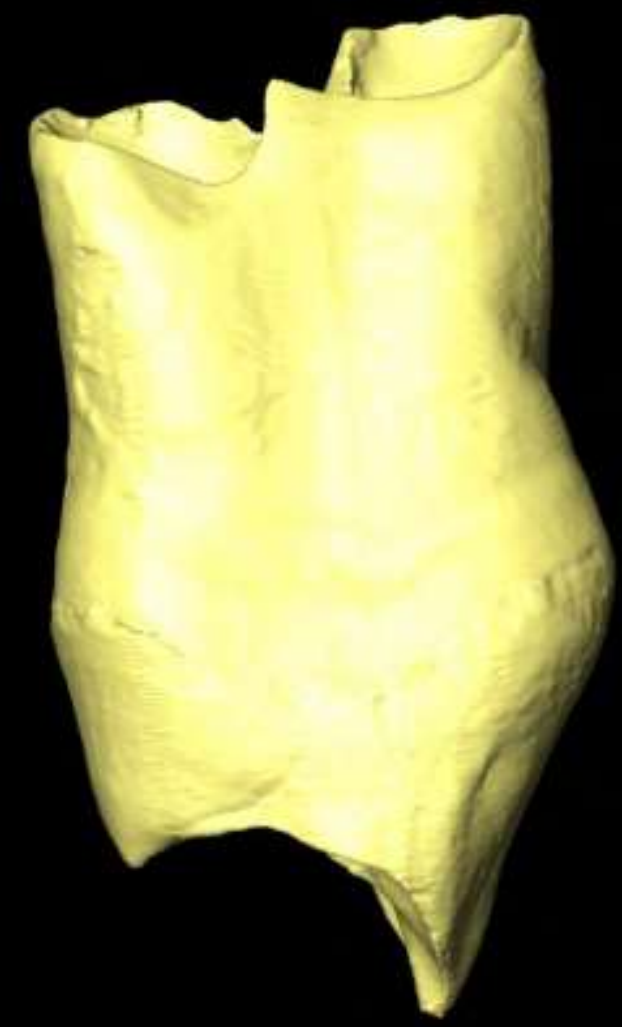

$3 \mathrm{~mm}$

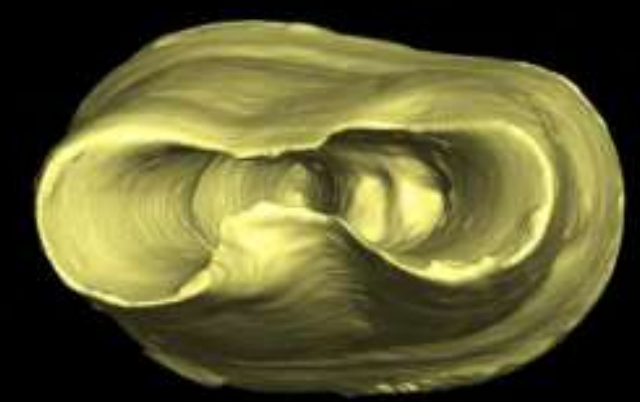





$$
\text { M18 - ULP3 - Pulp }
$$

Buccal

Distal

Lingual

PARTIALLY DIGESTED

Mesial 

Slices optimized for visualizing crown root development

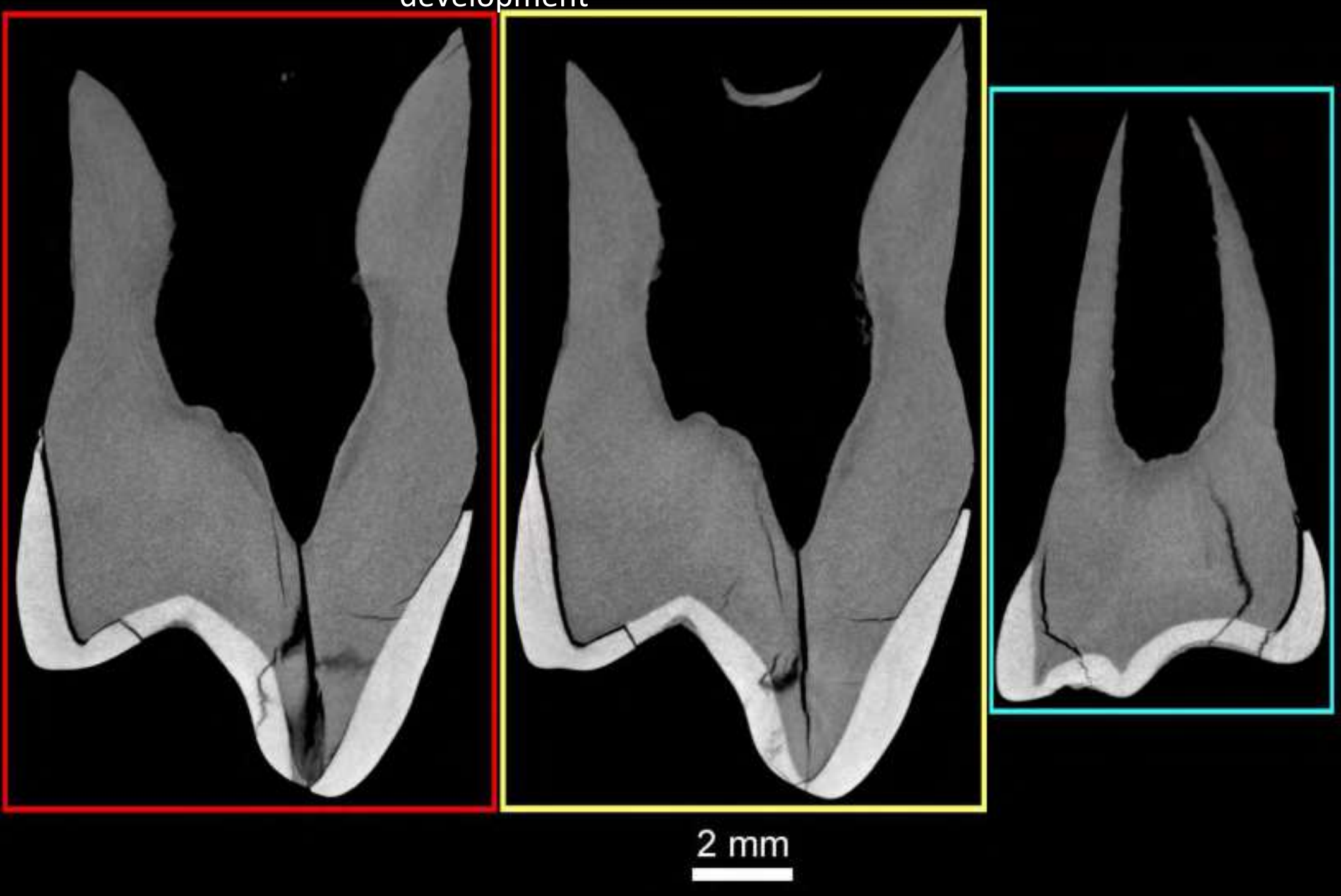




\section{M19 - ULM3}




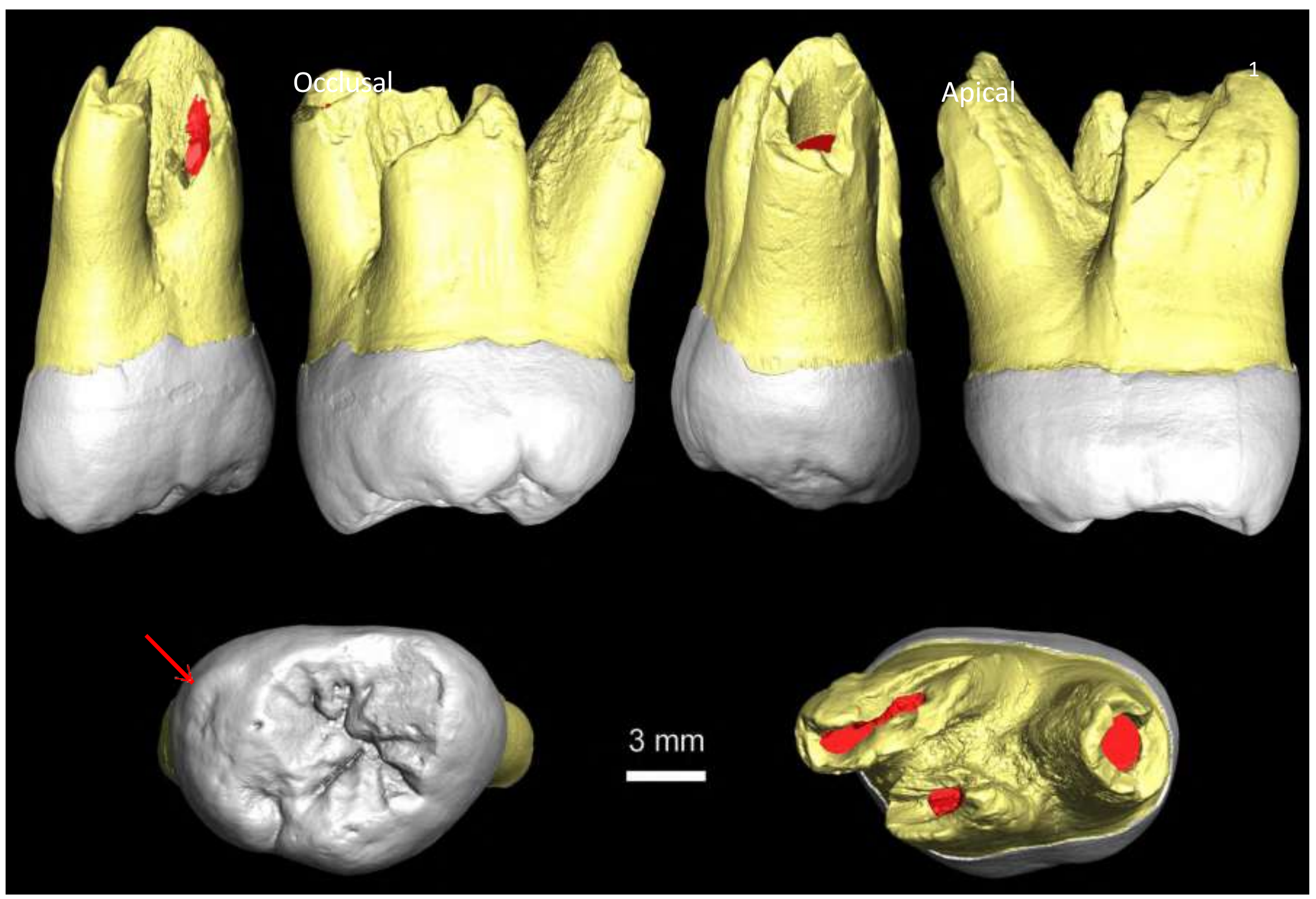




$$
\text { M19 - ULM3 - EDJ }
$$




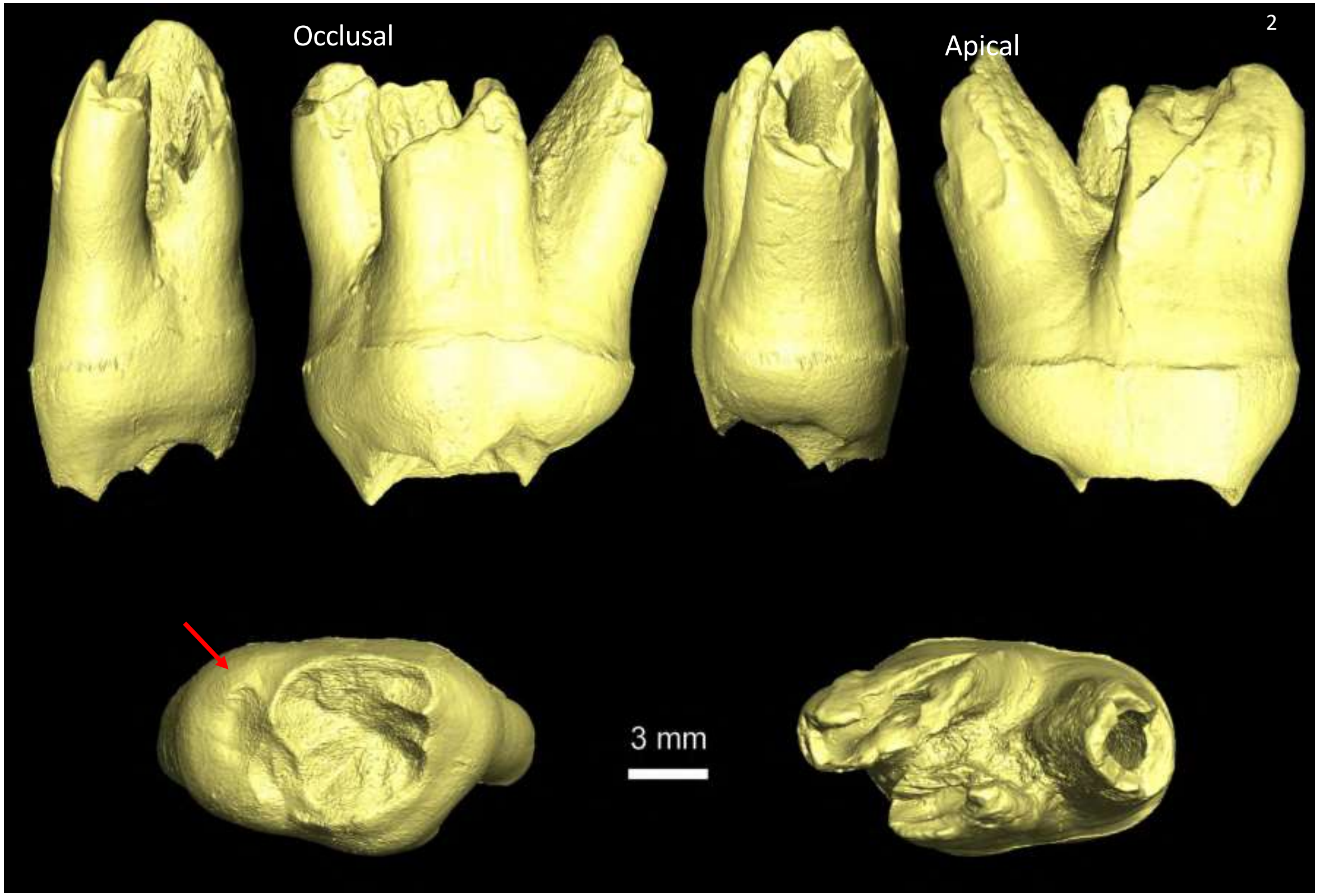




$$
\text { M19 - ULM3 - Pulp }
$$




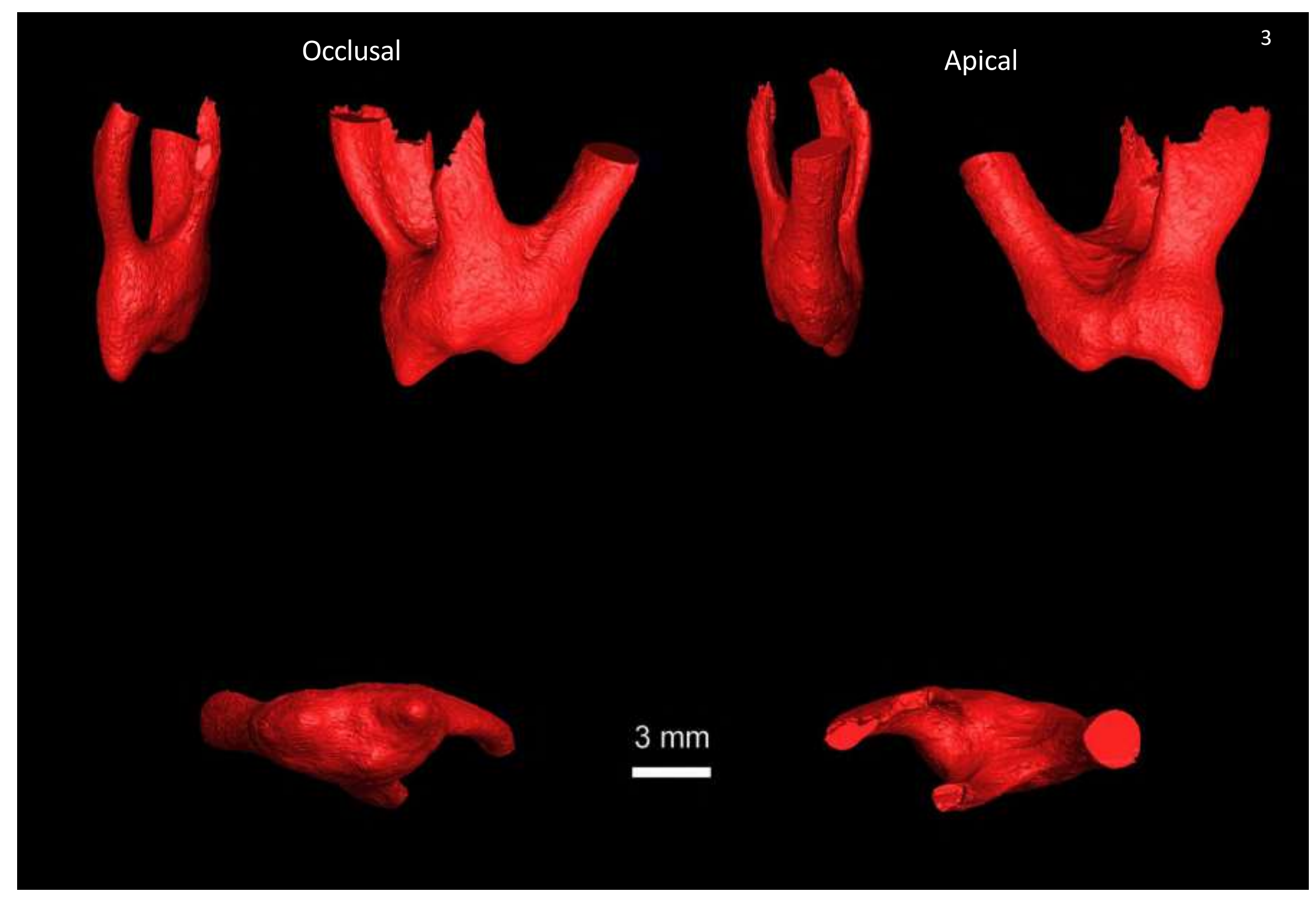




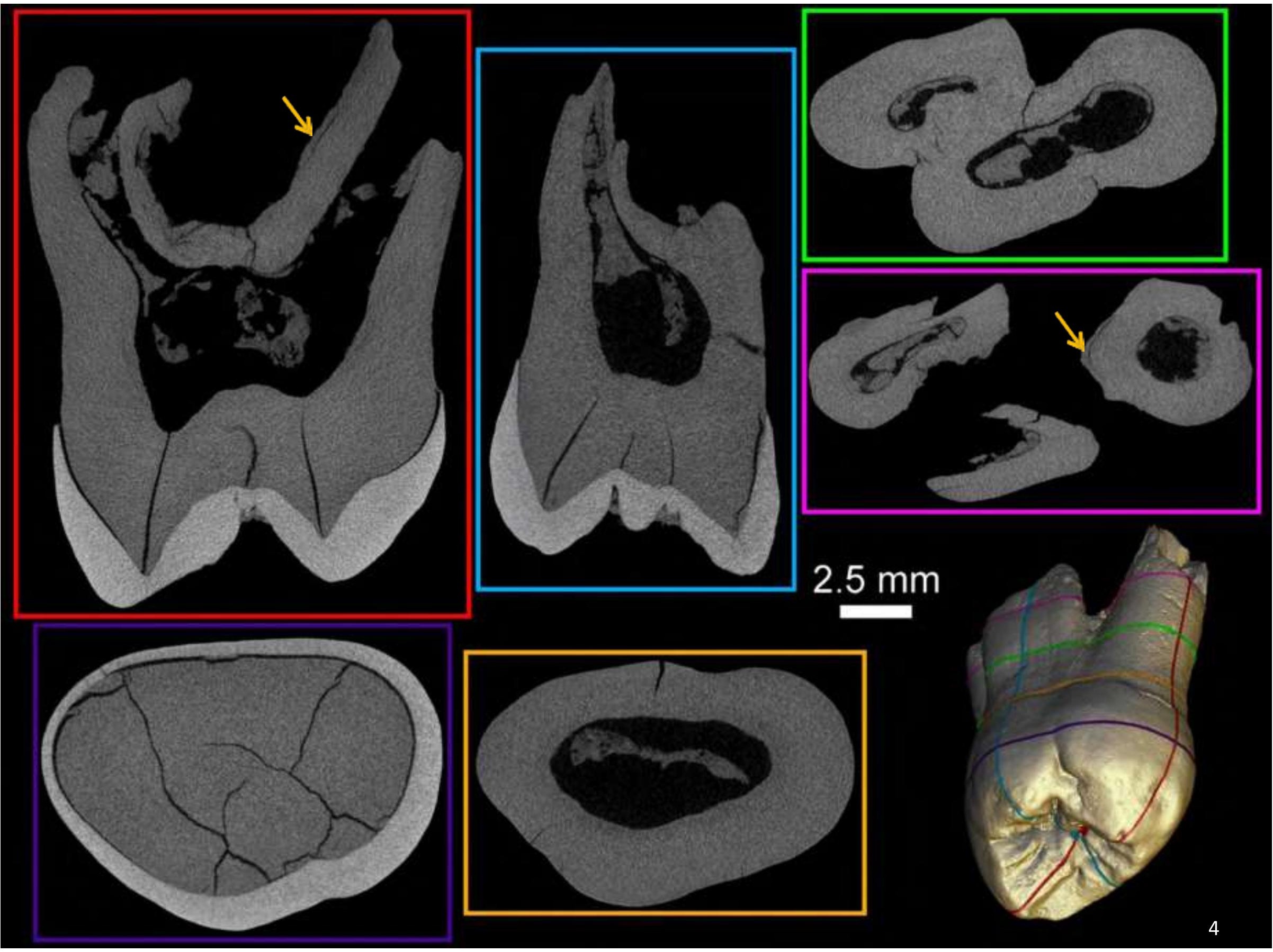



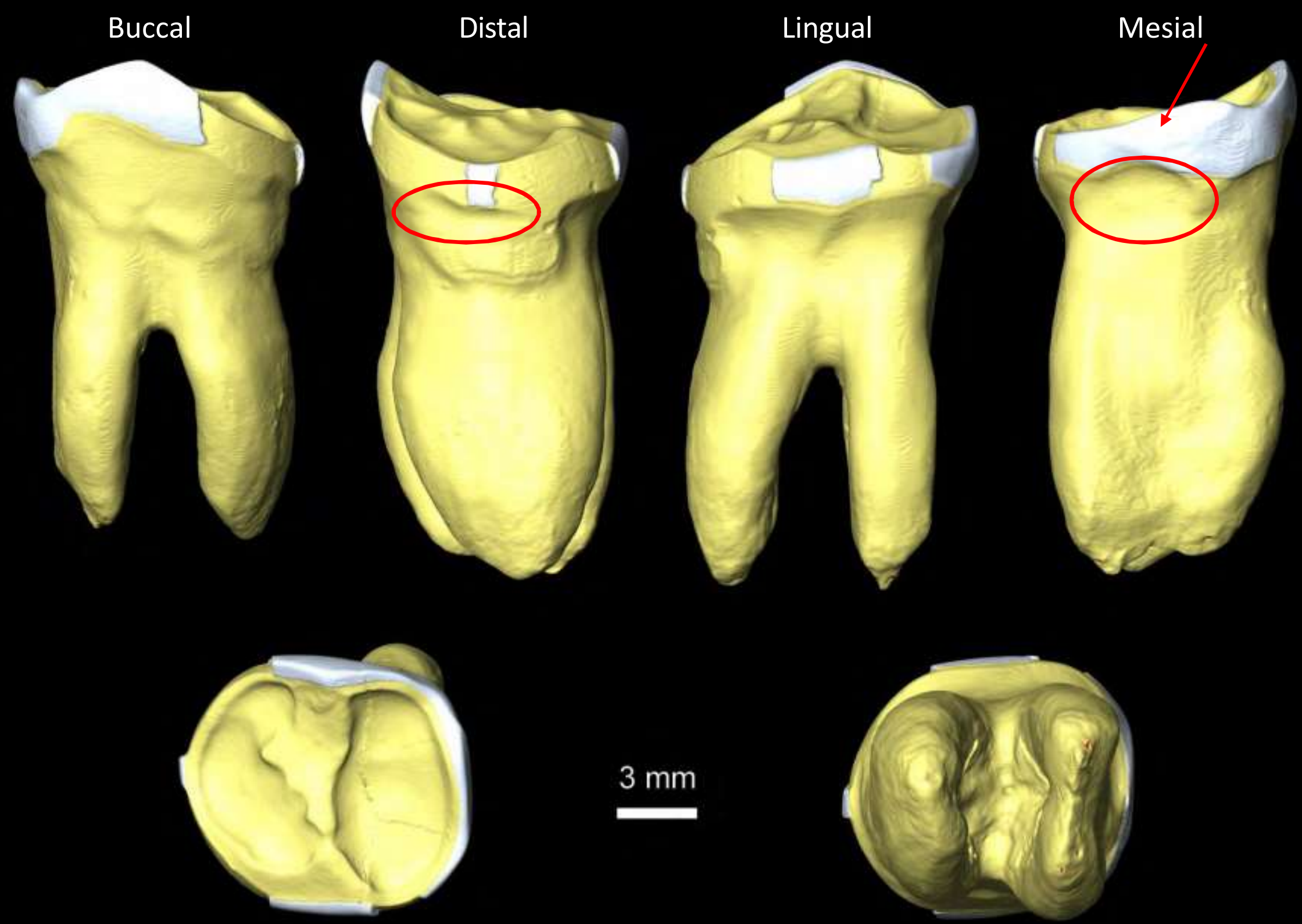

$3 \mathrm{~mm}$

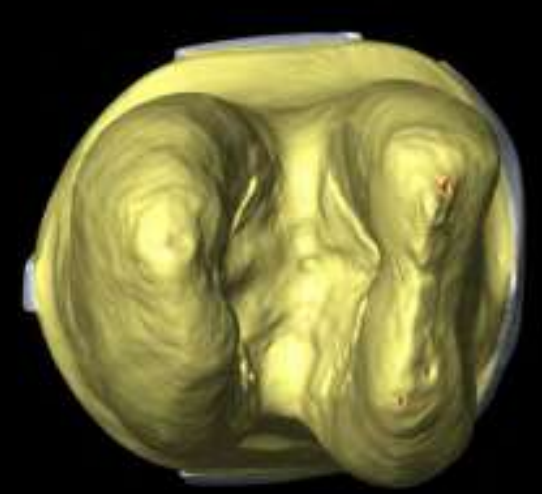


Buccal

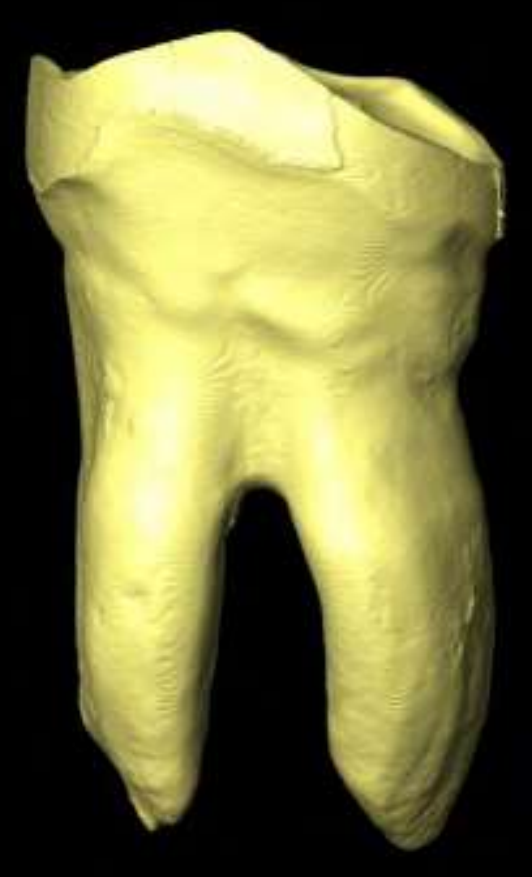

Occlusal
Distal
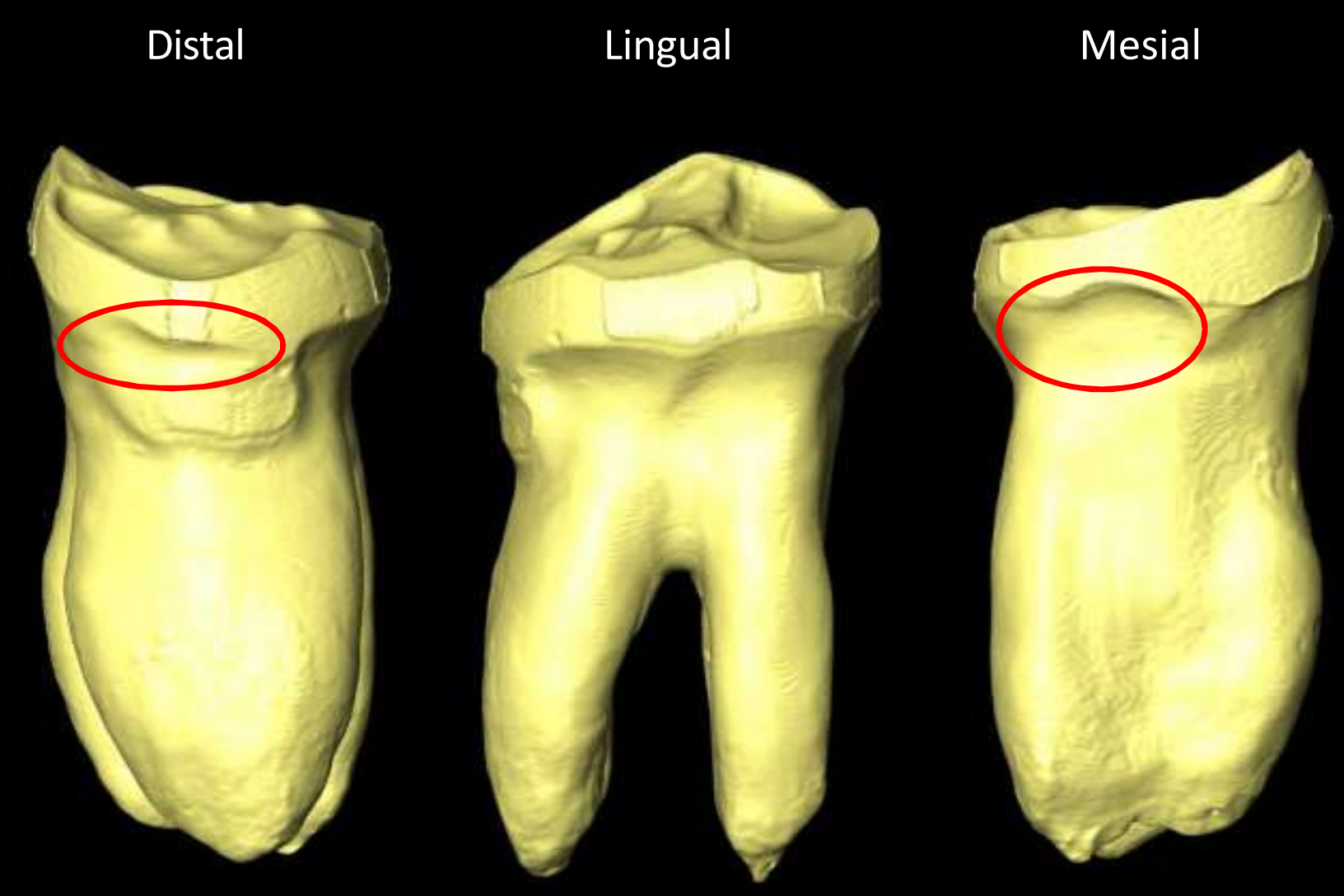

Lingual

Mesial 

M20 - LLM2 - Pulp

Buccal

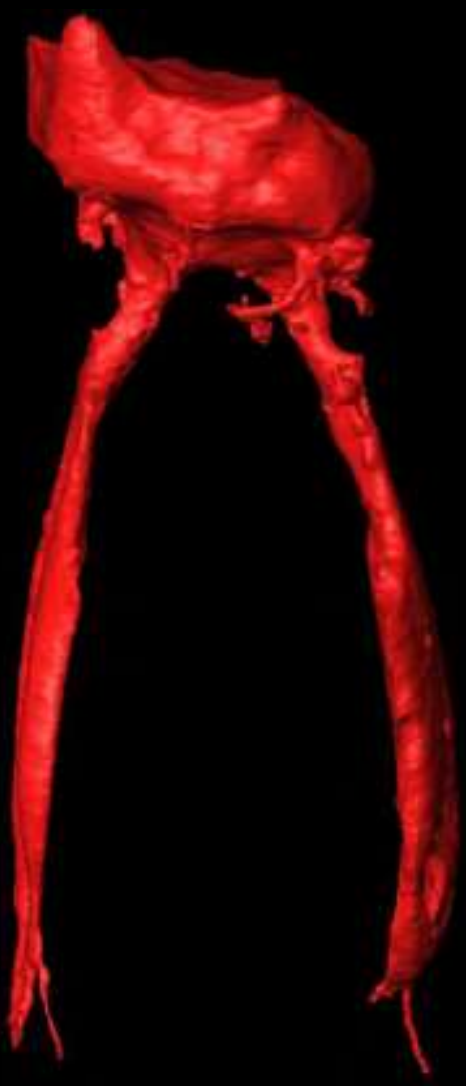

Distal

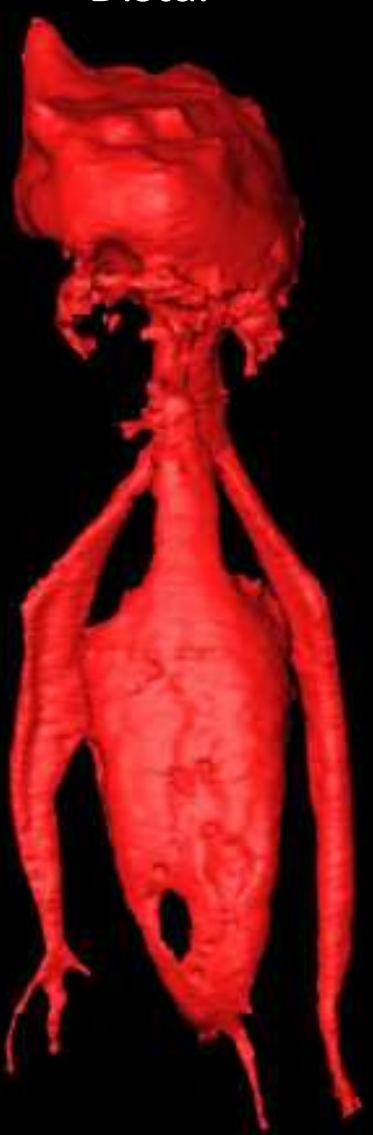

Lingual

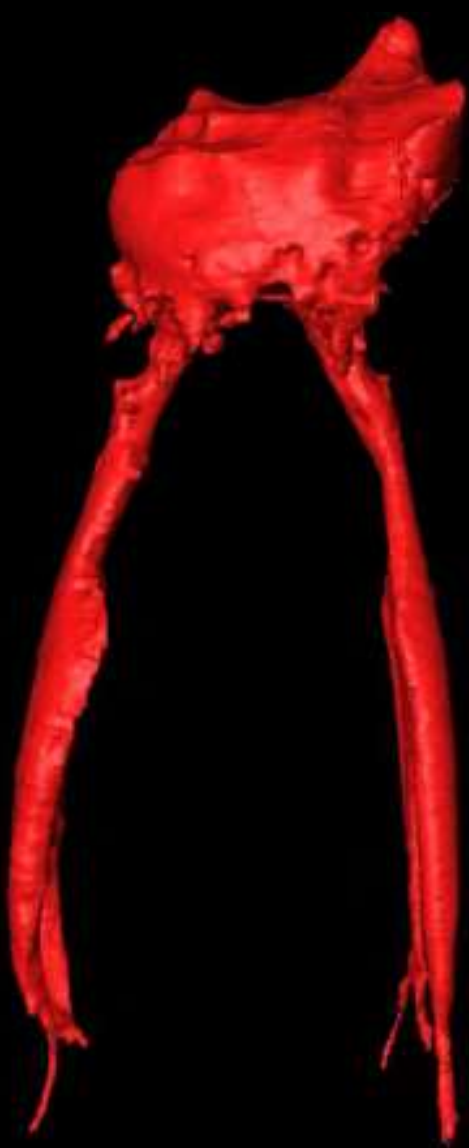

PARTIALLY DIGESTED

Mesial

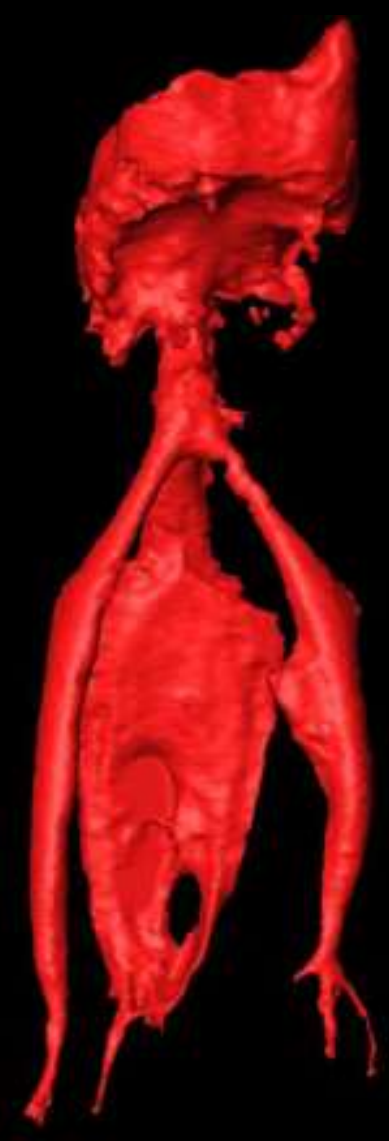

$2 \mathrm{~mm}$

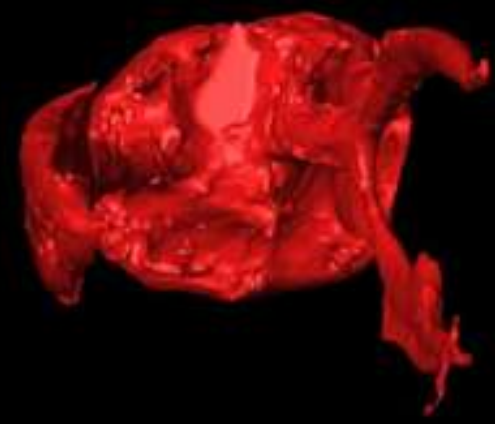





\section{M20 - LLM2 - 2D sections and hypercementosis}
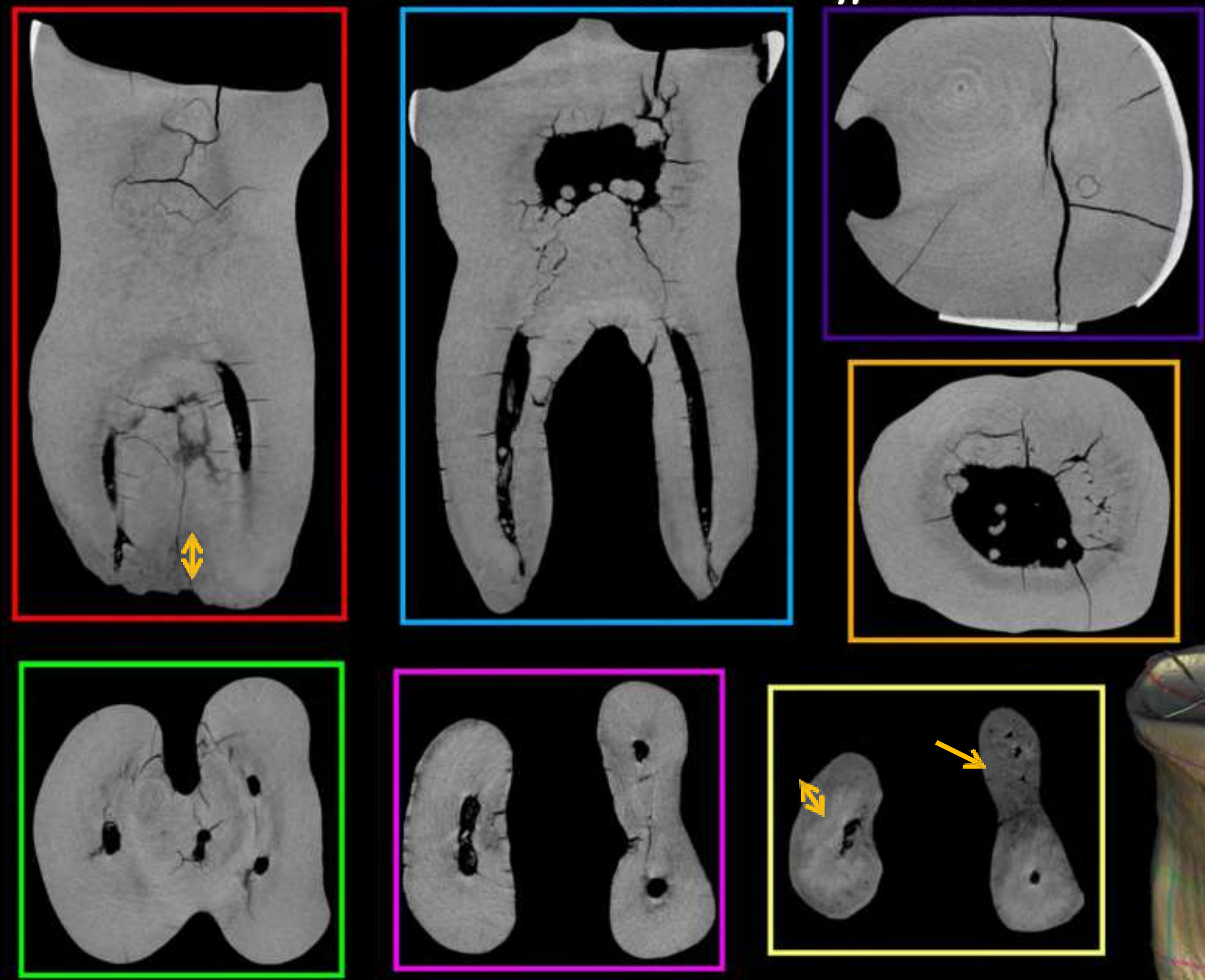

$2.5 \mathrm{~mm}$
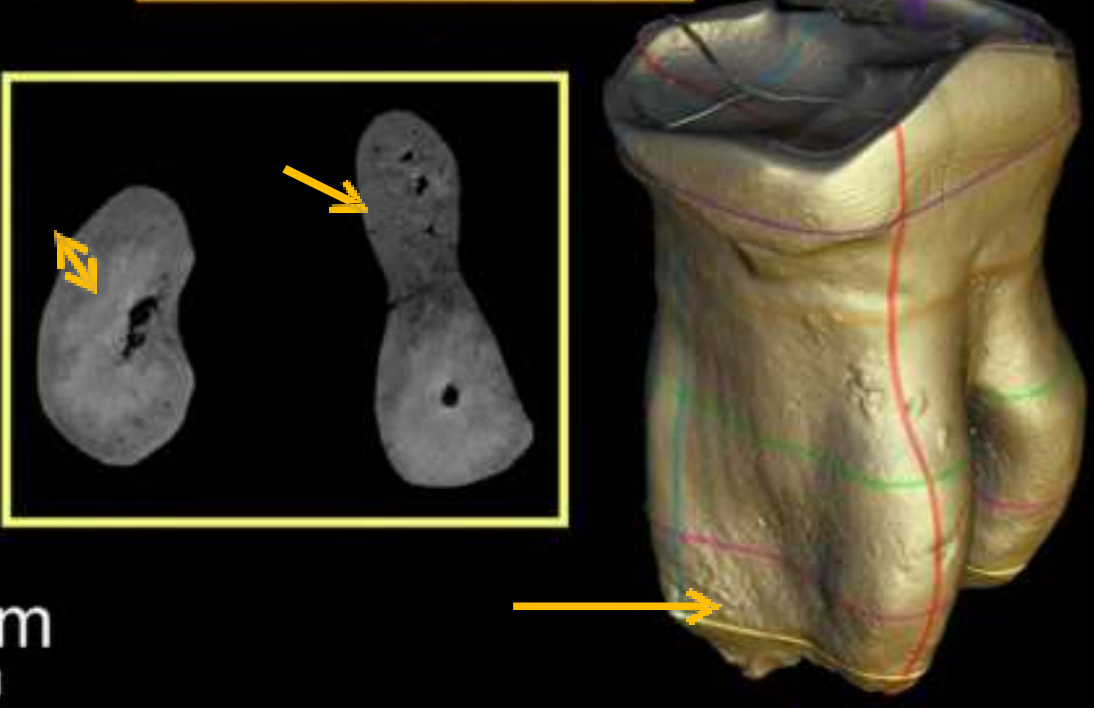


Buccal

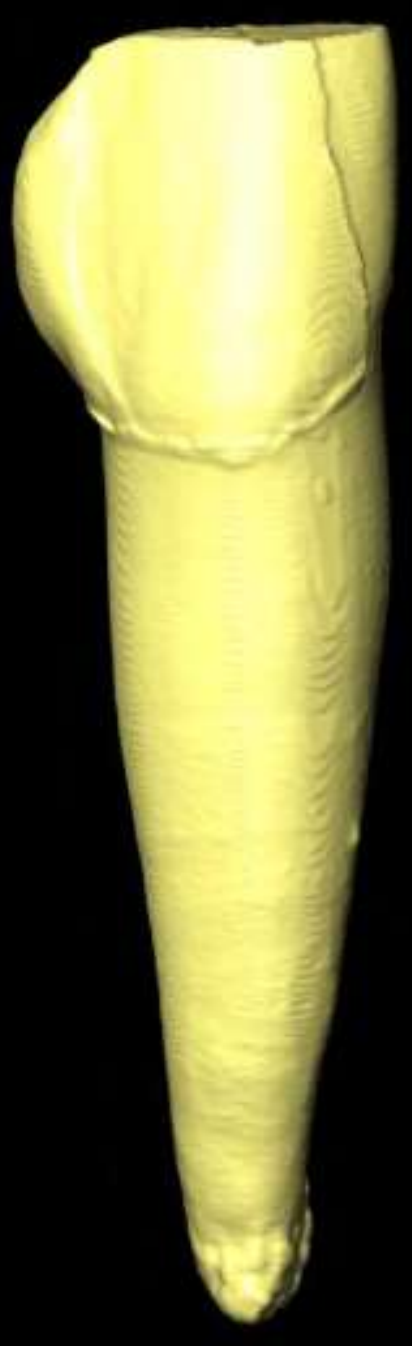

Distal

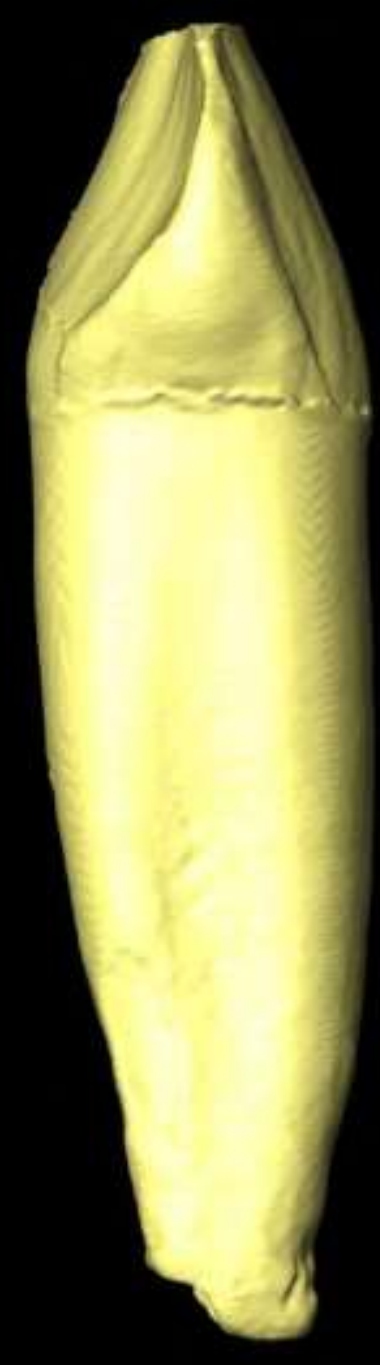

Lingual

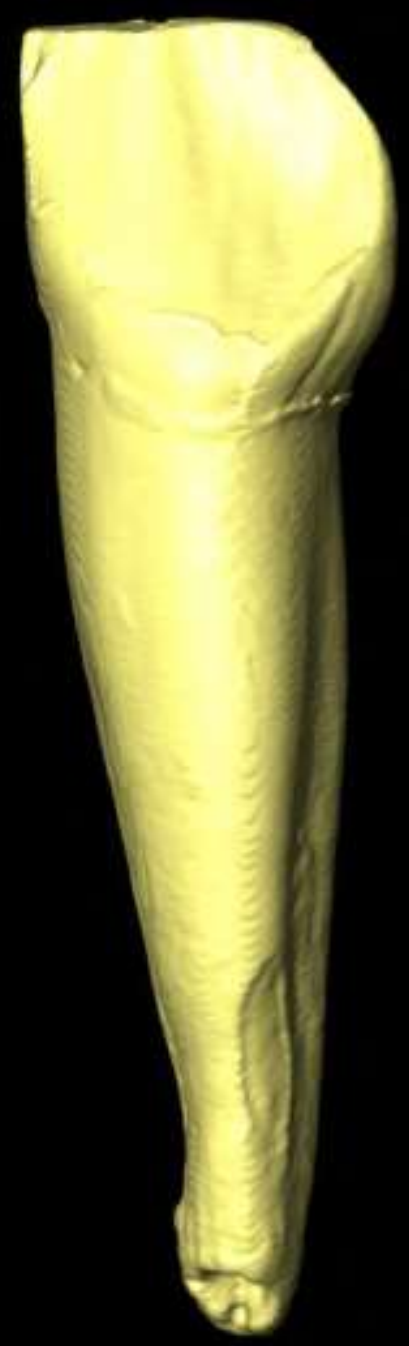

Mesial

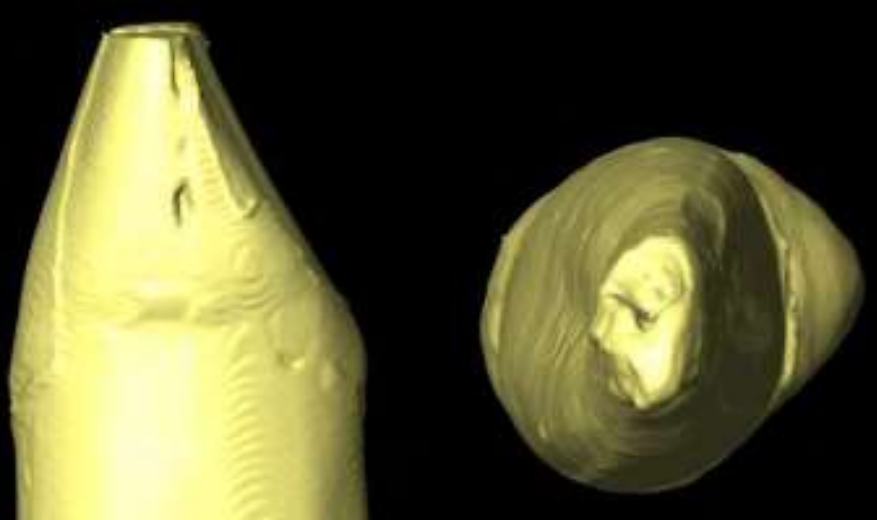

Apical 



\section{M21 - LRdI2 - Pulp}

Buccal

Distal

Lingual

Mesial

Apical

Occlusal $3 \mathrm{~mm}$ 



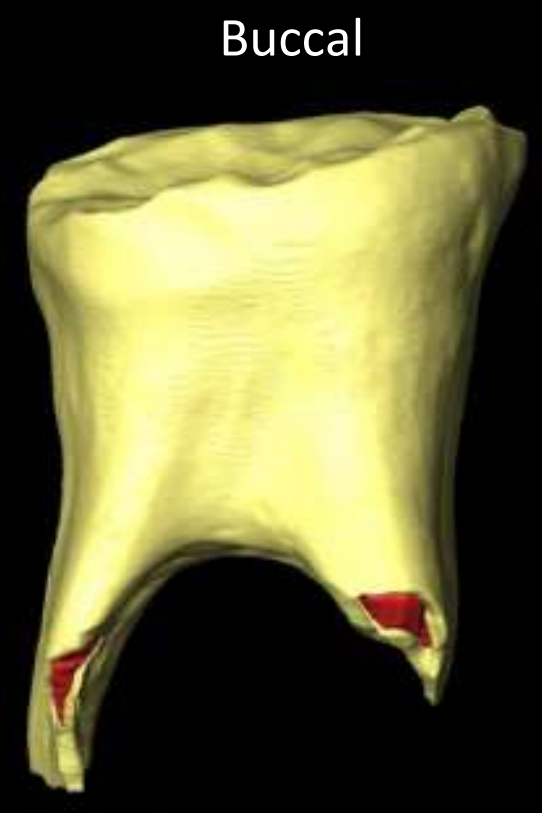

Lingual

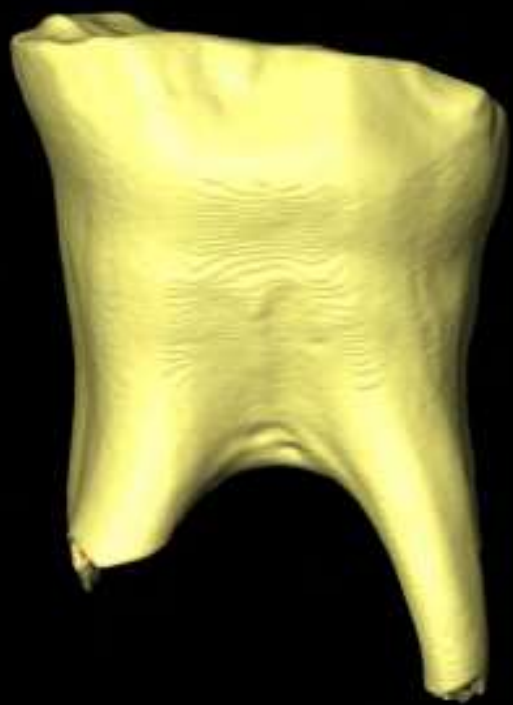

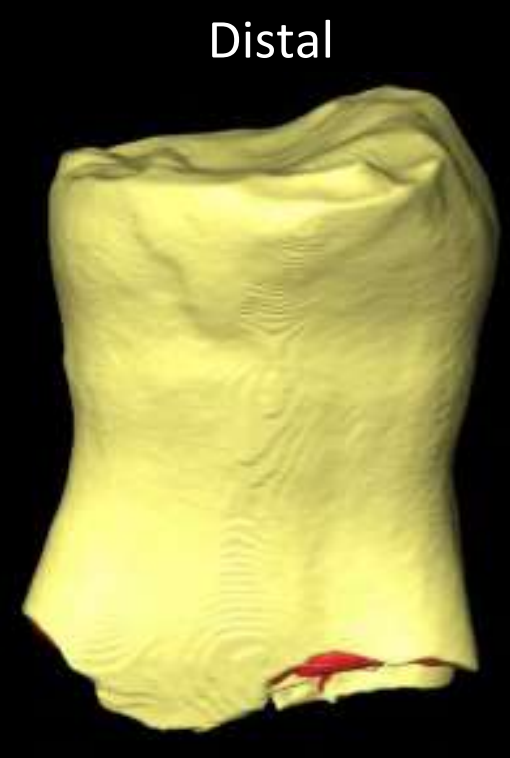

\section{Mesial}

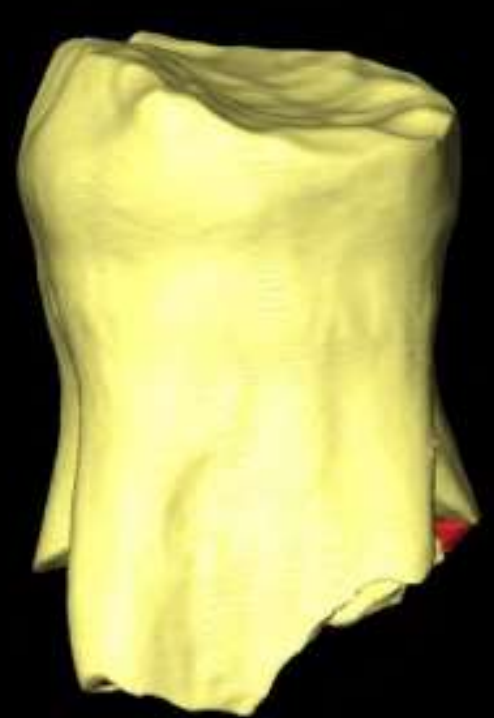

\section{Occlusal}

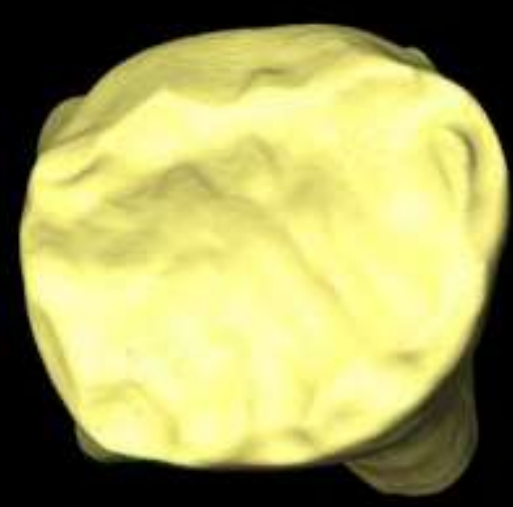
the remnants of enamel are thus not figured in a different color than dentine. 


\section{M22 - LLdM1 - Pulp}

Buccal

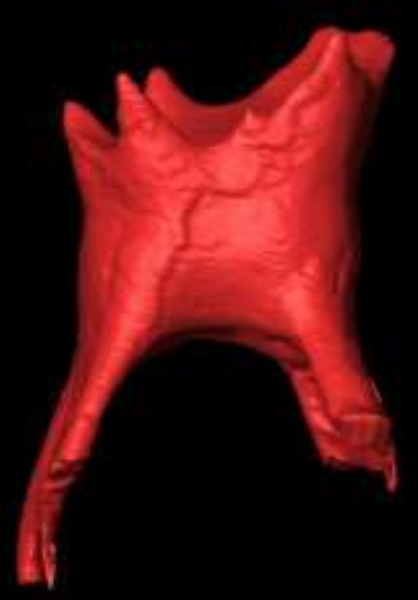

Lingual

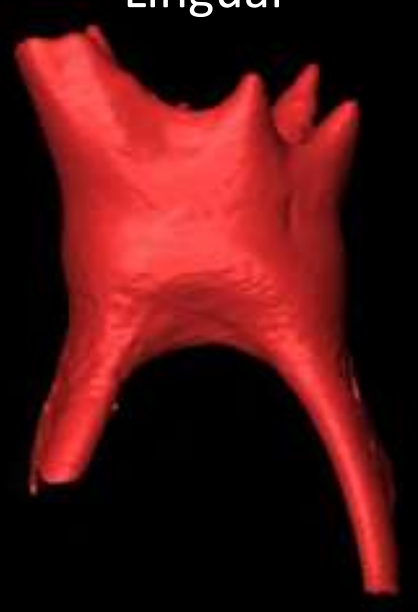

Distal

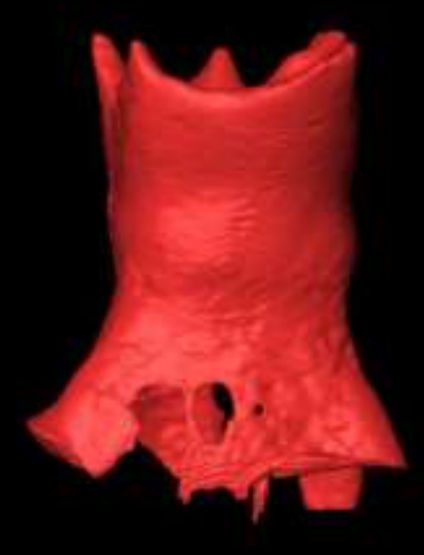

Mesial

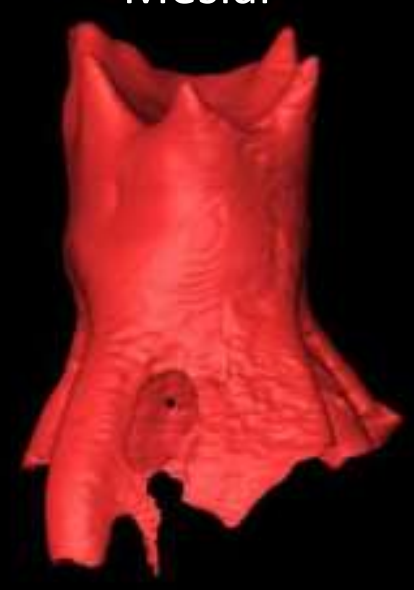

Occlusal

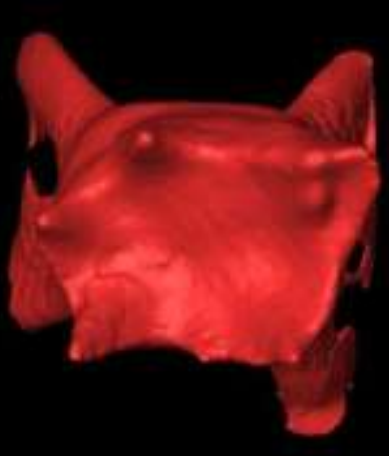

Apical

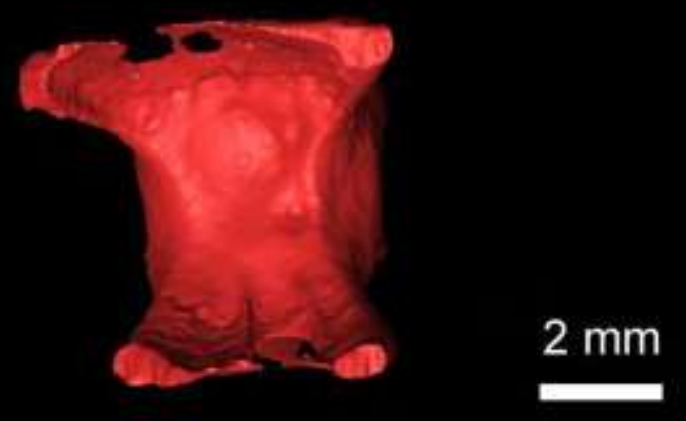




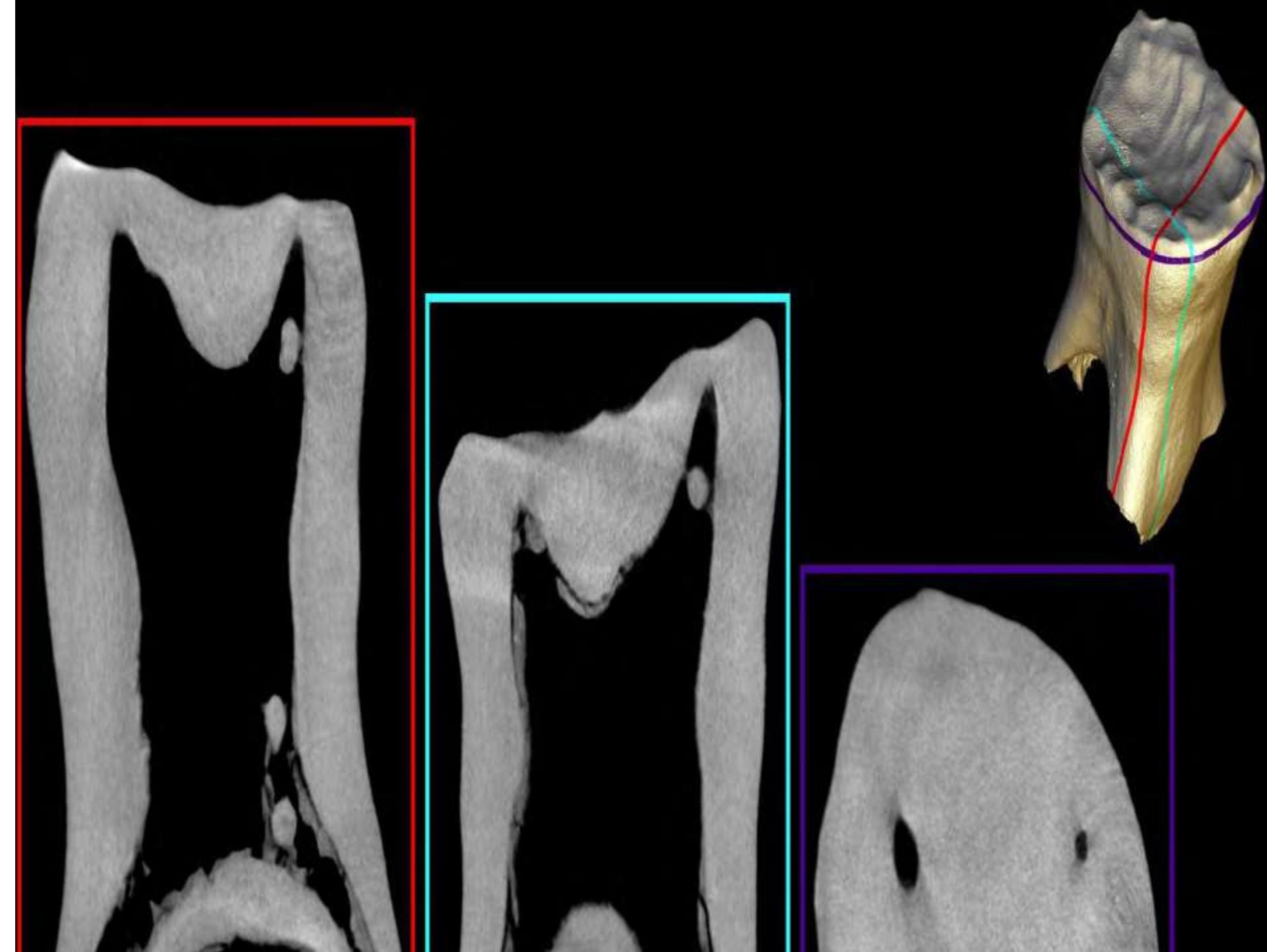




\section{M22 - LLdM1 - 2D sections*}



SOM Table S23. A.- Values of the components of two-dimensional (2D) enamel thickness measurements in the Marillac teeth.

\begin{tabular}{|c|c|c|c|c|c|c|}
\hline Marillac teeth & $W^{1}$ & $\begin{array}{c}\text { Enamel area } \\
\left(\mathrm{mm}^{2}\right)\end{array}$ & $\begin{array}{c}\text { Coronal dentine }+ \\
\text { pulp area }\left(\mathrm{mm}^{2}\right)\end{array}$ & $\begin{array}{c}\text { EDJ length } \\
(\mathrm{mm})\end{array}$ & $\begin{array}{l}\text { 2D AET } \\
(\mathrm{mm})\end{array}$ & 2D RET (scale-free) \\
\hline M13A-RI ${ }^{1}$ & 3 & 11.81 & 45.44 & 20.78 & 0.57 & 8.43 \\
\hline M13B-LI ${ }^{1}$ & 2 & 11.75 & 44.92 & 21.54 & 0.55 & 8.14 \\
\hline$M 13 C-R I^{2}$ & 2 & 15.87 & 35.88 & 24.14 & 0.66 & 10.98 \\
\hline M13D-LI2 & 3 & 14.82 & 39.23 & 22.95 & 0.65 & 10.31 \\
\hline M13E-RC' & 1 & 18.56 & 49.61 & 23.28 & 0.80 & 11.32 \\
\hline M13F-LP 3 & 2 & 21.87 & 48.62 & 21.87 & 1.00 & 14.34 \\
\hline M13G-LP 4 & 2 & 21.60 & 40.52 & 20.17 & 1.07 & 16.82 \\
\hline M19-LM ${ }^{3}$ & 1 & 23.33 & 37.71 & 20.04 & 1.16 & 18.96 \\
\hline $\mathrm{M} 14-\mathrm{RI}^{1 *}$ & $D^{2}$ & 2.78 & 17.33 & 12.65 & 0.22 & 5.27 \\
\hline $\mathrm{M} 15-\mathrm{R} \mathrm{I}^{2 *}$ & $D^{2}$ & 7.78 & 19.02 & 20.10 & 0.39 & 8.88 \\
\hline $\mathrm{M} 21-\mathrm{Rdi}_{2}$ & & 2.27 & 16.31 & 11.95 & 0.19 & 4.70 \\
\hline
\end{tabular}

${ }^{1}$ Wear stage according to Molnar, 1971; ${ }^{*}$ Regurgitated tooth. EDJ = enamel dentine junction; AET = average enamel thickness $(\mathrm{mm}) ; \mathrm{RET}=$ relative enamel thickness (scale free)

SOM Table S23. B.- Values of the components of three-dimensional (3D) enamel thickness measurements in the Marillac teeth.

\begin{tabular}{|c|c|c|c|c|c|c|}
\hline Marillac teeth & $W^{1}$ & $\begin{array}{c}\text { Enamel } \\
\text { volume }\left(\mathrm{mm}^{3}\right)\end{array}$ & $\begin{array}{l}\text { Coronal dentine } \\
+ \text { pulp volume } \\
\left(\mathrm{mm}^{3}\right)\end{array}$ & EDJ area $\left(\mathrm{mm}^{2}\right)$ & 3D AET (mm) & 3D RET (scale-free) \\
\hline M13A-RI ${ }^{1}$ & 3 & 116.49 & 229.13 & 202.06 & 0.58 & 9.42 \\
\hline M13B-LI ${ }^{1}$ & 2 & 123.85 & 256.14 & 201.50 & 0.61 & 9.68 \\
\hline $\mathrm{M} 13 \mathrm{C}-\mathrm{R} \mathrm{I}^{2}$ & 2 & 129.11 & 167.03 & 183.39 & 0.70 & 12.78 \\
\hline M13D-LI ${ }^{2}$ & 3 & 115.29 & 173.24 & 169.44 & 0.68 & 12.21 \\
\hline M13E-RC' & 1 & 141.71 & 212.36 & 174.80 & 0.81 & 13.59 \\
\hline M13F-LP3 & 2 & 152.26 & 191.80 & 163.49 & 0.93 & 16.15 \\
\hline M13G-LP 4 & 2 & 149.39 & 160.44 & 146.90 & 1.02 & 18.72 \\
\hline M19-LM³ & 1 & 208.73 & 265.79 & 191.11 & 1.09 & 16.99 \\
\hline $\mathrm{M} 14-\mathrm{RI}^{1^{*}}$ & $D^{2}$ & 25.68 & 175.75 & 80.10 & 0.32 & 5.72 \\
\hline $\mathrm{M} 15-\mathrm{R}^{2^{*}}$ & $D^{2}$ & 50.40 & 116.72 & 137.61 & 0.37 & 7.49 \\
\hline $\mathrm{M} 21-\mathrm{Rdi}_{2}$ & & 13.12 & 53.70 & 50.76 & 0.26 & 6.85 \\
\hline
\end{tabular}

${ }^{1}$ Wear stage according to Molnar, 1971; ${ }^{*}$ Regurgitated tooth. EDJ = enamel dentine junction; AET = average enamel thickness (mm); RET $=$ relative enamel thickness (scale free) 